\title{
A MIXED METHODS STUDY \\ ON EARLY CHILDHOOD SERVICES' \\ TOUCHSCREEN TABLET USE AND NON-USE \\ IN NEW ZEALAND
}

\author{
By \\ MICHAEL LUKE M. SANTAMARIA
}

\begin{abstract}
A thesis
submitted to Victoria University of Wellington

in fulfilment of the requirements

for the degree of Doctor of Philosophy
\end{abstract}

Victoria University of Wellington

2020 


\begin{abstract}
With the ongoing debate on young children's Information Communication Technology (ICT) use in early childhood education (ECE), empirical studies have reported that the increase in young children's access to and use of touchscreen tablets, hereafter referred to as tablets, could positively and negatively impact their learning and development. According to the New Zealand ECE curriculum, Te Whāriki (Ministry of Education, 2017), children growing up in the context of a changing society could benefit from using technology. This research, which explored tablet use in New Zealand's four major early childhood service types: education and care centres, home-based services, kindergartens, and playcentres, provides useful information on the reasons why services used and did not use tablets as well as how teachers/educators used tablets to support children's learning.
\end{abstract}

The two phases to this sequential explanatory mixed methods study were underpinned by two research paradigms, the postpositivist paradigm for the quantitative phase and the constructivist paradigm for the qualitative phase. First, a national survey that was sent to all early childhood providers from the four major service types and then a collective case study was conducted in two sub-phases. Phase 2A consisted of focus group interviews with a tablet non-user service from each of the four service types and a tablet user service from each of the four service types. Phase $2 \mathrm{~B}$ consisted of stimulated recall (SR) focus group interviews with the same tablet users who participated in Phase 2A.

The survey responses revealed considerable variation in the use of tablets and the purposes for which tablets were used. More education and care services and kindergartens used tablets than home-based services and playcentres. Both quantitative and qualitative phases revealed complexities involving tablet use such as the types of scaffolding used and issues surrounding screen time and policies on tablet use including the use of personally-owned tablets and cybsersafety concerns. Particularly, the findings from Phase 2 confirmed that the socialized nature involving tablet use aligned with Te Whariki. Thus, tablet use is not necessarily limited to a dichotomy of use and non-use but is spread across a spectrum ranging from limited, to specialised, and to comprehensive use. 


\section{Acknowledgements}

My utmost thanks go to my $\mathrm{PhD}$ supervisors, Associate Professor Sue Cherrington and Dr Mary Jane Shuker for all their support and guidance.

I thank the people from the early childhood services who participated in my study including my survey respondents, the umbrella organisations, the teachers/educators and their management, and the children as well as their parents. I also thank my pilot study participants.

My heartfelt appreciation goes to Lisa Woods for her patient guidance throughout my quantitative analyses and teaching me how to use R and SPSS software.

I thank the faculty and staff of the School of Education for their support throughout my PhD journey. I am thankful for the support given by the Student Learning team and the Faculty of Graduate Research. I also thank the New Zealand Association for Research in Education (NZARE).

Finally, I am thankful to the Maravilla, Lacson, Tuason, Shaigan, Santamaria, and Florendo families as well as my colleagues at Tawa School. 
Table of Contents

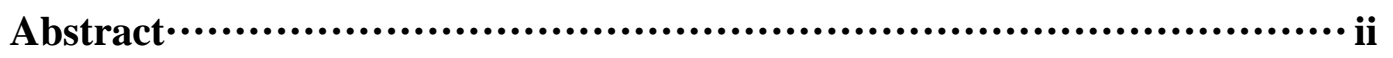

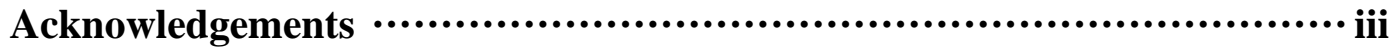

Table of Contents

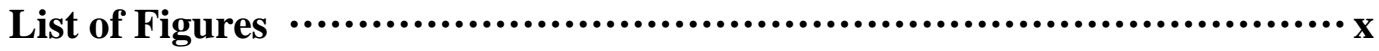

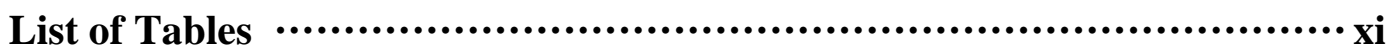

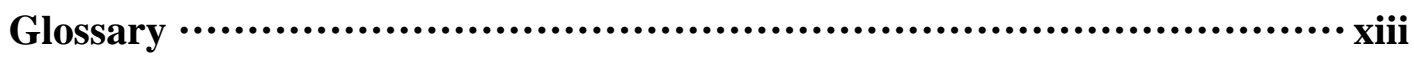

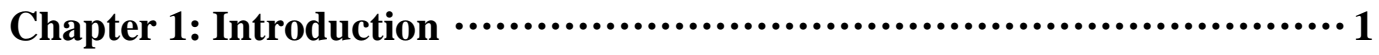

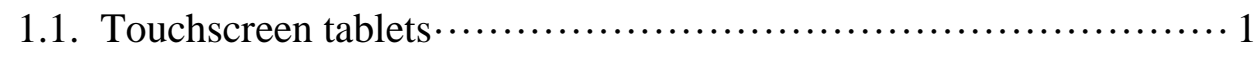

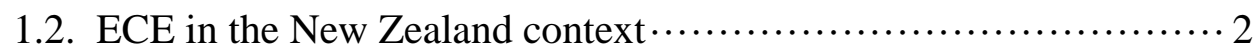

1.3. The development of my interest in this research $\ldots \ldots \ldots \ldots \ldots \ldots \ldots 5$

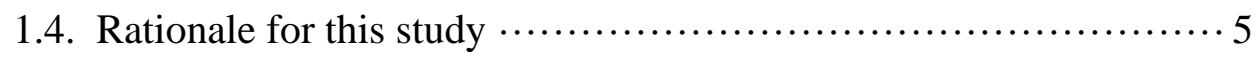

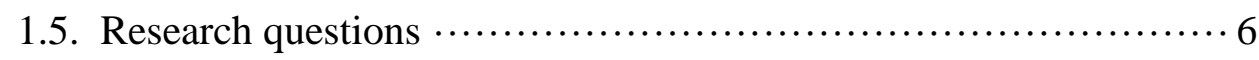

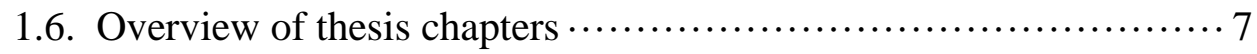

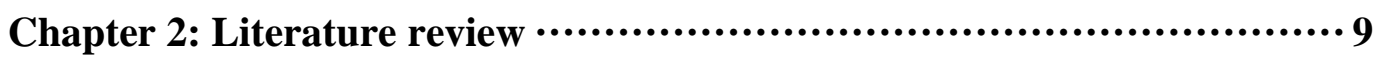

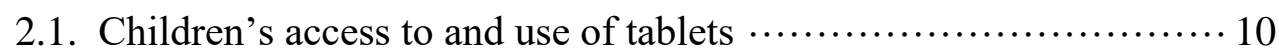

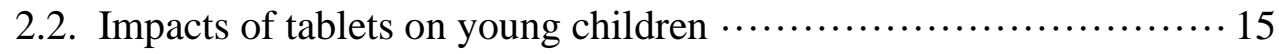

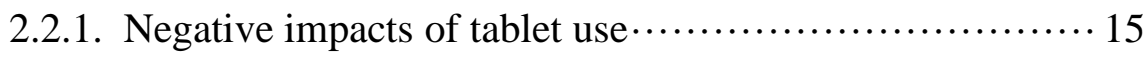

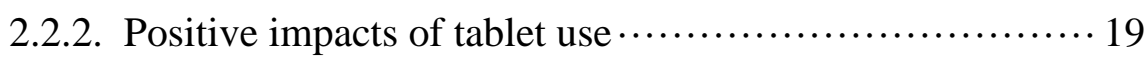

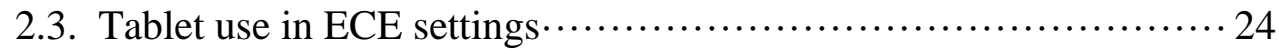

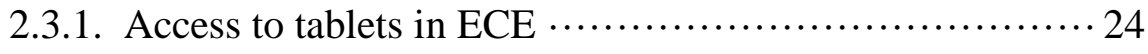

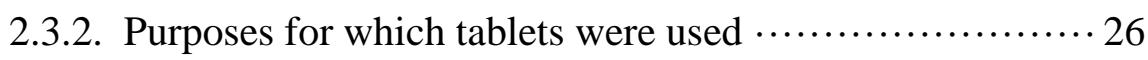




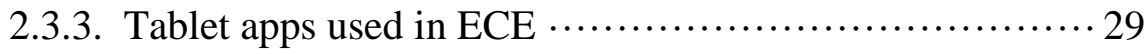

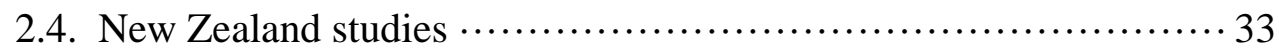

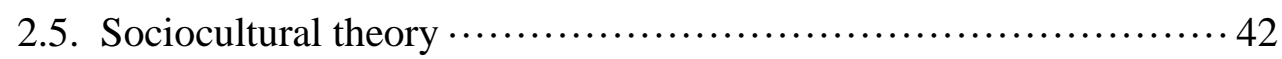

2.5.1. Scaffolding and guided participation $\ldots \ldots \ldots \ldots \ldots \ldots \ldots+\ldots, \ldots \ldots$

2.5.2. Scaffolding and mediation of ICT use $\ldots \ldots \ldots \ldots \ldots \ldots \ldots+\ldots$

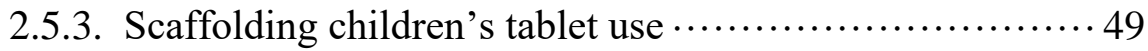

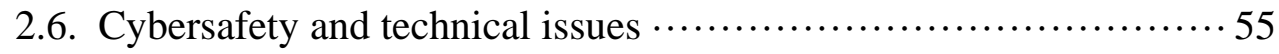

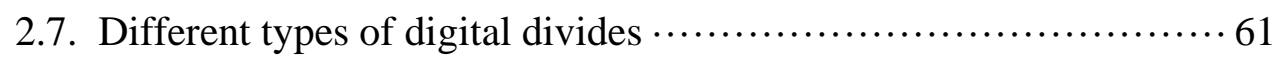

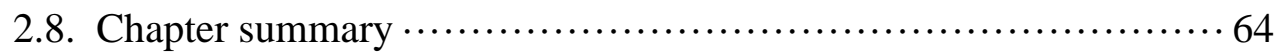

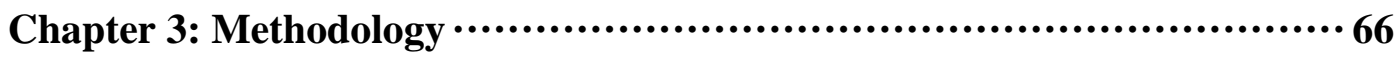

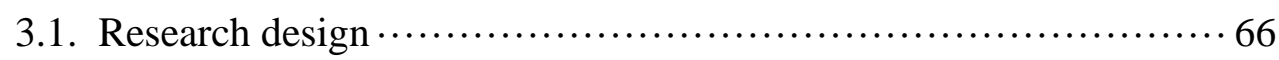

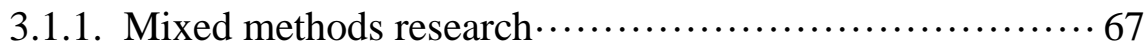

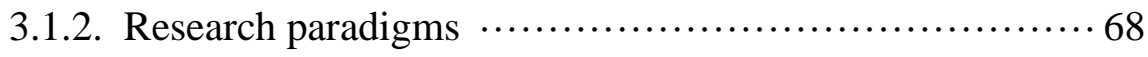

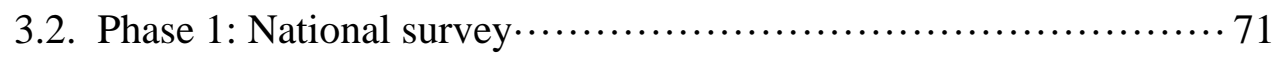

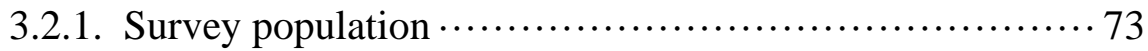

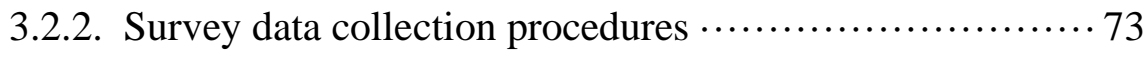

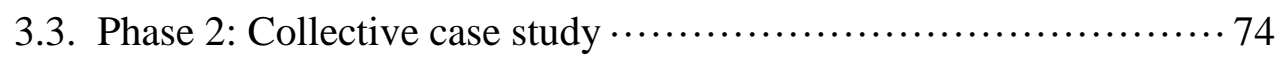

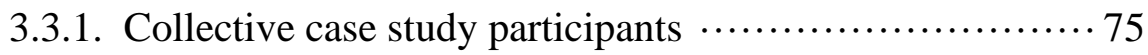

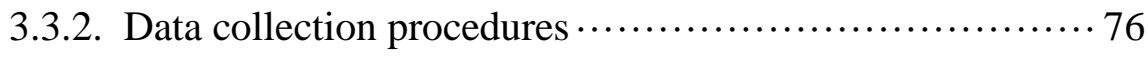

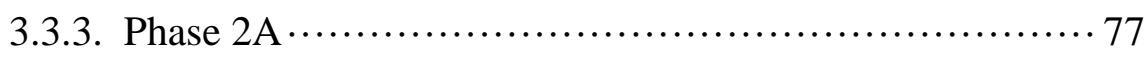

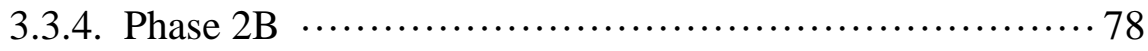

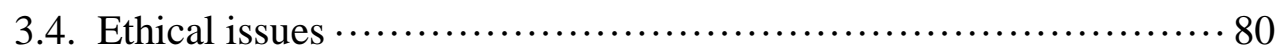




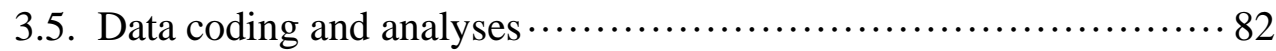

3.6. Trustworthiness in mixed methods research $\ldots \ldots \ldots \ldots \ldots \ldots \ldots \ldots . \ldots 3$

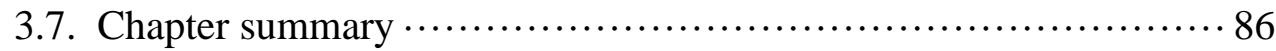

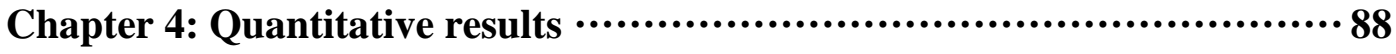

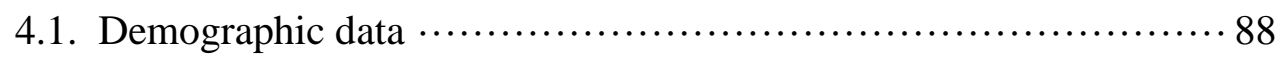

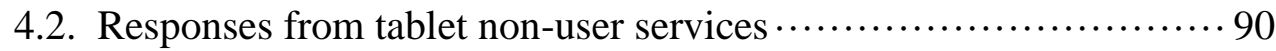

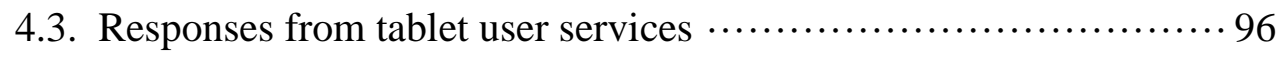

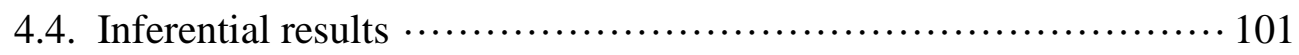

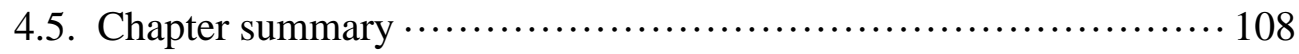

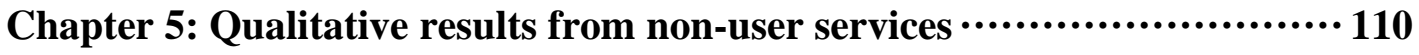

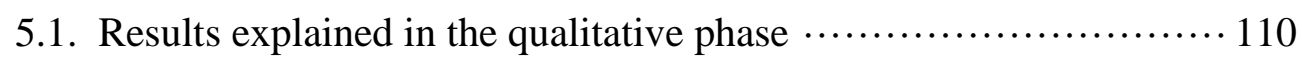

5.2. Phase 2A: Non-user services' collective case study $\cdots \ldots \ldots \ldots \ldots \ldots 110$

5.2.1. Non-user kindergarten: Anniwaniwa Kindergarten.......... 110

5.2.2. Non-user home-based service: Ekengia Homecare ......... 113

5.2.3. Non-user education and care service: Hūmārietanga

Childcare ............................................ 117

5.2.4. Non-user playcentre: Iorangi Playcentre $\ldots \ldots \ldots \ldots \ldots \ldots \ldots \ldots \ldots$

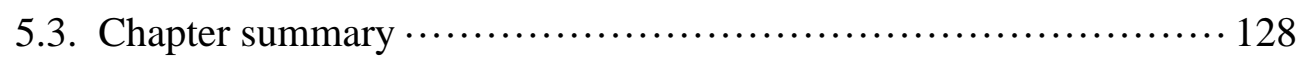

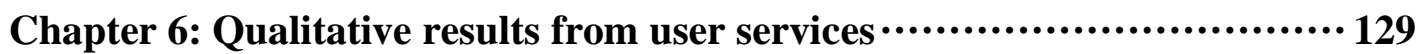

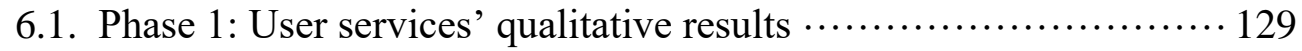

6.2. Phase 2: User services' collective case study $\ldots \ldots \ldots \ldots \ldots \ldots \ldots \ldots \ldots \ldots \ldots \ldots \ldots \ldots$

6.2.1. User home-based service: Koanga Wākāinga

Homebased 
6.2.2. User education and care service: Manaakitanga ELC $\cdots \cdots 146$

6.2.3. User kindergarten service: Nunui Kindergarten...$\ldots \ldots \ldots 162$

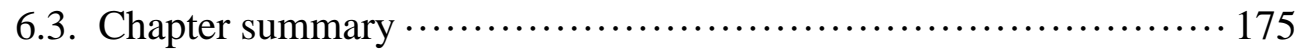

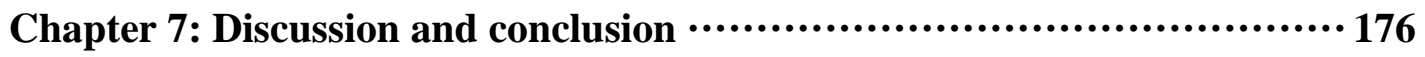

7.1. The extent of tablet use and non-use for teaching and learning amongst teachers/educators in New Zealand ECE services …........ 177

7.1.1. Extent of use and non-use according to demographics $\cdots \cdots 17$

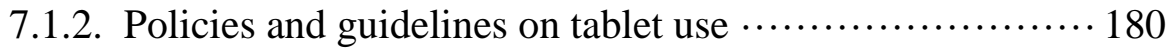

7.1.3. The fluidity between tablet use and non-use $\ldots \ldots \ldots \ldots \ldots 181$

7.2. Reasons for the non-use of tablets amongst teachers/educators in

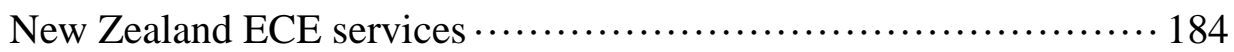

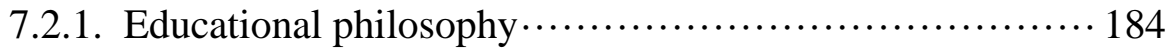

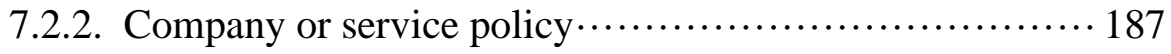

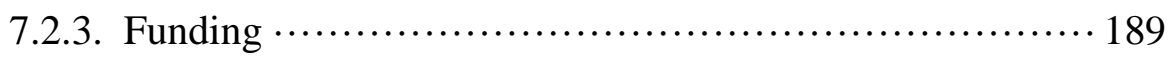

7.3. Teachers'/educators' use of tablets in ECE settings to support

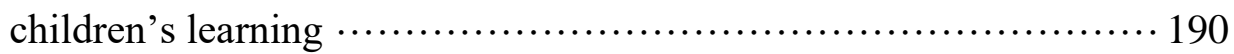

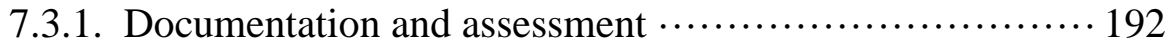

7.3.2. Conceptualising New Zealand's ECE services' tablet use $\cdot 193$

7.3.3. Considering tablet use through a sociocultural lens $\ldots \ldots \ldots 197$

7.4. Barriers and affordances to tablet use in ECE pedagogy $\cdots \ldots \ldots \ldots . \cdots 199$

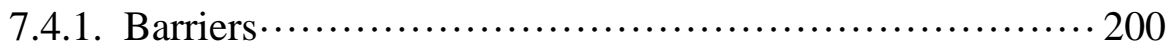

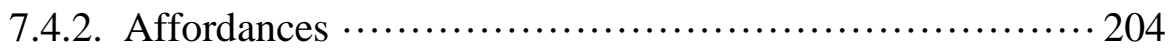

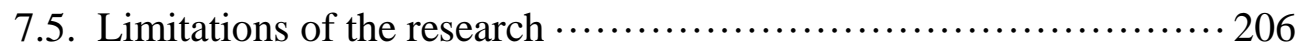


7.6. Recommendations for further research

7.7. Contributions to understanding tablet use in New Zealand's ECE contexts

7.8. Implications of this study

7.9. Conclusion

Appendix A: Information letter for early childhood teachers for Phase 1:

Survey

Appendix B: Online survey on touchscreen tablet use in early childhood education

Appendix C: Paper-based survey on touchscreen tablet use in early childhood education 250

Appendix D-1: Information sheet for umbrella organisations 263

Appendix D-2: Consent form for umbrella organisations 267

Appendix E-1: Information letter to early childhood services 268

Appendix E-2: Consent form for early childhood services (Phase 2A:

Touchscreen tablet non-user services)

Appendix E-3: Consent form for early childhood services (Phase 2A:

Teachers/Educators)

Appendix F-1: Information letter to early childhood services (Phase 2A

and 2B: Touchscreen tablet user services)

Appendix F-2: Consent form for early childhood services (Phase 2A and 2B: Touchscreen tablet user services) 
Appendix F-3: Consent form for early childhood services (Phase 2A and 2B: Teachers/Educators)

Appendix G-1: Information letter for parent/s and their child/ren (Phase

2B: Touchscreen tablet user services)

Appendix G-2: Consent form for parent/s and their child/ren (Phase

2B: Touchscreen tablet user services) 278

Appendix H: Phase 2A Focus group questions 279

Appendix I: Phase 2B Focus group questions 280 


\section{List of Figures}

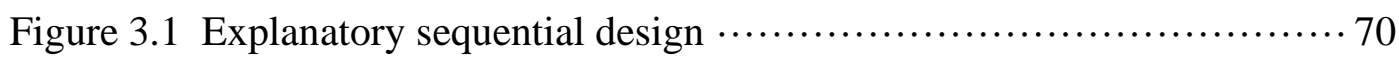

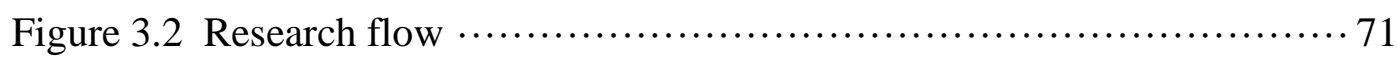

Figure 4.1 Tablet non-user/user services per service type $\ldots \ldots \ldots \ldots \ldots \ldots \ldots \ldots \ldots \ldots \ldots \ldots$

Figure 4.2 Non-user services: Use/non-use of personal tablets $\cdots \ldots \ldots \ldots \ldots \ldots \ldots 102$

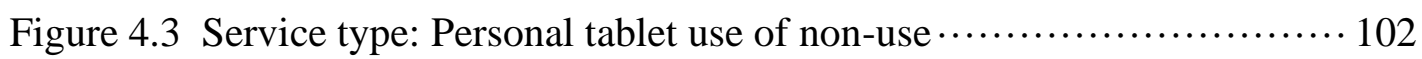

Figure 4.4 User services: Formal policies or guidelines per service type $\cdots \cdots \cdots \cdots 103$

Figure 4.5 User services: Formal policies or guidelines and screen time policy $\cdot 103$

Figure 4.6 Non-user's number of children and personal tablet use/non-use $\cdots \cdots \cdot 104$

Figure 4.7 Non-user's number of children licensed for per screen time policy $\cdots 105$

Figure 4.8 Number of teachers/educators using tablets and screen time policy $\cdot 106$

Figure 4.9 Number of teachers/educators and tablet use/non-use $\cdots \ldots \ldots \ldots \ldots \ldots 107$

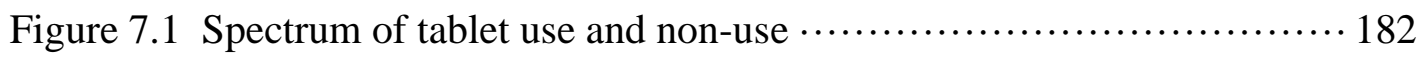

Figure 7.2 Spectrum of tablet use and non-use with cases $\ldots \ldots \ldots \ldots \ldots \ldots \ldots \ldots \ldots \ldots \ldots \ldots$ 


\section{List of Tables}

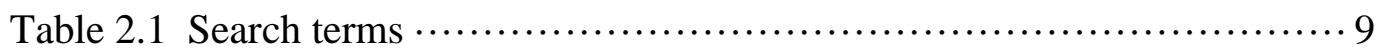

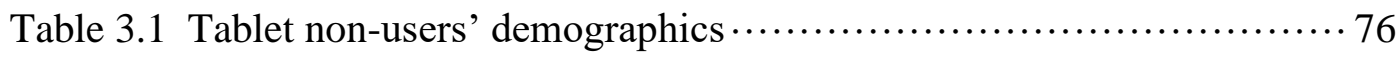

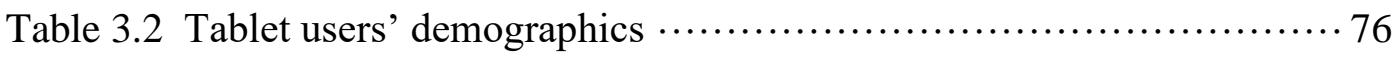

Table 4.1 Number of respondents per educational region $\cdots \ldots \ldots \ldots \ldots \ldots \ldots \ldots, 88$

Table 4.2 Maximum number of children each service is licensed for $\cdots \ldots \ldots \ldots . .69$

Table 4.3 Total number of teachers/educators at each service $\ldots \ldots \ldots \ldots \ldots \ldots \ldots . \ldots 9$

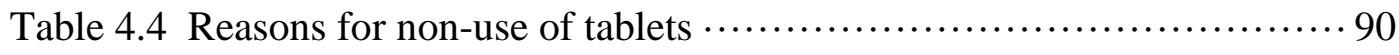

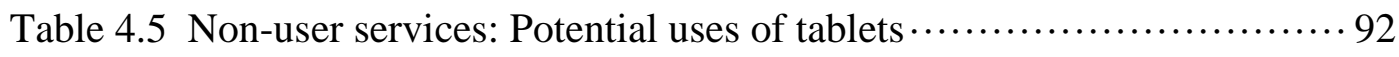

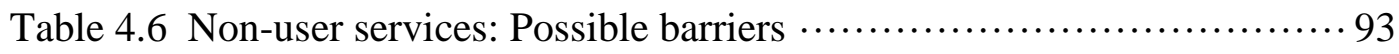

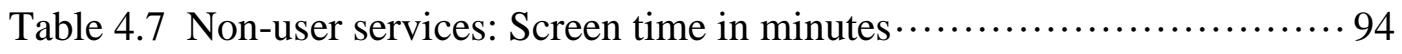

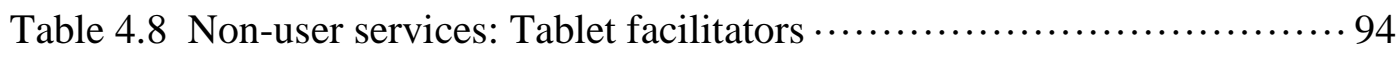

Table 4.9 Non-user services: Learning sources for tablet use $\ldots \ldots \ldots \ldots \ldots \ldots \ldots 9$

Table 4.10 User services: Maximum number of children using touchscreen

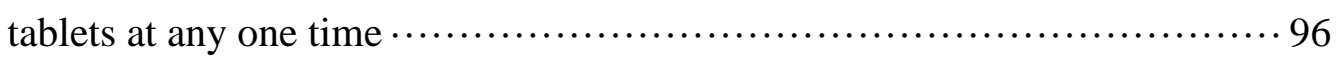

Table 4.11 User services: Maximum number of teachers/educators who use

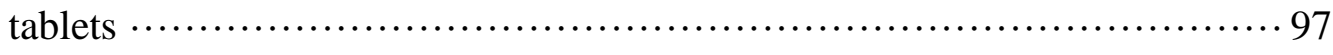

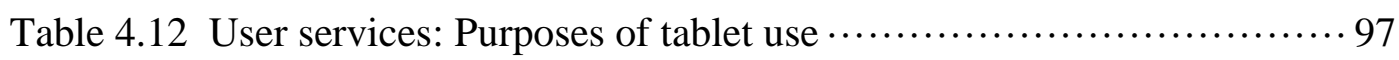

Table 4.13 User services: Reasons for not using tablets in the past $\ldots \ldots \ldots \ldots \ldots 99$

Table 4.14 User services: Learning sources for tablet use $\cdots \ldots \ldots \ldots \ldots \ldots \ldots \ldots \ldots \ldots$

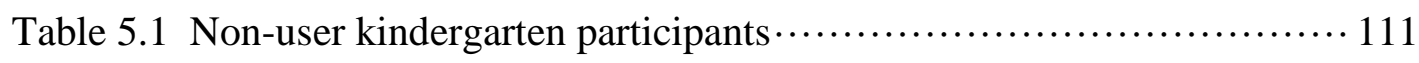

Table 5.2 Non-user home-based service participants $\ldots \ldots \ldots \ldots \ldots \ldots \ldots \ldots \ldots \ldots \ldots \ldots \ldots \ldots \ldots$

Table 5.3 Non-user education and care service participants $\cdots \ldots \ldots \ldots \ldots \ldots \ldots \ldots \ldots \ldots 118$ 


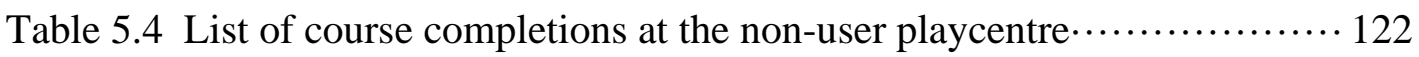

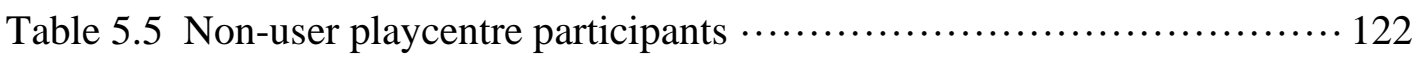

Table 6.1 How teachers/educators supported children's tablet use $\cdots \ldots \ldots \ldots \ldots \ldots 130$

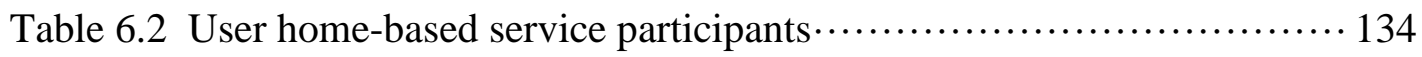

Table 6.3 Phase 2B SR-video episodes: User home-based service...$\ldots \ldots \ldots \ldots \ldots 135$

Table 6.4 User education and care service participants $\ldots \ldots \ldots \ldots \ldots \ldots \ldots \ldots \ldots \ldots \ldots \ldots \ldots \ldots$

Table 6.5 Phase 2B SR-video episodes: User education and care service $\cdots \cdots \cdots \cdot 149$

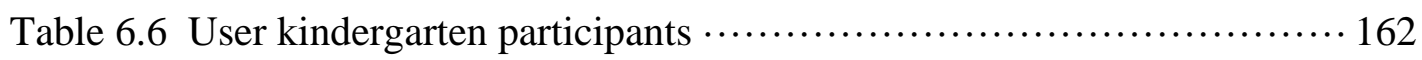

Table 6.7 Phase 2B SR-video episodes: User kindergarten $\cdots \ldots \ldots \ldots \ldots \ldots \ldots \ldots \ldots \ldots \ldots \ldots$ 


\section{Glossary}

Digital divide

Digital technology

Information communication technologies (ICT)

Kaiako

Kōhanga reo

Stimulated Recall (SR)

Te reo

Touchscreen tablets

Video-stimulated recall (video-SR)

Waiata

Whānau
Differences in the access to, use of, or impacts of information and communication technologies (ICT) between groups

Use of ICT to access digital media online usually through portable computers

The equipment and computer programmes that allow access, use, and sharing of information The Māori word for teachers and educators Meaning "language nest" in the Māori language. ECE services which only uses the Māori language An introspection procedure used for research on teaching to support participants' recall by showing artefacts such as photos and videos

The Māori language

Lightweight portable computers with a touchscreen interface such as iPads or Samsung tablets

The use of video-recorded episodes of teaching practices to stimulate the recall of teachers/educators

The Māori word for songs

The Māori word for family including the extended family and also kinship with people who are not related such as close friends 


\section{Chapter 1}

\section{Introduction}

Touchscreen tablets have been called pedagogical "game changers" (Laidlaw, O’Mara, \& Wong, 2015, p. 73). Despite plenty of research on their use for teaching and learning in international early childhood education (ECE) settings (e.g., Yelland \& Gilbert, 2017), studies about them in New Zealand are few. This research investigates the extent of tablet use amongst four service types in New Zealand. Data from this studies is intended to provide useful information on how tablets are used and if not, the services' reasons for not using them. In particular, this thesis intends to offer insights on how tablets are used to support teaching and learning.

\subsection{Touchscreen tablets}

Touchscreen tablets, also known as tablet computers and hereafter referred to as tablets, are lightweight, mobile devices with a flat, panel screen used for both display and input (McEwen \& Dubé, 2016; Neumann \& Neumann, 2014). These devices have features such as multimedia playback, digital photography, multitouch interface, long battery life, instant start-up, and wireless Internet connectivity. Whilst often possessing similar operating systems and functionality to touchscreen mobile phones, tablets differ in their telephony limitations and are usually $25 \mathrm{~cm}$ by $12 \mathrm{~cm}$ in size (Young, Trudeau, Odell, Marinelli, \& Dennerlein, 2012).

Higher-end tablets, such as iPads, have capacitive screens allowing a higher frequency of touch-based interaction compared to less durable resistive screens commonly found in children's tablets such as Leap Pads (Dubé \& McEwen, 2017). Users engage with various software applications, called apps, via gesture-based operating systems such as Apple iOS and Google Android that respond to pressure from fingers or a stylus on capacitive glass screens (Dubé \& McEwen, 2017; Kucirkova \& Sakr, 2016). Tablets with capacitive touchscreens, such as iPads and Samsung Tablets, have been frequently used in ECE (e.g., Marsh et al., 2015).

Tablets may have been commercially available since 2010, but their development was planned decades earlier. In 1968, Alan Kay conceptualised "a personal computer for all ages" (Kay, 1972, p. 1) that he called the Dynabook, an 
A4-sized portable multimedia computer with an attached keyboard, flat screen liquid crystal display (LCD) screen and handwriting recognition programmable for children's learning (Kay, 2012; Kay \& Goldberg, 1977). Since Samuel C Hurst developed early versions of tablets in 1971, they have been used pervasively as communication tools (Atkinson, 2008). In 1985, Buxton, Hill, and Rowley’s technical analyses of early tablets concluded that the gestural interface could replace many functionalities of a one button mouse whilst allowing users to make digital marks with strokes of a finger (e.g., painting). After years of weak commercial success (Atkinson, 2008), tablets eventually reached global distribution in 2010 with the phenomenal reception of the iPad which sold 300,000 units on its release day (Apple Inc., 2010) and over 9 million units the following year (Apple Inc., 2011).

According to Statista.com, since the iPad's release in April 2010, global tablet computer shipments have increased from 18.6 million to approximately 1.52 billion as of 2019 (Liu, 2019). A survey of tablet ownership amongst New Zealanders aged 18-years-old or older showed an increase from 29\% in 2013 to $51 \%$ $(n=1,075)$ in 2015 (Research New Zealand, 2015). Clearly, this strong uptake of tablets in New Zealand warrants investigation of their use by young children in educational contexts.

Tablets have increasingly been used by young children as tools for entertainment and informal education (Holloway, Green, \& Livingstone, 2013; Wartella, Kirkpatrick, Rideout, Lauricella, \& Connell, 2014). As of 2012, 80\% of top selling paid educational apps in Apple's App Store were marketed for consumption by young children (Shuler, Levine, \& Ree, 2012) and Lawrence (2018) reported the same proportion in 2017. Because tablets are amongst the tools that mediate children's participation, there is a need to discuss the advantages and disadvantages they bring to teaching and learning.

\subsection{ECE in the New Zealand context}

New Zealand's ECE system caters for children from birth to school entry which is five years old (Ministry of Education, 2017a). New Zealand's ECE service types include education and care services, kindergartens, home-based education and care services, playgroups, playcentres, ngā kōhanga reo (services utilising full Māori 
language), Te Aho o Te Kura Pounamu-the correspondence school, and hospitalbased services (Ministry of Education, 2014). Of these service types, the four with the highest proportion of participation at the time of data collection for this research were education and care (65\%), kindergarten (15\%), home-based (9\%), and playcentre (7\%) (Ministry of Education, 2017b).

Participation in ECE in New Zealand has been gradually increasing. A report on participation by the Ministry of Education (2018a) showed that the average number of hours of ECE attendance per week in 2018 was 21 hours and 27 minutes, a slight increase from 20 hours and 45 minutes in 2017. According to service type, children spend an average of 24 hours and 44 minutes in home-based services, 23 hours and nine minutes in education and care services, 17 hours and 22 minutes in kindergartens, and four hours and 11 minutes in playcentres each week (Ministry of Education, 2018a). Based on the ECE annual census (Ministry of Education, 2018b), participation in ECE has been steadily increasing from slightly more than 150,000 enrolments in 2005 to 202,772 in 2017. In 2018, the Ministry of Education's data showed that $65.5 . \%$ of the 202,772 children aged from birth to four-years-old who attended ECE with attendance rates higher for older children with $96.3 \%$ of fouryear-olds enrolled in ECE (Ministry of Education, 2018b).

New Zealand's ECE curriculum, Te Whāriki, is based on sociocultural theory which emphasises the importance of children's participation in society through guidance and support provided by teachers/educators (Ministry of Education, 2017a). Te Whāriki subscribes to "Vygotsky's ideas that learning leads development and occurs in relationships with people, places and things, mediated by participation in valued social and cultural activities" (Ministry of Education, 2017a, p. 61). These activities, which could include teaching and learning using tablets, are scaffolded by teachers/educators who base their teaching following set principles and strands. Te Whāriki means "the mat" in the Māori language (Ministry of Education, 1996, 2017a). The curriculum is a framework that allows kaiako - teachers or educatorsto exercise diversity and versatility in their pedagogy guided by weaving the principles and strands together. In this thesis, instead of using the term 'kaiako', I use teachers/educators to distinguish fully or provisionally certificated teachers from unqualified teachers. 
In relation to digital technology, the first iteration of Te Whāriki, published in 1996, stated only that children are growing up in the context of a changing society and that they could benefit from the use of technology (Ministry of Education, 1996). Within the strands in the updated Te Whāriki (Ministry of Education, 2017a), the contribution, communication, and exploration strands now specify how digital media or devices support children's learning. Contribution involves the right of children to participate in the learning community and develop reciprocal relationships with their teachers/educators by using digital and non-digital technologies. Communication involves children's learning to interact with others in different ways and to interpret the ways others connect with them so that they can become strong communicators by using tools, including digital devices, to engage with various digital formats. Exploration involves children's learning by exploring diverse ways of play and diverse learning environments including digital technology. The curriculum expects teachers/educators to provide a wide range of resources and to make purposeful use of them. This includes technology in supporting children in their preparation for primary schooling. In relation to this, Te Whāriki emphasises teachers'/educators' role in supporting "children to develop an understanding of security and safety when communicating in a digital world" (Ministry of Education, 2017a, p. 45).

The curriculum specifies digital technologies and digital media amongst the resources used in ECE and emphasises children's right to "access all learning experiences" (p. 39) and for them to have "access to sensory-rich, open-ended durable resources" (Ministry of Education, 2017a, p. 48). In order to guide children's learning, teachers/educators are expected to understand the importance of "materials, artefacts and tools and the signs and symbols of societies and cultures" (Ministry of Education, 2017a, p. 61). Te Whāriki encourages teachers/educators to provide a wide range of resources and opportunities for children to engage in holistic learning. These curriculum expectations mean that it is important to understand how teachers/educators are currently using digital technologies, including tablets, within their practice. 


\subsection{The development of my interest in this research}

I first used an iPad in 2013 whilst teaching at two kindergartens in Japan for children aged two- to five-years-old. I appreciated the portability and convenience of using an iPad and noticed that when children used tablets, they socialised more, collaborated better together, and improved in their self-esteem and ways of expressing what they learned through language, music, movement, numeracy, creative arts, and imaginative play. I observed that digital technology enabled children to explore different languages and cultures that were not physically available to them. I first started teaching young children in the Philippines where using digital technology in formal education was considered a luxury. When I began using digital technology whilst teaching in Japan, I learned to balance when to use digital and non-digital tools. This greatly enriched my career as an early childhood educator. There were many times when I also learned when to avoid using digital technology when teaching young children.

After completing my Master's degree in educational studies in Japan, I worked at the same two kindergartens for three years, and became interested in researching how tablets were used in ECE services for my $\mathrm{PhD}$. In 2012, I read Terreni's (2009) Master's thesis on interactive whiteboards and this sparked my interest in researching how teachers/educators used portable touchscreens in ECE settings.

From my own experience, I found tablets useful in kindergartens but many ECE services in Japan had their reasons for not using ICT. At one of the two kindergartens where I worked, teachers freely used their personal tablets and phones to document children's learning. I became interested in researching why some ECE services used tablets whilst others do not.

\subsection{Rationale for this study}

According to Jeong and Kim (2017), there is a need for further studies into the use of different types of information and communication technologies (ICT), especially regarding portable devices that supported mobility and collaboration amongst young children. Research on the use of mobile devices, particularly tablets, 
in ECE settings needs to be carried out as more and more children use them in their home environment. Teachers/educators have also found that tablets are easier to use compared to desktop or laptop computers (Plowman, McPake, \& Stephen, 2010; Radesky, Schumacher, \& Zuckerman, 2015). However, Cohen, Hadley, and Frank (2011) concluded that whilst young children learned the fine motor skills necessary to interact with tablets, providing "the device alone does not guarantee engagement and learning" (2011, p. 5). Because tablets are one of the many resources teachers/educators use as teaching tools, researchers have argued the need to facilitate their use (Beschorner \& Hutchison, 2013; Finch \& Arrow, 2017; Kirkorian, 2018). Therefore, it is important to investigate how tablets are used to scaffold children's learning in ECE services.

Research on ICT use in New Zealand ECE has been focused either on computers in general (e.g., Hatherly \& Chapman, 2013) or on iPads alone (e.g., Falloon, 2013). Research on tablets has been limited to a few service types, notably education and care services or kindergartens, and was usually about iPads (e.g., Finch \& Arrow, 2017; Khoo, Merry, Nguyen, \& MacMillan, 2015). Reports from services that chose not to use tablets (e.g., Gerritsen, Morton, \& Wall, 2016) did not explain why teachers/educators chose not use ICT or why services opted out from using digital technologies.

\subsection{Research Questions}

This study investigates tablet use and non-use in New Zealand's ECE sector to answer the following research questions:

1. What is the extent of tablet use and non-use for teaching and learning amongst teachers/educators in four ECE service types in New Zealand?

2. What are the reasons for the non-use of tablets amongst teachers/educators across these four ECE service types?

3. How do teachers/educators use tablets in ECE settings to support children's learning?

4. What are the barriers and affordances to tablet use in ECE pedagogy? 


\subsection{Overview of thesis chapters}

This chapter has given an introduction to touchscreen tablets and the ECE context in New Zealand. How my personal experience with using and not using an iPad in my ECE teaching inspired my research on the topic was explained. The rationale and research questions of this study were presented followed by an overview of chapters.

Chapter 2 presents a review of literature relevant to this research. Firstly, literature on children's access to and use of tablets are reviewed followed by a concise overview of international studies on the impacts of young children's access to and use of tablets. Then, studies on how these devices were used in educational contexts to support children's learning and development are examined. Next, research on issues surrounding the adoption of tablets in ECE services such as cybersafety and other technical issues are discussed. The theoretical framework which underpins this study is introduced followed by relevant concepts on technology.

In Chapter 3, the interpretive paradigms underpinning the design of this research and its methodology is outlined. Next, the research design is presented followed by details on how quantitative data and qualitative data were collected. Finally, the ethical aspects, data coding, and analysis are addressed.

Chapter 4 presents the quantitative results from Phase 1, the national survey. It begins with the results from the descriptive analyses followed by results from the inferential analyses. This chapter primarily answers the first two research questions.

The fifth and sixth chapters provide data from the collective case study which forms Phase 2 of this research. Chapter 5 presents results from the collective case study of tablet non-users while Chapter 6 details the results from the national survey's qualitative question based on responses from touchscreen user services followed by the collective case study of user-services. To further explain the results of the national survey, Chapter 5 addresses the second and fourth research questions and Chapter 6 answers the third and fourth research questions. 
Finally, in Chapter 7 the key findings from the survey and the collective case study are discussed. Then, the limitations of the research, and recommendations for futher research are provided followed by a section detailing the contributions of this research. A discussion on the implications for policy, practice, and professional development closes the thesis. 


\section{Chapter 2}

\section{Literature Review}

This chapter reviews the literature on tablet use by young children, particularly within ECE. This review is divided into different sections beginning with children's access to and use of tablets, followed by empirical studies and related guidelines about the developmental impacts of young children's tablet use. Then, international studies on tablet use in early childhood education (ECE) settings are examined before the chapter continues with an examination of New Zealand studies involving information and communication technologies (ICT), and tablets. Next, the theoretical framework underpinning this study is introduced. Finally, matters surrounding the adoption of ICT, including tablets, in ECE settings such as cybersafety and technical issues and relevant technological concepts are examined.

In locating studies on young children's access to and use of tablets, my initial search revealed a significant number of items at around 10,200 results. The number of these search results decreased when I used the Victoria University Library search engine and when I removed irrelevant search results such as studies on older children, including primary schoolchildren and adolescents. I also disregarded studies which included ICTs beyond "touchscreen tablets", "tablet computers", or "iPads". Table 2.1 shows the search terms I used for my literature review.

\begin{tabular}{|c|}
\hline Search Terms \\
\hline "touchscreen tablet" and "early childhood" \\
\hline "tablet computer" and "early childhood" \\
\hline "iPad" and "early childhood" \\
\hline "touchscreen tablets" "early childhood" "New Zealand" \\
\hline "tablet computer" "early childhood" "New Zealand" \\
\hline "iPad" "early childhood" "New Zealand" \\
\hline
\end{tabular}

\section{Table 2.1. Search terms.}

A considerable number of these studies have found both positive and negative impacts on young children using touchscreen tablets. Many of these studies took either a use or non-use stance so I found this a useful starting point for structuring this literature review. Services usually made the decision whether teachers/educators should use tablets with children or not. Thus, the binary stance made these studies 
easy to categorise based on the benefits of using tablets or the reasons as to why tablets should not be used.

\subsection{Children's access to and use of tablets}

To contextualise the importance of the issues surrounding young children and their exposure to tablets, this section provides information on the increases in children's use of digital technology and their access to digital media. Most of the results were from surveys conducted in the United States of America (USA), Canada, the United Kingdom (UK), European and Asian countries, Australia, and New Zealand (e.g., Bergström \& Höglund, 2014; Christensen, 2017; Ebbeck, Yim, Chan, \& Goh, 2015; Fridberg \& Redfors, 2018).

International and national surveys involving tablets were undertaken mostly by large organisations with some also providing guidelines on children's access to tablets in relation to their findings. Foremost is the Common Sense census, a longitudinal study composed of a series of cross-sectional tracking surveys on digital technology and media access and use of children eight-years-old and younger in the USA (Rideout, 2011, 2013, 2017). According to a 2017 report based on a survey of 1,454 parents, $98 \%$ of children eight-years-old and younger lived in homes with access to a mobile device. This was a significant increase from 52\% in 2011 as reported by 1,384 parents. More specifically, tablet computer access at home has gradually increased from $8 \%$ in 2011 to $40 \%$ in 2013, as reported by 1,463 parents, and to $78 \%$ in 2017 . There has been an increase in time spent on these devices from five minutes a day in 2011 to 48 minutes in 2017. In an adaptation of the Common Sense census, Kabali, Irigoyen, Nunez-Davis, Budacki, Mohanty, Leister, and Bonner (2015) surveyed families in an urban, low-income minority community in Philadelphia, PA. and found that $83 \%$ of 350 four-year-olds and younger owned tablet computers.

A more recent survey conducted by Eisen and Lillard (2017) investigated 43 four- to six-year-old children's ICT awareness and preferences by showing them photos of iPads, iPhones, computers, books, and televisions. The children, who were from a mid-Atlantic community in the USA, identified which ICT devices they perceived could be best used for work, reading, or learning tasks. When first shown 
the iPad picture, it was correctly identified by 35 children (81\%) with 41 children (95\%) reporting having seen an iPad before. Children ranked iPads second to telephones for use by adults at work and second to iPhones for reading. The tablet was ranked fourth for learning after televisions, iPhones, and computers by the children. When children's parents were asked how often children used tablets, smartphones, computers, televisions, and telephones, they reported that their children used tablets daily, second only to televisions. Additionally, Eisen and Lillard's (2017) comparison of parents' and their children's perceptions regarding the multifunctionality of these devices found that parents and their children equally ranked iPads and iPhones as the most multifunctional devices, followed by computers.

In the UK, young children's tablet use was compared through interviews with 200 parents of children under five in 2012 and 1,034 parents in 2015. Results showed that the number of young children who used tablets increased from $23 \%$ in 2012 to $73 \%$ in 2015 (Duff \& Leggett, 2012; Ehren \& Leggett, 2015). The 2015 CHILDWISE Monitor Pre-School Report (Ehren \& Leggett, 2015) found that threefifths of the children owned a tablet.

Examining children's access to and use of touchscreen technology more specifically, O'Connor's (2017) online survey of 226 British parents with children aged three and younger investigated parents' perceptions. According to the results, $92 \%$ reported that their children played with gaming apps whilst $67 \%$ used educational apps. Additionally, 37\% used video-chatting apps such as Skype and $24 \%$ used touchscreen devices to read e-books. Most parents (72\%) perceived that touchscreen devices were tools for learning new skills whilst half saw them as devices to access entertainment. Many parents (61.5\%) believed that children needed guidance when they used touchscreens. Almost all parents (85\%) established a screen time limit of 20 to 30 minutes a day for their children. This study reported that " $95 \%$ of parents had no guidance or information" relating to their children's touchscreen technology use (O’Connor, 2017, p. 96).

A significant four-phase study on children's media use in the UK was conducted by Marsh et al. (2015). The first two phases involved data collection 
about children's media use at home beginning with a survey of 2,000 parents with children aged five-years and under (Phase 1) and followed by case studies of children aged four-years and under and their families (Phase 2). Phase 3 studied children's use of apps in ECE services, and Phase 4 analysed specific apps.

In the first phase, $31 \%$ of 2,000 parents reported they personally-owned a tablet and detailed how their children used these devices and their apps (Marsh et. al., 2015). The study found that children used tablets daily at an average of 79 minutes on weekdays and 83 minutes on weekends. According to parents of three- to five-year-olds, their children could perform common tablet operations and navigate apps, except for using complex apps such as video apps and reading apps, as well as finding and buying new apps in the app-store. Parents of children two-years-old and under (47.7\% of 2,000 parents surveyed) reported that more than half of their children could swipe on the screen (54\%). Additionally, more than a third of children two-years-old and under could take photos, use creativity and learning apps, control the volume and power, drag and trace shapes, open/close apps, tap on the screen, draw using the tablet, drag items across the screen, and unlock the device. However, around $57 \%$ to $70 \%$ of the children aged two-years and under could not "click on a cross in a box to get rid of a pop-up, use gaming apps, resize objects by pinching and dragging, and show others (e.g., siblings) how to use the device" (Marsh et al., 2015, p. 10).

The second phase of Marsh et al.'s (2015) study consisted of interviews with and observations of children and their families about their access to and use of digital technology and media at home, parental engagement, and their values, beliefs and prior experiences relating to children and digital technology. How parents mediated their children's tablet use by managing apps and related digital media were observed. Key results in this study found co-viewing and co-use as well as two types of parental mediation: restrictive, active, or instructive mediation. Co-viewing and couse of tablets between parents and their children were observed. The case study phase found that children used tablets for play and creativity including imaginative and parallel play. It was observed that the shared viewing and use of digital technology and related media involved restrictive, active, and instructive mediation. Restrictive mediation limited children's access to digital media, whilst active and 
instructive mediation included both positive and negative ways of monitoring access to digital media such as active monitoring of digital technology use and preventing online threats.

The third and fourth phases of Marsh et al.'s (2015) study identified the most frequently used apps in school and the different forms of play they afforded. YouTube was the foremost app which afforded communication play, imaginative play, and role play as well as creativity and creative thinking. Other apps enabled children to engage in different forms of play such as social play, creative play, virtual locomotor play, deep play, exploratory play, mastery play, and object play. This study had recommendations regarding digital technology and media use such as examining apps to identify characteristics that limit or promote play and creativity. The study's specific recommendations were determining the purpose of an app, knowing which design features supported learning and engagement, and selecting apps with limited commercial properties. Equally important were supporting or scaffolding children's app use and choosing open-ended or similar apps which promoted play and creativity.

A further, smaller scale study by the UK's communications regulator, Ofcom (2017), interviewed 677 parents and found that $21 \%$ of three- to four-year-old children owned their own tablets. Of these children, $41 \%$ used their devices to watch television shows. The study found that parents' concerns about their children's exposure to inappropriate content included anti-social behaviour such as offensive language, sexually explicit content, and violence were often based on television viewing.

Other survey studies in the UK have reported an increase in access to and use of touchscreen devices by young children. A survey by Ahearne, Dilworth, Rollings, Livingstone, and Murray (2015) asked 82 parents of children aged one- to two-yearsold about their children's tablet use at home. Results showed that most of the parents (87\%) let their children play with their devices from nine to 26 minutes daily. Amongst the parents, 67 owned tablets and 58 of them reported actively looking for apps for their children to use. Parents reported that their children could swipe across the screen $(91 \%)$ and that their children could unlock touchscreen devices (50\%). 
Most of the parents (64\%) felt that touchscreen features were actively sought by their children.

According to an online survey for a UK project, Toddler Attentional Behaviours and Learning with Touchscreens, 713 of 715 parents of children aged six-months to three-years owned touchscreen devices at home (Bedford, Saez de Urabain, Cheung, Karmiloff-Smith, \& Smith, 2016). Results showed that $9.6 \%$ of the 613 children of participants had their own touchscreen devices. There was also an observable increase in tablet use with age. From a total number of 613 children, 123 of 11-month-olds and younger, 194 of 12- to 18-month-olds, 145 of 19- to 25month-olds, and 151 of 26- to 36-month-olds use tablets. Children's tablet use averaged 24.45 minutes a day.

Other countries have also reported similar trends in young children's access to and use of tablets. In Australia, a survey of 109 parents of three- to five-year-old children showed that $61 \%$ of them had access to tablets at home and were using them for an average of 20 minutes daily (Neumann, 2014). The only report found from New Zealand focused on digital technology use and access to digital media amongst six- to fourteen-year-olds (NZ On Air, 2015). Of the 708 households interviewed, $72 \%$ of parents said their children used tablets such as iPads or Samsung tablets, either at home $(59 \%)$ or outside the home $(29 \%)$. The report showed that whilst television was still the dominant media amongst households, tablet use in the country rivalled radio and computer use. Differences in tablet distribution across households were insignificant with slightly fewer tablets in households of Pacific Island families, parents under 40, and homes with annual income up to $\$ 50,000$ in New Zealand dollars. YouTube was the most popular and frequently accessed app.

The research reviewed above has clearly indicated that tablet use amongst young children is increasing across all age groups as well as in the number of minutes they spend using these devices. These studies showed that children could operate tablets and their apps at an early age of one- or two-years. Despite the international evidence that younger children are actively using tablets, there is no evidence in New Zealand about the use of these devices amongst children under fiveyears-old. Although not directly addressing this issue, this research will provide 
insights into tablet use amongst young children within ECE contexts. The increase in accessing and using tablets has led to concerns on how they affect young children's learning and development and these impacts are discussed next.

\subsection{Impacts of tablets on young children}

A considerable number of studies have found both positive and negative impacts of young children using tablets. Whilst many of these are directly relevant to this study and are reviewed later in this chapter, this section begins by presenting an overview of more peripheral studies to provide a broader context for this thesis. Studies reporting negative impacts resulting from young children's tablet use are located primarily from neuroscience, psychology, and child development literature. These studies are briefly surveyed before giving attention to research showing how young children's tablet use in educational settings has been found to positively impact children's learning and skills development.

2.2.1. Negative impacts of tablet use. Because tablets are a form of ICT, their use by young children has often been associated with the negative impacts of using other earlier forms of digital technology and screen media. Concerns about the impact of ICT on young children emerged in the 1980s with the fear that young children's computer use in classrooms could decrease their engagement in concrete activities, physically active play and their social interactions with peers (Healy, 1998; Swaminathan \& Wright, 2003). Exposure to screen media, including tablets, has also been argued to affect children's sleep patterns, health, behaviour, attention, language development, and academic performance (Ernest, Causey, Newton, Sharkins, Summerlin, \& Albaiz, 2014).

Young children's access to and use of tablets has been debated in recent years because of claims related to the impact of screen time on children's health. To address these potential issues on young children's health, well-being, and development, organisations have proposed guidelines on children's screen time and use of digital technology, including tablets. Guidelines have been set to restrict young children's access to and use of digital technology and related media (e.g., Carson, Tremblay, Spence, Timmons, \& Janssen, 2013). 
In its most recent response to children's increasingly habitual use of digital technology including iPads, the American Academy of Pediatrics Council on Communications and Media (AAPCCM) discouraged screen time amongst children aged two-years-old and under and recommended that other children have less than one to two hours of screen time a day and that parents monitor children's media use (Chassiakos, et al., 2016; Strasburger \& Hogan, 2013). Marsh et al. (2015) have, however, challenged these restrictions on children in early childhood, stating that touchscreen "tablets are appropriate for this age group if use is limited in nature and takes the form of co-use with parents" (p. 40).

Three earlier policy statements released by the AAPCCM in 2016 gave recommendations on children's digital technology and media use. Of interest to this study was the acknowledgement in the first policy statement that their recommendations were mostly based on studies involving children's television use. Across the three documents (Chassiakos et al., 2016; Hill et al., 2016; Radesky et al., 2016), recommendations related to young children included that parents develop a family media use plan and that trusted caregivers and parents scaffold children's ICT use, particularly for children aged under two years. Guidelines also included that digital technology use by children aged five-years and younger be limited to one hour a day and that fast-paced programmes be avoided. Switching off digital technology in the background and eliminating advertising from apps was also recommended (Radesky et al., 2016).

In line with these guidelines, Elkind (2016) argued that tablet use amongst children aged two- to five-years-old should be restricted. He also emphasised the importance of adults' scaffolding of young children's tablet use through social interactions to mitigate frustrations in learning and incorporate linguistic aspects to their learning. Similarly, Straker, Zabatiero, Danby, Thorpe, and Edwards (2018) argued the importance of informed and appropriate digital technology use by parents and professionals to support children's health, well-being, and educational development.

The World Health Organization (2019) issued its first-ever guidelines on screen time recommending that children under five-years-old should get no more 
than 60 minutes of screen time daily and that children younger than one-year-old be exposed to no screen time at all. These recommendations were particularly related to sedentary screen time such as children watching television and videos or playing video games as opposed to engaging in physical activities. In an online article posted on the Time Magazine website by the Associated Press (2019) and an online post of interviews by the Science Media Centre (2019), experts responding to these recommendations argued that these guidelines were an oversimplification of the issues involving screen time. Aside from pointing out that the data was insufficient for giving such recommendations, critics noted that these guidelines only focused on the quantity of screen time (Associated Press, 2019; Science Media Centre, 2019).

These experts argued that not all screen time is disadvantageous to young children. In particular, the Associated Press quoted Professor Andrew Przybylski of the University of Oxford who explained that these guidelines disregarded the content and context involving how children used tablets (Science Media Centre, 2019). In an interview published online by the Science Media Centre (2019), Przybylski explained that depending on context, screen time could have positive impacts on young children and their families by providing "relaxation, low energy play, or communication with family" (Science Media Centre, 2019, para. 18). Whilst the Associated Press (2019) described the World Health Organization's guidelines as similar to the recommendations of the American Academy of Pediatrics, Przybylski's argument (Science Media Centre, 2019) indicated that the American Academy of Pediatrics, which had revised its guidelines numerous times in the past few years, had already recognised that screen time is a much more complex issue and could not be simply treated in a generalised manner.

Several empirical studies have found that tablet use by young children has had a negative impact on their physical well-being and cognitive development. Much of the literature describing these negative impacts comes from neuroscience or other non-educational fields with the reported studies conducted outside educational settings. Illustrative examples of these studies are briefly reviewed here.

The effects of tablet use on children's physical health and wellbeing have been examined. In particular, survey studies on sleep and sleep onset (e.g., Cheung, 
Bedford, Saez de Urabain, Karmiloff-Smith, \& Smith, 2017; Lin, Cherng, Chen, Chen, \& Yang, 2015) have reported that tablet use was linked to more daytime sleep, less night-time sleep and delayed sleep onset. Howie, Coenen, Campbell, Ranelli, and Straker's (2017) laboratory study investigated three- to five-year-old children's head, neck, and trunk posture during non-screen toy play, television viewing, and tablet use. Their findings showed that compared to non-screen toy play, tablet use led to lower physical activity and more sitting time. The authors suggested supervision of children's tablet engagement to minimise musculoskeletal risks and extended periods of sedentary behaviours.

Spitzer (2013), in his review of literature on the impact of tablet use on children's cognitive development, argued that children required more physical ways - such as grasping, gripping, and pinching — of interacting with objects than was possible with tablets. In relation to this, several studies have examined differences in learning using real-world objects and digital objects (e.g., Choi, Kirkorian, \& Pempek, 2018; Hipp, Gerhardstein, Zimmermann, Moser, Taylor, \& Barr, 2017). Some studies have found that children had trouble transferring learning from $2 \mathrm{D}$ to $3 \mathrm{D}$ environments because they processed 2D images more slowly than 3D images. These studies concluded that videos impacted children's social development because screen media failed to teach real-world social cues such as eye gaze, pointing, and use of name (e.g., Choi \& Kirkorian, 2016; Kirkorian, 2018).

In connection to young children's application of 2D to 3D transfer of learning, Geng, Disney, and Mason (2016) studied two- and three-year-old children's use of paper and pencil to draw the image of a cat from an iPad gaming app. They found that the three-year-olds successfully demonstrated transfer of learning from the iPad to paper with the help of drawing and language cues. Their results aligned with Hipp et al.'s (2017) findings that social factors, such as scaffolding provided by an adult, helped enhance transfer of learning involving tablets.

These latter studies indicated that tablet use could negatively impact young children's sleep and sleep onset, physical activity, and 2D to 3D transfer of learning. Some of the literature reviewed have suggested that these negative impacts on young children could be mitigated by scaffolding how children use tablets. This suggestion 
is further explored in the next section's review of empirical literature on the positive impacts of tablet use.

2.2.2. Positive impacts of tablet use. This section reviews studies on the positive impacts of young children's tablet use in ECE settings. As these studies are peripheral to the focus of this research, only a brief review is provided across the following learning areas: gross and fine motor skills development; mark making including drawing and painting; literacy; science, technology, engineering and mathematics (STEM); and social development.

Several studies have reported that using tablets supported young children's development of gross motor skills such as stabilising and nodding. Young children's advanced fine motor skills such as general and precision tapping, pointing, swiping, and thumb pressing were also supported (e.g., Merchant, 2015; Dubé \& McEwen, 2017). For example, a recent cross-sectional study by Moon, Cho, Lim, Roh, Koh, Kim and Nam (2019) involving 117 three- to five-year-old children from four kindergartens in the cities of Seoul and Guri in South Korea found that three-year-old children showed a positive association between usage frequency of touchscreen devices and their fine motor skills development. Moon et al. (2019) did not specify which fine motor skills improved amongst the children. Their study used a crosssectional survey to investigate whether touchscreen devices, including tablets, supported young children's fine motor and language development.

A cross-sectional study investigating how tablets supported young children's fine motor skills was conducted by Souto et al. (2019). Their research was conduced at public and private day care centres in a small city in Brazil. Data was collected from parents of 78 children aged 24- to 42-months-old using a sociodemographic and interactive questionnaire and from the children using the Bayley-III Fine Motor Scale scores. The data were analysed using Chi-square and Mann-Whitney U tests. Although the study did not specify which fine motor skills improved, the researchers reported that children who used tablets had better fine motor skills than those who did not. Various screen time limits set by parents up to around an hour daily did not affect children's fine motor skills development. Regarding how tablets were used, children often used these with their parents for both passive and active activities. 
In contrast to the research by Spitzer (2013) and Choi et al. (2017) reviewed in section 2.2.1, tablets have been found to also support children's mark making activities. Crescenzi, Jewitt, and Price (2014) found that whilst using real paint and paper provided more sensory experiences, using tablets for mark making activities elicited continuous, faster, longer, a wider range, and more complex sequences of touches. When children's mark making practices using tablets were supported by adults, positive results in children's drawing (Couse \& Chen, 2010) and letter writing skills (Bigelow, 2013; Patchan \& Puranik, 2016) were noted. Di Cesare, Harwood, and Rowsell (2019) observed that the multimodality of tablets supported children's mark making and related activities using digital technologies.

Similarly, in a recent study, Borg (2019) examined how three-year-old children's use of the iPad app, Doodlecast, supported their mark making experiences. Her qualitative study explored how five children used two tablets for painting over a two-month span. The research, as a participant observer, instructed children how to use the app. Then, their interactions with the iPad were audio- and video-recorded. Compared to traditional mark making practices, digital art made using Doodlecast was "clean and tidy" (Borg, 2019, p. 16) whilst offering more affordances such as the ability to access a wider range of colours, using varied drawing styles, and easily saving, storing, and resuming work. The app enabled children to modify their work, learn how to comprehend feedback provided by the app, and explore painting in playful, risk-free ways.

There is an extensive body of research investigating the use of tablets for literacy learning, with many reporting positive outcomes. Studies have reported gains in young children's emerging knowledge of print and digital literacies and enriched connections between reading, writing, listening, and speaking (Beschorner \& Hutchison, 2013; Neumann, 2014). Young children's tablet use has also led to gains in phonological awareness (e.g., Christensen, 2017; Da Cunha, 2016) and vocabulary acquisition (e.g., Chiong \& Shuler, 2010; Walter-Laager, Brandenberg, Tinguely, Pfiffner, Schwarz, \& Moschner, 2016). Neumann's (2018) research on young children's use of literacy apps found gains in children's knowledge of print concepts as well as letter name and sound. In addition, this study found that "the level of scaffolding provided by a more knowledgeable person such as a teacher, 
parent, or peer, is an important factor that may influence the effectiveness of tablets in supporting emergent literacy" (Neumann, 2018, p. 244).

Three relevant studies investigating children's reading and comprehension reported the benefits of using tablets. Masataka (2014) reported gains in young children's language acquisition when they used iPads for reading. Roskos and Burstein's (2012) study found that the target words spoken by young children were higher when iPads were used while Cingel and Piper (2017) reported that parent mediation afforded through haptic e-book reading directed the child's attention to the story content (see also Krcmar \& Cingel, 2014). A recent study in New Jersey, USA, involving 13 children aged three- to five-years-old compared six children's e-book reading using iPads to a control group of seven children who used traditional paperbased picture books (Estevez-Menendez, An, \& Strasser, 2019). The researchers observed that the iPad group's reading comprehension and acquisition rate of new vocabulary words improved significantly more than the control group. They concluded that high-quality multimedia storybooks scaffolded young children's emergent literacy development. However, Estevez-Menendez et al. (2019) also cautioned teachers/educators that although the multimodality of tablets enhanced children's reading and learning from e-books, certain features could distract them from comprehending the story.

As for how tablet use supported ECE teachers and children's literacy learning, one study conducted at a suburban Midwestern elementary school in the USA was located. Lu, Ottenbreit-Leftwich, Ding, and Glazewski (2017) investigated how experienced iPad-using early childhood teachers used these devices with young children in their teaching practices and which literacy apps the teachers used to support daily literacy instruction. The four ECE teachers who participated in the study had been using iPads in the classroom from two to four years. Results from classroom observations and interviews with the teachers found that eight of the commonly used iPad apps were used more with teacher directed practices. Teacher directed practices were split into two categories: using iPads at learning stations which helped children focus on the task and allowed teachers to check on them for one-to-one instruction, and using iPad apps during transitions such as using skilland-drill apps whilst waiting for the next classroom activities. Four apps were used 
for developmentally appropriate practices. iPad use supported student communication, exploration, knowledge construction, and digital production projects - often with a peer. Overall, Lu et al. (2017) found that iPad and app use in ECE supported one-to-one learning, interdiscipinary projects, and allowed collaboration with peers.

Across several studies, the scaffolding, mediation, or guidance often provided by an adult whilst using tablets was found to have supported children's gains in literacy learning (e.g., Cingel \& Piper, 2017; Neumann, 2018; WalterLaager et al., 2016). Specifically, these studies indicated that whilst the features in tablets and apps helped children to engage with the learning content for longer, scaffolding, or other forms of social interaction played an important role in sustaining and directing children's focus.

Earlier research also found that tablets have supported learning in STEM subjects. In Sweden, Fridberg and Redfors (2018) found iPads useful for eliciting children's reflections on scientific concepts through video-recorded stimulated recall (video-SR) of science activities. Tablets have been found to be a useful additional resource when teaching STEM subjects, leading to child-centred learning, active engagement, use of divergent materials, and improved peer interaction and teacher scaffolding (Aldemir \& Kermani, 2017). Studies have found that young children are able to successfully translate learning between digital and concrete materials (Aladé, Lauricella, Beaudoin-Ryan, \& Wartella, 2016; Wang, Xie, Wang, Hao, \& An, 2016). Herodotou (2017) concluded that digital tools and concrete materials could equally teach science concepts as long as the "learning experience is mediated by more knowledgeable others (MKOs)" (p. 13) such as teachers and parents.

Many studies have examined young children's use of mathematics apps. Palmér (2015) found that mathematics app use led to increases in children's participation, their dialogues with the teacher, and subsequent numeracy skills learning. Similar results were observed by Spencer (2013) who found that young children's iPad use sustained their interest in numeracy skills learning. Other studies involving maths apps reported that when young children engaged with these apps using tablets, they had higher scores attributed to the variety of consistent, and 
effective mathematics instruction, higher learning progressions, and more opportunities to practise (e.g., Schacter \& Jo, 2016; Watts et al., 2016).

A final group of studies focused on how tablet use in ECE supported children's social skills development. Clarke and Abbot (2016) reported that because iPads were portable, allowing children to work together and to share information, their use led to positive gains in children's confidence in working with others, collaboration, and communication skills. A design-based research and video ethnography was conducted by Ralph and Petrina (2018) involving five three- to four-year-old children. Children's interactions with iPads were observed and from 206 behaviours noted, there were more prosocial behaviours (146) than non-social and antisocial behaviours. In a related mixed-methods study, Ralph (2018) found that using mobile touchscreen devices including iPads supported prosocial sharing behaviour amongst two- to five-year-old children. The study found that activities with media and technology use encouraged more children to view the screen together, take turns touching the iPads, and create images and animations together. There were more prosocial group behaviours than prosocial individual behaviours exhibited by children who used media and technology compared to when they were engaged in activities that did not involve use of digital technologies. In addition, more non-social behaviours were observed during activities that did not use digital technology compared to activities that used digital technologies.

Other international research has shown how tablets supported children's social development. Daniels (2017) observed that young children's tablet use led to positive play experiences, friendships, and shared interests. Many studies have reported that iPad use in pairs or small groups led to increased collaboration (e.g., Sakr, 2018; Yelland, Gilbert, \& Turner, 2014). Melhuish and Falloon's (2010) review attributed the lightweight and portable design of tablets to increased group collaboration and instruction amongst children. More recently, Sulaymani and Fleer's (2019) study found that tablets acted as a collaborative and instructional tool for four children aged five- and six-year-old children in Makkah city, Saudi Arabia. The study also found that these children learned self-regulation when sharing iPad use with a peer and their behaviours progressively changed from non-collaborative to collaborative use. 
As evidenced in this section of the literature review, tablets, when used in ECE settings have been found to lead to positive gains, especially in the development of motor skills, literacy and STEM learning, and social skills. Of note is that many of these studies attributed gains in children's development to the facilitationparticularly scaffolding — of children's use of tablets and their apps by peers and adults. The next section moves from this more general overview of studies investigating the benefits and drawbacks of tablet use to a more detailed review of the empirical literature that investigated the specific ways tablets were used in ECE settings.

\subsection{Tablet use in ECE settings}

With more educational studies reporting gains in young children's development when they used tablets, it is important to examine the empirical research on how these devices are used in ECE settings for documentation and assessment, documenting events, communication, and using apps for exploration, creativity, playing music and watching videos, and playing games.

2.3.1. Access to tablets in ECE. This section briefly discusses children's access to tablets in ECE contexts following on from the broader discussion of this issue in Section 2.1. The two studies located in this section introduce the different levels and kinds of barriers which affect the adoption of ICT, including tablets, in ECE settings.

Blackwell, Lauricella, Wartella, Robb, and Schomburg's (2013) 46-item survey, involving 1,329 early childhood educators, investigated ICT integration within ECE settings and teachers/educators' beliefs on technology adoption in ECE. Blackwell et al. (2013) categorised their results into two sections: first-order and second-order properties. The first-order properties were school type (service type), children's socio-economic status, the availability of a technology policy, and professional development on technology integration. The second-order properties consisted of attitudes and beliefs regarding the affordances and barriers to ICT use. Blackwell et al. (2013) found that "research is mixed on whether or not teacher beliefs and attitudes are significant predictors of use above and beyond first-order extrinsic barriers" (p. 311). Blackwell et al. (2013) concluded that personal 
limitations such as performance expectancy, effort expectancy, and social norms in the second order affected teachers' ICT adoption.

Blackwell et al. (2013) also identified specific barriers such as teachers'/educators' inhibitions, lack of access and support, and parents' or services' control of children's access to and use of technology. Results showed that the main predictors of ICT adoption and use in ECE were practitioners' attitudes and the affordances of a specific ICT type. Blackwell et al. (2013) suggested that barriers to ICT integration could be overcome by providing professional development, creating and implementing technology policies, and shifting teachers'/educators' perspectives towards the affordances of ICT.

In addition to identifying barriers, Blackwell et al. (2013) used Chi-Square tests to compare different types of technology. They found that whilst teachers' use of TVs/DVDs and computers still ranked high compared to using other ICTs, teachers' use of tablets was ranked higher than digital cameras, iPod/MP3 players, and E-readers. Additionally, the study identified the positive predictors of successful tablet adoption. These were the availability of a technology policy in a service, teachers'/educators" beliefs surrounding "children learning from technology" (Blackwell et al., 2013, p. 316), and teachers/educators with postgraduate qualifications. On the contrary, a negative predictor was those teachers/educators who perceived that technology was limited to administrative use. Blackwell et al. (2013) suggested that teachers'/educators' beliefs could be transformed through professional development and more findings on the effectiveness of using ICT in supporting children's learning.

Blackwell, Lauricella, and Wartella's (2016) survey study involved 411 teachers/educators from Head Start services, schools, and other ECE centres in different locations in the USA. The participants rated their confidence in relation to pedagogy, their attitudes towards technology, and demographics about their students' socio-economic status using a five-point Likert scale. Their study found that teachers'/educators' attitudes determined tablet use. When the results were analysed according to service type, Blackwell et al. (2016) found that those teaching at schoolbased services were more likely to use tablets than those at Head Start services (3.07 
times) and centre-based programmes (1.54 times). This study is examined further in the next section which discusses the purposes for which tablets were used.

2.3.2. Purposes for which tablets were used. The review of studies in the previous section examined what was involved in the adoption of tablets in ECE settings. This section continues the discussion of Blackwell et al.'s (2016) survey study discussed in Section 2.3.1. The results of this major study involving 411 teachers from Head Start services, schools, and other ECE centres showed that teachers who adopted tablets in their pedagogy focused more on student-centred ways of using the device. Blackwell et al. (2016) also found that those who perceived that tablets aided children's learning used them with children more often. Specifically, teachers with basic technology skills used tablets for paired and childcentred learning and taught technology skills to children. However, school-level support was linked to student-centred practices such as creative activities, paired learning and free choice. Thus, teachers with higher pedagogical skills and childcentred pedagogy most often used tablets. Blackwell et al. (2016) called for policies for professional development on educational technologies to address issues of teacher attitudes and further improve student-centred pedagogy involving ICT. As this study is highly relevant to many topics covered in this literature review, Blackwell et al.'s (2016) research findings will be revisited in later sections in this chapter.

Vaughan and Beers' (2017) exploratory study on using iPads as tools in an ECE centre in the USA outlined the specific ways tablets were used. Data from individual and focus group interviews involving eighteen teachers and data from notes during teacher meetings showed that more than half of the teachers primarily used iPads for parent communication $(n=12)$, and for information retrieval $(n=10)$. Some teachers used iPads for photography $(n=8)$, for lesson planning and team collaboration $(n=7)$, for music and exercise $(n=5)$, for playing YouTube videos $(\mathrm{n}=5)$, for facilitating children's social skills $(\mathrm{n}=4)$, and for building children's skills via apps $(n=4)$. A small number of teachers used iPads for documentation and notetaking $(n=3)$, for translation $(n=2)$, and for reading e-books $(n=1)$. Furthermore, Vaughan and Beers (2017) found that teachers' scaffolding of iPad use led to collaboration and positive socialisation amongst children. 
A study by Gray, Dunn, Moffett, and Mitchell (2017) also identified the different purposes for which tablets were used. Five primary schools and five nursery schools in Ireland participated in an extensive study on mobile device use in ECE (see also Moffett, Gray, Dunn, \& Mitchell, 2017). The four-phase mixed methods study collected data from unspecified numbers of children in ECE, year one, and year two school levels via semi-structured interviews, focus groups and questionnaires. Observations on how iPads were used by children and teachers showed that teachers directed children as they used iPads individually, in pairs, or in small groups for video-recording, photography, learning literacy and numeracy through apps, and creating e-books using open-ended apps. Gray et al. (2017) reported that teachers used iPads for documentation, planning and assessment, information retrieval and playing music or videos.

In addition to the purposes indicated by these two studies (Gray et al., 2017; Vaughan \& Beers, 2017), the common purposes for using tablets in ECE reported in several studies included documenting children's learning, engaging in creative activities, and communicating with children's families. At a multicultural prekindergarten classroom in an unspecified middle-sized city in the USA, Rowe and Miller (2017) studied how 37 four-year-old children composed e-books using iPads. Their study found that tablets were primarily used for photography and oral recordings. The iPad's features for photography, drawing, writing/typing, and audiorecording enabled these children and their teacher to create e-books. The teacher and the children used an e-book creator app in English and their own languages for documenting children's learning and sharing these with families (Rowe \& Miller, 2017).

A three-year study investigating how tablets were used by 49 children aged four- to five-years and their teachers/educators was conducted by Yelland and Gilbert (2017). The study, which was carried out in Melbourne, Australia, found that the camera app enabled children to use tablets for exploration. In addition, tablets were used for other purposes including information retrieval by accessing YouTube and other websites or apps, and for creating e-books. Yelland and Gilbert (2017) argued that whilst teachers found tablets appropriate for exploration, reflection, information retrieval, and creating e-books, children could also engage with 
educational apps that supported their linguistic, visual, oral, aural, and spatial learning.

Another study involving tablet use for documentation and creative purposes at a childcare centre in Southern Australia investigated 25 three- to four-year-old children's digital play and was conducted by Fleer (2014). This study found that children learned how to photograph, video-record, and create animations using the iPad. Results showed that participants engaged in imaginary situations whilst being aware of concrete objects and their physical environment. According to Fleer (2014), children who used the tablet for play learned "flickering" which she defined as the ability to engage in "collective and individual activity, between being in and out of an imaginary situation, and between play and learning" (Fleer, 2014, p. 208). This study provides a clearer understanding that children do not necessarily limit their play to tablets but could transition easily between activities in digital environments and the real world.

A similar study involving tablets being used for documentation and creative purposes was carried out by Rose, Fitzpatrick, Mersereau, and Whitty (2017). Their two-year case study at a childcare centre in New Brunswick, Canada investigated iPad use and found that four-year-olds and two classroom teachers used iPads outdoors for video-recording children's experiences with nature, storytelling, and other creative activities. Other uses were documentation through photography to study nature including living things and creating or playing music or videos (Rose et al., 2017). Another study in Canada found that iPads were cultural tools that enriched children's engagement with language and science through documentation such as photography, drawing, and e-book production (Moore, Hoskyn, \& Mayo, 2018). This longitudinal qualitative study at a science centre in Vancouver, Canada, collected data from 236 five- to six-year-old children from diverse backgrounds and cultures. Through observations, video-recorded conversations with children, and ethnographic photographs on tablet use, researchers found that iPads were used for literacy and science, as well as mark-making and other activities involving creativity (Moore et al., 2018). Touchscreen devices, such as iPads, were used to bridge the gap between literacy practices in the home and in the ECE classroom to support cultural participation and learner identity. 
An investigation into how tablets were used for creative purposes by Heydon, McKee, and Daly (2017) involved a case study of nine children aged four- to fiveyears-old and 15 elderly people at an integrated retirement and assisted living and day care facility in an unspecified urban city in the USA. They observed that iPads and the Book Creator app were used to document the processes and products of an intergenerational art programme. Tablet use allowed both children and adults to create digital and non-digital media which included photographs of their artwork and text or video- and audio-recorded explanations of their works. Intergenerational dyads revisited their respective works and talked about them using iPads, resulting in positive interpersonal relationships. Teachers commented that using iPads to review children's artworks was more efficient and less time consuming than using books and folders. Although tablets relied heavily on consistent internet connections, the capability to view images on them was a clear affordance. Heydon et al. (2017) observed that when children learned how to use tablets, they helped older participants use them. This contributed to the digital literacy learning of both children and adults with children acting as more knowledgeable others, otherwise known as MKOs. The next section continues this discussion, this time focusing on the purposes of tablet apps.

2.3.3. Tablet apps used in ECE. Of the studies located that involved tablet use in ECE, 13 were about which apps were used and for what purposes. The biggest amongst these studies was by Blackwell et al. (2016) which was introduced in the previous section of this literature review. Blackwell et al. (2016) used a Likert-scale to analyse the frequency of tablet use according to student-level variables (e.g., income), teacher-level variables (e.g., attitudes, pedagogy, and confidence), and school-level variables (e.g., school type and provision of support). Their analysis of apps showed that whilst YouTube was one of the top three app titles listed by the teachers, $79 \%$ of teachers tended to use literacy apps. Teachers who had higher ratings in the teacher-level variables involving pedagogy such as child-centred pedagogy had a closer association to their tendency to use tablets. Teachers' definition of apps included pre-installed tablet features and non-web-based software. In their perspective, "any program that runs on a tablet computer is an app" (Blackwell, et al., 2016, p. 66). Results showed that teachers used tablets on 
average 12.16 days each month. The study found that professional development at the school-level affected how frequently teachers used tablets and their apps.

With regards to how ECE teachers used tablets and their apps for childcentred learning, a case study in Queensland, Australia, by Gattenhof and Dezuanni (2015a) examined how iPads were used for documentation using four vignettes. They found that using iPads for art and photography helped children develop selfregulation, persistence, and reflective, creative, and investigative learning. Gattenhof and Dezuanni (2015b) also interviewed a pre-school child and a parent who described how iPads were used at their ECE service. Tablets helped the child create stories using photography and open-ended creative apps. Gattenhof and Dezuanni (2015b) concluded that tablets helped children communicate their interests and experiences by sharing the stories they made with their teachers and parents.

The documentation features of tablets also enabled children to engage in other creative activities. Fleer (2017a) explored how tablets were used by 103 threeto five-year-old children at three ECE centres in a city in Australia. Her three case studies involved interviews with the children and their six teachers on how they used tablets. Primarily, the teachers reported using tablets to photograph children's activities for documentation. Using tablets helped them arrange the photos sequentially to create slow animations of children's storytelling and share these with their parents. In an extension of her first study, Fleer (2017b) further examined children and their teachers' use of slow animations to recreate fairy tales. The same participants were video-recorded as they used iPads to photograph sequences of each story. Fleer (2017b) concluded that the documentation features of tablets were useful for creative use such as story writing. Fleer's studies (2017a, 2017b) reported that the documentation features of tablets were useful for creative use.

More studies have shown how teachers could support children's learning by using the documentation functionality of tablets in different ways. For example, Geist's (2014) case study in a Head Start setting in a USA city showed evidence of 10 two- to three-year-olds' exploration of 3D and 2D shapes using tablets. Four teachers used tablets to take photos of children and allowed children to reflect on their learning and experiences by viewing the photos. The children also used open- 
ended apps for storytelling, drawing, building, and animation as well as replaying music and videos on touchscreens (Geist, 2014).

The availability of different apps has added to the multifunctionality of tablets for carrying out a variety of learning activities in ECE services. Six studies were located that have investigated the use of apps with tablets. For instance, Dooley and Gattenhof (2015) interviewed 19 parents who participated in a programme to extend the use of iPads from two early childhood centres to children's homes. The study, undertaken in Brisbane, Australia, reported the different apps children used with iPads such as e-book apps, creativity apps (including drawing apps), and educational apps such as phonics apps. Participants were pleased about the playful and productive ways iPads supported their children's learning and stated that using iPads and their apps in ECE supported children's readiness for school. For this research, "creativity" meant using tablets and apps for content creation through video- or voice-recording features of tablets and music, art, or story telling apps including drawing and colouring apps.

Another study carried out in Canada reviewed iPad adoption in Ontario's kindergarten curriculum. Tsumura's (2017) action research focused on how two classrooms for five-year-old children adopted tablets and involved two teachers using four iPads and five iPad minis. Tsumura (2017) found that iPads were useful tools for communication with parents, and for documentation and scaffolding of learning. Yet, teachers encountered barriers to iPad integration such as connectivity, device management issues, and technical issues which affected their preparation time. The teachers hesitated to use iPads as behaviour management tools and preferred that children did not play games on them even if they were classified as "educational". The study found that some iPad-based activities did not match aspects of play-based learning or traditional practices such as handwriting instruction and activities involving printing.

Tablets have also been used for viewing and playback of digital media for educational purposes. Lynch and Redpath (2014) investigated 12 pre-primary children's use of iPads and iPods in Australia. They reported that the four- to fiveyear-old children used two kinds of apps: closed apps for literacy learning through 
"skill and drill" games and open-ended apps, such as drawing, storytelling, communication, and creative apps. Gaming apps supported children's independent practise of literacy skills and freed the teacher to do other activities such as guided reading whilst open-ended apps enabled children to move from handwritten or drawn work to using drawing apps in conjunction with other functions - such as the iPad's screenshot feature or audio recording, to share their final work through social networking apps. This study found that children used iPads to engage with literacy apps, to watch stories or movies, and to create e-books, which their teacher shared with the school community online. Lynch and Redpath (2014) asserted that children's ways of using iPads should move from "listening and looking" to producing (p. 161).

Referring back to Blackwell et al.'s (2016) survey study, an examination of how teachers facilitated tablet use revealed clear differences on how these devices were used depending on students' socio-economic status. When compared to teachers with low-income students, teachers with middle-income students used tablets for individual activities. Students belonging to the high-income level income group were less likely to use tablets for free choice and individual activities compared to those from low- and middle-income groups.

Continuing the discussion on how tablet apps were used, Oliemat, Ihmeideh, and Alkhawaldeh (2018) studied iPad use by 13 four- to five-year-olds, 13 six- to seven-year-olds, and 14 seven- to eight-year-olds at three kindergartens and seven primary schools in Jordan. Children were interviewed about how they used their personal tablets and their kindergarten/school's iPad for literacy and numeracy. Children were observed using tablets and their apps to retrieve information from the internet, watch YouTube videos, listen to music, play games, access educational websites, and view photos from other websites/apps such as Instagram (Oliemat et al., 2018).

Another exploration on how tablet apps were used in ECE was by Arnott, Grogan, and Duncan (2016) who carried out a study at a pre-school in Scotland. They found that 25 three- to five-year-old children used tablet apps to document, explore, and play creatively. The children's use of videos and apps offered open- 
ended exploration, peer interaction, and creative expression. Arnott et al. (2016) concluded that tablets were used to extend children's investigation of their interests.

The international literature reviewed in this section has shown how tablets were used in ECE settings for a variety of purposes, particularly for documentation. The multifunctionality of tablets allowed teachers/educators and children to use them for documentation, creativity, information retrieval, and literacy and numeracy learning, usually through apps which also had a combination of features. Tablets also enabled teachers/educators and children to use different apps for different purposes to make creative work. This section reviewed the usefulness of tablets and their apps for the teaching and learning of young children in overseas ECE contexts, and this begs the question whether the same applies to New Zealand. The next section focuses on ICT and tablet use in New Zealand's ECE settings.

\subsection{New Zealand studies}

Although ICT has increasingly permeated children's lives in New Zealand (NZ On Air, 2015; Research New Zealand, 2015), studies on tablets in ECE are scant. This section begins with literature more broadly focused on the use of ICTs in $\mathrm{ECE}$ and is followed by those involving tablet use in the sector.

Early research about ICT in New Zealand's ECE sector has mainly focused on the impacts of technology use. Bolstad's (2004) literature review of ICT use in ECE and their impacts included findings regarding children's behaviours and social interactions with and around computers, children's engagement with ICT in ECE services and at home, and teachers'/educators' use of and access to ICT. Bolstad (2004) argued that ICT potentially filled a variety of roles in ECE. Teachers could try using ICT to scaffold and document children's learning which could be shared with parents. Children may integrate ICT into their individual and collaborative play, including their learning with peers or adults. Additionally, ICTs possibly could be used as communication tools amongst children, teachers/educators, parents/families, and researchers. Bolstad (2004) asserted that adopting ICT into policies, curriculum, and pedagogy, could strengthen teaching practices in ECE. Thus, she argued that teachers/educators can support children's learning and development through the appropriate use of and access to ICT but that this would 
require access to professional development on ICT use, being able to use ICT for administration and information management, and ECE services being provided with ICT access and infrastructure.

Guidelines from New Zealand's Ministry of Education including Foundations for Discovery (Ministry of Education, 2005) and Kei Tua o Te PailAssessment for Learning: Early Childhood Exemplars (Carr, Lee, \& Jones, 2009) also have also encouraged ECE teachers'/educators' ICT use. Foundations for Discovery (Ministry of Education, 2005) was the New Zealand government's ECE ICT Framework which aimed to encourage the use of ICT to support effective learning and teaching in ECE services. This framework supported services in decision-making around investment in and use of ICT, for teaching and learning, administration, and information management.

Through Foundations for Discovery, the New Zealand government acknowledged the potential benefits of ICT as tools in ECE and aimed towards effective ICT development, use, and investment in the sector. This was to "support the ECE Strategic Plan's goals of increasing participation in quality ECE services, improving quality, and promoting collaborative relationships" as well as to "harness the potential of ICT to support learning and teaching practice, and to make informed decisions about ICT in ECE settings" (Ministry of Education, 2005, p. 2). These guidelines aligned with the first iteration of Te Wharriki (Ministry of Education, 1996) that using ICT was not an end in itself, but a tool used by teachers/educators to support their ECE practice.

Foundations for Discovery (Ministry of Education, 2005) further supported diversity in educational philosophy by enabling teachers/educators to determine whether to provide access to and use of ICT. This included considering how to support young children's appropriate use of ICT by guarding them against exposure to inappropriate content, and by encouraging them to use ICT collaboratively. These guidelines encouraged ECE services and families/whänau to share knowledge on ICT use and effective learner-centred practices with each other through collaborative ways such as using ICT for communication. 
Subsequent guidelines and policies have outlined how ICT is relevant to the Exploration/Mana Aotūra and Communication/Mana Reo, two strands of the first version of Te Whāriki (Ministry of Education, 1996). Book 20 of Kei Tua o Te PailAssessment for Learning: Early Childhood Exemplars, Information and Communication Technology (ICT) - Te Hangarau Pārongo me te Whakawhitwhiti (Carr et al., 2009), exemplified the aims of Foundations for Discovery (Ministry of Education, 2005). The book provided examples of ICT use and posed reflective questions to help teachers/educators use ICT for documenting and assessing children's learning, as well as encouraging exploration and communication by using ICT as tools for learning (Carr et al., 2009).

Bolstad's (2004) review and the Ministry guidelines were published before the proliferation of tablets. Yet, despite the increased uptake in tablets in New Zealand (Research New Zealand, 2015), there have been few studies about their use with local ECE services. These few studies on ICT or tablet use at the service level are examined next.

Research in New Zealand's ECE has often focused more generally on ICT than tablets. For example, the New Zealand Council for Educational Research conducted a survey of ICT use across New Zealand in 2007 involving 242 managers and 402 ECE teachers from education and care, kindergarten, home-based, playcentre, Pasifika education and care, and hospital-based services (Mitchell \& Brooking, 2008). Results showed that the types of ICT mostly used by managers and teachers were computers, emails, the internet, and digital cameras. Participants reported using digital technologies primarily for documentation and assessment of children's learning, including photography, creating resources, and communication with parents. Teachers expressed that they had limited confidence and expertise in using ICT and wanted more guidance on ICT use. Kindergartens were found to be more likely to adopt ICT than home-based services and playcentres whilst education and care services fell in between kindergartens and playcentres (Mitchell \& Brooking, 2008).

Later research focused on how professional development supported teachers'/educators' ICT use. Cherrington et al. (2009) conducted a mixed methods evaluation of the ECE ICT Professional Learning Programme (ECE ICT PLP). Their 
study involved document analysis, the development of an evaluation matrix, an internet survey with 178 responses from teachers in ECE services, semi-structured telephone interviews with five facilitators and the National Leader of the ECE ICT PLP, and six case studies of ECE services. The evaluation was focused on the effectiveness of the programme and provided some insights into access to and use of digital technologies and related media such as computers, cameras, microscopes, and the internet. Results showed that increased ICT skills and ICT-related transformation of pedagogical practice enhanced learning outcomes amongst young children (Cherrington et al., 2009). This conclusion aligned with Thornton's (2009) doctoral thesis on 12 teachers' use of a blended learning approach to support leadership development. Her case studies found that ICT integration benefitted communication and action learning towards leadership development in the sector (Thornton, 2009).

In connection with how teachers/educators used ICT at the service level, Oldridge (2010) examined ICT adoption in ECE in three phases. Through a survey, Phase One collected data about the types of ICT, uses of ICT, and related demographic information from six education and care services, five kindergartens, two playcentres, and one Montessori centre. In Phase Two, responses were collected from 135 families and from 10 teachers as well as two ECE centres who responded to a questionnaire about perceptions and practices regarding ICT use. Phase Three consisted of interviews with five teachers and four children. The survey showed that digital still cameras, telephones, and computers were the three types of ICT available in most services with teachers having the most access to computers followed by children. ICT was used for taking photographs, playing computer games, making videos, browsing the internet, watching DVDs or videos, and communication by email or telephone.

Oldridge's (2010) results showed that more than half the teachers indicated that they learned about ICT from each other through what they called "collegial support" (p. 109) followed by professional development courses and learning on their own. When playcentres and the Montessori service were compared to education and care services and kindergartens, the latter indicated that they had experienced "a steady progress and increasing use" of ICT (p. 110). This study 
found that the quality of ICT adoption depended on teachers' beliefs in their ability to accomplish tasks using ICT including their perceptions about pedagogy, multiliteracy, barriers to ICT integration, and how policy affects practice. According to Oldridge (2010), the barriers to ICT adoption were cost or availability of the equipment and its technical support, obsolete technology, lack of teacher/educator time, lack of teacher/educator interest or knowledge, teachers/educators not understanding the value of using ICT, and teachers'/educators' knowledge and philosophies about effective teaching.

Studies about ICT in general continued with Merry's (2017) recent investigation into how a sociocultural view of learning supported student teachers' integration of ICT into their pedagogy. Participants were 230 students of early childhood initial teacher education of which 104 participated in this study's second phase and 126 participants in its third phase. Merry (2017) developed the Teacher Education ICT Appropriation Model (TEAM) which applied sociocultural theory to ICT use in initial teacher education. Merry's (2017) model addressed teachers' beliefs and attitudes that affect their behaviour, relational trust between student teachers and teachers, ICT as cultural tools, and sustained engagement during ICT use.

Several studies have focused on more specific ICTs such as Terreni's (2009) research on interactive whiteboards (IWB). Using participant observation for her master's thesis, Terreni (2009) investigated eight children's engagement in activities using an IWB at a kindergarten. Results showed that whilst IWBs enabled children to engage in a wider range of visual art activities in a larger scale than computers and laptops, IWBs were considered as another type of digital tool. IWBs supported children's collaboration and motor skills development. Children who used IWBs in this study showed gains in their creative thinking and technical skills. Teachers were responsible for guiding children in using the technology and assisting them in producing tangible products (Terreni, 2009). Terreni's (2010) subsequent article on the use of IWBs in ECE indicated that compared to using a mouse, touchscreen interfaces helped children easily manipulate digital objects. She argued that IWBs supported two- to four-year-old kindergarteners' learning experiences involving 
visual arts as these devices supported teachers'/educators' scaffolding of children's ICT use, reflection of children's art experiences, collaboration, and peer support.

Recurring themes amongst these studies include the adoption of ICT based on teachers'/educators' beliefs and educational philosophies, together with their use for documentation and assessment, and collaborative and creative purposes. Of interest is how each of these themes affect teachers'/educators' decisions to use tablets in ECE and for what purposes. Five studies located that are reviewed next focus specifically on teachers and children's use of tablets including iPads.

In an investigation on whether iPad use in ECE enriched children's learning, Fagan and Coutts' (2012) findings aligned with Bolstad's (2004) review. Their qualitative study on whether to use iPads involved observations of iPad use in one kindergarten and in one childcare centre. These services consulted with parents in the community regarding iPad use. Teachers/educators used tablets for exploration, creativity, leadership, collaboration, communication, and documentation of learning. The computing functions which aided in their work were made portable with iPads and when combined with the integration of word processing, communicative and photography functions led to seamless documentation, assessment, and collaboration or sharing of information. This study recommended five open-ended apps which enriched children's creativity and supported their literacy, numeracy, musical, and fine motor skills development. These apps utilised the multifunctionality of iPads allowing children to engage with them for various purposes, using features such as the camera, audio and video recording, and writing or drawing on the screen.

Similarly, Hatherly and Chapman's (2013) case study at an education and care service for two- to five-year-olds found that iPad use aligned with Te Whäriki's (Ministry of Education, 1996) literacy and communication goals through intentional teaching and child-led learning. Data was collected from five teachers-including the centre manager - through observations and interviews about their reflection on children's learning. Hatherly and Chapman (2013) reported that teachers aimed to develop children's literacy skills and emphasised a balance of using iPads and nondigital books. Teachers observed that children were naturally inclined to using iPads and emphasised that their service's overall goal was to encourage children to read non-digital books. 
Continuing this review on tablet use by teachers/educators and children, Khoo, Merry, Nguyen, Bennet, and MacMillan's (2013) study involving iPad use at one education and care centre is examined. The researchers collected data through observations of iPad use and teacher-child conversations and found that children aged five-years-old and under used iPads in child-led explorations including photography, communication with peers using apps, and reflection on their own learning. Results showed that teachers used iPads for collaboration, socialisation, communication, documentation, and information retrieval. As a collaboration tool, iPads improved the quality of teachers' interactions with children and enhanced their scaffolding of children's learning. As a result, the improved interactions served as a model to children's own interactions with their peers. The communicative features of iPads enhanced peer learning and exploration. The increased access to information enabled by iPads and their multimodality in capturing, reviewing and creating content supported seamless documentation and communication of information.

Khoo, Merry, Nguyen, and MacMillan's (2015) case study investigated two teachers' and around 40 children's iPad use in an education and care service. Interviews with the teachers revealed that iPad use supported Te Whäriki's (Ministry of Education, 1996) principle of relationships, Nga Hononga, as iPads enabled children and teachers to collaborate in small groups. Referring to sociocultural theory, Khoo et al. (2015) argued that in their study, tablets did not drive the teaching and learning, but the relationships teachers had with the children, their parents, and families. Additionally, Khoo et al. (2015) reported that teachers/educators used iPads and apps for observation, information retrieval, communication, and documentation. Tablets enabled children to contribute to their own learning stories resulting in enhanced relationships between teachers/educators and children. They suggested that teachers/educators should examine their pedagogical beliefs and reimagine or adapt their practices to use the affordances of iPads whilst being aware of appropriate guidelines for children to engage productively with iPads. This study found that using tablets enriched ECE teachers'/educators' and children' social interactions. Instead of simply allowing children to explore iPads through trial and error, teachers/educators modelled the limits and social etiquette around using tablets resulting in peer learning and collaborative use (Khoo et al., 2015). 
Two studies were located that focused on teachers' perceptions on the potential uses of iPads in ECE settings. Almashaileh (2016) interviewed four ECE teachers for her master's research. She found that teachers believed iPads and apps supported teaching and learning by allowing teachers to access a variety of content. According to these teachers, the main affordances of iPads were their portability and ease of use. Almashaileh (2016) found that the potential uses of iPads were for literacy, numeracy, and language learning, for collaborative and cooperative learning, and for documentation and assessment. Another study reported the perceptions of ECE teachers. Interviews with five ECE teachers - two from a private centre and three from a kindergarten — initially found that the children's parents saw iPads as unnecessary toys (Finch \& Arrow, 2017). The teachers perceived that using iPads was isolating and caused anti-social behaviour. Yet, Finch and Arrow's (2017) observations of teachers scaffolding three- to five-year-old children's use of iPads revealed that this resulted in appropriate turn-taking and peer collaboration.

An ethnographic case study at a kindergarten in Hawkes Bay conducted by MacCallum and Bell (2019) aimed to determine how mobile devices, including tablets, supported three- to five-year old children's learning and communication. The study, conducted in 2012, involved a three-month trial of two iPads between two teachers. Observations and meetings with the teachers revealed that initially they needed professional development around managing the use of tablets effectively. After gaining confidence the teachers quickly learned how to solve issues regarding iPad use independently. iPads were used for creativity-to create e-books and drawing pictures, for documentation - to take photos and videos, and assessment - to add learning evidence and outputs on learning stories and for teachers to write comments on this evidence and outputs. By using tablets, teachers were able to collaborate and reflect not on student learning alone but also on their teaching practices.

In contrast to the studies reviewed to date in this section, Gerritsen et al.'s (2016) study surveyed the amount of active playtime and screen time of three- to four-year-olds across four types of ECE services (80 private day cares, 76 community day cares, 45 public kindergartens, 31 playcentres, and five kōhanga reo services) in the Manukau and Waikato regions. Their study revealed that children's 
computer and tablet use at community day care centres and kindergartens ranged from daily to monthly use. Although some service types reported that they did not use digital technology because they preferred children to engage in free-play and other physical activities, the study did not elaborate on why all of the 31 playcentres that participated in the study did not use computers/tablets. Gerritsen et al. (2016) reported that, generally, services perceived that young children's engagement with televisions, DVDs, computers and tablets encouraged sedentary behaviours that affected children's health negatively. The study stressed the need for policies and guidelines that supported children's physical activity and limited their screen time. With regards to teacher/educator practice, Gerritsen et al. (2016) recommended that teachers participate in professional development that would promote the health of children and fight childhood obesity.

To add to the limited ECE literature on tablet use in New Zealand, two studies involving children in early primary levels are reviewed. The first was by Falloon (2013) who investigated 18 five-year-old children's engagement with four iPad apps. Video-recording of paired app use showed that children engaged with a select number of around four to ten apps. Falloon's (2013) analysis of free and paid apps showed that apps had the potential to support, impede, or place parameters on children's learning. He suggested the need to support teacher choices on app selection and their use.

Another study on early primary schoolchildren's tablet use by Falloon and Khoo (2014) involved a class of 19 children aged five-years-old. Ten iPads were supplied for the research which investigated children's talk and collaboration whilst engaging in using three creative apps. Children worked in pairs with a teacher to form eight pairs and one group of three. Interactions were audio and video recorded and tablet activities were recorded using screen display capture. The collection of data were grouped into 68 instances which were categorised into three types of talk: cumulative (passive, supportive, affirming, and non-critical type of talk), disputational (non-collaborative, usually involving conflict, argument, or disagreement), and exploratory (constructive criticism, debates, and justification of actions). This study found that children exhibited more cumulative (46) and 
exploratory (14) talk than disputes (8) leading Falloon and Khoo (2014) to suggest that iPad use led to more collaborative working relationships amongst the children.

This section has outlined how children, teachers/educators, and services used tablets in New Zealand's ECE settings. Whilst earlier studies focused on ICTs in general, most of the studies reviewed involved a specific type of digital technology, such as IWBs, iPads, or their apps. There were only two studies which made comparisons across different service types. According to these local studies, tablets were generally used for a variety of purposes. Documentation, exploration, and creativity were the commonly reported purposes for adopting them in ECE settings. Many of the studies reviewed found that tablet use encouraged collaboration between children and their peers as well as between children and teachers/educators. The empirical studies on ICT and tablet use exemplify the need for further research on tablets in New Zealand, especially at the service level. This study intends to investigate whether there are differences in how tablets are used across service types. Additionally, any such variations on how tablets are used across different service types could provide better understanding of the complexities involved in adopting these devices in ECE. Of these complexities, some commonalities are the use of tablets for documentation, creativity, and communication. A few notable differences across these studies highlighted teachers'/educators' varying perceptions of how these devices should be used and that tablets were used individually or in groups.

The next section introduces the theoretical framework which underpins this research, beginning with sociocultural theory followed by its application in relation to ICT or tablet use in ECE settings.

\subsection{Sociocultural theory}

This section explains sociocultural theory which, as noted in Chapter 1, underpins New Zealand's ECE curriculum, Te Whāriki (Ministry of Education, 2017a), and thus informs teachers'/educators' practices. One of the fundamental concepts of sociocultural theory is that the human mind is mediated by interactions with more knowledgeable persons (Lantolf, 2000). This concept is based on Vygotsky's (1978) ideas and linked to the understanding that learning precedes 
development, and that this learning is enhanced through socially mediated activity using tools and signs.

Sociocultural theory argues that learning occurs through social and cultural interactions using physical tools or signs which are conceptual tools (Vygotsky, 1999). As a mediated process, learning begins socially through mediated interaction between a child and more knowledgeable or experienced members of the society such as parents, teachers, and peers (Vygotsky, 1978). Lantolf (2000) explained that humans use signs to mediate and change relationships with others and with oneself and use tools to change the physical world and its circumstances. Signs are used to "establish an indirect, or mediated, relationship between ourselves and the world" (Lantolf, 2000, p. 1). Human cultures create physical and psychological tools and succeeding generations use, modify, or make new tools. Tools contribute to the transformation of the social and material environment, changing the way humans live in this world (Lantolf \& Thorne, 2007). Humans' use of tools consequently regulates and mediates behaviour and cognition through their action (Lantolf, 2000). Through interactions with teachers/educators, parents, other family members, and peers, children learn how to use tools and signs in their culture and society.

One of the main principles of Vygotsky's (1978) sociocultural theory involved children's interactions with more knowledgeable others (MKOs). Values and skills are transmitted socially and culturally, often through play or in educational settings "under adult guidance or in collaboration with more capable peers" (Vygotsky, 1978, p. 86). Vygotsky (1978) described MKOs as those better educated, developed, or skilled than the learner. This MKO-learner transaction influenced the learner's autonomy (Vygotsky, 1978). By interacting with and imitating MKOs and using tools and signs, children actively participate in learning skills, constructing knowledge, and forming views and attitudes. In this pedagogical model, the materials provide the framing for concept formation.

Hedegaard (2007) explained that the concept of MKO applies to young children in ECE settings because they learn scientific and everyday concepts "spontaneously in collaboration with others through everyday activities" (p. 246). Fleer and Hedegaard (2010) elaborated that, as MKOs, teachers play the role of 
conceptual mediator by working together with children to solve problems or clarify concepts. In Western ECE settings, this is usually carried out through individualised, play-based programmes in facilitative and nondirective ways. Fleer and Hedegaard (2010) argued that, instead of acting as passive providers of learning tools, ECE teachers should be recognised as active agents in children's learning. To support children in achieving their learning milestones, teachers are expected to understand the commonly available tools in ECE settings, according to their educational philosophy. Hedegaard stated that:

If pedagogues and parents do not pay attention to playthings and educational play materials, but rather let commercial interest determine the choice, the child may appropriate skills and competencies that are inappropriate in relation to the child's everyday life, and this can be detrimental to the child's development of a theoretical orientation to his or her surroundings. (Hedegaard, 2007, p. 273)

Another of Vygotsky's (1978) key concepts is the zone of proximal development (ZPD) which he defined as the range of a child's task completion with support. Vygotsky defined the ZPD as "the distance between the actual developmental level as determined by independent problem solving under adult guidance, or in collaboration with more capable peers" (1978, p. 86). Thus, without support from MKOs, a child could not act independently. The MKO structures learning experiences and provides guidance in increments to support a child's success in performing tasks. However, as a child became independent and reached their zone of actual development (ZAD) - the range of task completion a child could do without support - a new set of learning tasks which required support entered the ZPD (Vygotsky, 1978). Fleer and Hedegaard (2010) explained that adults work with young children by using pedagogies relevant to children's everyday activities at home and in their community. Within the ZPD, teachers use different pedagogical strategies to support a child who is willing to engage in the activities (Fleer \& Hedegaard, 2010).

2.5.1. Scaffolding and guided participation. In this section, pedagogical strategies involved in children's learning underpinned by sociocultural theory are discussed. Specifically, these strategies involve the concepts of scaffolding (Bruner, 1983) and guided participation (Rogoff, 1990). 
Bruner (1983) conceptualised scaffolding based on Vygotsky's notions of how learning was mediated by adults or peers. He coined the term "scaffolding" to describe the learning process of "setting up the situation to make the child's entry easy and successful and then gradually pulling back ... as he [sic] becomes skilful enough to manage it" (Bruner, 1983, p. 60). Bruner and his fellow psychologists, Wood and Ross (Wood, Bruner, \& Ross, 1976), conceptualised scaffolding as the provision of external support in the early stages of learning. This support is gradually withdrawn in later stages as the child exhibits the ability to complete the task independently. Scaffolding is a common strategy for teaching young children and is often given verbally (Bruner, 1983).

A similar concept concerning how MKOs support children in accomplishing tasks is guided participation (Rogoff, 1990). This cognitive apprenticeship framework involves novice users gaining knowledge and skills from MKOs whilst participating in daily routines and activities. The concept of guided participation involves the "processes and systems of involvement between people as they communicate and coordinate efforts while participating in culturally valued activity" (Rogoff, 1995, p. 142). Whilst scaffolding focuses on enabling children to perform tasks independently, moving their ZPD to ZAD, guided participation focuses on how adults enabled children to do adult-like tasks. However, children do not only learn from the expertise of others but also from the social contexts where interactions with MKOs occur. Interactions between MKOs and learners cannot be separated from the cultural context as "both guidance and participation in culturally valued activities are essential to children's apprenticeship in thinking" (Rogoff, 1990, p. 8).

Rogoff (1990) explained that guided participation could be tacit or explicit as long as it involved a shared focus, purpose and collaboration between children and adults. Adults enable children to perform everyday tasks by providing proximal and distant support. As children observe and interact with MKOs, they learn skills, solve problems, and use tools in their social and cultural contexts. Adults provide guidance by linking children's current levels of understanding to a new level through varying levels of participation. Through guided participation, "children appropriate an increasingly advanced understanding of and skill in managing the intellectual problems of their community" (Rogoff, 1990, p. 8). 
This section has provided an overview of sociocultural theory and its related concepts. Next, how sociocultural theory and its related concepts link to children's access to and use of ICT, particularly tablet use, is elaborated.

2.5.2. Scaffolding and mediation of ICT use. This section introduces categories of scaffolding and ways of mediating use of ICTs, including tablets, in educational contexts. The empirical research that has investigated scaffolding and mediation of ICT use in educational contexts goes beyond the ECE sector and is drawn upon here to enable these ideas to be explored. In relation to sociocultural theory, Lantolf (2000) argued that the internet, computers, and their software, known as technological artefacts, mediate learning. He asserted that the use of these technical tools is critical in the formation of a child's practical intelligence. Like books, computers transform how activities are done according to one's social context. Lantolf (2000) argued that because digital technologies have developed in the past decades, computers have become a necessary tool for communication and learning.

Kay (1972) conceptualised the development of touchscreen tablets to include guiding children's learning in a social environment according to Vygotsky's ideas and sociocultural theory. Stephen and Edwards (2018) explained that the development of current tablets, such as iPads, was based on Kay's (1972) understanding of the "philosophical and theoretical ideas that have informed the provision of play-based learning in early childhood education for generations" ( $p$. 31). Kay (2012) described new technologies, including computers, as "amplifiers" (p. 1) for children's activities.

Drawing on sociocultural theory to understand how children access and use digital technology, Stephen and Edwards (2018) asserted that certain tools allow children to engage in mature play which link everyday understandings to scientific concepts. In the digital age, watching a YouTube video on the iPad introduced children to the concept of how digital data is accessed through the interconnections of different technologies. To achieve this understanding, Stephen and Edwards (2018) explained that through "pedagogic action" adult involvement is needed "to 
bridge either end of the proximal or 'nearest' zone of the child's understanding" ( $p$. $81)$.

With regards to using digital technology for the teaching and learning of younger children, Jacobs (2001) proposed a scaffolding model for early childhood and primary teachers which included technology use. She developed this model for teaching in multicultural, inclusive, hands-on, engaging, and active learning settings. In this model, teacher preparation begins with a theoretical foundation of appropriate practices involving child development, teaching skills, strategies, and methods, and technology use. Then preparation continues through field experience, practise, and reflection. Of interest is the model's acknowledgment that teachers and their students could benefit from the advances in technology as some technical features are capable of scaffolding children's learning. One example was how teachers, parents, and children could use technology in assessment by creating learning portfolios. When teachers follow the principles of the model, they become aware of the prevalence of apps masquerading as "educational". This leads to teachers becoming more effective in scaffolding children's app use thus mitigating the impacts of badly designed apps such as those providing a plethora of choices and those excessively triggering app features instead of helping users focus on content and learning (Jacobs, 2001).

From their empirical findings, Yelland and Masters (2007) identified three types of scaffolding of which the first two are related to MKO-learner interactions. Cognitive scaffolding involved solving problems and understanding concepts and procedures. Teachers used questions and modelling, encouraged children to collaborate with their peers, and assisted in planning and drawing diagrams. By working collaboratively, children learned how to plan and implement strategies, to listen to and acknowledge alternative viewpoints, and to reach an agreement on the next steps towards completing a task. Affective scaffolding pertains to positive feedback and encouragement to stay on task and complete them. The third type of scaffolding - technical scaffolding — was provided by the computer programmes though features and functionalities incorporated in a programme's design to help children understand concepts and solve problems more easily. Despite the availability of technical scaffolds, teachers, as MKOs, still needed to highlight these 
features by using strategies that involved affective scaffolding and cognitive scaffolding.

Continuing the discussion of scaffolding using ICTs by MKOs, Troseth, Russo, and Strouse (2016) argued that there were differences in scaffolding passive screen media use such as television from scaffolding the use of interactive technologies such as tablets. They found that the use of interactive technologies was scaffolded in two ways. Cognitive scaffolding occurred when adults role modelled attentiveness and directed children's attention to important screen-based content. Social scaffolding involved using feedback cues such as gaze direction, using childdirected speech, and appropriate responsiveness to children's actions. The authors concluded that traditional screen media did not provide social cues such as eye gaze and verbal responses like a real person would. Troseth et al. (2016) found that children learned better when the use of touchscreen devices was skilfully scaffolded by an adult.

Drawing on Vygotsky's (1978) sociocultural theory, Hirsh-Pasek, Zosh, Golinkoff, Gray, Robb, and Kaufman (2015) asserted that tablets were cultural tools that support the scaffolding of children's learning. They identified four principles to evaluate the educational effectiveness of tablets and their apps. These were active, engaging, meaningful, and social learning. The first principle involved supporting active learning through intrinsic and extrinsic motivation and feedback. The next principle highlighted the importance of child engagement through their participation in active learning. The third principle emphasised the importance of meaningful learning involving using apps that taught children skills such as problem solving. Finally, the fourth principle focused on achieving social interaction by scaffolding children's app use. Hirsh-Pasek et al. (2015) argued that of these principles, social interaction through effective scaffolding was the most important because interactions helped children become actively involved in their learning.

To illustrate these four principles, Hirsh-Pasek et al. (2015) reviewed three children's apps and laid them out on a four-by-four grid. The vertical axis classified whether the app rated low or high based on these four principles. The horizontal axis evaluated how educational the apps were. Through this grid, educational apps could 
be identified as having a low value (with low principle scores and educational value), irrelevant to children's current learning goals (with low principle scores but high in educational value), were simply playful (with high principle scores but low in educational value) or provided deep learning (with high principle scores and educational value). Hirsh-Pasek et al. (2015) also argued that scaffolding was necessary to prevent children's haphazard use of tablets and their apps and to assure age-appropriate content was accessed.

Having discussed in this section the role of scaffolding in supporting children's ICT use, the next section examines studies which have focused more specifically on MKOs' scaffolding of children's tablet use.

2.5.3. Scaffolding children's tablet use. With regards to different models and principles of scaffolding, this section reviews empirical literature investigating how children's use of ICT, including tablets, is scaffolded. The review in this section draws on studies across the ECE and primary sector.

The earliest study located in my search for literature on how MKOs scaffolded young children's tablet was conducted in New South Wales, Australia by Verenikina and Kervin (2011). They investigated pre-schoolers' collaboration and imaginative play at home through case studies of three families. Firstly, three parents of three- to four-year-olds were interviewed regarding their children's engagement with digital media. This study was followed by a review of apps selected for children's use in the next phase. Finally, observations of children's iPad use and their consequent interactions with siblings and parents were carried out. Results revealed that parents and more knowledgeable siblings collaborated with the children, providing scaffolding and technical support when necessary. Verenikina and Kervin (2011) proposed the need to support parents or older siblings through information that could upskill them so they could provide more effective technical support when scaffolding app use.

A similar investigation in a multicultural kindergarten in a suburban area in Oslo, Norway revealed the importance of actively scaffolding tablet use. Sandvik, Smørdal, and Østerud (2012) observed eight teachers' and 25 four- to five-year-olds' use of tablets and their apps for almost a year. The teachers created an environment 
for positive engagement and cooperation whilst scaffolding tablet use by connecting digital content to real-world concepts. Results found that teachers' active scaffolding of tablet use fostered both verbal and non-verbal communication and interaction between the children and their teachers (Sandvik et al., 2012).

In their in-depth examination of scaffolding involving ICT, Yelland and Masters (2007) conducted a two-year case study involving 10 pairs of primary schoolchildren aged seven- to eight-years in an inner-city school in Australia. Each pair used a computer programme called Geo Logo to draw a house in two attempts, one with teacher scaffolding and another without. Yelland and Masters (2007) argued that teachers fulfilled an important role as MKOs in ensuring that children had opportunities to "maximize their potential and use higher-order thinking skills to solve problems" (p. 380). Teachers' decisions on the level and type of scaffolding depended on numerous factors such as the task and its concepts and processes, a child's needs and interests, and collaborative opportunities with peers. As MKOs, teachers needed to be aware of these factors (Yelland \& Masters, 2007).

Mediation of tablet use through social interaction was investigated in Texas, USA by Reynolds-Blankenship (2013). Her doctoral research involved 25 five- and six-year-old kindergarten children's iPad use during free play. She provided three iPads as additional play items for children to choose during their free play for 12 weeks. Based on data collected from audio-recorded data, observations of and interviews with the children, reflexive journals, and field notes, ReynoldsBlankenship (2013) concluded that iPad use resulted in child-centred teaching and learning. Reynolds-Blankenship (2013) asserted that teachers played a key role as mediators of social interactions and active participation whilst they worked with children. It was interesting how teachers developed a turn-taking system to mediate conflicts regarding iPad use.

Another investigation carried out by Reich, Korobkova, Black, and Sumaroka (2013) in a city in the USA involved examining five four- to twelve-year-old children's play behaviour when using digital devices including iPads. Although the children had different ages and the setting was at home, this study is still useful as it analysed use of tablets using concepts from sociocultural theory. The authors 
observed that guided participation in joint play and sharing of digital devices between siblings and adult family members provided rich social contexts. They observed that children's digital media use was scaffolded by parents and older or more capable peers, as well as by the devices' features. Additionally, their study found that more technically skilled children also assisted parents in their digital media use. Verbal interactions such as cheering, commenting, and enquiring between dyads of children were observed as one child engaged with the digital device and another watched. Children's use of devices with older siblings and parents also offered opportunities for cooperative conversations, collaboration, and parallel play. Reich et al. (2013) argued that ICT and digital media were tools of the present culture which offered opportunities for scaffolding and guided participation. They asserted that in sociocultural theory, using cultural tools including digital devices, such as iPads, in conjunction with guided participation, mediation, and scaffolding benefitted children's learning.

Several studies have linked tablet use within ECE services to Vygotsky's (1978) concept of MKOs by providing evidence on how MKOs scaffolded children's tablet use. Fleer's (2013) case study in an Australian city involved video-recorded observations of a four-year-old child with special needs who used an iPad. The technical features of the iPad helped adult MKOs support the technological language learning through photography. The open-ended music app, Garage Band, helped develop the child's creativity. Through these features, the child and adults collaborated within their family's cultural practices. Furthermore, the study found that the iPad encouraged adult-child collaboration including imitation and providing guidance. Fleer (2013) argued that the way the child imitated MKOs' tablet use matched Vygotsky's (1978) concept.

A small case study carried out by Zipparo, Robinson, and Hazeldene (2015) identified how a teacher scaffolded young children's iPad use at a preschool in an Australian city. In this study, the educator scaffolded tablet use with the objective of supporting children's schooling and found that children also acted as MKOs when they taught adults and peers how to use iPads and their apps. Zipparo et al. (2015) concluded that with children and adults both fulfilling the role of MKOs, positive MKO-learner relationships, collaboration of ideas, and peer support resulted in 
tablets being used for communication and exploration, including information retrieval.

With regards to how parents' scaffolded children's tablet use, Kucirkova and Sakr (2016) presented their case study findings as two vignettes. They observed how Vygotsky's (1978) sociocultural theory applied to young children (age, location, and number of participants were unspecified) and their parents' tablet use. In this study, children used iPads to co-create e-books with the guidance of their parents. Kucirkova and Sakr (2016) found that through parent-child social interactions, including parents acting as MKOs when mediating or scaffolding iPad use, children learned to use the tablets independently, such as taking photographs.

A mixed methods study by Bullock, Shumway, Watts, and MoyerPackenham (2017) in Utah, USA, investigated 35 three- to four-year-old children's engagement with sequencing and seriation apps using tablets. The qualitative preand post-tests showed that although children exhibited gains in numeracy and expressive language, some children regressed in their learning. Regression was attributed to technical difficulties and frustration when using tablets. This study found that compared to simply relying on technical scaffolding provided by tablets and apps, children learned better when teachers'/educators' and parents' scaffolded children's understanding of the app features. Bullock et al. (2017) argued that some children "may need explicit scaffolding to perceive and access features that the apps afford" (p. 507) and that teachers could identify these when children expressed frustration, had difficulties using tablets and their apps, or exhibited a disconnect when learning mathematical concepts. Aside from interceding to provide children with positive experiences whilst using tablets, adults could also scaffold children's use of the device by questioning purposefully, giving clear instructions, and carefully monitoring and limiting use.

A recent study by Tavernier and $\mathrm{Hu}$ (2017) pointed out the different ways teachers scaffolded young children's iPad use. In their investigation on how eight four- to five-year-olds began using tablets in an international kindergarten in Hong Kong, the teacher began by explaining and demonstrating the activity involving iPads. Each pair of children used one iPad for a day. The teacher monitored and 
supported children as they used the iPads to take photos of themselves and the toys they played with, and audio-recorded self-introductions and explanations of their toys and their activities such as using a jigsaw app to learn numeracy. Afterwards, the children were instructed to look at the photos and listen to the recordings of their partners. Whilst teachers' use of guided interaction strategies included demonstrating, explaining, instructing, managing, monitoring, prompting, feedback and supporting, Tavernier and $\mathrm{Hu}$ (2017) found that instructing and demonstrating were used most often, being evident across all activities.

Findings from Tagawa's (2018) collective case study conducted in California, USA emphasised the importance of MKOs in scaffolding young children's tablet use. This doctoral research involved interviews with five ECE teachers and observations and video-recordings of iPad use in five classrooms. According to the teachers, children's use of tablet alone did not necessarily afford meaningful learning. According to Tagawa (2018), scaffolding of iPads supported children's developmentally appropriate use of the device. Scaffolding was carried out through close supervision of children's tablet use and probing a child's intended actions when apps presented a set of choices.

Aside from scaffolding provided by adults, collaboration with more knowledgeable peers also supported children's learning using tablets. Winters and Memme's (2017) case study of iPad use in two Canadian kindergarten classrooms for children aged three- to five-years-old involved iPad use with both adult and peerscaffolding. The services' guidelines helped teachers/educators scaffolded children's co-use of tablets. Differences in social hierarchies were observed depending on the contexts where tablets were used. Some children took on the role as mentors to support other children who were inexperienced with using tablets. When creative apps were used, there was no observable social hierarchy amongst children as each child contributed to the activity. These activities involved using iMovie and LEGO Movie Maker apps for video- and audio-recording, storytelling, scrapbook making, and presentations. Children's use of other creative apps such as Storybook Maker and Puppet Pals led to shared discussion and equal collaboration on ideas resulting in problem solving and cooperation as they created original stories (Winters \& Memme, 2017). 
In a more recent case study in Alberta, Canada, Kirova and Jamison (2018) collected data using surveys, classroom observations, and video-recordings of oneon-one scaffolding of tablet use by 25 pre-schoolers, 13 parents and two classroom teachers. This study found that teacher scaffolding encouraged children to use the iPad in different ways for learning whilst peer scaffolding afforded deeper engagement with apps. Using iPads in pairs or small groups encouraged social interaction. Teachers' role modelling of iPad use encouraged children to use the device collaboratively through peer scaffolding. It was observed that this form of role modelling led to children supporting each other through tutoring and modelling which involved cooperation, collaboration, questioning, physical gestures, and prompting. Kirova and Jamison (2018) stressed that children's skills and knowledge could be brought to a higher level of independent performance through teacher scaffolding.

A study on scaffolding enabled by apps showed evidence of how tablet software provided cognitive, affective, and technical scaffolding. Holloway, Haddon, Green, and Stevenson (2018) examined how Vygotsky's (1978) ZPD and Wood et al.'s (1976) scaffolding were incorporated in parent-child use of tablets and their apps. The researchers interviewed 21 parents of children under five years of age: nine in London, UK, and 12 in Perth, Australia. Firstly, the study explained how tablets and their apps provided cognitive scaffolding by adjusting the speed and language used to suit young children and repeating, when necessary. Next, affective scaffolding used badges or other similar reward tokens and cheering or clapping from characters to reinforce positive results. Finally, apps were designed to provide technical scaffolding to support children's navigation of apps. Through co-use with children, parents also provided similar cognitive and affective scaffolding, but their form of technical scaffolding was exhibited by helping children manage the technical features of tablets and apps. Results showed that additional cognitive and affective scaffolding provided by parents through encouraging, redirecting, and correcting added to the technical scaffolding provided by tablets and their apps. Based on their observations of parents and their children's tablet use, Holloway et al. (2018) concluded that parents' cognitive and affective scaffolding were more fluid than and added to the technical scaffolding provided by apps. In relation to sociocultural 
theory, a more specific case study within Holloway et al.'s (2018) research found that even with the app's built-in scaffolds, the child sometimes did not fully engage with the app. In this case study, having the child's mother present to provide additional scaffolding and enrich the app's affordances through additional interaction with her son and the app, established a shared learning environment for her son and added human agency to support the child's learning. This human agency supports sociocultural theory specifically on how the parent scaffolded her son's learning in terms of fully interacting with the reading app.

Relevant to this literature review is Burnett's (2017) examination of the features of tablets. She acknowledged that although their screen size could be an affordance, when these devices are used in groups, other viewers' line of sight could be easily blocked.

Whilst tablets and their apps provided technical scaffolding, the studies reviewed showed that assistance provided by MKOs was important to children's tablet use and enhanced their learning and development. Although these issues have been explored to some extent in New Zealand's ECE sector, studies have primarily focused on education and care services and kindergartens. In New Zealand, teachers'/educators' perspectives on the adoption of tablets have not been examined, especially those from non-user services. Additionally, there needs to be more investigation about teachers'/educators' reflection and perspectives on tablet use at their ECE service. Next, I review the cybersafety and technical issues that could be encountered when using tablets in ECE.

\subsection{Cybersafety and technical issues}

Even though tablets have been lauded for their ease of use, their communication and information retrieval capabilities, and their portability (e.g., Almashaileh, 2016; Gray et al., 2017), some studies have reported that devices were prone to cybersafety concerns, fragility, and battery issues when using them in ECE (e.g., Blackwell, 2014; Lynch \& Redpath, 2014). In response to these concerns, Hart-Davis (2017) developed a detailed guide for deploying iPads in classrooms. This comprehensive guide highlighted the affordances of the device and suggested ways to resolve issues such as managing features, settings, and children's access. 
Guides such as Hart-Davis' (2017) tended to provide solutions at the technical level but did not explain how teachers/educators could use the features and settings of tablets for teaching and learning.

Even though the benefits of using tablets made evident through the review of literature in sections 2.2.2 to 2.4 and 2.5.2 to 2.5.3 outweigh the disadvantages of using tablets in ECE, there are still potential disadvantages which affect how these devices are used in ECE. This section discusses cybersafety and technical issues regarding the adoption of tablet in ECE services as well as related concerns including administration and logistics.

Neumann, Merchant, and Burnett (2018) investigated parents' and teachers' views on young children's tablet use. The case study interviewed four parents of children aged 20- to 36-months-old and two teachers in an ECE centre in the north of England. Overall, participants perceived that using tablets helped children learn about new technologies and the importance of how to use these devices. Parents reported that their children liked using tablets and exhibited engagement and motivation in learning new digital skills and knowledge such as mark making and phonics in a multimodal environment. Teachers had similar responses and added that tablet computers allowed children to extend their learning from the classroom to their own homes. The home-school link enabled by tablets contributed to consistency in learning. Yet, both parents and teachers expressed concerns about the misuse and overuse of these devices which could potentially impact children's socialisation and interactions. Parents expressed feelings of guilt when they recalled using tablets for settling or distracting children. They also raised concerns over cybersafety issues such as breaches of children's privacy, inappropriate purchases, and children accessing inappropriate content. Parents mitigated these issues by closely monitoring their children's tablet use. However, for them, the perceived learning benefits of using tablets still outweighed the potential disadvantages. The researchers reported that parents and teachers emphasised the balanced use of tablets with "traditional" (Neumann et al., 2018, p. 10) or non-digital activities to avoid potential overuse and misuse. 
In their review of issues on ICT use in education, Ernest et al. (2014) collected 60 statements from online videos, newspapers, books and other print articles, internet-based articles including blogs and wikis, and position statements regarding children's access to and use of media, technology, and screen time. These statements were grouped into four categories: positive benefits, concerns, balanced approaches, and "unclassified" which included statements that had contrasting views. They argued that although using digital technology enhanced children's learning and skills development, many statements expressed concerns about addictive and antisocial behaviour and exposure to inappropriate and harmful content. Ernest et al. (2014) emphasised how "harmful commercialism" (p. 84) affected children through screen-based advertising and marketing. They suggested that adults should be aware of the positive and negative impacts that screen time and digital media use bring to children and thus should balance children's access to and use of digital technology.

Risks to cybersafety were also identified according to a review of 400 apps from iTunes and Google Play by the United States Federal Trade Commission (Mohapatra \& Hasty, 2012). The findings showed that 60\% (235) of these apps that were targeted for children's use as "kids' apps" transmitted device information to third parties such as developers, advertisers, analytics companies, or other third parties. Of these, 14 apps transmitted the device's location or phone number raising cybersafety concerns about children's tablet use (Mohapatra \& Hasty, 2012).

In relation to this, young children and their parents were reportedly unaware of these online risks involving content and commercialism. A report on ICT use by 70 families with children eight-years-old and younger by Chaudron (2015) identified that tablets were the children's favourite device. Ten families from each of seven European countries - Belgium, Czech Republic, Finland, Germany, Italy, UK, and Russia - participated in this qualitative study. Interview results reported that children strongly preferred tablets to other digital devices but had little awareness about the online risks involving their use. Children were reported to "have limited or no perception of online risks ... inappropriate age content or problematic experiences with pop ups and in-app purchases" (Chaudron, 2015, p. 7). Parents usually managed their children's digital technology and media use by restricting access. Yet, the study found that parents had little knowledge of their children's online activities. 
Despite parents expressing their concerns about violence, strong language, sexual content, or unwanted contact, this study reported that some children knew how to bypass cybersafety settings.

The safety of young children who use tablets has been a general concern in Europe. In a cross-national project, Holloway et al. (2013) reviewed nearly 400 studies on internet-related behaviours of children aged eight-years-old and younger. These studies, carried out in 25 European countries, reported that children's internet access and use were not always "safe and beneficial" (Holloway et al., 2013, p. 4) as they could independently access inappropriate content. They found that some apps did not disclose data collection which potentially put children's privacy and safety at risk. Additionally, parents and family members could inadvertently share photographs and videos of their children. To address these issues, Holloway et al. (2013) suggested the development of age-appropriate content, data collection transparency by software designers, policies to mitigate risky and erroneous data collection, and parental education regarding their children's digital activities and information.

Educating teachers/educators and children on appropriate tablet use could be a solution for addressing issues regarding commercialism, content, and cybersafety. Edwards, Nolan, Henderson, Mantilla, Plowman, and Skouteris (2018) studied the cyber-safety awareness of 70 four- to five-year-old children and their four ECE teachers/educators in Australia. Edwards et al. (2018) grouped the different ways children used digital media into family use, information, and entertainment. The first category related to internet use by and for family members, the second focused on access to and production of information, and the third involved enjoying movies and games for fun or relaxation. Results showed that sociocultural practices, such as scaffolding by parents or older peers, could make children more aware of cybersafety issues and the appropriate use of tablets. Edwards et al. (2018) stressed that teachers/educators who worked in services which used ICT were responsible for teaching young children to be aware of their digital media use and related online risks. 
Several studies have reported issues including administrative and technical concerns that prevented teachers/educators from maximising the educational affordances of tablets. In Ireland, Walsh and Farren (2018) investigated the barriers involving iPad use encountered by five teachers of children aged three- to 12-yearsold. According to interviews with the teachers and reflections from teachers' journals, using iPads had a positive impact on education, but their use had potential disadvantages. Whilst tablets afforded a range of content and different ways of communication and information retrieval, having iPads required the teachers to limit and to monitor children's internet access. Although iPad use helped with documentation, there were times when children's work was inadvertently deleted, the iPad was unavailable or not sufficiently charged, or the work could not be printed. Searching for engaging and up-to-date apps was also time consuming for teachers. Teachers reported that even though individual iPad use led to positive impacts and promoted collaboration amongst children, the cost of acquiring tablets and the added requirement of educating students about internet safety were potential issues. The major technical issues were the inconsistent, or lack of, wireless internet connection, iPads or apps freezing, and the lack of necessary features or functionality for specific tasks. Teachers were equally divided on whether use of iPads individually or in groups was beneficial as results depended on how they scaffolded children's use. Walsh and Farren (2018) reported that teachers found professional development about using iPads and apps in educational settings a necessity.

Adopting tablets for use in ECE has led to issues requiring added technical support, teacher/educator preparation time, and costs for the devices and their apps. Flewitt, Messer, and Kucirkova (2015) investigated tablet use at a nursery with around 16 three- to four-year-old children, a primary classroom for four- to fiveyear-olds, and a special school for seven- to 13-year-old children in England, UK. Video-recorded observations of interactions around iPads and pre-/post-study interviews with children and their teachers/educators showed that iPads and their apps helped children develop their creativity, independence, motivation, technological expertise, communication, and collaboration. However, teachers/educators still encountered challenges. They reported that iPad use led to addictive and overstimulating digital gaming, wasted teachers/educators' time 
looking for appropriate apps, led to a reduction in children's outdoor or physically active play, made children reliant on texting instead of talking, and caused conflicts in turn-taking. Teachers/educators reported that the cost, technical problems and subsequent lack of technical support, and their own lack of confidence impacted children's learning. They stressed the importance of supervising iPad use by “"keeping a balance' between learning activities with traditional and new media and making the most of technology 'to enhance teaching'" (Flewitt et al., 2014, p. 296).

Aside from added financial burdens to services, studies found that teachers/educators and children could become reliant on their device, potentially affecting teachers'/educators' work and children's learning and development. In their review of policies in early primary education in Victoria, Australia and Alberta, Canada regarding tablet use, O'Mara, Laidlaw, and Blackmore (2017) reported that schools in Australia intended to introduce "bring your own device" (BYOD, p.92) programmes whilst schools in Canada followed a "site-based decision-making" (p. 92) policy which meant that individual schools decided on particular spending priorities, such as technology spending. With tablets easily adopted by early primary students, the increased use of iPads led to issues such as the cost of repairing/replacing broken devices. O’Mara et al. (2017) also identified educational concerns such as the weakening of children's handwriting skills, iPads and apps replacing teachers, and teachers'/educators' and children's overreliance on these devices.

In the USA, Blackwell's (2014) study on tablet use amongst three kindergartens and six pre-school teachers revealed the difficulties they faced in finding appropriate apps and tracking student progress. Teachers remarked that updating numerous devices was tedious as digital information could be mistakenly erased and information was lost when updating devices. They perceived that tablets could potentially be used for meaningless play, especially for apps without progress tracking systems. Inconsistent internet connections were frustrating to them, especially for those who used apps reliant on wireless internet connectivity such as video apps. 
This review has revealed that significant responsibilities have been placed on teachers/educators who were expected to use their professional judgment with regards to young children's access to and use of digital technology, including tablets. With the reported issues surrounding using tablets for teaching and learning, teachers/educators were expected to be aware of the advantages and disadvantages of ICT use (e.g., Radich, 2013). The review has also identified the scant research on teachers/educators who opted not to use ICT, particularly tablets (e.g., Finch \& Arrow, 2017; Gerritsen et al., 2016). These studies were not entirely focused on tablet use and did not delve into teachers'/educators' reasons for not using tablets. With studies reporting that there were some ECE service types which opted not to use these devices, it is important to include these service types in the research on tablets. Their rationale for not using tablets, which is explored in this thesis, could support the ECE sector to make more informed decision-making. The next section outlines the concept of digital divides and how these affect ICT use in educational settings, including ECE.

\subsection{Different types of digital divides}

This section explains digital divides and how they extend into educational settings. The concept of digital divides involves different variables such as access to resources, differences in technological ability, and ways of using or not using specific ICTs. For the purposes of this literature review, this discussion on digital divides is limited to ICT use and the characteristics of users and non-users. This review begins with Murdock (2002b) who expanded on this notion to include access to and use of ICT for information seeking, communication, and content creation.

Arguing against the notion of a singular digital divide, Murdock (2002b) grouped users into three categories: excluded users who did not use ICT, peripheral users limited in their ICT use, and core users who used ICT comprehensively. For people in the digital age, digital divides involved the "dynamics that enable them to move on, or force them to remain in the same place, or stop running altogether" (Murdock, 2002a, p. 388). Murdock proposed that ICT adoption is fluid, meaning that people could opt to shift from using technology to not using it depending on the context. Murdock (2002b) further argued that digital divides could not be resolved 
through the provision of access and use of ICT resources alone because how people used technologies in their communities was complex. According to Murdock (2002a, 2002b), access to and use of the internet and computers are rights of citizens in the digital age. Yet, this proposed fluidity did not explain why people shifted from using to not using ICT and vice versa.

Selwyn (2003) expanded Murdock's (2002a, 2002b) perspective and criticised how peoples' access to and use of ICT were divided into "haves and havenots" or "information rich and information poor" (p. 100). To him, much of the research in ICT focused on only those who used digital technologies and "simply pathologised the 'have nots' in terms of individual deficits" (Selwyn, 2003, p. 101). Selwyn (2003) argued that the reasons for ICT-use were not always based on what he called the "equipment gap" (p. 103) but could also stem from "ideological refusal" (p. 104) or from anxiety caused by the potential stress of using ICT. Selwyn (2003) proposed a shift in perspective from considering ICT non-users as "information have-nots" to reconsidering their views as "information want-nots" because people may have had opportunities to access and use them but had their own reasons such as "resisting ICT in terms of implications for traditional patterns of work and life" ( $p$. $105)$.

To Selwyn (2003), non-use of ICT should not be an obstacle but instead a positive part of social choice. Reasons for not using ICT were complex and fluid because they were dependent on economic, material, and psychological factors. Furthermore, non-users varied from general resistance to using ICT to using some specific digital technologies whilst resisting others. He argued that non-users could not be blamed for not using ICT simply because material resources and economic capacity were the commonly recognised barriers to ICT adoption. Selwyn (2003) asserted that "despite the endless ... research ... that surrounds information and communications technology we still know little about the patterns of non-uptake and non-use of new technologies" (p. 101). His statement is important to one of the aims of this thesis which deliberately sets out to investigate why teachers do and do not use tablets. Furthermore, Selwyn (2003) argued against negative labelling of ICT non-users such as 'defectors' and 'laggards' because these labels positioned them as impediments to social innovation. Finally, to Selwyn (2003) using technology was 
not always "a 'good' thing" (p. 112) because "for some people 'dealing with everyday problems' does not and will not involve personal use of ICT” (p.112).

Digital divides are more complex than simply having access or not having access to ICT. Wei, Teo, Chan, and Tan (2011) identified three categories of digital divides. The first category involved access based on groups of people who had digital devices and access to the internet and those who did not. The second, capability divide, grouped people according to their ability or inability to use the digital devices or software. The third, outcome divide, was based on whether people used technology comprehensively or not. Wei et al. (2011) theorised that individuals, organisations, and societies began in the first category and transitioned to the second and then the third category.

In the educational technology sector, there are different ways in how technology is adopted and used. Keirl (2015) illustrated these ways using three curriculum scenarios for Technology Education: the disillusionist case, the specialist case, and the comprehensive case. Teachers/educators in the disillusionist case abandoned or rejected the idea of technology education because technology learning should be addressed in other curriculum areas. In the specialist case, teachers/educators restricted technology education to a subject or learning area. In the comprehensive case, technology education was fully integrated into the curriculum as a subject, as an integrated cross-curricular project and through all other school activities. Keirl (2015) focused on how ICTs are taught and used in educational settings. His three curriculum scenarios illustrated that how teachers consider the use of technology is not limited to the exclusive categories of users and non-users.

The digital divides described by Murdock (2002b), Keirl (2015), and Wei et al. (2011) could be categorised into three groups of people: those who did not use ICT, those who limited ICT use, and those who used ICT comprehensively. Amongst these, Murdock (2002a) proposed that digital divides are fluid whilst Selywn (2003) argued that non-use of ICT should not be limited to inadequate resources and that individuals who did not use ICT had the right to exercise their social choice and individual reasons and thus should not be labelled negatively. The 
investigation provided by this study will identify if empirical evidence supports this argument in New Zealand's ECE context.

\subsection{Chapter summary}

In this chapter, I have reviewed literature relevant to this study by first discussing access to and use of tablets by young children (e.g., Marsh et al., 2015; Rideout, 2011, 2013, 2017) followed by a review of international studies (e.g., Kirkorian, 2018) on the impacts of digital technologies including tablets (e.g., Spitzer, 2013) and their many benefits when used in educational settings (e.g., Ernest et al., 2014). Then, New Zealand studies (e.g., Khoo et al., 2015) on tablet use in ECE were examined. In New Zealand, the scant research on tablets such as iPads has focused on a limited number of ECE service types. These studies mostly involved education and care services and kindergartens (e.g., Dooley \& Gattenhof, 2015; Fagan \& Coutts, 2012). Additionally, numerous studies focused on children's tablet use (e.g., Falloon \& Khoo, 2014) with very few reporting data on teachers/educators' use at a service level (e.g., Hatherly \& Chapman, 2013). Many of these studies attributed their results to scaffolding or mediation by teachers/educators, parents, or older peers/siblings. Focusing on the scaffolding of tablets by MKOs, especially by teachers/educators, Vygotsky's (1978) sociocultural theory was introduced followed by a discussion of related concepts, particularly Bruner's (1983) scaffolding and Rogoff's $(1990,1995)$ guided participation. These concepts were linked to studies on technology use in ECE settings (e.g., Jacobs, 2001). Of these, Troseth et al. (2016) stressed the importance of active scaffolding of children's tablet use. These empirical studies argued the need for teachers/educators to scaffold children's ICT use (e.g., Reich et al. 2013; Zipparo et al., 2015).

As reviewed, teachers/educators fulfilled the role of gatekeepers of children's access to and use of tablets (e.g., Finch \& Arrow, 2017), yet investigations on their pedagogies involving tablet use are few. The complexities surrounding tablets and their use by young children and ECE teachers/educators have been identified in this literature review. To better understand these complexities in New Zealand's ECE sector, there is a need to explore how tablets are presently used in various early 
childhood services as current literature does not provide a comprehensive picture of their use or non-use across the four main ECE service types. Gaining a greater understanding of current use and the reasons behind teachers' decisions will support services in making an informed decision regarding whether they choose to use tablets or not. In particular, research on tablet non-user services is required to offer a more balanced perspective on the ongoing tablet debate in ECE. The next chapter discusses the research design and methodology used to undertake this study on why services choose to use or not use tablets and investigating how, if services use TST, teachers/educators use these devices to support children's learning in ECE. 


\section{Chapter 3}

\section{Methodology}

This chapter presents the research methodology beginning with the sequential explanatory mixed methods design adopted for this project and followed by discussion of the research paradigms underpinning each phase of this study. Then, the two phases of the data collection are explained. Phase 1 comprised a national survey distributed to services from four early childhood education (ECE) service types in New Zealand. The survey population and data collection procedures are explained. Phase 2 was a collective case study with two sub-phases. Details about the services that participated in the collective case study and the qualitative data collection procedures are presented. Then, the ethical issues involved in this research are discussed. The coding and analyses procedures using descriptive and inferential statistics for Phase 1 and thematic analysis for Phase 2 are explained. Finally, I elaborate on the validity and reliability of this research design and data collection procedures.

\subsection{Research design}

Research can be quantitative or qualitative with each approach having its own characteristics. Quantitative research examines measurable and observable data. Focusing on specific and narrow purposes, research questions, and hypotheses, quantitative research uses instruments with preset questions and response choices to gather data. In quantitative research, data are analysed using statistics to describe, compare, or relate variables. The advantages of quantitative research are its efficient data analysis, statistical analyses of variables, bias control, and capability to draw conclusions from a large number of participants. Yet the objectivity of quantitative research constrains context and makes participants' voices impersonal (Creswell 2015b; Fraenkel, Wallen \& Hyun, 2015; Mertens, 2015).

In response to these limitations, qualitative research can be used to explore problems or phenomena in-depth. Qualitative research aims to understand research problems through participant-focused data collection. Data are usually collected from a small number of individuals and analysed into themes. However, qualitative 
research is broad and general with its subjectivity and reliance on soft data (Denzin \& Lincoln, 2018a; Mackey \& Gass, 2016; Merriam \& Tisdell, 2016).

Sammons stated that the mixing of quantitative and qualitative components leads to a better description and understanding of "variation in and contributors to differences in educational effectiveness" through "mutual illumination" (2010, pp. 699-700). In this project, I use an explanatory sequential mixed methods design beginning with a quantitative phase followed by a qualitative phase (Creswell, 2015a; Creswell, 2015b; Green et al., 1989). It is necessary to include a qualitative study to clarify the findings from the quantitative component (Creswell, 2015a; Fraenkel et al., 2015).

3.1.1. Mixed methods research. To benefit from the advantages of both quantitative and qualitative research methods, this study uses mixed methods research. By utilising both quantitative and qualitative research methods, mixed methods research designs resolve the close-ended, objective, and contextual limitations of quantitative research and the open-ended, subjective, and small-scale disadvantages of qualitative research. The advantages of quantitative research are its ability to draw conclusions from large numbers of people, efficient data analysis, capability to investigate relationships within data, and bias control (Creswell, 2015a; Creswell, 2015b). The advantages of qualitative research are its ability to obtain detailed perspectives from a few people, and contextual collection of participant data usually presented in story form (Creswell, 2015a; Creswell, 2015b). Because quantitative research can be close-ended, impersonal, and limited in context, and qualitative research can be open-ended, highly subjective, and limited to a few people, the mixing of methods addresses these disadvantages compared to using one method (Creswell, 2015a; Wiersma \& Jurs, 2009). Mixed methods research is defined as the integration of two data sources - quantitative and qualitative - to take advantage of their strengths, leading to a better description and understanding of variables (Creswell, 2015a). However, mixed methods research requires rigour, skill and time in both quantitative and qualitative data collection and analyses (Creswell, 2015b; Tashakkori \& Teddlie, 2010). Therefore, mixed methods explain, explore, and validate research using qualitative and quantitative data sets (Fraenkel et al., 2015). 
In this study, the explanatory sequential mixed methods design was used as outlined by Creswell (2015a). This involved a main quantitative phase of data collection and analysis followed by a supporting phase. Qualitative data were gathered from a purposive group of participants "to help explain the quantitative results" and analysed thematically (Creswell, 2015a, p. 6). The key to this design is to identify which of the quantitative results needs further explanation in the qualitative phase (Creswell, 2015a; Creswell, 2015b). The two data sources were analysed separately, beginning with the quantitative statistical results followed by the qualitative findings (Creswell \& Creswell, 2018). This design was chosen in order to obtain an overview and to know the trends on tablet use and non-use by ECE services across service types using a national survey. Then, based on the survey results, the issues identified could be investigated further using a collective case study. Additionally, beginning with a national survey allowed services to express their willingness to participate in the qualitative phase of this study. This approach to the research design offered an unobtrusive means for collecting data by allowing potential participants to make the decision whether or not to respond to the survey and to indicate interest in participating in Phase 2 of the study.

3.1.2. Research paradigms. Mixed methods research draws upon multiple paradigms (Denzin \& Lincoln, 2018c; Greene \& Hall, 2010; Mertens, 2015). Denzin and Lincoln (2018b) defined a paradigm as a "set of beliefs that guide action" (p. 97) which governs the underlying assumptions and research methodology. A postpositivist paradigm underpins the quantitative component. In their explanation of the characteristics of postpositivism, Lincoln, Lynham, and Guba (2018) as well as Mertens (2015) stated that the paradigm is systematic, objective, and generalised. The paradigm still acknowledges human limitations as researchers' theories, hypotheses, and background knowledge can influence the observed reality. To address these limitations, maintaining objectivity and neutrality whilst conducting research is necessary.

This study uses the postpositivist paradigm for the quantitative phase and the constructivist paradigm for the qualitative phase. The postpositivist paradigm focuses primarily on quantitative, objective research. Ascribing to the postpositivist paradigm allowed me to gather quantitative data on tablet use and non-use in ECE 
services whilst being removed from the process so as not to influence the data (Lincoln et al., 2018; Mertens, 2015). By adopting a postpositivist paradigm, I aimed to "get as close to the answer as possible" (Lincoln et al., 2018, p. 119).

A constructivist paradigm underpins the qualitative component by emphasising that the role of the researcher using this paradigm is to understand the socially constructed reality from the participants' perspectives (Creswell, 2015b; Lincoln et al., 2018; Mertens, 2015). Constructivism focuses on social contexts and interpretation involving researchers' engagement with participants leading to coconstructed perspectives usually in the form of narratives (Creswell \& Poth, 2017; Denzin \& Lincoln, 2018b; Lincoln et al., 2018). The transactional nature of constructivism allowed me to engage the participants as a facilitator of shared conversation and to co-construct their perspectives (Denzin \& Lincoln, 2018b; Lincoln et. al, 2018; Mertens, 2015) on tablets use and non-use dialectically.

Since quantitative and qualitative research use separate paradigms, mixed methods research can suffer from incompatibility between paradigms (Denzin \& Lincoln, 2018b; Greene \& Hall, 2010). Therefore, mixed methods research requires a stance for selecting and using paradigms (Greene \& Hall, 2010; Johnson \& Gray, 2010).

Two key stances identified by Greene and Hall (2010) were dialectics and pragmatism. The dialectic stance questions and considers different sides of the research problem (Johnson \& Gray, 2010) whilst using the strength of different paradigms to better understand the phenomenon (Greene \& Hall, 2010; Teddlie \& Tashakkori, 2010). New, reframed, or enhanced understandings and multiple assumptions may lead to loss of focus and overwhelm (Greene \& Hall, 2010). The pragmatic stance does not ascribe to traditional methods and allows mixed methods researchers to focus on workable solutions within contexts. However, this stance can lead to a haphazard mixing of multiple data sources.

Johnson and Gray (2010) suggested the combination of both stances into the dialectical pragmatic stance because it allowed "construction of new research approaches and designs and sets of working assumptions" (p. 89). When used in mixed methods research, the dialectical pragmatic stance creates a dialogue between 
different perspectives (Green \& Hall, 2010; Johnson \& Gray, 2010; Johnson \& Christensen, 2017). The dialectic pragmatic stance helped "represent a plurality of interests, voices, and perspectives" (Green \& Caracelli, 1997, p. 14), particularly about tablet use and non-use amongst different ECE service types. This stance enables researchers to adopt dialectics to listen and carefully consider multiple viewpoints whilst applying the core philosophies and methodologies of pragmatism (Johnson \& Gray, 2010). Furthermore, Johnson and Gray (2010) explained that this stance allows researchers to select and utilise paradigms appropriate for quantitative and qualitative components. At the same time researchers can maintain a workable middle ground to avoid dualism between paradigms and the dogmatism of a single paradigm (Johnson \& Gray, 2010). I chose dialectical pragmatism, the combination of these stances, as it was most appropriate for this research. Whilst maintaining a dialectical pragmatist stance, this study adopted postpositivism for its quantitative component (Phase 1) and constructivism for its qualitative component (Phase 2) as shown in Figure 3.1.

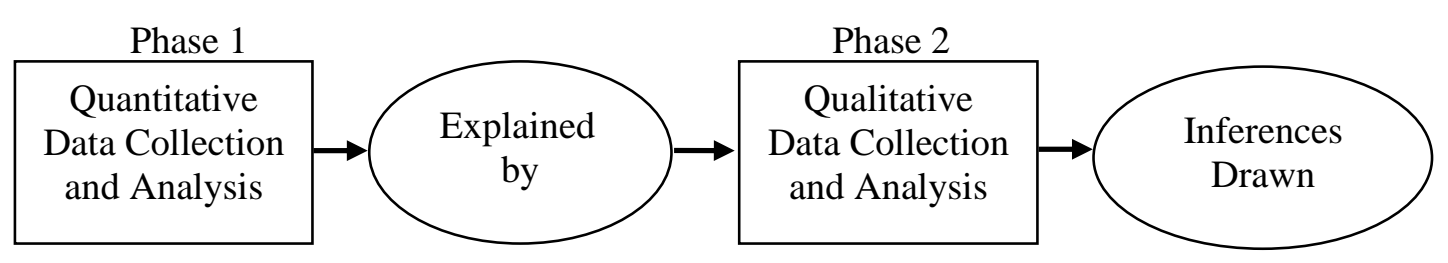

Figure 3.1. Explanatory Sequential Design. Reprinted from A Concise Introduction to Mixed Methods Research (p.39), by J. W. Creswell, 2015, Thousand Oaks, CA: SAGE. Copyright (2015) by SAGE Publications, Inc. Reprinted with permission.

The quantitative (Phase 1) and qualitative (Phase 2) components of this study were carried out sequentially. Phase 1 was a national survey of tablet use and nonuse amongst four ECE service types in New Zealand (education and care, homebased, kindergarten, and playcentre). Phase 2 was a collective case study of services that used or did not use tablets. Phase 2 had two sub-phases: semi-structured focus group interviews for participating services (Phase 2A) and a second semi-structured focus group interview using of video-SR for tablet user services (Phase 2B).

Figure 3.2 presents the research flow which began with the national surveythe quantitative phase. This was followed by a qualitative phase necessary to explain the results of Phase 1. 


\section{PHASE 1: NATIONAL SURVEY}

Online and postal survey sent to

education and care services, home-based services, kindergartens, and playcentres

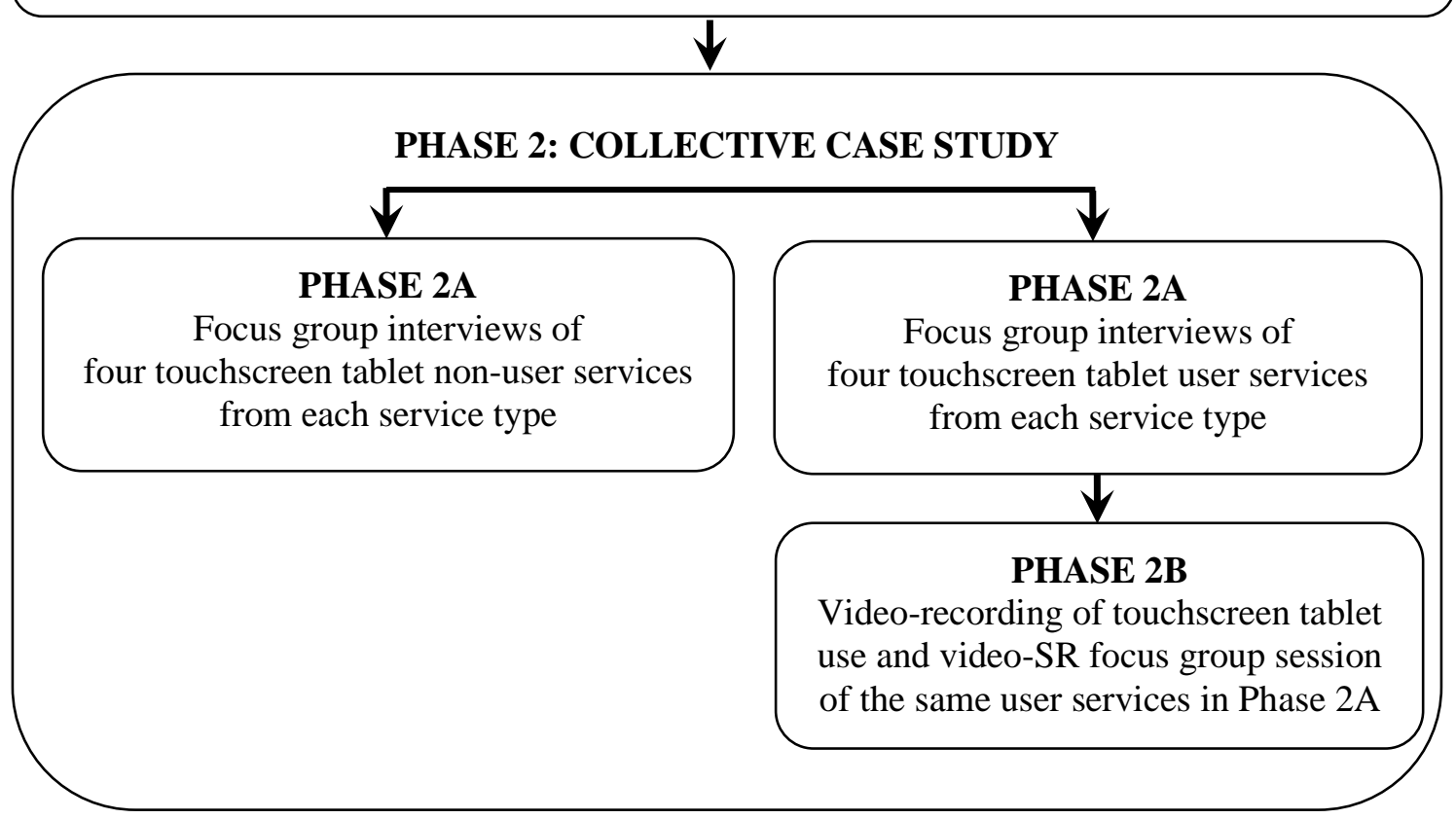

Figure 3.2. Research flow. Adapted from A Concise Introduction to Mixed Methods Research (p.39), by J.W. Creswell, 2015, Thousand Oaks, CA: SAGE. Copyright (2015) by SAGE Publications, Inc. Adapted with permission.

In this section, the explanatory sequential mixed methods research design adapted for this study was outlined. In the next section, the design for Phase 1 of this study is presented.

\subsection{Phase 1: National survey}

Surveys are used to collect data from a large population. This method of data collection is effective when gathering beliefs, attitudes, practices, and opinions about policies at a specific point in time (cross-sectional) or over time (longitudinal) with quantitative surveys allowing various means of statistical analyses (Creswell, 2015b; Fraenkel et al., 2015; Mertens, 2015).

Cross-sectional surveys can be general or specific in examining current attitudes, practices, needs, and programme evaluations at a single point in time and on a national scale (Creswell, 2015b; Fraenkel et al., 2015). This survey type collects data to examine "differences between defined groups... that take place in a larger defined population" (Wiersma \& Jurs, 2009, p. 196). Furthermore, crosssectional surveys can compare practices in educational settings because they are 
drawn from an entire population and do not require random sampling, hypothesis testing and inferential statistics (Creswell, 2015b).

There are two forms of cross-sectional surveys: researcher-based and participant-based. In researcher-based surveys, the researcher completes the survey whilst asking respondents questions. In participant-based surveys, respondents complete the survey on their own (Creswell, 2015b). A participant-based crosssectional survey is appropriate for this research, using both online and paper-based surveys (See Appendices A, B, and C) to gather data on tablet use and non-use amongst four major ECE service types in New Zealand.

The survey asked respondents to answer the questions collectively as a team of teachers/educators representing their service. There were 33 questions and each service could answer a maximum of 20 questions depending on their responses. The survey questions were drawn from the literature review - particularly focusing on questions that have not been asked in prior research on tablets and were adapted to fit the context of New Zealand's early childhood sector. One of the demographic questions asked services to identify which educational region their service was located. One of these regions, Tai Tokerau was renamed to "Northland/Whangarei" to avoid confusion amongst the respondents and the readers of this thesis. The paper-based survey had the same questions but with a different set of instructions indicating which question respondents should answer next depending on their previous response.

Creswell and Creswell (2018) proposed that research instruments should be piloted to identify biases, refine questions, and adjust research procedures to match actual situations. With regards to the survey, piloting was necessary to refine the questions and adapt the distribution and collection procedures for both online and paper-based surveys (Creswell \& Creswell, 2018). Thus, a pilot survey was carried out using Qualtrics (an online survey tool) with a parallel paper-based version at two ECE services in February 2017. The survey was revised based on feedback received from the pilot study participants who were also excluded from the distribution sample. 
Based on feedback from the pilot study, comments were minimal and there were no major changes. The total number of the questions were decreased by merging questions together as the survey initially had about a total of 40 questions. The wording of some choices was changed to improve the clarity of questions. One pilot study participant commented that teachers/educators preferred to answer questions in a narrative form, especially on how tablets were used for teaching and learning, so the equivalent question on user services' perceived barriers and affordances to using tablets for teaching and learning was changed to allow a qualitative response. Considering that some questions might not apply to all services, the survey was structured so that respondents were not required to answer all questions except for the key question which asked if a service used or did not use tablets. This meant that the total number of respondents for individual questions varied at times.

3.2.1. Survey population. I used the list of all registered ECE services from the Ministry of Education's online ECE directory for February 2017 (Education Counts, 2017) for distribution of the survey. This directory had 4,571 registered ECE services but casual education and care services, and hospital-based services were excluded from the sample because their numbers were few. Additionally, Te Kōhanga Reo services was excluded because I did not have sufficient knowledge of Māori customs (tikanga) and ability in Māori language (reo) to carry out research at these services. With these services (490) excluded, there were 4,051 potential respondents. Consent was obtained from umbrella organisations who managed some of the registered early childhood services through an introductory information letter (see Appendix D). Umbrella organisations of 588 services did not give their consent and these services were removed from this study. Email and postal addresses were cross-checked multiple times with early childhood services' websites and the ECE directory to ensure accuracy of email and postal addresses. Checking the accuracy of the ECE directory helped me identify 13 services which did not have any or a working email address. Thus, I emailed the anonymous survey link to 3,451 early childhood services and posted the paper-based survey to 13 services.

3.2.2. Survey data collection procedures. Survey distribution began in late February 2017 and continued until April 2017, as umbrella organisations gradually 
provided consent. According to Creswell (2015b) and Mertens (2015), maintaining a data record is essential in research, so I used Microsoft Excel and Qualtrics to create databases to track consent, distribution, reminders and service information for Phase 1. To enhance the response rates, reminders (Creswell, 2015b) were emailed or posted in mid-March and in mid-April. The survey closed on 03 May 2017.

To encourage completion and response rates, services that completed the survey could enter a draw for one of ten gift vouchers. A total of 361 responses$10.4 \%$ response rate-were received.

The next section presents the research design for Phase 2. Firstly, I discuss what a collective case study is and explain how this was used in Phases 2A and 2B. Then, I provide details about participant recruitment and the data collection procedures of the collective case study.

\subsection{Phase 2: Collective case study}

According to Merriam and Tisdell (2016), a case study aims to describe an object of a phenomenon through an investigative approach based on information from individuals, groups, or institutions. Stake (2006) called this object the quintain and he argued that the researcher's aim was to understand the quintain through a study of one or many cases. A collective study of many cases is possible when single cases shared common characteristics when grouped together (Stake, 2006). According to Stake (1995), there are three types of case study design frameworks: intrinsic, instrumental, and collective. Whilst the intrinsic case study aims to understand a single case and the instrumental case is used to refine theory in understanding an issue, the collective case study involved multiple or nested cases which are examined in unison, in parallel, or in sequential order. As collective case studies involve more than one case, these cases are usually examined separately and holistically (Stake, 1995). A collective case study, as Stake (1995) noted, is a study of several sites, schools or teachers. Case studies provide a rich and thick description of an issue but can become subjective and limited (Merriam \& Tisdell, 2016; Mertens, 2015). Albeit more rigorous in data management and planning, a collective case study addresses the weaknesses of a single case study by allowing cross-case 
analyses and generalisability between cases (Merriam \& Tisdell, 2016; Stake, 2006). For these reasons, I chose to study the cases collectively in a sequential method.

Phase 2 was necessary to explain the results of Phase 1. Since Phase 1 surveyed four different service types to gain the perspectives of services who used or did not use tablets, Phase 2 was a collective case study of services representing these different perspectives and who had indicated their willingness to participate in focus group interviews.

Phase 2 had two sub-phases. Phase 2A aimed to collect data from the four service types that used tablets and four service types that did not through semistructured focus group interviews. Phase $2 \mathrm{~B}$ collected additional data from the same four user services by video-recording their tablet use and using this as a stimulus at a second focus group interview where the teachers/educators viewed and discussed content of the selected video clips shown to them. I selected which episodes of tablet use to video-record based on the survey responses and information given by teachers/educators during introductory meetings when I asked for information about their service and from their statements during Phase 2A. Phase 2A and 2B were piloted at one kindergarten from March to April 2017.

Wiersma and Jurs (2009) suggested using databases for analysis and to track personal biases, research details, and chronological records. I used databases to manage participants' details such as service type, tablet use/non-use, participants' pseudonyms, location, and other identifying information.

3.3.1. Collective case study participants. Selection of collective case study participants required identifying a target population and inviting a representative sample (Creswell, 2015b). I selected two participating services per service typeone tablet user and one non-user-from the willing participants for a total of eight target collective case study participants. Stratified purposeful sampling was used to select participants based on their availability. Mertens (2015) defined this sampling method as a selection of cases based on specified criteria. Since the study aimed to collect data from both user and non-user services, services from each group were invited to participate to gather "a balanced representation of views" (Mertens, 2015, 
p. 11). From here on the purposeful aspect of the sampling method was based on the logistics and resources available for this research.

Information letters and consent forms (see Appendices E, F, and G) were sent to each service to invite them to participate in Phase 2 and were followed up with emails and phone calls. Whilst one tablet user playcentre was initially willing to participate in Phase 2, the service withdrew from the study prior to data collection. Therefore, no tablet user playcentre participated in this study.

Data collection for this phase began on 11 May 2017 and ended on 13 September 2017. The following tables present profiles of the tablet user and nonuser services who participated in Phase 2. Some identifying characteristics were not included in participant descriptions to ensure their confidentiality.

\begin{tabular}{|c|c|c|c|c|}
\hline Service type & $\begin{array}{c}\text { No. of } \\
\text { Teachers/Educators }\end{array}$ & $\begin{array}{c}\text { ECE Teaching } \\
\text { Experience }\end{array}$ & $\begin{array}{c}\text { Age } \\
\text { Range }\end{array}$ & $\begin{array}{c}\text { Maximum No. } \\
\text { of Children }\end{array}$ \\
\hline Education and care & 6 & 1 to 16 years & $\begin{array}{c}30 \mathrm{~s} \text { to } \\
40 \mathrm{~s}\end{array}$ & $\begin{array}{c}50 \\
\text { (16 under-twos) }\end{array}$ \\
\hline Kindergarten & 5 & 14 to 20 years & $\begin{array}{c}40 \mathrm{~s} \text { to } \\
50 \mathrm{~s}\end{array}$ & $\begin{array}{c}16 \text { per teacher } \\
\text { (2 to 7 years old) }\end{array}$ \\
\hline Home-based & $\begin{array}{c}2 \text { visiting teachers, } \\
30 \text { educators }\end{array}$ & 4 to 21 years & $\begin{array}{c}20 \mathrm{~s} \text { to } \\
50 \mathrm{~s}\end{array}$ & $\begin{array}{c}4 \text { per educator } \\
\text { (2 under two) }\end{array}$ \\
\hline Playcentre & 30 parents & $\begin{array}{c}1 \text { term to } \\
20 \text { years }\end{array}$ & $\begin{array}{c}20 \mathrm{~s} \text { to } \\
50 \mathrm{~s}\end{array}$ & $\begin{array}{c}30 \\
\text { (18 under-twos) }\end{array}$ \\
\hline
\end{tabular}

Table 3.1. Tablet non-users' demographics.

\begin{tabular}{|c|c|c|c|c|}
\hline Service type & $\begin{array}{c}\text { No. of } \\
\text { Teachers/Educators }\end{array}$ & $\begin{array}{c}\text { ECE Teaching } \\
\text { Experience }\end{array}$ & $\begin{array}{c}\text { Age } \\
\text { Range }\end{array}$ & $\begin{array}{c}\text { Maximum No. } \\
\text { of Children }\end{array}$ \\
\hline Education and care & 5 & 5 to 15 years & $\begin{array}{c}20 \mathrm{~s} \text { to } \\
40 \mathrm{~s}\end{array}$ & $\begin{array}{c}40 \\
\text { (12 under-twos) }\end{array}$ \\
\hline Kindergarten & 5 & $\begin{array}{c}1 \text { term to } \\
7 \text { years }\end{array}$ & $\begin{array}{c}20 \mathrm{~s} \text { to } \\
50 \mathrm{~s}\end{array}$ & $\begin{array}{c}40 \\
\text { (3 to 5 years old) }\end{array}$ \\
\hline Home-based & $\begin{array}{c}2 \text { visiting teachers, } \\
17 \text { educators }\end{array}$ & 6 to 20 years & $\begin{array}{c}20 \mathrm{~s} \text { to } \\
50 \mathrm{~s}\end{array}$ & $\begin{array}{c}4 \text { per educator } \\
\text { (2 under-twos) }\end{array}$ \\
\hline
\end{tabular}

Table 3.2. Tablet users' demographics.

3.3.2. Data collection procedures. Qualitative data were collected through focus group interviews. Video-recorded data was necessary to provide, as much as possible, teachers/educators with a complete picture of tablet use by the respective children in their services. I also video-recorded the focus group interviews with teachers/educators who participated in Phase 2. Knoblauch, Schnettler, Raab, and Soeffner (2006) explained that video data is "multi-sensual and sequentially ordered, 
enclosing both diachronic and synchronic elements such as speech and visual conduct, gesture, mimic expressions, representation of artefacts" (p. 14). I used two audio recorders and a video-recorder to collect verbal and non-verbal interactions and to maintain accuracy of transcripts. Henderson and Tallman (2006) stated that video-recording enhances recall accuracy of video-SR sessions whilst establishing validity of the video-recorded episodes through internal member checking as participants viewed recordings and reflected on them. The same video camera was used to record episodes of tablet use for Phase 2B. I acknowledged that participant fatigue can be a concern when numerous or lengthy video-recorded episodes are used for SR (Henderson \& Tallman, 2006). So, I followed Henderson and Tallman's (2006) recommendation by limiting the video episodes to a maximum of seven 5- to 10-minute video episodes (up to 30 minutes in total). Additionally, participant fatigue was addressed by prompting if questions had already been answered, priming the context before playing the videos and stating when the last video was about to be played. The video-recordings of tablet use enabled the participants to view and discuss children and teachers' verbal and nonverbal interactions which provided rich and thick descriptions for the data collection (Fraenkel et al., 2015; Henderson \& Tallman, 2006).

3.3.3. Phase 2A. Phase $2 \mathrm{~A}$ consisted of focus groups interviews. Focus group interviews collect shared understanding by asking open-ended questions (Creswell, 2015b; Mertens, 2015). To Kreuger and Casey (2015), focus groups are a means to collect data from a group of people with common characteristics in a permissive environment where each participant can share their perspective or point of view on a topic. Focus group interviews enable shared understandings from practitioners to be collected whilst also obtaining information and encouraging participants who are shy to speak on their own (Creswell, 2015b). According to these descriptions, focus group interviews were appropriate to New Zealand's ECE settings where teachers/educators worked as a team. Thus, teachers/educators were invited to participate in the semi-structured focus group interviews as a team.

The focus group sessions used a semi-structured interview. This is a qualitative form of data collection that allows the interviewer to follow-up different angles of an issue by probing and eliciting dialogue compared to using a preset list of 
questions or an interview guide (Brinkmann, 2018). The semi-structured nature of the focus group interviews also allows participants and the interviewer to "not focus on the right question but instead focus on the stories to emerge" (Creswell \& Poth, 2017, p. 153). The interview questions (see Appendices H and I) were also piloted at one kindergarten. This kindergarten was not included in the focus group sample.

Members of the teaching team from their respective services were invited to participate in the focus groups. Each service's focus group interview was undertaken independently from those of other services and the identities of participants, videorecorded episodes, and identifying service information were not shared between services. In this study, the focus groups had a minimum of three and a maximum of twelve participants (see Chapters 5 and 6 for details on the participants).

Teachers/educators interacted with each other's statements within their teaching team resulting in rich descriptions of each case (Creswell, 2015b; Merriam \& Tisdell, 2016). Using focus group interviews helped establish rapport with participants as they were not focused on me as the interviewer but on each other's statements (Creswell, 2015b; Mertens, 2015; Schwandt \& Gates, 2018). I also established rapport through information letters, and by remaining neutral during the interview and whilst video-recording (Creswell, 2015b).

Before beginning each focus group session, I briefly restated the contents of the information letter and the consent form. There were occasions when some teachers/educators chose not to participate, left during the focus group session, joined only one of two focus group sessions (in the case of tablet user services), or initially decided not to join but changed their minds and participated in a focus group session. For user services, focus group interview sessions for Phases 2A and 2B lasted approximately 60 minutes for each session. Sessions were video-recorded and audio-recorded for transcription and to collect data on practitioners' verbal and nonverbal interactions (Creswell \& Poth, 2017; Mondada, 2006).

3.3.4. Phase 2B. Phase 2B consisted of focus group interviews using videoSR sessions. Stimulated Recall (SR) is an introspection procedure used for research on teaching usually with the support of video-recorded episodes to stimulate the recall of participants' cognitive activity (Gass \& Mackey, 2016; Henderson \& Tallman, 2006; Mackey \& Gass, 2016). SR procedures have been used to study 
cognitive strategies and other learning processes such as teacher/educator behaviours in complex, interactive contexts involving novel, uncertain, and non-deliberate behaviors (Lyle, 1999). Henderson and Tallman (2006) stated that SR is less intrusive compared to think-aloud methods, supports participants' memory-recall, and adds to the validity by removing personal bias compared to self-reporting methods which lack any stimulus. Different stimuli could be used for SR with videorecordings as the most preferred stimuli because these provide accurate audio and visual accounts (Gass \& Mackey, 2016; Henderson \& Tallman, 2006).

SR interviews are not structured interviews because a participant's selfreflection may lead to unrelated responses thus affecting reliability (Friedman, 2012; Henderson \& Tallman, 2006). SR is incorporated into interviews when the interviewer asks questions such as "What is happening here?" after playing videorecorded episodes (Friedman, 2012). This approach allows SR to capture the decision making, interactive thoughts and actions of teachers/educators (Friedman, 2012; Henderson \& Tallman, 2006). For this research, episodes for video-recording were mostly decided during an initial meeting with the service management and the information they provided in the survey. Approximately five episodes, which were up to a maximum length of around five minutes long, were shown during video-SR sessions. The circumstances surrounding each video was explained before playing the video to the teaching team. The teachers/educators then talked about what happened in the video. Often the teacher/educator who was present in the videorecorded episode spoke first. I would probe and lead the discussion back to the topic if the teaching team veered off (See Appendix I). If the participants started talking about the next video-recorded episode or another video-recorded episode in the episodes to be shown, I would transition the discussion to that video. This happened naturally because topics often got repeated. Then a short summary discussion concluded each video-SR session.

Phase 2B required video-recorded episodes of tablet use amongst user services for the video-SR interview sessions. My first day at a user service began with an introductory meeting with the teaching team then I used the rest of the day and the next few days to distribute and collect consent forms from parents. Then, I spent one to two days at each service video-recording episodes of teachers/educators 
and children using tablets. Most of the video-recorded episodes were taken on the first day. I referred to the survey responses and notes from the initial introduction meeting or phone/email correspondence with the teaching team to note what kind of tablet episodes to video-record. If I missed out on other ways tablets were used, I prioritised recording these on the second day. Video-recorded episodes of tablet use enabled me to collect data in the least intrusive way possible by not interrupting or hindering teachers/educators and children during the session and thereby supporting the ethics of this study (Henderson \& Tallman, 2006). To maximise participants' recall, I scheduled video-SR interview sessions from immediately after sufficient video-recorded episodes of tablet use had been collected to no later than a week and at a time that suited the participants (Henderson \& Tallman, 2006; Mackey \& Gass, 2016).

These video-recorded episodes were edited prior to showing them in Phase 2B. The videos were played back to the focus group participants using a 9.5-inch tablet. The size allowed participants to easily view the video-recordings and for me to easily play back or advance the video as requested by some participants.

\subsection{Ethical issues}

Ethical approval for this study was gained from Victoria University of Wellington's Human Ethics Committee (RM 23433) on 03 December 2016. Information letters and consent forms gathered informed consent from participants. These explained that the survey was anonymous and that the case studies were confidential (Creswell, 2015b; Creswell \& Poth, 2017; Fraenkel et al., 2015). These documents also explained data collection. In relation to the survey, information letters and consent forms were first sent to national or umbrella organisations and then once permission was received, individual services were sent the anonymous survey link. For services which belonged to umbrella organisations, if the organisation had five or more services, then consent was sought. Otherwise, services from organisations with less than five services were treated as standalone services and their information letters and consent forms were sent directly to each of them. Obtaining consent from playcentres involved seeking initial approval from the Playcentre Federation - the national organisation which oversaw each regional 
playcentre umbrella organisation at the time of data collection-followed by obtaining consent from each regional umbrella organisation.

To ensure services' identities are fully masked, I used pseudonyms for participants including the names of services, teachers/educators, and children used during the focus group interviews. To ensure that participating services and teachers/educators could not be identified, the descriptions of participants sometimes included incomplete information. Phase 1 respondents were informed that the survey link was anonymous and that they could only reveal their identities if they willingly provided contact information when answering the last three questions at the end of the survey. The paper-based survey indicated that, for anonymity, the respondents should not indicate their postal address when they sent in their completed survey. Maintaining the confidentiality of the participants' identities was important (Creswell, 2015b; Christians, 2018; Dalli \& Stephenson, 2010).

Video-recording of children in ECE services for Phase 2 of the study involved potential ethical issues such as children's reactions to the researcher's presence/video-recorder, sharing the recorded images of children, and potentially filming inappropriate teaching practices (Dalli \& Stephenson, 2010; Danby, 2017). These potential ethical issues required multiple levels of consent beginning with information letters and consent forms requiring the signature of umbrella organisations and ECE service managers (See Appendix D) before distributing information letters and consent forms to the teachers/educators (See Appendices E, and F) and parents (See Appendix G). Obtaining consent from parents for research involving their children was of importance (Dalli \& Stephenson, 2010; Danby, 2017; Mondada 2006; Loveridge, 2010) so I obtained consent for video-recording children by giving their parents information letters and consent forms explaining the research and detailing that their children will only be video-recorded when they used touchscreen-tablets. Children whose parents did not provide consent were not videorecorded and if these children entered the view of the video camera, I immediately stopped recording.

The information letters and consent forms outlined that I would cease videorecording if children were distressed or if their behaviour might be construed as negative. I also avoided video-recording potentially harmful incidents, any 
identifying details of the service, or instances of children expressing distress or discomfort. Engagement and interactions involving tablets usually required close-up shots which avoided unintentionally capturing images of children without consent or other irrelevant interactions happening in the background. In addition to providing information letters and consent forms, prior to video-recording tablet use, the teachers/educators were informed that they could ask not to be video-recorded or request that certain video-recorded episodes be deleted. The teachers/educators asked me to explain my research to the children often during mat time. When I was asked to explain the data collection procedures to children, I told them that they could tell me to stop video-recording at any time, but this never happened. I also explained the procedures to the parents when I met them at the drop off point to collect consent forms. I did not ask the children for their permission before videorecording because most were already engaged with the device and I did not want to disrupt this before beginning to record. Aside from myself and my supervisors, only teachers/educators viewed the video-recorded episodes in their own respective service's video-SR session.

\subsection{Data coding and analyses}

Data coding and analyses differed for each phase of this research. For Phase 1, I initially used Qualtrics and SPSS to analyse the results of the national survey using descriptive statistics and then identified which questions could be analysed using inferential statistics (Creswell, 2015b; Creswell \& Creswell, 2018). I consulted with two statisticians to confirm the reliability and validity of the quantitative analyses. I also used thematic analyses on all qualitative responses in Phase 1. For Phase 2, I used thematic analysis to analyse practitioners' knowledge, thinking and interactions, the discussion flow, and their teaching strategies (Gass \& Mackey, 2016).

Qualitative analysis involved inductive and deductive coding categories and these codes were grouped into categories and sorted into concepts (Creswell, 2015b; Creswell \& Creswell, 2018; Révész, 2012). I followed Creswell’s (2015b; Creswell $\&$ Creswell, 2018,) adaptation of Tesch's (2013) coding and analyses procedures used in qualitative research. I read the transcriptions, selected and interpreted each interview, and clustered similar topics into nodes before coding and organizing these 
topics into categories. Then I reduced categories and identified their interrelationships, assembled the categories for preliminary analysis, and recoded other existing data necessary for analyses. After reading through each of the qualitative data, I used NVivo to group statements into nodes and grouped these nodes into themes and descriptions (Baralt, 2012; Henderson \& Tallman, 2006).

A specific coding system was used to track statements. The code first specified the service type - education and care (E\&C), home-based (HB), kindergarten $(\mathrm{K})$ and playcentre $(\mathrm{P})$ - followed by a number to identify the service resulting in this format "[service type/respondent number]". To track statements from participants and whether these came from Phase 2A (P2A) or Phase 2B (P2B), I used the code "[service type/sub-phase/transcript line number]". I analysed cases independently (within-case analysis) and with other cases (cross-case analysis) to determine the themes and descriptions were related to each other (Creswell \& Poth, 2017; Merriam \& Tisdell, 2016). I carried out the cross-case analysis by identifying interrelated themes and descriptions from the qualitative data. Validation of the interpreted meanings were checked with the organised raw data.

Analysis was done iteratively following the sequence of the research design (Creswell, 2015b; Teddlie \& Tashakorri, 2010), beginning with analyses of quantitative responses from Phase 1 and followed by analyses of qualitative responses from Phase 1 and Phase 2 to explain the results. All interviews were transcribed and analysed following Creswell's (2018) linear and hierarchical data analysis in qualitative research adapted from Tesch's (2013) coding process.

The final section of this chapter outlines how I maintained trustworthiness and validity in the design and data collection procedures for Phases 1 and 2 of the research.

\subsection{Trustworthiness in mixed methods research}

Trustworthiness in research involves reliable and valid data collection and analysis without bias and error (Creswell \& Creswell, 2018; Fraenkel et al, 2015; Johnson \& Christensen, 2017). Along with fairness and authenticity, trustworthiness contributes to the rigour in research (Mertens, 2015; Morse, 2018). The 
confirmability, credibility, dependability, and transferability of the research reflects its trustworthiness (Creswell \& Creswell, 2018; Morse, 2018).

Mixed methods research allowed me to check qualitative data against the quantitative data and collection procedures (Creswell, 2015a; Merriam \& Tisdell, 2016). The multiple levels of data collection and analysis contributed to the validity of this research (Creswell \& Poth, 2017; Johnson \& Christensen, 2017; Merriam \& Tisdell, 2016). Quantitative and qualitative data obtained from four service types enabled me to include a variety of representative services in this study thereby maximising the variation of the data collection methods (Fraenkel et al., 2015; Johnson \& Christensen, 2017). I gathered quantitative data from four service types in Phase 1 whilst in Phase 2, I collected data to represent each of the user and nonuser services from the four service types. The collective case study used in Phase 2 contributed to validity because the sequential flow of the research contributed to interconnectivity between data sources (Creswell \& Poth, 2017). This established sequential validity - how the order of quantitative and qualitative components addressed each other (Johnson \& Christensen, 2017). Furthermore, this study had complementarity because the qualitative phase of the research design clarified the results of the quantitative phase (Johnson \& Christensen, 2017; Mertens, 2015).

Validity refers to the accuracy of inferences, interpretations, and actions involving data analyses (Creswell, 2015b; Fraenkel et al, 2015; Mertens, 2015). I established validity through examination and review by experts who were statisticians, early childhood education lecturers, and experienced early childhood education and care professionals in relation to piloting the data collection procedures (Creswell, 2015b; Fraenkel et al., 2015; Merriam \& Tisdell, 2016). The transcriptions and video-recordings of focus group interviews also provided rich and thick descriptions of cases (Merriam \& Tisdell, 2016). The use of audio and videorecordings supported external validity because I had multiple recordings as bases for the transcriptions (Henderson \& Tallman, 2006).

The video-SR episodes provided accurate evidence of tablet use. This was supported by the recall of teachers/educators confirmed through the focus group interviews (Henderson \& Tallman, 2006). In general, using SR also contributed to internal validity by gathering rich, thick descriptions from participants who 
interacted with each other's statements (Mackey \& Gass, 2016). Aside from simply collecting data through focus group interviews, the video-recordings of tablet use for the additional video-SR sessions helped participants to provide their reflections on rich data shown to them through their verbal and non-verbal engagement with the video-recordings and amongst themselves (Henderson \& Tallman, 2006; Mondada, 2006).

Reliability involves consistency and stability in developing the instrument and using it in data collection (Creswell, 2015b; Fraenkel et al, 2015; Johnson \& Christensen, 2017). Establishing reliability contributes to the validity of the research (Creswell, 2018; Fraenkel et al., 2015; Mackey \& Gass, 2016). Ambiguous and unclear questions, variation in instrument administration, misinterpretation, and fatigue amongst participants affect reliability (Creswell \& Creswell, 2018). Again, I used examination and review by experts (Creswell, 2015b; Merriam \& Tisdell, 2016) to address these reliability issues by consulting university statisticians and ECE experts to review the survey. I followed their suggestions to amend certain response choices and change some of the wording in the survey and interview questions. After revising the survey, I asked the same ECE experts to review the focus group questions. Then, I pilot tested both the survey and the focus group questions as well as the data collection method. The teachers who participated in the pilot suggested amendments to the survey to eliminate ambiguity in wording. As evident in the survey, reliability was established through consistency in data collection procedures (Wiersma \& Jurs, 2009).

I mainly used Qualtrics to distribute the online-survey and collect responses. Although I had only one response to the paper-based survey, I transferred the responses to Qualtrics. I used computer assisted analyses via Microsoft Excel, Qualtrics, SPSS and NVivo (Creswell \& Creswell, 2018; Fraenkel et al., 2015; Johnson \& Christensen, 2017) and coded and analysed the data myself to avoid issues involving intercoder-reliability (Révész, 2012).

Intra-rater reliability could also affect reliability when interviewers are not consistent which could lead to differences in coding (Gass \& Mackey, 2016; Wiersma \& Jurs, 2009). To address this issue, I interviewed focus group participants myself using two audio-recorders and a video camera. The transcripts and 
recordings also served as validity and reliability checks (Creswell, 2015b; Révész, 2012) and using recorded data, particularly video-recordings, contributed to internal reliability (Wiersma \& Jurs, 2009).

Pre-interview meetings prior to SR interviews were important to introduce myself and explain the study as well as identify services' specific preferences on the data collection approach (Henderson \& Tallman, 2006) such as how consent from parents should be sought, how video-recordings should be conducted, and how the interview process should be carried out. I used Phase 2A to gain a general impression of how teachers/educators used tablets before video-recording them and showing the episodes at video-SR interviews. SR required minimal training and using video-SR addressed recall accuracy issues (Gass \& Mackey, 2016; Henderson \& Tallman, 2006). I maintained reliability in video-SR data collection by conducting the sessions myself and scheduling video-SR sessions up to a maximum of a week after video-recording episodes of teachers/educators' and children's tablet use. Gass and Mackey (2016) stated that explaining video content helps put participants at ease if they know what will be shown in the videos played back, so I briefly described the content of the video-SR episodes before playback. Henderson and Tallman (2006) explained that revisiting transcripts of video-SR sessions multiple times added to reliability in data collection. Aside from listening to the audio and video-recordings multiple times and rechecking transcripts of focus group sessions, I also sent copies of transcripts to the respective participants for them to comment on accuracy. The respondents validated the collected data through member checking or participant validation (Creswell, 2015b; Johnson \& Christensen, 2017; Merriam \& Tisdell, 2016).

\subsection{Chapter summary}

In this chapter, I have explained the research design which began with a quantitative component (Phase 1), followed by a qualitative component (Phase 2). I discussed the adoption of the dialectical pragmatic stance (Johnson \& Gray, 2010) involving the postpositive paradigm for Phase 1 and the constructivist paradigm for Phase 2. 
In Phase 1, I investigated the research phenomena by developing, piloting, and distributing a national survey to collect quantitative data from an identified sample. I explained how I chose the collective case study and recruited participants for this research. Additionally, I discussed the formulation of the semi-structured interview questions, piloting, and data collection for Phase 2A's focus group interviews and Phase 2B's video-SR sessions. I elaborated on the importance of SR and the effectiveness of video-SR to understand the teachers'/educators' thoughts on tablet use. Then, ethical issues regarding data collection were discussed. Next, I explained how I analysed the quantitative data using descriptive and inferential statistics followed by details on how I coded and analysed the qualitative data. Finally, I discussed how I maintained the trustworthiness in this research.

In the next chapter, I outline the results of the quantitative phase of this study. Firstly, results from the descriptive statistical analysis of the national survey are detailed. Then, the results from questions and responses that were further analysed using inferential statistics are presented. 


\section{Chapter 4}

\section{Quantitative results}

This chapter presents the results from this study's quantitative component. The research design for Phase 1, which involved a national survey sent to four major ECE service types, was discussed in the previous chapter. The survey was distributed to 3,464 early childhood services and 361 responses (10.4\%) were received. Of these, 354 services (10.2\%) answered some, if not all, the questions.

Teachers/educators were asked to complete the survey as a team representing their service. The survey results are presented using descriptive statistics, beginning with data from five demographic questions followed by the descriptive results from non-user services and from user servics. Results from responses with sufficient data for inferential analyses using Chi-Square and the Mann-Whitney U test are outlined. Finally, Phase 1 findings that could be further explained in Phase 2 are elaborated.

\subsection{Demographic data}

In this section, results from the demographic questions are presented beginning with non-user services followed by user services. The survey relied on self-reporting from the respondents. The first question asked services to identify their service type. Responses from 349 services were received, specifically 215 from education and care services, 22 from home-based services, 66 from kindergartens and 46 from playcentres. In the second question, services identified their location from ten educational regions set by the Ministry of Education. Table 4.1 shows the distribution of respondents according to each region.

\begin{tabular}{|l|c|c|}
\hline \multicolumn{1}{|c|}{ Educational Regions } & Number & \% \\
\hline Auckland & 93 & $26.7 \%$ \\
\hline Bay of Plenty, Rotorua, Taupo & 28 & $8.0 \%$ \\
\hline Canterbury & 46 & $13.2 \%$ \\
\hline Hawke's Bay, Gisborne & 14 & $4.0 \%$ \\
\hline Nelson, Marlborough, West Coast & 14 & $4.0 \%$ \\
\hline Northland, Whangarei & 23 & $6.6 \%$ \\
\hline Otago, Southland & 21 & $6.0 \%$ \\
\hline Taranaki, Whanganui, Manawatu & 24 & $6.9 \%$ \\
\hline Waikato & 33 & $9.5 \%$ \\
\hline Wellington & 52 & $14.9 \%$ \\
\hline \multicolumn{2}{|r|}{ Total } & 348 \\
\cline { 2 - 3 }
\end{tabular}

Table 4.1. Number of respondents per educational region. 
Services were also asked to indicate the maximum number of children they were licensed for, and 341 responded. Table 4.2 shows that more than half of the respondents indicated that their service was licensed for between 25 to 49 children $(59.5 \%)$. Results of this question were used for the Mann-Whitney U test (see Figure 4.7) reported in Section 4.2.

\begin{tabular}{|c|c|c|}
\hline Maximum number of children licensed for & Number of services & $\boldsymbol{\%}$ \\
\hline$<25$ & 33 & $9.7 \%$ \\
\hline $25-49$ & 203 & $59.5 \%$ \\
\hline $50-74$ & 60 & $17.6 \%$ \\
\hline $75-99$ & 27 & $7.9 \%$ \\
\hline$>99$ & 18 & $5.3 \%$ \\
\hline & 341 & $100 \%$ \\
\hline
\end{tabular}

Table 4.2. Maximum number of children each service is licensed for.

Services were requested to specify the total number of teachers/educators in their team, and 340 survey respondents answered this question. Table 4.3 shows that almost half of the respondents $(41.5 \%)$ indicated that they had five to nine teachers/educators in their team. When grouped with services that had less than five (22.1\%), the majority of respondents have fewer than 10 teachers/educators in their team $(63.6 \%)$. Data on the number of teachers/educators using tablets and the data from Table 4.3 were analysed for the Mann-Whitney U test reported later in Section 4.2 (see Figures 4.8 and 4.9).

\begin{tabular}{|c|c|c|}
\hline Total number of teachers/educators & Number of services & $\%$ \\
\hline$<5$ & 75 & $22.1 \%$ \\
\hline $5-9$ & 141 & $41.5 \%$ \\
\hline $10-14$ & 53 & $15.6 \%$ \\
\hline $15-19$ & 24 & $7.1 \%$ \\
\hline $20-24$ & 21 & $6.2 \%$ \\
\hline$>24$ & 26 & $7.6 \%$ \\
\hline Total & 340 & $100 \%$ \\
\hline
\end{tabular}

Table 4.3. Total number of teachers/educators at each service.

The final question asked if services currently used tablets or not. Rather than influence responses by providing parameters around what constituted use or non-use, this question was deliberately left open-ended. Thus, responding services made their own judgement as to whether they were a user or non-user service. Out of 338 responses, 176 services (52.1\%) did not use tablets, whilst 162 (47.9\%) used tablets. 
4.2. Responses from tablet non-user services. Respondents from non-user services were offered nine possible reasons why a service would not use tablets and were asked to select the degree to which each reason applied to them. Table 4.4 shows the results arranged from highest to lowest in the response "almost always applies".

\begin{tabular}{|l|c|c|c|c|c|c|c|c|c|}
\hline \multirow{2}{*}{ Reason } & \multicolumn{2}{|c|}{$\begin{array}{c}\text { Almost } \\
\text { always } \\
\text { applies }\end{array}$} & \multicolumn{2}{c|}{$\begin{array}{c}\text { Sometimes } \\
\text { applies }\end{array}$} & \multicolumn{2}{c|}{$\begin{array}{c}\text { Rarely } \\
\text { applies }\end{array}$} & \multicolumn{2}{c|}{$\begin{array}{c}\text { Never } \\
\text { applies }\end{array}$} & \multirow{2}{*}{ Total } \\
\cline { 2 - 10 } & $\%$ & $\mathbf{n}$ & $\%$ & $\mathbf{n}$ & $\%$ & $\mathbf{n}$ & $\%$ & $\mathbf{n}$ & \\
\hline Educational philosophy & 56.9 & 83 & 17.1 & 25 & 4.8 & 7 & 21.2 & 31 & 146 \\
\hline Company/service policy & 31.0 & 39 & 13.5 & 17 & 13.5 & 17 & 42.1 & 53 & 126 \\
\hline Funding & 27.8 & 35 & 30.2 & 38 & 4.0 & 5 & 38.1 & 48 & 126 \\
\hline $\begin{array}{l}\text { Use of another type of } \\
\text { technology (Smartboards, } \\
\text { overhead projectors, } \\
\text { laptop computers) }\end{array}$ & 22.0 & 27 & 13.8 & 17 & 9.8 & 12 & 54.5 & 67 & 123 \\
\hline $\begin{array}{l}\text { Initial teacher training did } \\
\text { not cover tablets }\end{array}$ & 12.6 & 14 & 12.6 & 14 & 12.6 & 14 & 62.2 & 69 & 111 \\
\hline $\begin{array}{l}\text { Equipment needs } \\
\text { repair/incompatibility }\end{array}$ & 9.7 & 11 & 11.5 & 13 & 10.6 & 12 & 68.1 & 77 & 113 \\
\hline $\begin{array}{l}\text { Lack of technical } \\
\text { expertise }\end{array}$ & 7.6 & 9 & 26.1 & 31 & 16.8 & 20 & 49.6 & 59 & 119 \\
\hline $\begin{array}{l}\text { Lack of professional } \\
\text { development }\end{array}$ & 6.9 & 8 & 25.0 & 29 & 14.7 & 17 & 53.5 & 62 & 116 \\
\hline $\begin{array}{l}\text { We used them before, } \\
\text { but we stopped }\end{array}$ & 5.3 & 5 & 5.3 & 5 & 2.1 & 2 & 87.4 & 83 & 95 \\
\hline
\end{tabular}

Table 4.4. Reasons for non-use of tablets.

When "almost always applies" and "sometimes applies" responses were combined, educational philosophy (74.0\%) was still the foremost reason respondents did not use tablets. Funding became the second reason respondents did not use tablets (58.0\%). Respondents were divided on company/service policy with more non-users selecting "rarely applies" and "never applies" (55.6\%) than "almost always applies" and "sometimes applies" (44.5\%).

The last option asked if a service had stopped using tablets and allowed respondents to indicate their reasons. Of the 17 services that indicated specific reasons why they discontinued, four services reported they had experienced technical issues. Two services perceived tablet use affected children negatively such as "they encourage sedentary behavior" [NU-E\&C/P1/8] and "children's brains were hijacked" [NU-K/P1/132]. Six services reported that because parents or the 
community did not approve of tablet use, they discontinued using these devices. One service elaborated that:

The young child is still developing socially, emotionally, physically, cognitively. Just because they can use tablets and other similar devices at this stage it doesn't mean they should. They take away from other much more developmentally important learning at this age. [NU-E\&C/P1/56]

Five other services responded as follows: "the children had little respect for the technology and had to be supervised with it" [NU-K/P1/119], "supervision of their use is limited" [NU-E\&C/P1/21], "teachers not knowing how to use them" [NU-K/P1/121], and that their service "used tablets for a child with special needs only" [NU-E\&C/P1/39]. Three services reported "handwriting reports" [NU$\mathrm{HB} / \mathrm{P} 1 / 107]$, using "non-computer resources simply made more sense for the intended learning outcomes" [NU-E\&C/P1/58] and "teachers already have laptops" [NU-K/P1/135].

When asked if their service intended to use tablets, 93 (55.7\%) indicated they had no intention of using them for teaching and learning, 50 (29.9\%) were unsure at that time, and 24 (14.4\%) intended to acquire tablets. The time of acquisition ranged from within one month to 36 months with a median of six months.

The next question asked respondents to rate the likelihood of each potential use if they did have a tablet (see Table 4.5). The top "most likely" response was documentation and assessment (66.2\%), which included the use of learning stories, portfolios, blogs and websites. When "most likely" and "likely" responses were combined, the foremost potential use was exploration (94.1\%) followed by documenting events (89.4\%) and playing music (88.5\%). When "least likely" and "never" responses were combined, the least likely potential use was playing games (66.1\%), followed by communication with institutions $(65.0 \%)$ and communication with other services (61.4\%). 


\begin{tabular}{|l|c|c|c|c|c|c|c|c|c|}
\hline \multirow{2}{*}{ Potential Uses } & \multicolumn{2}{|c|}{$\begin{array}{c}\text { Most } \\
\text { likely }\end{array}$} & \multicolumn{2}{c|}{ Likely } & \multicolumn{2}{c|}{$\begin{array}{c}\text { Least } \\
\text { likely }\end{array}$} & \multicolumn{2}{c|}{ Never } & \multirow{2}{*}{ Total } \\
\cline { 2 - 10 } & $\%$ & $\mathbf{n}$ & $\mathbf{\%}$ & $\mathbf{n}$ & $\mathbf{\%}$ & $\mathbf{n}$ & $\mathbf{\%}$ & $\mathbf{n}$ & \\
\hline $\begin{array}{l}\text { Documentation and } \\
\text { assessment }\end{array}$ & 66.2 & 45 & 20.6 & 14 & 7.4 & 5 & 5.9 & 4 & 68 \\
\hline Documenting events & 63.6 & 42 & 25.8 & 17 & 6.1 & 4 & 4.6 & 3 & 66 \\
\hline Exploration & 55.9 & 38 & 38.2 & 26 & 4.4 & 3 & 1.5 & 1 & 68 \\
\hline Creativity & 52.4 & 33 & 28.6 & 18 & 15.9 & 10 & 3.2 & 2 & 63 \\
\hline Information retrieval & 50.0 & 33 & 31.8 & 21 & 7.6 & 5 & 10.6 & 7 & 66 \\
\hline $\begin{array}{l}\text { Communication with } \\
\text { children's families/whānau }\end{array}$ & 46.2 & 30 & 26.2 & 17 & 15.4 & 10 & 12.3 & 8 & 65 \\
\hline Playing music & 39.3 & 24 & 49.2 & 30 & 3.3 & 2 & 8.2 & 5 & 61 \\
\hline Watching videos & 23.3 & 14 & 23.3 & 14 & 43.3 & 26 & 10.0 & 6 & 60 \\
\hline $\begin{array}{l}\text { Communication with other } \\
\text { services or umbrella } \\
\text { corporation }\end{array}$ & 21.0 & 13 & 17.7 & 11 & 30.7 & 19 & 30.7 & 19 & 62 \\
\hline $\begin{array}{l}\text { Communication with } \\
\text { institutions (universities, } \\
\text { government offices, etc.) }\end{array}$ & 16.7 & 10 & 18.3 & 11 & 35.0 & 21 & 30.0 & 18 & 60 \\
\hline Playing games & 13.6 & 8 & 20.3 & 12 & 32.2 & 19 & 33.9 & 20 & 59 \\
\hline
\end{tabular}

Table 4.5. Non-user services: Potential uses of tablets.

From a list of possible barriers, non-users were asked to rate the likelihood of each impacting on their use of tablets. The "most likely" possible barrier was preference towards traditional practices (37.9\%). When "most likely" and "likely" responses were combined, the foremost possible barriers were preference towards traditional practices (77.3\%) followed by apps did not fit educational goals (76.2\%). These two possible barriers aligned with responses to the earlier question on why non-users did not use tablets where the main reason was educational philosophy. The next possible barriers were lack of professional development $(69.3 \%)$ and glitches and apps not working (68.3\%). When "least likely" and "never" responses were combined, children circumventing security functions $(56.7 \%)$ was the "least likely" amongst non-user's possible barriers followed by lack of support from administration (53.4\%). Table 4.6 shows these possible barriers. 


\begin{tabular}{|l|c|c|c|c|c|c|c|c|c|}
\hline \multirow{2}{*}{\multicolumn{1}{|c|}{ Possible barriers }} & \multicolumn{2}{|c|}{$\begin{array}{c}\text { Most } \\
\text { likely }\end{array}$} & \multicolumn{2}{c|}{ Likely } & \multicolumn{2}{c|}{$\begin{array}{c}\text { Least } \\
\text { Likely }\end{array}$} & \multicolumn{2}{c|}{ Never } & \multirow{2}{*}{ Total } \\
\cline { 2 - 9 } & $\%$ & $\mathbf{n}$ & $\%$ & $\mathbf{n}$ & $\mathbf{\%}$ & $\mathbf{n}$ & $\mathbf{n}$ & $\mathbf{n}$ & \\
\hline $\begin{array}{l}\text { Preference towards } \\
\text { traditional practices }\end{array}$ & 37.9 & 25 & 39.4 & 26 & 18.2 & 12 & 4.6 & 3 & 66 \\
\hline Internet connection problems & 34.4 & 21 & 31.2 & 19 & 29.5 & 18 & 4.9 & 3 & 61 \\
\hline $\begin{array}{l}\text { Lack of professional } \\
\text { development on the basics of } \\
\text { ICT }\end{array}$ & 26.2 & 17 & 43.1 & 28 & 29.2 & 19 & 1.5 & 1 & 65 \\
\hline $\begin{array}{l}\text { Updates and } \\
\text { updating problems }\end{array}$ & 25.8 & 16 & 35.5 & 22 & 29.0 & 18 & 9.7 & 6 & 62 \\
\hline Glitches and apps not working & 25.4 & 16 & 42.9 & 27 & 25.4 & 16 & 6.4 & 4 & 63 \\
\hline Lack of functionality & 24.6 & 15 & 31.2 & 19 & 41.0 & 25 & 3.3 & 2 & 61 \\
\hline $\begin{array}{l}\text { Lack of tablet technical } \\
\text { training }\end{array}$ & 23.8 & 15 & 38.1 & 24 & 28.6 & 18 & 9.5 & 6 & 63 \\
\hline Personal beliefs on technology & 23.4 & 15 & 39.1 & 25 & 29.7 & 19 & 7.9 & 5 & 64 \\
\hline $\begin{array}{l}\text { Battery problems, charging } \\
\text { time }\end{array}$ & 22.6 & 14 & 40.3 & 25 & 29.0 & 18 & 8.1 & 5 & 62 \\
\hline Finding appropriate material & 21.3 & 13 & 42.6 & 26 & 27.9 & 17 & 8.2 & 5 & 61 \\
\hline $\begin{array}{l}\text { Tracking children's progress } \\
\text { using apps }\end{array}$ & 21.0 & 13 & 43.6 & 27 & 21.0 & 13 & 14.5 & 9 & 62 \\
\hline $\begin{array}{l}\text { Apps do not fit educational } \\
\text { goals }\end{array}$ & 20.3 & 12 & 55.9 & 33 & 17.0 & 10 & 6.8 & 4 & 59 \\
\hline $\begin{array}{l}\text { Children circumventing } \\
\text { security functions }\end{array}$ & 20.0 & 12 & 23.3 & 14 & 45.0 & 27 & 11.7 & 7 & 60 \\
\hline $\begin{array}{l}\text { Lack of support } \\
\text { from administration }\end{array}$ & 18.3 & 11 & 28.3 & 17 & 36.7 & 22 & 16.7 & 10 & 60 \\
\hline $\begin{array}{l}\text { New apps and } \\
\text { their incompatibility }\end{array}$ & 14.5 & 9 & 41.9 & 26 & 32.3 & 20 & 11.3 & 7 & 62 \\
\hline
\end{tabular}

Table 4.6. Non-user services: Possible barriers.

Services were asked if they did use tablets, whether they would implement formal policies or guidelines for staff. From a total of 70 responses, $68(97.1 \%)$ services said they would implement formal policies/guidelines for staff whilst two (2.9\%) would not. The survey enquired if the non-user services had a screen time policy regarding children's engagement with screen media (including TVs, DVDs, tablets, smart phones). From a total of 159 responses, 135 (84.9\%) said "no" whilst $24(15.1 \%)$ responded "yes". Responses with affirmative answers were further asked how many minutes of screen time per day they would allow (see Table 4.7). Of interest is that 10 services responded " 0 minutes" to the question implying that either they had a screen time policy that was not limited to a specific number of minutes or that they did not allow any screen time at all. 


\begin{tabular}{|c|c|c|c|c|c|}
\hline Minutes & 0 & 10 & 15 & 30 & \multirow{2}{*}{$\mathrm{N}=24$} \\
\hline $\begin{array}{c}\text { Number of } \\
\text { services }\end{array}$ & 10 & 4 & 5 & 5 & $\mathrm{~N}$ \\
\hline
\end{tabular}

Table 4.7. Non-user services: Screen time in minutes.

Non-users responded to a hypotethical question asking if they owned tablets to indicate the maximum number of children they would allow to use them at any one time. There were 69 responses, with the minimum number of children being zero and the maximum 25 with a median of three. The Mann-Whitney $U$ test was identified as a statistical tool that could be used to understand this data further and thus was used for inferential analysis as shown in Figure 4.7 later in the chapter. Services were asked if children, whānau/parents, and teachers/educators used their personally-owned tablets in their service. Out of 168 responses, this occurred in half of the services $(n=84,50 \%)$.

Non-user services were asked to indicate who would monitor tablet use if they used tablets. Respondents were requested to indicate all that applied from a fixed set of options. Table 4.8 shows that the majority of the responses identified that monitoring would be undertaken by a fully certificated teacher/educator $(41.0 \%)$.

\begin{tabular}{|c|c|c|}
\hline \multirow{2}{*}{ Facilitators } & \multicolumn{2}{|c|}{ Responses } \\
\hline & $\%$ & $\mathbf{n}$ \\
\hline A fully certificated teacher/educator & $41.0 \%$ & 48 \\
\hline A provisionally certificated teacher/educator & $27.4 \%$ & 32 \\
\hline Parents or adult whānau & $18.8 \%$ & 22 \\
\hline Peers the same age or younger & $6.8 \%$ & 8 \\
\hline Older children & $5.1 \%$ & 6 \\
\hline There would be no monitoring/facilitator & $0.9 \%$ & 1 \\
\hline & Total & 117 \\
\hline
\end{tabular}

Table 4.8. Non-user services: Tablet facilitators.

Respondents were asked to indicate how tablets might be used. The choices allowed multiple responses. From a total of 69 responses, $56(81.2 \%)$ chose using tablets in groups with a teacher/educator, 48 (69.6\%) stated individually with a teacher/educator, 20 (29.0\%) selected individually, and 18 (26.1\%) indicated in groups. The latter two both implied that there was no teacher/educator involvement to scaffold children's tablet use. 
A final multiple-response question posed to non-user services asked how they would learn to use tablets for teaching and learning. The most frequently identified learning sources were through personal use (69.1\%) and through collaboration with other teachers/educators (60.9\%). As seen in Table 4.9 below, there was more than a $30 \%$ difference between these top two "most likely" choices and the remaining responses. When "most likely" and "likely" responses were combined, through personal use (90\%) and through collaboration with other teachers/educators $(85 \%)$ were still the foremost responses. When "least likely" and "never" responses were combined, from university courses (86\%) was the least amongst respondents' preferred learning sources.

\begin{tabular}{|l|c|c|c|c|c|c|c|c|c|}
\hline \multirow{2}{*}{ Learning sources } & \multicolumn{2}{|c|}{$\begin{array}{c}\text { Most } \\
\text { likely }\end{array}$} & \multicolumn{2}{c|}{ Likely } & \multicolumn{2}{c|}{$\begin{array}{c}\text { Least } \\
\text { Likely }\end{array}$} & \multicolumn{2}{c|}{ Never } & \multirow{2}{*}{ Total } \\
\cline { 2 - 10 } & $\mathbf{\%}$ & $\mathbf{n}$ & $\mathbf{\%}$ & $\mathbf{n}$ & $\mathbf{\%}$ & $\mathbf{n}$ & $\mathbf{\%}$ & $\mathbf{n}$ & \\
\hline Through personal use & 69.1 & 96 & 20.9 & 29 & 0.72 & 1 & 9.4 & 13 & 139 \\
\hline $\begin{array}{l}\text { Through collaboration with } \\
\text { other teachers/educators }\end{array}$ & 60.9 & 81 & 24.1 & 32 & 2.3 & 3 & 12.8 & 17 & 133 \\
\hline $\begin{array}{l}\text { Through videos and } \\
\text { online information }\end{array}$ & 26.4 & 29 & 41.0 & 45 & 15.5 & 17 & 17.3 & 19 & 110 \\
\hline $\begin{array}{l}\text { From IT-related } \\
\text { professional development } \\
\text { courses }\end{array}$ & 25.8 & 31 & 31.7 & 38 & 21.7 & 26 & 20.8 & 25 & 120 \\
\hline $\begin{array}{l}\text { From other professional } \\
\text { development courses }\end{array}$ & 16.5 & 18 & 43.1 & 47 & 19.3 & 21 & 21.1 & 23 & 109 \\
\hline From Ministry resources & 12.8 & 14 & 34.9 & 38 & 29.4 & 32 & 22.9 & 25 & 109 \\
\hline $\begin{array}{l}\text { From books and } \\
\text { printed material }\end{array}$ & 11.5 & 12 & 27.9 & 29 & 34.6 & 36 & 26.0 & 27 & 104 \\
\hline From university courses & 2.0 & 2 & 11.9 & 12 & 42.6 & 43 & 43.6 & 44 & 101 \\
\hline
\end{tabular}

Table 4.9. Non-user services: Learning sources for tablet use.

This section has outlined the non-user services' responses to the survey. Amongst the choices of reasons for not using tablets, the top reason that "almost always applies" was educational philosophy. More than half of non-users indicated they had no intention of using them for teaching and learning. However, if they were to use tablets, the top purpose would be for documentation and assessment. If they had tablets, the "most likely" barriers indicated were teachers/educators' preference towards traditional practices and internet connection problems.

The majority of non-user services $(97.1 \%)$ said they would implement policies or guidelines for staff if they used tablets but only 10 non-users reported 
implementing a screen time policy. Non-user services were split equally concerning children's, whānau's/parents', and teachers'/educators' use of their personally-owned tablets. The majority specified a fully certificated teacher/educator would facilitate tablet use and this facilitation would be in groups with a teacher/educator (81.2\%). Most non-user services stated that they would "most likely" learn to use tablets through personal use $(69.1 \%)$ and through collaboration with other teachers/educators (60.9\%). The next section presents descriptive analyses from user services. Questions for user services paralleled the ones asked to non-user respondents but were not hypothetical.

4.3. Responses from tablet user services. The descriptive data from the survey responses of user services is reported next. The questions were similar to those posed to non-user services.

Respondents were asked to indicate the number of children who used tablets at their services. Eleven respondents gave a range of numbers such as " 3 to 4 " or "6 to 10 " and qualitative responses such as "to listen to music" [U-E\&C/P1/2016] and "small group" [U-K/P1/328]. From these responses, those with a maximum number were included in the descriptive analyses (see Table 4.10) whilst those with descriptive responses were removed. The data in Table 4.10 was used for the MannWhitney U test (see Figure 4.7) reported later in section 4.2.

\begin{tabular}{|c|c|c|}
\hline Maximum number of children & Number of services & $\boldsymbol{\%}$ \\
\hline$<5$ & 83 & $52.5 \%$ \\
\hline $5-9$ & 52 & $32.9 \%$ \\
\hline $10-14$ & 13 & $8.2 \%$ \\
\hline $15-19$ & 8 & $5.1 \%$ \\
\hline$>19$ & 2 & $1.3 \%$ \\
\hline \multicolumn{2}{r|}{ Total } & 158 \\
\cline { 1 - 2 }
\end{tabular}

Table 4.10. User services: Maximum number of children using tablets at the any one time.

Furthermore, users were asked how many teachers/educators used tablets in their teaching. The number of teachers/educators ranged from zero to 22 (See Table 4.11). 


\begin{tabular}{|c|c|c|}
\hline Maximum number of teachers/educators & Number of services & \% \\
\hline$<5$ & 77 & $52.7 \%$ \\
\hline $5-9$ & 47 & $32.2 \%$ \\
\hline $10-14$ & 8 & $5.5 \%$ \\
\hline $15-19$ & 4 & $2.7 \%$ \\
\hline $20-24$ & 3 & $2.1 \%$ \\
\hline$>24$ & 7 & $4.8 \%$ \\
\hline \multicolumn{2}{r|}{ Total } & 146 \\
\cline { 1 - 2 }
\end{tabular}

Table 4.11. User services: Maximum number of teachers/educators who use tablets.

Respondents were requested to indicate all that applied from 11 choices in response to a question about how they used tablets for teaching and learning (see Table 4.12). The most frequent purpose was documentation and assessment (53.1\%). When "almost every day" and "twice/thrice a week" were combined, the most frequent purpose became playing music (70.7\%) followed closely by documentation and assessment $(68.1 \%)$. The third reason was creativity whether "almost every day" and "twice/thrice a week" were combined $(65.3 \%)$ or not (41.7\%). The least selected purpose was communication with institutions (universities, government offices, etc.) whether "once a week or less" and "never" responses were combined $(93.8 \%)$ or remained as "never" $(75.0 \%)$.

\begin{tabular}{|l|c|c|c|c|c|c|c|c|c|}
\hline \multirow{2}{*}{\multicolumn{1}{|c|}{ Purposes }} & \multicolumn{2}{|c|}{$\begin{array}{c}\text { Almost } \\
\text { every day }\end{array}$} & \multicolumn{2}{c|}{$\begin{array}{c}\text { Twice/thrice } \\
\text { a week }\end{array}$} & \multicolumn{2}{c|}{$\begin{array}{c}\text { Once a } \\
\text { week or less }\end{array}$} & \multicolumn{2}{c|}{ Never } & \multirow{2}{*}{ Total } \\
\cline { 2 - 10 } & $\mathbf{\%}$ & $\mathbf{n}$ & $\mathbf{\%}$ & $\mathbf{n}$ & $\mathbf{\%}$ & $\mathbf{n}$ & $\mathbf{\%}$ & $\mathbf{n}$ & \\
\hline Documentation and assessment & 53.1 & 78 & 15.0 & 22 & 17.0 & 25 & 15.0 & 22 & 147 \\
\hline Playing music & 46.0 & 69 & 24.7 & 37 & 14.7 & 22 & 14.7 & 22 & 150 \\
\hline Creativity & 41.7 & 60 & 23.6 & 34 & 17.4 & 25 & 17.4 & 25 & 144 \\
\hline $\begin{array}{l}\text { Communication with } \\
\text { children's families/whānau }\end{array}$ & 37.4 & 52 & 18.0 & 25 & 18.7 & 26 & 25.9 & 36 & 139 \\
\hline Documenting events & 31.2 & 44 & 14.9 & 21 & 35.5 & 50 & 18.4 & 26 & 141 \\
\hline Exploration & 30.4 & 41 & 12.6 & 17 & 35.6 & 48 & 21.5 & 29 & 135 \\
\hline Information retrieval & 26.5 & 36 & 30.2 & 41 & 32.4 & 44 & 11.0 & 15 & 136 \\
\hline Watching videos & 12.1 & 17 & 23.6 & 33 & 42.1 & 59 & 22.1 & 31 & 140 \\
\hline Playing games & 7.5 & 10 & 9.7 & 13 & 32.8 & 44 & 50.0 & 67 & 134 \\
\hline $\begin{array}{l}\text { Communication with other } \\
\text { services or umbrella } \\
\text { corporation }\end{array}$ & 5.5 & 7 & 6.3 & 8 & 20.3 & 26 & 68.0 & 87 & 128 \\
\hline $\begin{array}{l}\text { Communication with } \\
\text { institutions (universities, } \\
\text { government offices, etc.) }\end{array}$ & 1.6 & 2 & 4.7 & 6 & 18.8 & 24 & 75.0 & 96 & 128 \\
\hline
\end{tabular}

Table 4.12. User services: Purposes of tablet use. 
In a follow-up question, user services were asked to explain how their teachers/educators supported children using tablets. These qualitative responses are presented in the next chapter.

User services were asked if they had formal policies or guidelines for staff on using tablets for teaching and learning. From 152 responses, 105 services (69.0\%) had one whilst 47 services $(31.0 \%)$ did not. In relation to this, user services were asked if they had a screen time policy. From 152 responses, 125 services (82.2\%) did not have any screen time policy and 27 services (17.8\%) did. The 27 services that responded to having a screen time policy were asked to indicate the number of minutes in a day when children could engage with screen media. Five services indicated 30 minutes, seven said 15 minutes, six reported 10 minutes, whilst eight services answered 0 minutes. The median was 10 minutes.

Respondents were then asked how they used tablets: in groups or individually and with a teacher/educator or without. Because the question allowed multiple responses, the total responses were more than the total number of user services. From 318 responses, 126 (39.6\%) chose in groups with a teacher/educator and 102 $(32.1 \%)$ indicated individually with a teacher/educator. From responses that did not involve facilitation by a teacher/educator, 52 (16.4\%) respondents selected individually and 38 (12.0\%) stated in groups.

User services were asked to identify who monitored tablet use by selecting all responses that applied from six options. From 206 responses, 121 services (58.7\%) indicated a fully certificated teacher/educator and 49 services (23.8\%) indicated $a$ provisionally certificated teacher/educator. Fifteen services (7.3\%) stated peers the same age and younger, 11 services (5.3\%) selected older children, and seven services $(3.4 \%)$ indicated parents or adult whānau. Three services (1.5\%) indicated that there was no monitoring/facilitator, whilst one service selected all five facilitative options.

User services were asked, if they had not used tablets in the past, to choose their reasons for not using tablets (see Table 4.13). Although the "most likely" reasons were funding (39.4\%) and educational philosophy (35.5\%), respectively, when "most likely" and "likely" responses were combined, educational philosophy 
became the foremost reason (58.1\%) ahead of funding (56.3\%). The response we used them before and just stopped was not a reason which applied to any users.

\begin{tabular}{|c|c|c|c|c|c|c|c|c|c|}
\hline \multirow{2}{*}{ Reason } & \multicolumn{2}{|c|}{$\begin{array}{l}\text { Most } \\
\text { likely }\end{array}$} & \multicolumn{2}{|c|}{ Likely } & \multicolumn{2}{|c|}{$\begin{array}{l}\text { Least } \\
\text { likely }\end{array}$} & \multicolumn{2}{|c|}{ Never } & \multirow{2}{*}{ Total } \\
\hline & $\%$ & n & $\%$ & $\mathbf{n}$ & $\%$ & n & $\%$ & $\mathbf{n}$ & \\
\hline Funding & 39.4 & 28 & 16.9 & 12 & 14.1 & 10 & 29.6 & 21 & 71 \\
\hline Educational philosophy & 35.5 & 22 & 22.6 & 14 & 9.7 & 6 & 32.3 & 20 & 62 \\
\hline Lack of technical expertise & 20.6 & 13 & 22.2 & 14 & 19.1 & 12 & 38.1 & 24 & 63 \\
\hline Company/service policy & 19.0 & 11 & 10.3 & 6 & 17.2 & 10 & 53.5 & 31 & 58 \\
\hline $\begin{array}{l}\text { Use of another type of technology } \\
\text { (e.g., Smartboards, overhead } \\
\text { projectors, laptop computers) }\end{array}$ & 18.0 & 11 & 27.9 & 17 & 11.5 & 7 & 42.6 & 26 & 61 \\
\hline Lack of professional development & 14.5 & 9 & 25.8 & 16 & 17.7 & 11 & 41.9 & 26 & 62 \\
\hline $\begin{array}{l}\text { Initial teacher training } \\
\text { did not cover tablets }\end{array}$ & 13.8 & 8 & 10.3 & 6 & 24.1 & 14 & 51.7 & 30 & 58 \\
\hline $\begin{array}{l}\text { Equipment needs } \\
\text { repair/incompatibility }\end{array}$ & 13.6 & 8 & 13.6 & 8 & 20.3 & 12 & 52.5 & 31 & 59 \\
\hline $\begin{array}{l}\text { We used them before and just } \\
\text { stopped }\end{array}$ & 0.0 & 0 & 0.0 & 0 & 0.0 & 0 & 100.0 & 39 & 39 \\
\hline
\end{tabular}

\section{Table 4.13. User services: Reasons for not using tablets in the past.}

User services were asked how they learned to use tablets for teaching. The foremost reason was through personal use whether "almost always true" and “occasionally true" responses were combined (96.6\%) or not $(87.3 \%)$ followed by through collaboration with other teachers/educators whether "almost always true" and "occasionally true" responses were combined (90.3\%) or not (71.6\%). When "rarely true" and "never true" responses were combined, from university courses was the least preferred learning source $(90.8 \%)$. Table 4.14 below shows these results. 


\begin{tabular}{|l|c|c|c|c|c|c|c|c|c|}
\hline \multirow{2}{*}{ Learning Sources } & \multicolumn{2}{|c|}{$\begin{array}{c}\text { Almost } \\
\text { always true }\end{array}$} & \multicolumn{2}{c|}{$\begin{array}{c}\text { Occasionally } \\
\text { true }\end{array}$} & \multicolumn{2}{c|}{$\begin{array}{c}\text { Rarely } \\
\text { true }\end{array}$} & \multicolumn{2}{c|}{$\begin{array}{c}\text { Never } \\
\text { true }\end{array}$} & \multirow{2}{*}{ Total } \\
\cline { 2 - 10 } & $\mathbf{\%}$ & $\mathbf{n}$ & $\mathbf{\%}$ & $\mathbf{n}$ & $\mathbf{\%}$ & $\mathbf{n}$ & $\mathbf{\%}$ & $\mathbf{n}$ & \\
\hline Through personal use & 87.3 & 131 & 9.3 & 14 & 0.7 & 1 & 2.7 & 4 & 150 \\
\hline $\begin{array}{l}\text { Through collaboration } \\
\text { with other } \\
\text { teachers/educators }\end{array}$ & 71.6 & 96 & 18.7 & 25 & 3.0 & 4 & 6.7 & 9 & 134 \\
\hline $\begin{array}{l}\text { Through videos } \\
\text { and online information }\end{array}$ & 21.6 & 25 & 27.6 & 32 & 22.4 & 26 & 28.5 & 33 & 116 \\
\hline $\begin{array}{l}\text { From IT-related } \\
\text { professional } \\
\text { development courses }\end{array}$ & 15.3 & 18 & 33.9 & 40 & 14.4 & 17 & 36.4 & 43 & 118 \\
\hline $\begin{array}{l}\text { From other professional } \\
\text { development courses }\end{array}$ & 10.7 & 12 & 27.7 & 31 & 22.3 & 25 & 39.3 & 44 & 112 \\
\hline $\begin{array}{l}\text { From books and printed } \\
\text { material }\end{array}$ & 7.0 & 8 & 25.4 & 29 & 21.1 & 24 & 46.5 & 53 & 114 \\
\hline From Ministry resources & 2.7 & 3 & 14.4 & 16 & 24.3 & 27 & 58.6 & 65 & 111 \\
\hline From university courses & 0.9 & 1 & 8.3 & 9 & 21.1 & 23 & 69.7 & 76 & 109 \\
\hline From the children & 0.0 & 0 & 100.0 & 1 & 0.0 & 0 & 0.0 & 0 & 1 \\
\hline
\end{tabular}

Table 4.14. User services: Learning sources for tablet use.

This section has outlined responses to the user services' section of the survey such as the number of children and teachers/educators who use their tablets at their services. Amongst the choices of purposes for using tablets, the top reason given was again documentation and assessment. When asked if they had a specific screen time policy, the majority did not have one, even though more than half of user services said they had general policies or guidelines for staff.

When asked to choose who would facilitate tablet use, more than half specified a fully certificated teacher/educator with one-third choosing in groups with a teacher/educator and another third choosing individually with a teacher/educator. Services indicated that funding and educational philosophy where the most common reasons for not using tablets in the past. Most user services stated that they learned through personal use and through collaboration with other teachers/educators. This section presented the results of the descriptive analyses of Phase 1. In the next section, I present the inferential analyses results involving Chi-Square and MannWhitney U tests. 


\subsection{Inferential results}

Based on the descriptive statistical results in Phase 1, I identified responses to questions which could be analysed further using inferential statistics to provide more in-depth answers to the research questions. Ordinal data with sufficient frequencies were analysed using non-parametric tests whilst data that had too many categories and too few cell counts were not analysed. The first non-parametric test used was the Chi-Square test to determine if there were associations between questions. Then, Mann-Whitney U was used to compare two groups based on their median. These tests aimed to identify if there were significant associations between questions in the survey.

Using the Chi-Square test, I identified the relationship between service type and tablet use and non-use. Figure 4.1 illustrates that tablet non-user and user services were not equally distributed per service type, confirmed by a Chi-Square test result, $X^{2}(3, N=338)$, Chi-Square $=31.27, p<0.01$. More kindergartens used tablets whilst fewer playcentres and home-based services did. Fifty percent of education and care services used tablets.

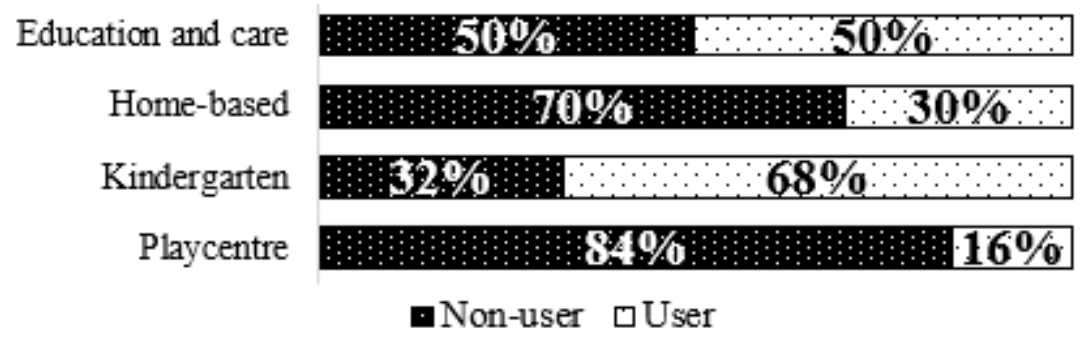

Figure 4.1. Tablet non-user/user services per service type.

The survey also asked non-user services to indicate if they intended to acquire tablets in the near future, did not intend to acquire tablets, or were unsure. The results were analysed with whether respondents allowed or did not allow parents, children and/or teachers/educators to use their personal tablets at the service. Figure 4.2 shows that there is a significant difference between non-user services' intentions regarding the future acquisition of tablets and allowing use of personal tablets in their service. The Chi-Square test results confirmed this, $X^{2}(2, N=167)$, Chi-Square $=20.22, \mathrm{p}<0.01$. Except for respondents who chose unsure at this time, more services that allowed use of personal tablets intended to acquire tablets in the near future. Similarly, more services that did not allow the use of personal tablets 
had no intention to acquire tablets for teaching and learning. However, more services that allowed use of personal tablets were unsure whether to acquire tablets or not.

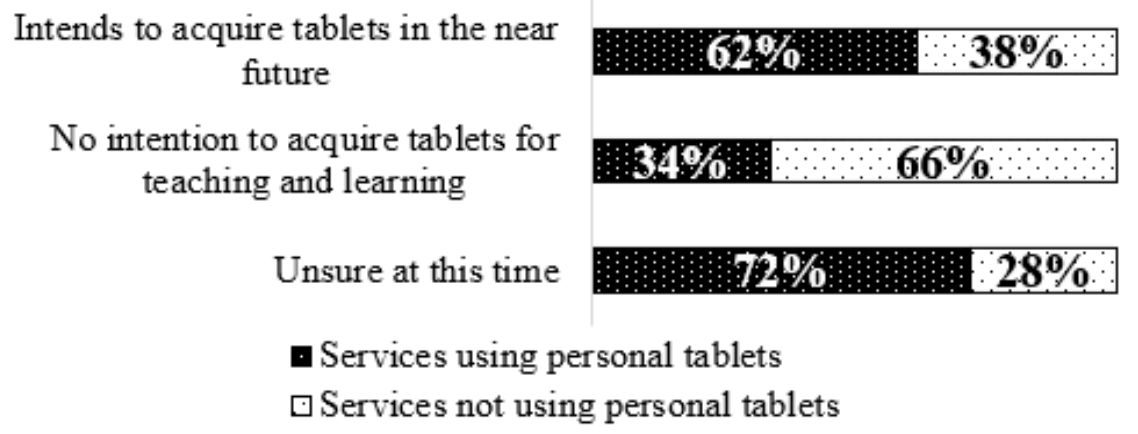

Figure 4.2. Non-user services: Use/non-use of personal tablets.

An analysis of whether non-user services allowed personal tablet use by parents, children, and teachers/educators according to service type was undertaken. Results showed a significant difference amongst service types and use of personal tablets as confirmed by a Chi-Square test: $\mathrm{X}^{2}(3, \mathrm{~N}=168)$, Chi-Square $=14.32, \mathrm{p}$ $<.01$. Figure 4.3 below shows that more home-based services and playcentres allowed the use of personal tablets.

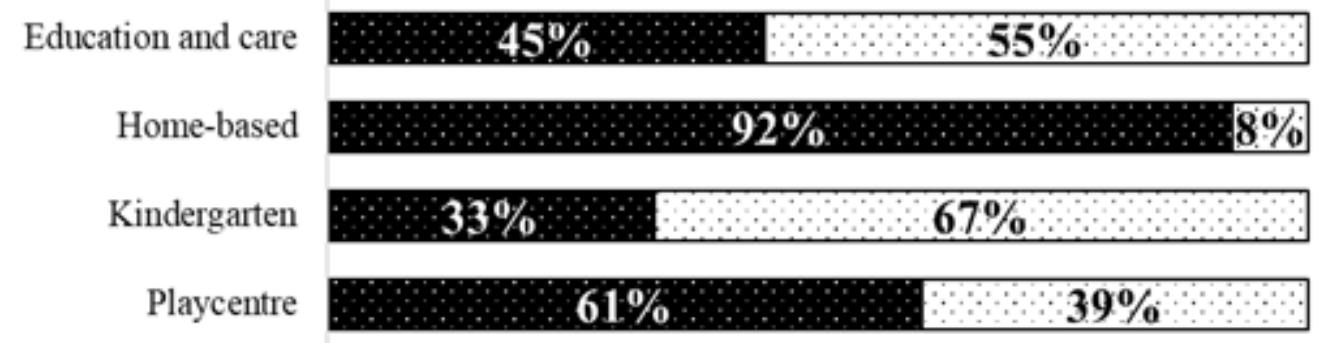

- Services allowing personal tablet use

口Services not allowing personal tablet use

Figure 4.3. Service type: Personal tablet use of non-use.

User services' results regarding formal policies or guidelines for staff on the use of tablets were analysed according to service type. A Chi-Square analysis per service type showed a significant association when tested at the $5 \%$ significance level, $\mathrm{X}^{2}(3, \mathrm{~N}=152)$, Chi-Square $=8.49, \mathrm{p}=.04$. Figure 4.4 below shows that more kindergartens, home-based services, and education and care services had implemented a formal policy or guidelines for staff on their use of tablets. A greater 
proportion of playcentres did not have formal policies/guidelines for staff as survey responses from playcentres had indicated that they did not use tablets with children.

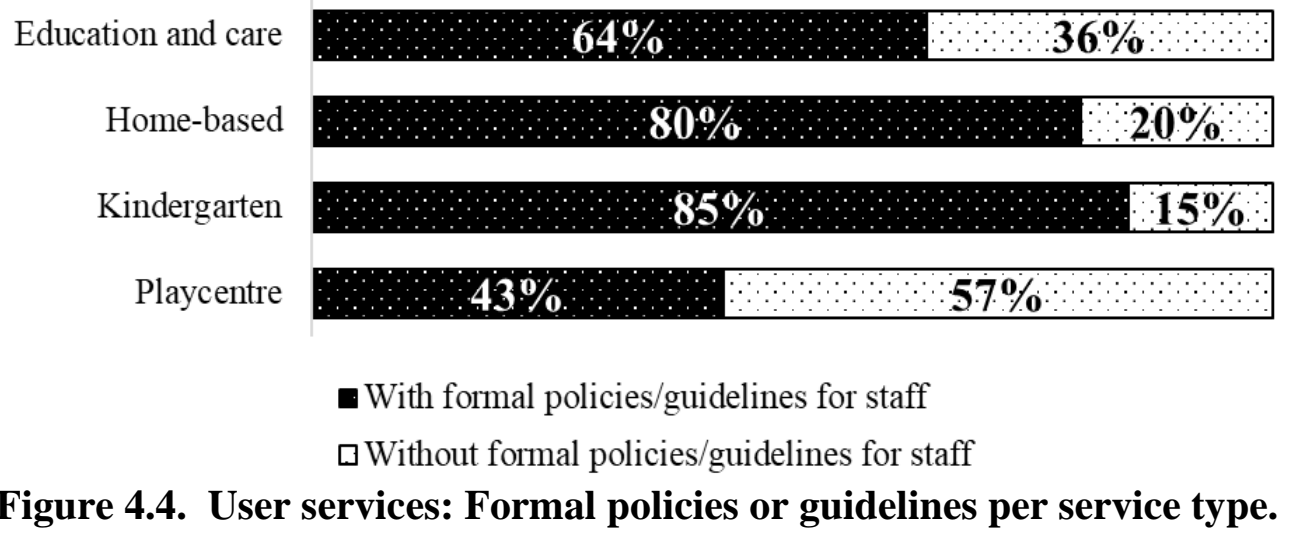

Additionally, user services' responses about the implementation of a screen time policy for children who engaged in screen media were analysed along with their responses to having a formal policy or guidelines for staff on tablet use. A ChiSquare analysis per service type showed a significant association when tested at the $5 \%$ significance level, $X^{2}(3, N=152)$, Chi-Square $=4.37, p=.04$. Figure 5.5 below shows that having a screen time policy did not necessarily mean that a service also had fomal policies/guidelines for staff. Additionally, Figure 4.5 illustrates that there are more services without both formal policies/guidelines for staff and a screen time policy.

With formal policies/guidelines

$230 \% 0 \%$

Without formal policies/guidelines

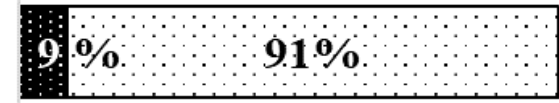

- With a screen time policy $\square$ Without a screen time policy

\section{Figure 4.5. User services: Formal policies or guidelines and screen time policy.}

Mann-Whitney U test was used to identify if there was a significant difference between the maximum number of children who could use tablets at nonuser services where personal tablets by parents, children, or teachers/educators were used for teaching and learning. Figure 4.6 shows that there is a significant difference between the two questions $(\mathrm{p}=0.041)$. Although the median of services that allowed personal tablet use was 3.0, the median of services that did not was 2.0, Figure 4.6 
shows that if non-users did have tablets, those who did not allow use of personal tablets had limited the number of children who could use the devices to fewer than five. For this question, if respondents provided a range of numbers, I used the maximum number they indicated for the analysis because the question asked them to indicate the maximum number of children.

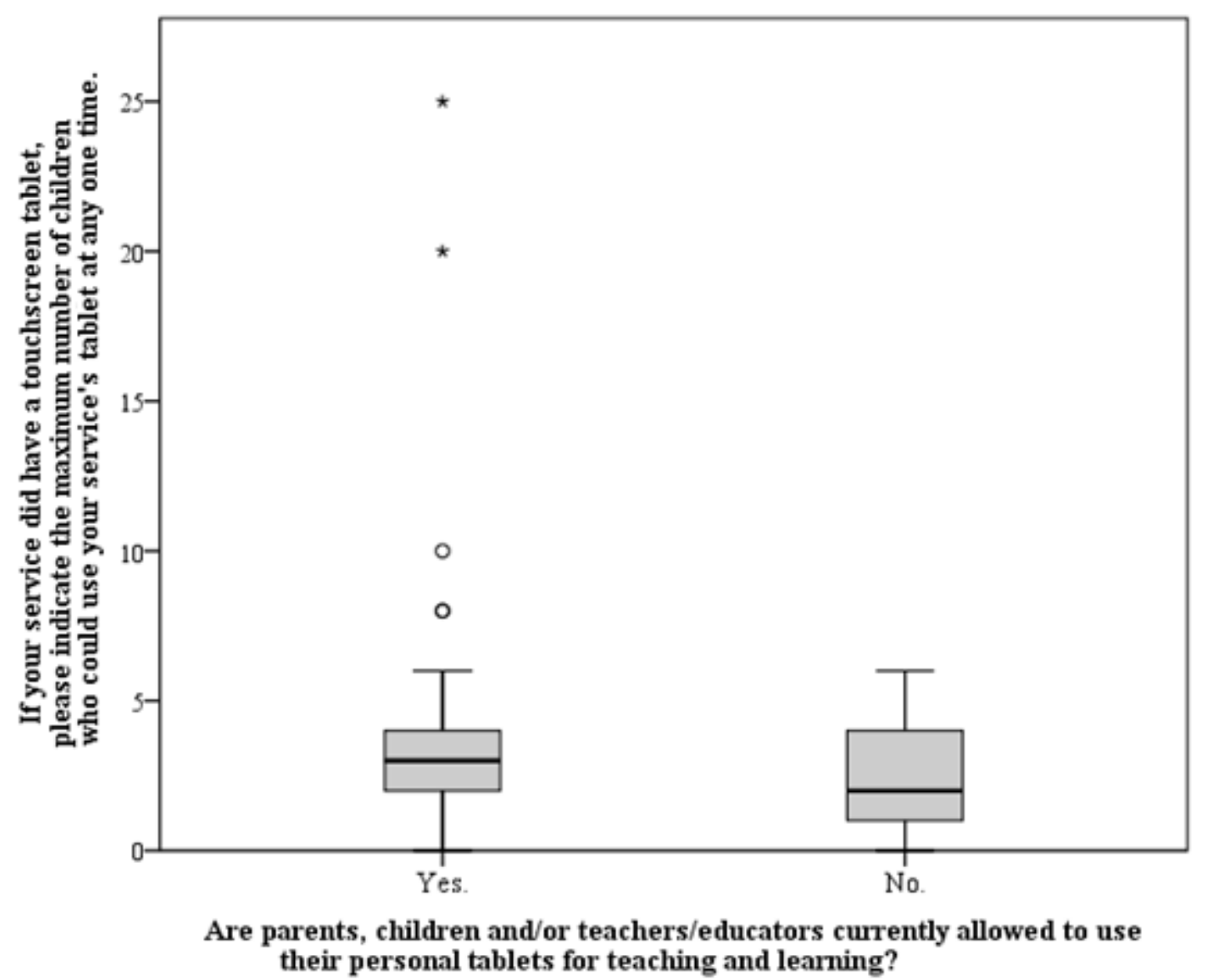

Figure 4.6. Non-user's number of children and personal tablet use/non-use.

Next, the Mann-Whitney U test was used to identify if there was a significant difference between the maximum number of children from non-user services and whether they implemented a screen time policy for children who engaged with screen media. The hypothesis test showed a significant difference between the number of children from non-user services and non-users' implementation of a screen time policy $(\mathrm{p}=0.041)$. Services with screen time policies had a median of 41.5 children and non-user services had a median of 35 children. The boxplots shown in Figure 4.7 indicate that, generally, services that implemented a screen time policy were licensed for more children. The range of the number of children was slightly more amongst non-user services that had no screen time policy. 


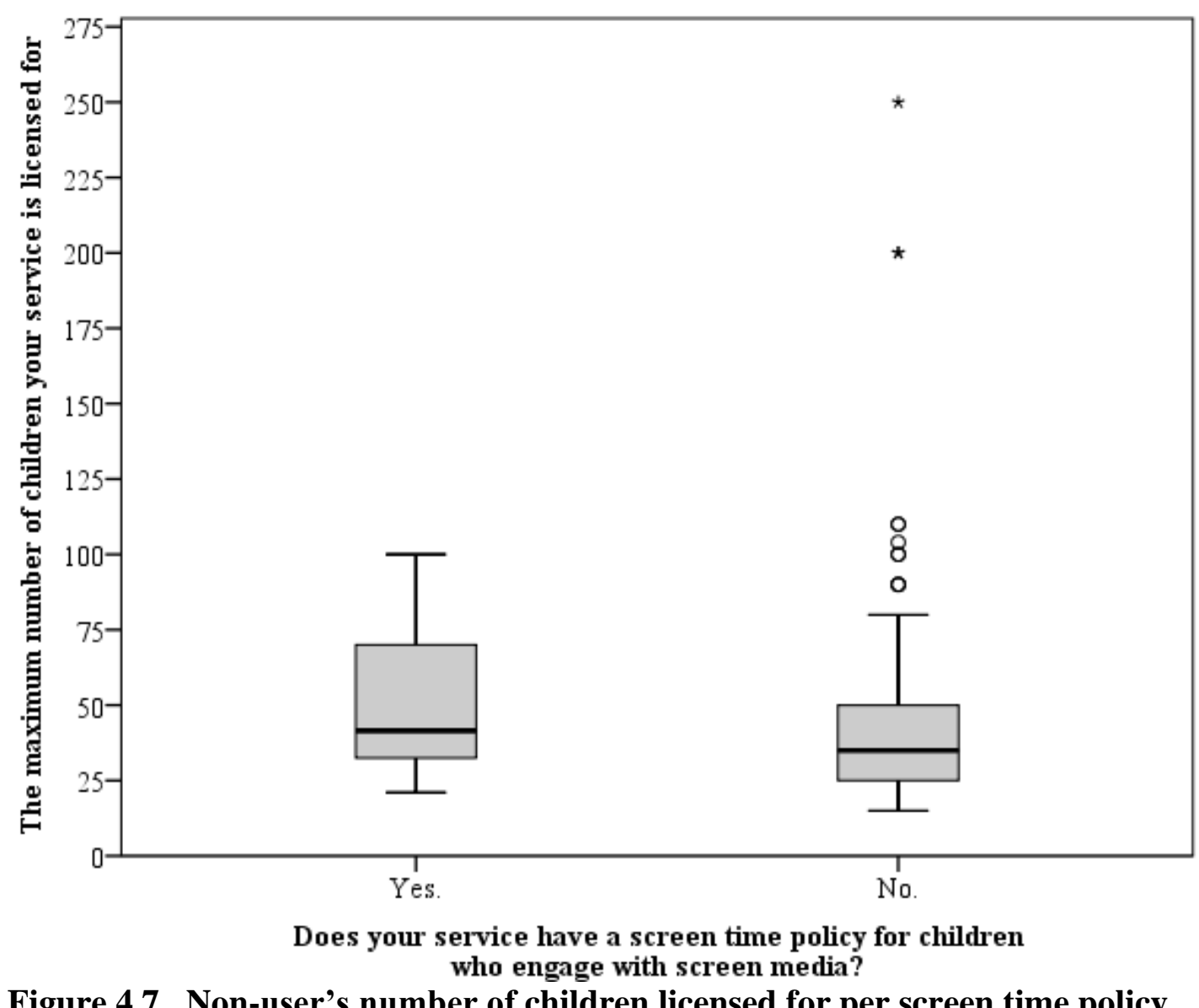

Figure 4.7. Non-user's number of children licensed for per screen time policy.

A Mann-Whitney U test was used to analyse the number of teachers/educators in user services who used tablets for teaching and learning, compared with their implementation of a screen time policy for children who engage with screen media. The results showed a significant difference between the responses to the two questions $(\mathrm{p}=0.046)$. Figure 4.8 shows the results including the median number of teachers/educators in services that had a screen time policy (5.0) and the median among those who did not (4.0). Compared to the wider and more sporadic range in the number of teachers/educators amongst services without a screen time policy, services with a screen time policy had a more consistent number of teachers/educators - at a range from four to eight. 


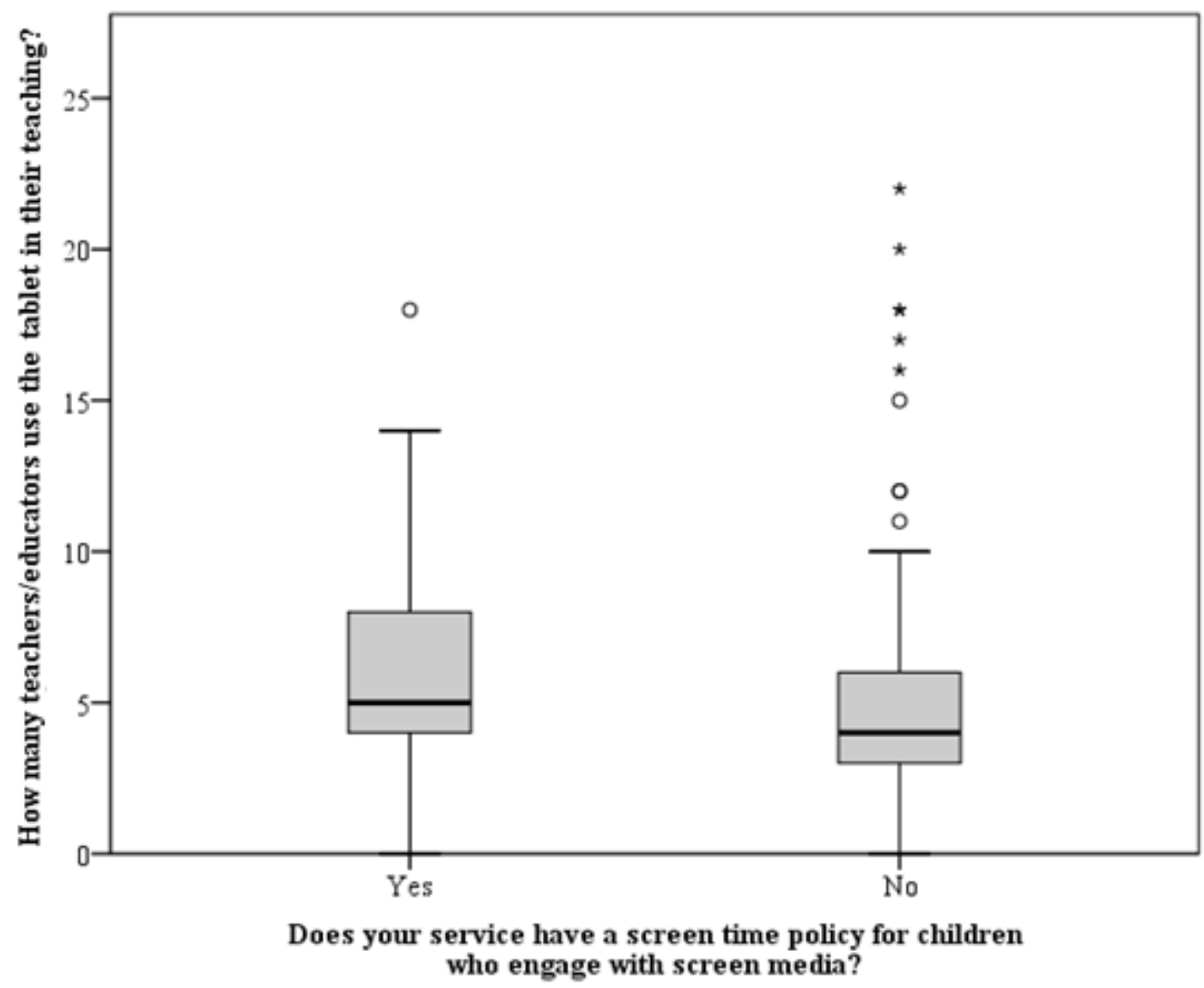

Figure 4.8. Number of teachers/educators using tablets and screen time policy.

A Mann-Whitney $U$ test was used to identify if there was a significant difference between the maximum number of teachers/educators and whether or not each service used a tablet for teaching and learning. The hypothesis test showed a significant association between the number of teachers/educators and the use/non-use of tablets amongst services $(\mathrm{p}=0.014)$. Figure 4.9 shows that the user services generally had fewer teachers/educators. Despite the small difference between the medians of user services (8.0) and non-user services (7.0), the boxplot in Figure 4.9 shows that user services had significantly fewer total numbers of teachers/educators compared to non-user services. 


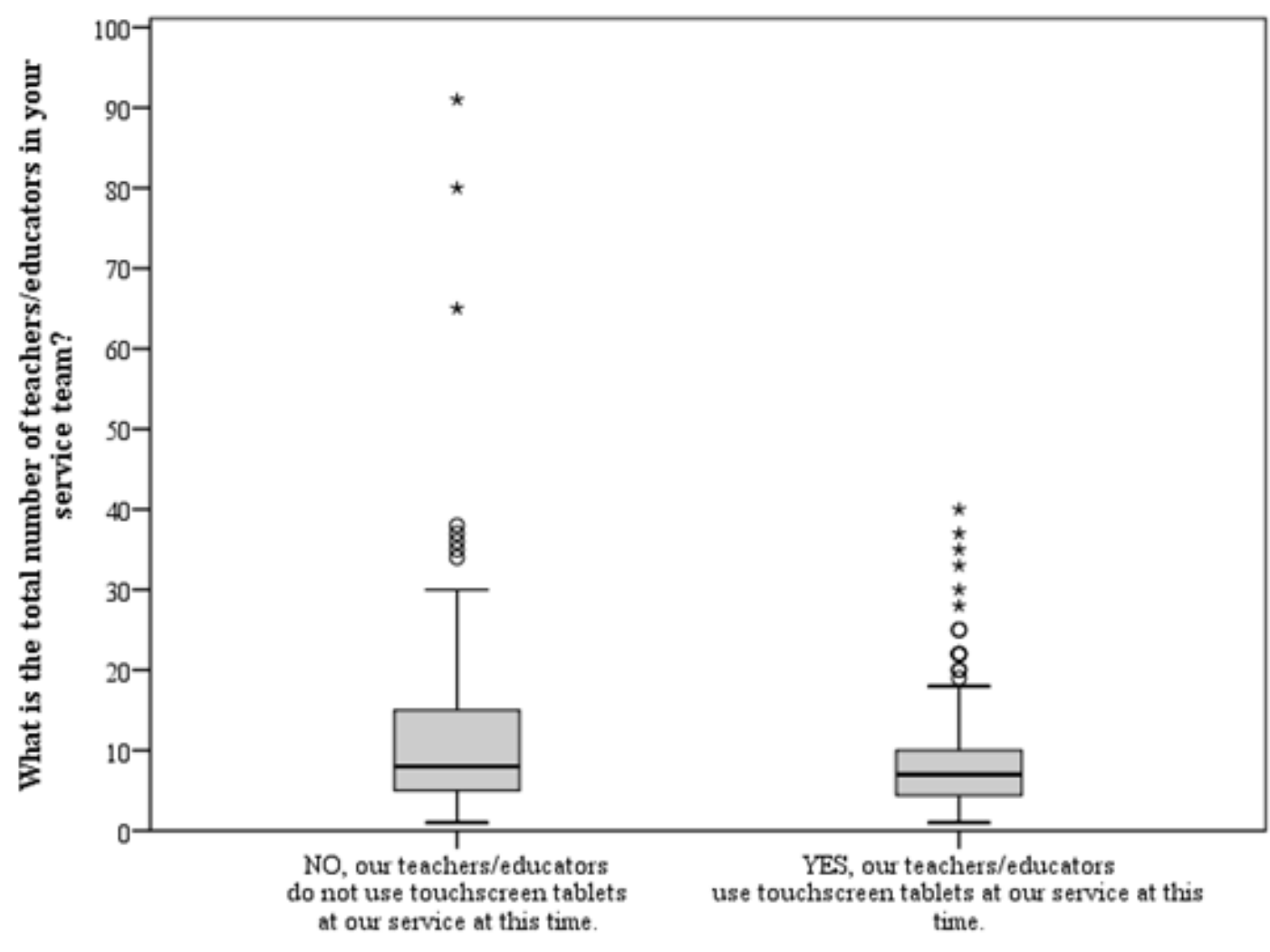

Are teachers/educators in your service presently using tablets at your service?

Figure 4.9. Number of teachers/educators and tablet use/non-use.

This section discussed the inferential analyses results from the national survey. Firstly, Chi-Square tests revealed significant differences between service type and tablet use or non-use. Further Chi-Square tests showed a significant association between non-user services who intended to acquire tablets in the near future and those who allowed use of personal tablets at their services. A significant difference between services with/without policies or guidelines for staff on tablet use and service type was observed. Services that had a screen time policy did not necessarily have policies or guidelines for staff's tablet use.

The Mann-Whitney U non-parametric test was used to further analyse questions based on the medians. This inferential statistical test revealed a significant association between children who could use tablets at non-user services and services allowing use of personal tablets. Additionally, using the same test, there was a significant relationship between the number of teachers/educators using tablets for teaching and learning and user services' implementation of a screen time policy. The same test showed that services with a smaller teaching team were likely to use tablets 


\subsection{Chapter summary}

This chapter has presented the quantitative results from the national survey, beginning with the demographic data: service type, maximum number of children per service, number of teachers/educators per service, and use/non-use of tablets.

Next, the results of the descriptive statistics analyses of the survey responses were shown beginning with non-user services followed by user services. Non-users' main reason for not using tablets was educational philosophy followed by company or service policy and funding. When asked how they would use tablets if they had one, the foremost response was for documentation and assessment. Most non-users $(97.1 \%)$ would implement formal policies and guidelines for staff regarding tablets. They would prefer to use these devices with groups facilitated by a teacher. Half of non-users that responded to the survey allowed the use of personally-owned tablets. They indicated that a potential barrier to adopting tablets was their preference for traditional practices. More than half of non-users (69.1\%) reported that they would learn how to use tablets through personal use.

User services' responses were shown beginning with the number of children and teachers/educators who used tablets per service. Most user services allowed less than five children to use tablets at one time. The most reported use for tablets was for documentation and assessment followed by playing music and creative activities. More than half of the user services $(69.0 \%)$ had policies and guidelines regarding tablet use. More services preferred that tablets were used in groups and facilitated by a teacher/educator with more than half preferring a fully certificated teacher to monitor children's tablet use. More than half of user services who did not use tablets in the past cited educational philosophy (58.1\%) as their main reason followed by funding (56.3\%).

Using inferential statistics, results from Qualtrics, Microsoft Excel, and SPSS analyses that had significant associations between question pairs were identified. These data involved the use of Chi-Square and Mann-Whitney U tests. Based on Chi-Square analyses results, the results from pairs of questions that showed significant association were service type and tablet use/non-use, non-user services who intended to acquire tablets in the near future, and those who allowed use of 
personal tablets. Additionally, services with/without policies or guidelines for staff on tablet use and service type, and screen time policy and having policies/guidelines for staff also had significant statistical relationships. The Mann-Whitney U test found numerous results with significant associations. The first was between children who could use tablets at non-user services and services allowing use of personal tablets. Secondly, there was a significant relationship between the number of teachers/educators using tablets for teaching and learning and user services' implementation of a screen time policy. The third was between the maximum number of children non-user services were licensed for and whether or not each service had a screen time policy. Finally, the fourth result with a significant association was between the maximum number of teachers/educators at each service and tablet use/non-use.

In the next chapter, I present data from the qualitative phase of this research. Firstly, I outline non-user services' responses to the qualitative question in the national survey. Then, I present Phase 2 results from each of the seven cases beginning with four non-user services and followed by three user services. 


\section{Chapter 5}

\section{Qualitative Results from Non-User Services}

This chapter is the first of two which outline the results from the qualitative data of this study. Here, the case reports for Phase 2A focus group interviews from non-user services are presented.

\subsection{Results explained in the qualitative phase}

The collective case studies undertaken in Phase 2 enabled results from the national survey that needed explanation through further qualitative investigation to be addressed. Firstly, for non-users, the general themes that required further investigation were their reasons for not using tablets, particularly concerning educational philosophy and teachers/educators' preferences towards traditional practices. Non-users' intentions to acquire tablets for teaching and learning and possible barriers that may arise with use also needed further clarification. Nonusers' responses concerning policies and guidelines on tablet use and its relation to screen time policies surrounding digital media use is another theme addressed in this chapter. This theme also included use of personally-owned tablets at their services. These issues were explained in Phase 2A.

\subsection{Phase 2A: Non-user services' collective case study}

The results from four non-users are presented. One non-user service was selected from each of the four service types. I begin this section by discussing the results from the service which used tablets the least and close with a service that initially claimed to be a non-user but recently acquired an iPad to use for documentation.

5.2.1. Non-user kindergarten: Aniwaniwa Kindergarten. The first of the four tablet non-user services, Aniwaniwa Kindergarten's umbrella organisation had two separate kindergartens. The first kindergarten was established in 1993 and the second in 1996. The service's six teachers, who were in their forties to fifties and whose teaching experiences ranged from fourteen to twenty years, had worked at the kindergartens from three to twenty years. For the purposes of this study, both 
kindergartens were considered one service as the teachers all worked as one team under one management.

The kindergartens did not use ICT because they followed the Rudolf Steiner educational philosophy. Thus, there was no digital technology present anywhere in the classrooms and outside play areas of the kindergartens. Teaching and learning focused on the use of natural materials for play.

Five teachers met at one of the kindergartens for the focus group interview which was held on 13 September 2017 (See Table 5.1).

\begin{tabular}{|c|c|}
\hline Pseudonym & Role \\
\hline Aramoana & Provisionally certificated teacher \\
\hline Alice & Fully certificated teacher \\
\hline Arona & Fully certificated teacher \\
\hline Atarangi & Fully certificated teacher \\
\hline Angela & Fully certificated teacher \\
\hline
\end{tabular}

Table 5.1. Non-user kindergarten participants

During their interview, these teachers restated that Aniwaniwa Kindergarten's reasons for not using tablets were based on their educational philosophy. The service limited children's access to digital screen media to avoid technology-related sedentary activities. During the focus group interview, the teachers explained that their foremost reasons for not using tablets or any other type of digital technology for teaching and learning stemmed from their service's special character.

The teachers believed that using tablets for play limited children to a prescriptive or fixed play environment and took away freedom of selection from children. According to the teachers' perceptions, digital technology limited children's imaginations. The teachers observed that children simply imitated adults' use of digital technologies and concluded that children had become used to resources and activities being given to them as opposed to using their own creativity and being resourceful.

The teachers also believed that children's learning should focus on natural play because it supports their neurological and physical development. Angela stated that children, “sitting with their neck down, swiping... aren't helpful to their development" [NU-K/P2A/102-104]. Aramoana illustrated this further: 
...when you compartmentalise learning to just one vehicle of expression, you're losing so much experience and ...it's like we're putting this stuff on the children and so it's not actually ...free play because the adults are defining the premise of how it works whereas if a child, instead of playing a game about farm animals, is swiping and listening to the horse neigh or the dog barking. If they're actually... seeing it, it's such a different experience... it is so different too and it's so tangible, real and balanced. [NU-K/P2A/300306]

To the teaching team, children's natural play with peers supported the development of their communication skills. Teachers explained their perceptions about how tablets affected children's interactions and peer learning. The service's philosophy on peer learning was that "young ones are learning from old ones and... old ones are learning how to look after young ones. And none of that belongs on a small screen" [NU-K/P2A/111-113]. They perceived children had too much access to digital technologies at home and as a result brought certain behaviours into the service. Thus, whilst teachers expected children to play together and interact with teachers and other children, they had observed children walking into things as they held sticks to their ears to imitate adults talking on mobile phones. Arona noted that some children imitated adults using computers during play by putting up pretend cardboard computers and typing on them. When this occurred, she instead encouraged children to play by "building houses...” [NU-K/P2A/373-374].

The service's goal was to provide children with active play opportunities and to teach children to connect with people, animals, and nature. The service often visited locations where they could play in a natural environment without needing toys. At the service location, children were expected to engage in tactile and creative activities through making their own toys. Teachers believed that by not using tablets at their service, children were more creative and imaginative, physically active, and social. They collectively stressed that tablet use led to sedentary activity as they perceived that brain development required constant physical movement. Atarangi exemplified their belief that screen media did not provide children with the learning and development they valued:

It's someone else's imagination. It's on the screen. It's not their picture. They are looking at someone else's picture. But we are hoping to create their own images from stories being told orally... [NU-K/P2A/136-138] 
The service's teaching team believed that social activity was best carried out without using ICT and that when children were mentally present in their education, this led to them creating memorable and joyful learning experiences in connection with people, animals, and the natural environment. The teaching team observed that the four-year-old children experienced learning by being social because the openended and sociocultural environment nurtured their development. However, the teaching team agreed that children's access to and use of digital technology and media at home could make it difficult for them to "be in very different environments throughout the day" [NU-K/P2A/344].

Without technology to facilitate communication, teachers directly engaged in dialogue with children and parents when they made their assessments which they kept in handwritten or printed learning portfolios. A few teachers admitted to taking photos with their personally-owned digital devices such as touchscreen phones to add to their documentation and assessment of children's learning. Alice and Arona, respectively, explained that the service provided parents/whānau literature about their educational philosophy to encourage them to "do a similar thing at home" [NU$\mathrm{K} / \mathrm{P} 2 \mathrm{~A} / 345$ ] and continue "keeping the media for later" [NU-K/P2A/352-354].

In summary, Äniwaniwa Kindergarten's case for not using tablets was based on their educational philosophy. The teachers agreed with their service's educational philosophy on not allowing tablet use. They believed that this policy supported children's cognitive development, fostered creativity, and encouraged imaginative play. This was done through the provision of an ICT-free environment where children could play and create using their physical senses and by being in a natural environment which enabled them to connect with people and animals.

\subsubsection{Non-user home-based service: Ekengia Homecare. This section} presents the case report for the non-user home-based service. This service employed two fully certificated visiting teachers and 30 educators who each provided homebased childcare in their own homes. The visiting teachers' experiences ranged from eight to twenty-one years. One of the visiting teachers was one of the founders and directors of the service whilst the other had been with the service for one year. The teachers'/educators' ages ranged from their late twenties to their fifties. The 
educators' ECE experiences ranged from four to twenty-one years. The educators had a mix of ECE work experience including working as nannies and teaching at kindergartens or education and care services. Along with the two visiting teachers, 10 educators participated in the focus group session as shown in Table 5.2.

\begin{tabular}{|c|c|}
\hline Pseudonym & Role \\
\hline Edna & Fully certificated visiting teacher and co-owner of the service \\
\hline Erina & Fully certificated visiting teacher \\
\hline Ellen & Educator with level 4 ECE qualification \\
\hline Emily & Educator with level 3 ECE qualification \\
\hline Eva & Educator with level 3 ECE qualification \\
\hline Elaine & Educator with level 3 ECE qualification \\
\hline Eunice & Educator with level 3 ECE qualification \\
\hline Etta & Educator with level 3 ECE qualification \\
\hline Erihapeti & Educator with unspecified educational background in ECE \\
\hline Esther & Educator \\
\hline Evelyn & Educator \\
\hline Emma & Educator \\
\hline
\end{tabular}

*Levels 3 and 4 are equivalent to the last two years of secondary schooling in New Zealand. Table 5.2. Non-user home-based service participants.

The service's main educational philosophy was that children should engage in free outdoor play without using digital technology. Thus, children were expected to spend most of their time outdoors. Once a week, educators and their children met with a visiting teacher at an outdoor location, such as a park, a reserve, or a beach. At these locations, the teaching team expected children to engage in physical activities. The teachers perceived that digital technology was prevalent in children's lives and that the service was supporting children's development by limiting their access to and use of ICT and giving them time to go "out to get fresh air" [NHB/P2A/129] and help build up their immune system. Relationships were built with the adults, especially with teachers/educations, and the service emphasised that these relationships could not be replaced by a screen.

The visiting teachers and educators identified that they did not use tablets for teaching and learning due to the service's focus on children interacting with others and the environment around them. Visiting teachers and educators had observed that using tablets led to sedentary behaviours and when these devices were taken from children, they became aggressive. Teachers/educators discussed their views that reliance on tablets impacted on how children learned to socialise, for instance, Ellen argued that children's emotions were being desensitised: 
...because they don't know how to recognise how they feel and things like that, so they can't reach out and tell someone how they are feeling. [NU$\mathrm{HB} / \mathrm{P} 2 \mathrm{~A} / 200-201]$

The teachers/educators believed that tablets and other digital media affected children's development with some suggesting that using tablets did not offer the same level of cognitive development such as like building imagination compared to engaging in physical activity. The teaching team believed that the reduction in physical activities children had in when using iPads was a barrier to children's learning and development. Tablet use did not help children learn how to assess risks or teach children how to climb trees. Elaine observed that when children saw adults use touchscreen devices, the children suddenly stopped what they were doing and wanted to borrow the devices and interact with the screen.

The main concern of the teaching team was that compared to engaging with the digital world, engaging with the natural environment supported children's development. Erina explained her view that tablets influenced children's beliefs so that when children engaged with touchscreen technologies, the digital world became more important to them than engaging in the real world. She noticed this when children talked more about "what app they've got... Or what games their parents bought them..." [NU-HB/P2A/206].

Teachers/educators believed that physical activities supported children's physical development and provided and psychosocial benefits such as self-control, resilience, confidence, and creativity. As the director, Edna explained their service's educational philosophy to parents during enrolment stressing that their service focused on children's outdoor play. Erina explained:

Our service is quite unique, so we have a really particular niche market, our philosophy might not fit with all families. So, that's why Edna has really good conversations with them about what we're all about and getting to know the family and making sure that there is a right fit and so that parents, when they do enrol their children, they know that they will not be sitting in front of a laptop and they will be spending more time outside. [NU-HB/P2A/567572]

The visiting teachers perceived that other ECE services allowed the use of digital technologies, but their service's unique character offered something different to parents and their children. Visiting teachers and educators perceived that children had excessive access to tablets and other screen media at home. Eunice explained: 
I don't use the iPads and things like that because I know they get it a lot from home. I just changed my whole house around with loose parts and my kids [that she cared for] are coming off that part of the screens. It's like they can do other stuff than on screen. [NU-HB/P2A/139-141]

The educators expressed how they felt that it was wrong for tablets and other digital media devices to tell children that they were wrong. Ellen compared how tablets demanded a fixed response compared to free play and argued that "a child is never told they're wrong unlike with these apps on technology" [NU-HB/P2A/147148]. They specified that this way of interacting was contrary to their service's educational philosophy. Furthermore, the teaching team expressed caution regarding children's confidentiality and exposure to inappropriate material. Erina believed that ads that popped up when children used tablets could contain inappropriate content, thus teachers/educators did not want to expose children to these. She perceived that teachers/educators had issues monitoring tablet use because children can "look anything up and that some ads popped up" [NU-HB/P2A/524] because they happened so quickly.

The service allowed the use of personally-owned digital devices, particularly educators' touchscreen phones, for documentation and to play music in the background. Emily explained that she used her phone for documentation in order "to capture an achievement... and I'll write about it" [NU-HB/P2A/465-467]. The teaching team observed that children and their parents/whānau appreciated how tablets made children's learning stories more accessible. Edna explained the service's policy and guidelines on digital media use was that staff could use them as long as children did not engage with digital devices. "Photographs can't be shared through Snapchat and Facebook. We need to monitor confidentiality" [NUHB/P2A/542-543]. Ekengia Homecare limited digital technology use to its teachers/educators with the aim of protecting children's privacy.

Even while the teachers/educators acknowledged the usefulness of using Educa, a learning story app for documentation and assessment, the teaching team expressed concerns with the additional responsibilities necessary when using tablets, such as managing passwords and making sure children did not access these devices to prevent their exposure to inappropriate content. This included role modelling use, making sure that children's confidentiality was maintained, and supporting children's 
outside and social activities. Although the service agreed that using tablets for documentation and administrative work could be convenient, they noted that the Ministry of Education still preferred paper-based documents such as timesheets. As long as children did not have direct contact with tablets, the visiting teachers reported that they used touchscreen devices for professional development by letting the teaching team "watch something on YouTube" [NU-HB/P2A/406].

To summarise, Ekengia Homecare's teachers/educators believed that using tablets hindered children's interaction with people and places. At enrolment, visiting teachers explained their service's educational philosophy to parents. Although the service allowed personal use of touchscreen devices such as mobile phones, use was limited to documentation and for playing music in the background. The service only used their touchscreen devices for professional development of teachers/educators and for purposes that did not involve a child directly engaging with these devices. Because the service allowed limited personal use of touchscreen devices, Ekengia Homecare is a non-user service that limited teachers'/educators' access but did not allow children to have access to tablets. In the next section, the non-user education and care service's focus group interview results are presented.

\subsubsection{Non-user education and care service: Hūmārietanga Childcare.}

This service was established in 2009 and operated in a suburb within a medium-sized city. The centre employed six teachers whose experiences ranged from one to sixteen years at other services and one to eight years work experience at Hümārietanga Childcare. The teachers were all in their thirties or forties. Three teachers were provisionally certificated whilst the rest were fully certificated. The head teacher had owned the centre- one of three private education and care services - since 2009. Hümārietanga Childcare employed four additional staff for administration, resource teaching, and other roles such as IT or technical support. Five teachers participated in the focus group interview (See Table 5.3) held on 9 June 2017. Analyses of the transcript showed that fully certificated teachers (Harriet, Hinewai and Huihana) contributed significantly more to the discussion. 


\begin{tabular}{|c|c|}
\hline Pseudonym & Role \\
\hline Harriet & Fully certificated teacher \\
\hline Hinewai & Fully certificated teacher, head teacher and service owner \\
\hline Hermione & Provisionally certificated teacher \\
\hline Huihana & Fully certificated teacher \\
\hline Haeata & Provisionally certificated teacher (left during the interview) \\
\hline
\end{tabular}

\section{Table 5.3 Non-user education and care service participants.}

As the head teacher and service owner, Hinewai explained that their main reason for not using tablets was financial and she repeated this point seven times. Hinewai explained that, added to the lack of funding in their budget, Hümärietanga Childcare was a private service and thus could not apply for grants. Although the service did not use tablets, there were other ICTs available to support children's learning. Harriet emphasised this whilst pointing to the video projector screen in the room which the teachers used to watch videos and play music in the background. The service allowed teachers to use their personal touchscreen devices-particularly their touchscreen mobile phones, for playing music and letting children watch videos. The teachers who used their own personal touchscreen devices admitted to using their own internet data allowances on their own mobile devices to support children's learning. Huihana reported that she let children use her phone to play educational games:

To help them load up apps for writing with their finger. And we'd play games, maths games, spelling... to introduce letters and words that went with our theme for the week, like we'd have focus letters of the alphabet... As long as it linked to what we were doing in our curriculum. [E\&C/P2A/79-83]

Teachers' engagement in the interview led them to consider how they might incorporate the use of iPads in their centre beginning with using Hinewai's personally-owned iPad. The teaching team concurred that using iPads could benefit children overall, stating that children were already knowledgeable about iPads and similar digital technology because "technology is where we're at..." [NU$\mathrm{E} \& \mathrm{C} / \mathrm{P} 2 \mathrm{~A} / 165]$. Huihana supported this reasoning by asserting that children will "definitely be using it after ECE to primary school" [NU-E\&C/P2A/166]. Hinewai specified the ages of the children that should use the device, "It'll be the older kids. It'll be the three-and-a-half and the four-year-olds..." [NU-E\&C/P2A/519-520]. In consideration of her team's perceptions on tablet use, Hinewai offered to use her iPad in small groups of children in the service's transition group: 
I could actually bring my iPad in... And we could probably trial it with the transition class. We've got guys here in our admin area who are really good with IT, so they could probably come [and help]. [NU-E\&C/P2A/237-241]

During the interview, the teaching team decided to develop a policy around using this iPad for their transition group with Hinewai stating, "We have to prepare a set of procedures on how to use this" [NU-E\&C/P2A/369-370]. Their discussion about developing this policy involved supervision including teaching and modelling self-regulation and cybersafety, screen time limits, a self-review on how to integrate iPad use with their transition group, and to survey parents. Teachers agreed to closely supervise the children who would use Hinewai's iPad. They planned to use the tablet in small groups with "one teacher sitting with three children" [NUE\&C/P2A/302-309]. Supervision should include teaching children how to selfregulate their tablet use as Hinewai understood that monitoring digital media use at all times was not feasible. They decided that this potential issue could be mitigated by setting a screen time limit of up to an hour daily and figuring out how to use the tablet's technical features to limit children's access such as limiting children's app and internet use.

The teachers planned to explain to the children that iPads are expensive and to teach children how to take care of it. A part of this was supporting children in managing their own iPad use because the teachers felt introducing the device would teach self-discipline. The teaching team brought up their concerns over addiction to digital technology and related digital media and altogether agreed that balancing access to and use of this iPad was necessary. Thus, the team agreed to "use it as a resource to engage children in meaningful experiences and not just something to use to occupy their time or something for them to watch a movie..." [NU-E\&C/P2A/6878]. Teachers believed it was important to role model and closely supervise children's tablet use to prevent other related issues such as sedentary activity and effects on children's eyesight and neurological development. Hinewai set the following expectations:

...if we know how to use the iPads in a really positive way, we can use that as a powerful means of supporting our children's learning. We shouldn't just use it as, "Okay, let's just keep them quiet. Put them in front and put a movie on". And I think, it's gotta be used appropriately so children can learn, and a learning tool for teachers too. [NU-E\&C/P2A/158-163] 
As part of considering how they might introduce tablets to children, teachers discussed how they could support early mathematics and literacy through educational games. The teaching team thought that using iPads on rainy days would be the most beneficial use of time because they preferred that children engage in physically active play outdoors when the weather was fine. Huihana reported that they could use the iPad to help children's development of:

...cognitive skills, their hand and eye coordination for writing. That's just a different way of learning how to write. Introducing how it goes with their hands and movements which is the same with crayons. It's just another tool... [NU-E\&C/P2A/146-148].

The teachers recalled their personal experiences of how they learned to use ICT, usually through hands-on experience for school or work. They planned to collaborate with the service's IT support staff to help the teaching team.

Teachers/educators were expected to learn about tablets from each other. The team also discussed the possible acquisition of more iPads. Hermione suggested, "We could use our own iPads and bring it in" [NU-E\&C/P2A/497]. Huihana added they could acquire more iPads for the service through "fundraising" [NU-E\&C/P2A/494495].

Whilst members of the team seemed relatively comfortable in using tablets for the transition class, they expressed hesitation in using tablets for younger children. Hinewai believed that tablets could impact children's health.

Personally, I don't feel comfortable about watching the under twos... But when I see young kids with those kinds of apparatuses, I always worry about what's happening, you know, with their vision... [NU-E\&C/P2A/359-362]

Some of the teachers reported a lack of confidence and knowledge in using tablets. Hinewai perceived that "The older ladies [teachers] wouldn't even touch the iPad" [NU-E\&C/P2A/273-274]. Harriet and Hinewai believed that this lack of confidence stemmed from a lack of "knowhow" [NU-E\&C/P2A/277-278]. Harriet explained that not using tablets encouraged children to "go outside and enjoy the sunshine... which is a good thing" [NU-E\&C/P2A/49-51]. This discussion led to the teachers expressing their need for professional development in using iPads and their apps such as learning story apps. Harriet explained that having professional development training about iPads could help the team gain "knowledge of how they can be a disadvantage to their learning and things like that" [NU-E\&C/P2A/43-44]. 
Later in the discussion, Hinewai asserted that the iPads "can be used as a very positive resource and also if teachers know how to use it" [NU-E\&C/P2A/126-127].

Finally, the team thought it was important to survey parents before trialing tablet use with their transition class. Hinewai believed that the survey "is important. ...because they might not want their children to have these" [NU-E\&C/P2A/424425]. The teachers wanted to make sure that parents were comfortable with their plan and the policies they would set up before trialing the iPad. They accepted this additional responsibility as they understood that the availability of digital technologies had changed their roles and responsibilities concerning the teaching and learning of young children.

The data from Hümärietanga Childcare showed that whilst the service did not use tablets, their discussion on the use of these devices in the focus group interview led to the teaching team considered a trialled use. The service had ICT facilities available for children's use but due to the owner's concern over the cost of purchasing a tablet, they did not use one at the service. Instead, teachers used their own personal touchscreen devices and the service's screen projector rather informally and haphazardly to play games, listen to music or watch videos with children. During the focus group interview, the teachers agreed to trial using an iPad for the three- to four-year old children in their transition class with a teacher closely supervising use in small groups. The service owner stressed that her iPad should be used for specific learning purposes.

5.2.4. Non-user playcentre: Iorangi Playcentre. This service was one of 20 parent-led playcentres administered by a local association. There was a total of 30 parents volunteering at the playcentre with their ages ranging from their twenties to their fifties. These parents had been undertaking volunteer work as educators from one term to twenty years at the playcentre. As educators, parents were required by the New Zealand Playcentre Federation to complete three of six courses about playcentre from the Playcentre Diploma in Early Childhood and Adult Education. A minimum of four parents who had completed up to course three was required to form the core leadership team. Table 5.4 shows the number of parents who had completed or were working on courses. 


\begin{tabular}{|c|c|c|}
\hline Course & Number of completions & Number of enrollees \\
\hline 1 & 7 & 4 \\
\hline 2 & 5 & 4 \\
\hline 3 & 4 & - \\
\hline Total & 16 & 8 \\
\hline
\end{tabular}

Table 5.4. List of course completions at the non-user playcentre.

The focus group interview was held on 14 June 2017 at the playcentre. Two days prior to the interview, the playcentre received one iPad from their Playcentre Association for documenting occupational safety and health. The local name for this was called "GOSH" to stand for "good occupational safety and health" as its slogan was "Gosh it's easy!". Because the service originally did not intend to own a tablet this recent acquisition necessitated a discussion about the policy and parameters for its use, including within the focus group interview. Table 5.5 details the focus group participants who also part of the core leadership of Iorangi Playcentre.

\begin{tabular}{|c|c|}
\hline Pseudonym & Role \\
\hline Ihāpera & Co-president with ECE teaching background, completed Course 3 \\
\hline Isabel & Rolls and Roster officer, completed Course 3 \\
\hline Irene & Health and Safety officer, working on Course 2 \\
\hline Inia & Bicultural officer, completed Course 1 \\
\hline
\end{tabular}

Table 5.5. Non-user playcentre participants.

According to the core leadership team, the playcentre did not use tablets because they felt these devices would distract children and disrupt activities. Ihāpera explained that the playcentre focused on children's "natural and spontaneous play" [NU-P/P2A/16-19] and having tablets and other screen media would contradict this educational philosophy. The playcentre's aim for educating young children was to provide them with real-life experiences. Ihāpera explained that they:

\begin{abstract}
...really want to stick to the real sensory, nitty-gritty... real life touching and interacting as opposed to using a screen... I guess that's not playcentre philosophy for us to be introducing that kind of thing and that's why we congregate to get some feedback here. I think we really do come up with those shared philosophies. And someone who wanted to be integrating, bringing an iPad into children's learning would probably be, actively be, discouraged. [NU-P/P2A/368-373]
\end{abstract}

The playcentre preferred "to spend money on other things than the iPad" [NU-P/P2A/103]. The playcentre allowed parents/educators to use their personal digital devices, usually their own touchscreen phones, to take photos and document children's learning and activities. However, the educators felt that when children saw phones brought out, they became distracted and their activities were disrupted. 
Isabel noted that the novelty of touchscreen phones distracted children from their work as they would stop what they were doing when the educators "take a photo or a video...so, that moment is lost" [NU-P/P2A/386-387]. They discussed the possibility of designating the $\mathrm{Pad}$ as the tool for documentation and discouraging use of personal touchscreen devices. The leaders discussed the features of the iPad and found it more suitable for documentation as it would capture the details without repetitive "rewinding and playing" [NU-P/P2A/517]. They reported using digital cameras prior to switching to using touchscreen phones because of the latter's convenience. Ihāpera explained their hesitation in using the playcentre's new iPad as children:

...would stop what they were doing and want to come and see the photos... I wonder if having an iPad out is going to be so much of a focus for them. [NU$\mathrm{P} / \mathrm{P} 2 \mathrm{~A} / 72-74]$

Educators perceived that tablet use impacted children's learning and development. Ihāpera believed that digital media did not teach children how to comprehend other senses such as taste. Furthermore, it made reality and "everyday interactions boring" [NU-P/P2A/754-755]. To Isabel, the digital features of interactive stories could distract children from deeply understanding the story.

And from what I've read as well, like an interactive story like they have on ebooks and e-learning, when you press like a sound or a cat comes up and talks to you, apparently, from evidence was that's more distracting to the child. They actually don't learn from the story. They'd learn a lot more and understand and get more from the story if you're just reading it aloud and if it wasn't moving and talking to you and having all these distractions. Because that's still starting out new... building neural pathways... Well, even me, I get distracted by those things as well. If I read, if I look at it again and there're too many sounds, and pop-ups... [NU-P/P2/286-294]

Iorangi Playcentre's educational philosophy involved technology-free play, but with a new iPad available, educators understood the need to explain to children, parents, and other educators how the device would be used. The core leadership team wanted to uphold the playcentre's ethos of teaching self-sufficiency and creativity to children by using open-ended resources and imagination, both of which the educators perceived the tablet could not provide sufficiently. They acknowledged that digital devices and screen media were common place in society and children's homes. Ihāpera perceived that parents' use of personally-owned touchscreen phones could impact children's privacy: 
If I use my personal phone for taking photos of children at the centre, then I'm potentially walking out in public with these photos and what happens when these photos go out there, for instance... that's also one of our concerns. [NU-P/P2/92-94]

The educators believed that limiting documentation to the service's iPad could resolve this issue and maintain children's privacy. To them, children were unlikely to miss out by not having comprehensive use of the iPad as they observed that children had access to tablets and similar digital technologies at home. Because tablets were ubiquitous in society due to their ease-of-use, the educators believed that children could easily learn how to use iPads at a later time. The core leadership team perceived that introducing tablets to children could lead to behavioural issues such as children expressing frustration when they were asked to stop using the iPad and expressing boredom when they had spent a long time not using the device. Ihāpera compared digital technology to "flavor enhancements with food" [NU-P/P2A/753] because when children became used to tablets, they no longer enjoyed real sensory experiences. Another issue the educators wanted to address was children aged twoyears-old and younger accessing and using iPads. The core leadership team referred to research that reported the negative impacts of tablet use by this age group.

Therefore, educators planned to inform children that the iPad was going to be used for documentation for health and safety purposes only. Irene suggested that children should be informed that their iPad only for "boring adult stuff” [NU-P/P2A/380]. Ihāpera gave a scenario on how educators could reply when children ask to use their iPad:

Then we have a bunch of kids coming... "Oh! Can we do something...?" We have to have a unified response for that... "No, this is only for GOSH." [NU$\mathrm{P} / \mathrm{P} 2 / 399-400]$

In the interview, educators were undecided if they would allow children to look at photos on the iPad. They perceived that compared to the small screen size of touchscreen mobile phones and the potential issue of parents sharing photos beyond the playcentre, having a dedicated iPad with its bigger screen for taking and viewing photos would be much safer. Educators explained that the bigger screen size could be useful for group discussion.

Ihāpera asserted that their new iPad should replace educators' use of personally-owned mobile phones, recalling many instances when children became 
distracted when educators were using their personal phones. One example she recalled was when a child behaved negatively and disrupted play activities because that child saw Inia bring out her touchscreen phone and wanted to play with it. Ihāpera expected that educators could discuss how the use of their iPad would be implemented at Iorangi Playcentre, that there would be:

... some really fine lines in terms of what's okay and what's not... And I think we're probably gonna find ourselves having some quite animated discussions just on where that line does sit... because, we're always looking at photos together on our phones... and to be looking at them on the iPad... Yeah, it'll be interesting to see where we go with it... [NU-P/P2A/596-602]

The educators discussed how some apps could be used with children and how to select legitimately educational apps. However, Ihāpera asserted that the ethos of Iorangi Playcentre was centred on creative, non-digital play for children to understand the difference between digital and real-world skills. Ihāpera felt that the iPad and its apps should not be used with children because the main intention for using their newly acquired tablet was:

...for taking photos, writing stories, doing GOSH. That is how I envision it as a tool instead of paper, not like doing apps or anything like that... [NU$\mathrm{P} / \mathrm{P} 2 \mathrm{~A} / 334-336]$

The leadership team discussed issues surrounding adults' use of digital technologies. They brought up issues regarding social media, especially about "people posting things on their own Facebook page" [NU-P/P2A/121]. Due to the prevalence of digital technology in people's daily lives, the team understood that many were unaware of the risks in using these technologies. They considered this as a barrier to tablet use. Ihāpera explained how she had realized the addictive nature of social media and her need to curb its use and simply focus on using it for communication. She realized that she "had to take some personal steps back and check the Facebook page once every couple of days ... because that's one of our main points of communication" [NU-P/P2A/164-167]. Irene agreed saying, "If the adults are gonna use it, then they're not allowed to play games either" [NUP/P2A/384-385]. Ihāpera considered the idea of using the iPad for observations when her fellow educators began discussing how their new iPad could improve documentation and assessment through video-recording children and making movies from collected photos: 
Ihāpera: ...you do get more understanding than from a photo... Each person can interpret that video. I think that's quite an interesting... Inia: That sort of lens from someone....

Ihāpera: Because everybody can see different perspectives from a photo. However, from a movie... It's the children telling a story, perhaps...

Irene: Yeah.

Ihāpera: It becomes their voice, in a way. [NU-P/P2A/549-553]

Educators further discussed how they could easily refer to previous documentation through the iPad's big screen and have group discussions about the photos/videos. Inia asserted that using the iPad to show children their learning stories and then "get them to comment on it or ...do the captions for it" [NU$\mathrm{P} / \mathrm{P} 2 \mathrm{~A} / 554-555]$ would be one of the ways she thought the tablets could be used with children. The educators talked about the importance of giving children the opportunity to add their own voices in their assessments. Ihāpera and Inia gave a detailed explanation:

Ihāpera: It's really interesting to hear children's perspective... There are different styles of observation and one of them is a child's voice. One of them is a whānau voice. Another is... a learning story, another one is... you can caption photos. Children's voices are really valuable too.

Inia: ...get some insight.

Ihāpera: Yeah... what they were actually doing and what their purpose was... [NU-P/P2A/570-576]

Ihāpera reminded the core leadership team that letting children use the iPad would bring additional responsibilities for which the service might not be prepared. These additional considerations to educators' roles involved monitoring appropriate content when children viewed videos, knowing how to evaluate and select educational apps, and the development of a privacy policy to be "attached to the enrolment forms" [NU-P/P2A/223].

The core leadership acknowledged that guidelines for iPad use would not be just limited to children but also include adults visiting their service as well as parents and whānau. They agreed that they "need to have consensus on what's it for and what it's not for, who uses it, where we keep it during the session" [NU-P/P2A/449482] from the playcentre's other educators, parents, and adult whānau. The team decided to make an announcement in a meeting stating that with "having received our new iPad... we are wondering how we're going to... and what kind of 
boundaries and set of rules we're gonna but in place" [NU-P/P2A/179-181]. Ihāpera suggested they could consult with other playcentres and the local playcentre association on how to set practical boundaries for tablet use. This could include adopting policy and guidelines from Inia's previous playcentre. The development of a policy surrounding tablet use for adults alone were ideas emerging from the discussion "as what was decided ... will be our draft... and then we'll evaluate it in four months' or six months' time" [NU-P/P2A/706-707]. This discussion around policy helped the core leadership consider guidelines regarding the playcentre's Facebook account to allow parents who did not wish to join the group to "opt out if they so choose" [NU-P/P2A/147]. The team acknowledged that once the policy document was decided upon by the wider Playcentre membership, it would still be a fluid document that would need to adapt to changes in contexts.

To summarise, Iorangi Playcentre adhered to their educational philosophy on digital technology-free play. However, having recently acquired an iPad from their local playcentre association prior to the focus group interview, educators thought about adopting guidelines from previous playcentres participants had been involved in for use at Iorangi Playcentre. Their local playcentre association wanted the playcentre to use the iPad for documenting health and safety issues, but the educators also decided to use it to document children's learning because of its portability, bigger screen, and video-recording functionality. Educators perceived that using their service-owned iPad was safer compared to allowing parents to use their personally-owned mobile phones for documentation. Educators recognised the need to consult with children, parents/whānau and educators about the new iPad and how it would be used within the playcentre. The core leadership team intended to consult with their playcentre association and with other local playcentres to inform and update their related policies on confidentiality, cybersafety, and the extent to which children could use the iPad with the educators. Owning an iPad and considering its use to support children's learning through documentation and assessment no longer categorised Iorangi Playcentre as a non-user service because its educators plan to use its tablet for specific purposes. 


\subsection{Chapter summary}

This chapter has presented the qualitative results collected from non-user services in Phase 2. From the four non-user services that participated, Aniwaniwa Kindergarten and Ekengia Homecare explained that their educational philosophy was the main reason for not using tablets at their services. These users limited tablet use and thus were assigned to the limited group. As for Hümārietanga Childcare, the service decided to trial iPad use with older children to prepare them for their transition to primary schooling. Educators at Iorangi Playcentre did not have any plans to use tablets but they reconsidered this when their local playcentre association had just provided them with an iPad for documenting health and safety. During the focus group interview, the core leadership team also planned to include documenting children's learning and events at their service using the same iPad.

Teachers/educators at Hūmārietanga Childcare and Iorangi Playcentre decided to develop policies and guidelines on iPad use. There is a shift in tablet use by some services. Those who identified themselves as non-users in the survey engaged in discussion about possible use of tablets. The focus group interviews influenced the thinking of teachers/educators about whether to use or not use tablets.

The qualitative results from the non-user service cases presented in this chapter have explained the national survey's quantitative results in relation to the reasons for not using tablets, the purposes tablets were used-particularly documentation and assessment, how young children's tablet use was scaffolded and by whom, and finally whether services had policies and guidelines for staff involving tablet use and screen time. The next chapter discusses qualitative results from userservices collected from both Phases 1 and 2 of the study. 


\section{Chapter 6}

\section{Qualitative Results from User Services}

This chapter outlines the qualitative results focusing on user services. Firstly, I present the qualitative results from the national survey which asked user services how tablets were used for teaching and learning. Their responses were grouped into categories according to each service type. Based on these results, how teachers/educators used tablets for teaching and learning also needed further investigation through video-SR sessions in Phase 2B. Qualitative data collected from Phase 2 is intended to explain and confirm the responses to the survey based on actual cases. The user services' case reports include results from the focus group interviews in Phase 2A and video-SR focus group interviews in Phase 2B. Finally, I close with a chapter summary.

\subsection{Phase 1: User services' qualitative results}

This section presents the qualitative survey results regarding how teachers/educators from user services supported children's learning using tablets. There were 143 services who gave qualitative responses in response to this question and these were coded into categories. Not included in Table 6.1 were responses from 10 education and care services, one home-based service, two kindergartens and five playcentres who indicated that, although the service used tablets, they did not let children use tablets. Of interest was that all the playcentres who responded to this question indicated that they did not use tablets with children. 


\begin{tabular}{|l|c|c|c|c|c|c|c|}
\hline \multicolumn{1}{|c|}{ Categories } & $\begin{array}{c}\text { Total } \\
\text { responses } \\
\text { by service }\end{array}$ & \multicolumn{2}{|c|}{$\begin{array}{c}\text { Education } \\
\text { and care }\end{array}$} & \multicolumn{2}{|c|}{$\begin{array}{c}\text { Home- } \\
\text { based }\end{array}$} & \multicolumn{2}{|c|}{ Kindergarten } \\
\cline { 2 - 10 } & $\mathbf{N}$ & $\mathbf{n}$ & $\%$ & $\mathbf{n}$ & $\%$ & $\mathbf{n}$ & $\%$ \\
\hline $\begin{array}{l}\text { Research and extending } \\
\text { children's interests }\end{array}$ & 82 & 58 & 70.7 & 2 & 2.4 & 22 & 26.8 \\
\hline $\begin{array}{l}\text { Facilitating children's use } \\
\text { and access to tablets }\end{array}$ & 81 & 53 & 65.4 & 3 & 3.7 & 25 & 30.9 \\
\hline Supporting learning through apps & 49 & 27 & 55.1 & & & 22 & 44.9 \\
\hline Assessment and documentation & 48 & 29 & 60.4 & 1 & 2.1 & 18 & 37.5 \\
\hline $\begin{array}{l}\text { Listening to music or watching } \\
\text { videos }\end{array}$ & 38 & 24 & 63.2 & 1 & 2.6 & 13 & 34.2 \\
\hline Use with groups of children & 24 & 13 & 54.2 & & & 11 & 45.8 \\
\hline $\begin{array}{l}\text { Implementing policies or } \\
\text { guidelines on touchscreen } \\
\text { tablet use }\end{array}$ & 12 & 7 & 58.3 & & & 5 & 45.8 \\
\hline $\begin{array}{l}\text { Communicating with parents, } \\
\text { whānau and other teachers }\end{array}$ & 11 & 7 & 63.6 & & & 4 & 36.4 \\
\hline Screen time limit & 9 & 4 & 44.4 & & & 5 & 55.6 \\
\hline Use as a planning tool & 8 & 8 & 100.0 & & & & \\
\hline Use for settling children & 5 & 4 & 80.0 & & & 1 & 20.0 \\
\hline $\begin{array}{l}\text { Children can use without a } \\
\text { teacher/educator }\end{array}$ & 2 & 1 & 50.0 & & & 1 & 50.0 \\
\hline
\end{tabular}

Table 6.1. How teachers/educators supported children's tablet use.

The most frequently occurring categories were teachers/educators using tablets for research and extending children's interests $(\mathrm{E} \& \mathrm{C}=58, \mathrm{HB}=2, \mathrm{~K}=22)$ and facilitating children's use and access to tablets $(\mathrm{E} \& \mathrm{C}=53, \mathrm{HB}=3, \mathrm{~K}=25)$. With regards to using tablets for research and extending interests, $17(\mathrm{E} \& \mathrm{C}=11, \mathrm{HB}=1$, $\mathrm{K}=6)$ of the 82 responses specified researching to extend "children's interests" [U$\mathrm{E} \& \mathrm{C} / \mathrm{P} 1 / 232]$. A service specified that their "teachers lead research into interests of children" [U-E\&C/P1/293]. Additionally, five services $(\mathrm{E} \& \mathrm{C}=3, \mathrm{~K}=2)$ reported related responses such as extending children's learning, activities, interests, or experiences. A kindergarten responded, "The iPads are used as a tool to extend learning through reflection" [U-K/P1/317]. There were 77 services $(\mathrm{E} \& \mathrm{C}=55$, $\mathrm{HB}=2, \mathrm{~K}=20$ ) that reported using tablets for research, searching for photos/videos or looking up information. A service reported that they:

...use it to research things of interest with the children... we found a cockroach and we looked up on the iPad to see what it ate and if it would cause harm to the children .... and what type of cockroach it was. [U$\mathrm{E} \& \mathrm{C} / \mathrm{P} 1 / 219]$

Within the category of facilitating children's use and access to tablets, respondents described how they supervised or monitored children's tablet use (34 
services: $\mathrm{E} \& \mathrm{C}=26, \mathrm{HB}=2, \mathrm{~K}=6$ ). One service stated, "Our children are always monitored by a teacher" [U-E\&C/P1/190]. Other respondents described using a range of teaching strategies to facilitate tablet use including collaboration, scaffolding, role modelling, managing children's tablets/internet access, selecting apps children could use, and facilitating turn-taking. Nine services $(E \& C=3, K=6)$ reported collaborating or "working alongside" children [U-K/P1/296], for example, "We use them in collaborative practice — discussion with children" [U-E\&C/P1/278]. Eight services ( $E \& C=4, \mathrm{HB}=1, \mathrm{~K}=3$ ) specified scaffolding tablet use: one responded, "We sit alongside them to scaffold skills and correct use" [U-E\&C/P1/207].

From the nine services that indicated role modelling $(\mathrm{E} \& \mathrm{C}=6, \mathrm{~K}=3)$, one responded that they worked alongside children to "role model basic skills" [U$\mathrm{K} / \mathrm{P} 1 / 305]$. Of the services who indicated that they select apps for children to use $(\mathrm{E} \& \mathrm{C}=4, \mathrm{~K}=1)$, one explained this was done, "by choosing the content and working with children" [U-E\&C/P1/208]. Nine services indicated that they facilitated app use through turn-taking $(\mathrm{E} \& \mathrm{C}=4, \mathrm{~K}=5)$, with one responding that they used, "visuals/timers for those children who require this to learn about turn-taking and how to finish" [U-K/P1/294]. Six education and care services indicated other ways they supported children's tablet use such as encouraging use and making tablets readily available. However, one service indicated that they restricted children's tablet access by "storing them out of reach of children" [U-E\&C/P1/201].

Several other sub-categories which occurred less frequently were also identified. These were supporting learning $(\mathrm{E} \& \mathrm{C}=19, \mathrm{~K}=22)$ which involved using creativity apps $(\mathrm{E} \& \mathrm{C}=6, \mathrm{~K}=5)$, literacy apps $(\mathrm{E} \& \mathrm{C}=6, \mathrm{~K}=10)$, and general educational games and apps $(\mathrm{E} \& \mathrm{C}=7, \mathrm{~K}=7)$. Creativity apps included art apps and related picture/moviemaking apps. One service explained how they supported children through creative apps, "We purposefully teach skills, so they develop the expertise to lead this (i.e. take photos, make movies)" [U-E\&C/P1/204]. Using literacy apps involved creating books, listening to stories or using story-telling apps and interactive books. Some services explained how they supported literacy using tablets through dictation and writing apps, for example, "For letter recognition we might spell a word aloud or write it down for a child to copy" [U-E\&C/P1/253]. 
Services that described using apps in general indicated using a range of apps such as educational games, learning apps, and interactive apps.

Assessment and documentation $(\mathrm{E} \& \mathrm{C}=28, \mathrm{HB}=1, \mathrm{~K}=18)$ were often stated as separate tablet activities. Eight services $(\mathrm{E} \& \mathrm{C}=5, \mathrm{~K}=3)$ that used tablets for assessment reported using them for learning stories, online portfolios or learning story apps, with one explaining that "They use it to access Storypark to show children their stories" [U-K/P1/303]. Documentation $(\mathrm{E} \& \mathrm{C}=23, \mathrm{HB}=1, \mathrm{~K}=15)$ involved taking photos and videos of events and activities involving children, for instance one service mostly used "them to document learning through photos and videos... We teach children to take photos to document their own learning for revisiting" [U-K/P1/305].

Eight education and care services stated they used tablets as a planning tool. One wrote that "Kaiako use the tablets to complete assessment and planning" [U$\mathrm{E} \& \mathrm{C} / \mathrm{P} 1 / 195]$. In addition to using tablets for documenting learning, several respondents $(\mathrm{EC}=7, \mathrm{~K}=4)$ reported using tablets to communicate information about children's learning. For example, one service indicated, "We have recently started using Educa as an online tool for communicating with parents" [U-E\&C/P1/223]. For another service, iPads were, "not toys, they are communication devices to support children's blogs, the centre blog, and children's research projects" [U$\mathrm{E} \& \mathrm{C} / \mathrm{P} 1 / 193]$.

The category listening to music or watching videos $(\mathrm{E} \& \mathrm{C}=25, \mathrm{HB}=1, \mathrm{~K}=13)$ included playing music to groups of children using tablets. Teachers/educators would play music videos for children to dance with or sing to during mat time or as background music. One service specified, "We use the Samsung tablet and Boom Box for mat times and attach the Data Show Projector to iPads for some children to view activities" [U-E\&C/P1/276].

The category use with groups of children $(\mathrm{E} \& \mathrm{C}=12, \mathrm{~K}=11)$ had subcategories which included group use with a teacher/educator $(\mathrm{E} \& \mathrm{C}=9, \mathrm{~K}=5)$ or with other more experienced/confident children $(\mathrm{E} \& \mathrm{C}=4, \mathrm{~K}=6)$, with an education and care service stating, "Sometimes it is used for children working in small groups with a teacher on a specific child-led project" [U-E\&C/P1/186]. Services allowed collaborative tablet 
use amongst children led by more confident or experienced peers. A service described their system that they called "iPad Buddies - using other children who have confidence to find their way around the iPad" [U-E\&C/P1/243] whilst another explained that they "use more experienced children to support the less experienced" [U-K/P1/306].

In Table 6.1, between two and 12 services responded to the question about the ways they supported children's learning. These responses were coded to each of the last six categories. Of interest was that none of the home-based services' responses were coded to any of these six categories. In responding to the question of how services supported children's tablet use, some respondents explained their policies and guidelines on using tablet use for teaching and learning $(\mathrm{E} \& \mathrm{C}=7, \mathrm{~K}=5)$. Teachers/educators $(\mathrm{E} \& \mathrm{C}=2)$ stated they had rules on how tablets could be used with one noting that they reiterated "rules about safety and cybersafety" [U-E\&C/P1/189]. Policies/guidelines for access included teachers/educators' roles as gatekeepers, for example "Internet is accessible, with the safety net in place... We have a policy for the use of the internet and interactive white board" [U-K/P1/295]. Another service noted that using passwords discouraged children from independent tablet use, whilst another stated, "We are currently working on creating a policy and reviewing our iPad use with children" [U-K/P1/290].

Few services used tablets for settling children $(E \& C=4, K=1)$. One stated that "Educators have used tablets as a settling mechanism for new children" [UE\&C/P1/227]. Another explained how they settled children by imitating how children used tablets at home, "We use them as a settling in tool with familiar apps or videos from home" [U-E\&C/P1/207]. Of note was that only two services used tablets without teacher/educator facilitation $(\mathrm{E} \& \mathrm{C}=1, \mathrm{~K}=1)$. Both services emphasised that they encouraged children's independent use of tablets.

The qualitative survey responses of how user services supported children's learning using tablets were discussed in this section. The most prominent categories were facilitating use and access of tablets and using them for research and extending children's interests. Next, the collective case study from user services are presented. 


\subsection{Phase 2: User services' collective case study}

This section presents data collected from three services that participated in Phases 2A-semi-structured focus group interviews, and 2B-video-SR sessions discussing video-recorded episodes of teachers'/educators' tablet use. Amongst the user-services that expressed their willingness to participate in Phase 2, four userservices were invited but the only tablet user playcentre withdrew from participating in Phase 2 prior to data collection. Two services had changes in participants between sub-phases due to the availability of some teachers/educators and these are indicated in their respective case reports. I begin with Koanga Wākāinga Homebased which used tablets in specialised ways.

6.2.1. User home-based service: Koanga Wākäinga Homebased. This user home-based service employed two visiting teachers, with each visiting teacher overseeing up to 10 educators. The visiting teachers' ECE experiences ranged from seven to fifteen years. The service had been operating for ten years and both visiting teachers managed it as directors since acquiring ownership in 2015. The visiting teachers were fully certificated early childhood teachers. The service had 17 educators who provided home-based care and education. The teachers' and educators' ages ranged from their late twenties to their fifties and they had ECE experiences ranging from six to twenty years such as working as nannies or through teaching in education and care services. Both visiting teachers and two educators used tablets for teaching and learning. Table 6.2 shows the pseudonyms and background information of the interviewees.

\begin{tabular}{|c|c|c|}
\hline Pseudonym & Role & Participation \\
\hline Kahikatea & Visiting teacher and co-owner of the service & Phases 2A \& 2B \\
\hline Kahukura & Visiting teacher and co-owner of the service & Phases 2A \& 2B \\
\hline Kauri & Educator & Phases 2A \& 2B \\
\hline Katarine & Educator & Phases 2A \& 2B \\
\hline
\end{tabular}

\section{Table 6.2. User home-based service participants.}

The Phase 2A focus group interview was held on 21 August 2017 and videorecording of tablet use at the service was carried out on 22 and 23 August 2017. The Phase 2B video-SR interview was undertaken on 23 August 2017 immediately after the final video-recording. There were eight video-recorded episodes shown in the Phase 2B interview (See Table 6.3). Two of four children who went to Katarine's 
home used her Samsung tablet whilst two of four children who went to Kauri's home used her iPad.

\begin{tabular}{|c|c|c|}
\hline \multicolumn{2}{|r|}{ Participants } & Description \\
\hline 1 & $\begin{array}{l}\text { Kauri and two boys (Kereti } \\
\text { and Keith) }\end{array}$ & $\begin{array}{l}\text { Kereti and Keith taking turns using a writing app with } \\
\text { Kauri monitoring their use. }\end{array}$ \\
\hline 2 & $\begin{array}{l}\text { Katarine and two girls } \\
\text { (Krissy and Kathy) }\end{array}$ & $\begin{array}{l}\text { Krissy and Kathy taking turns using a writing app } \\
\text { using Kahikatea's stylus with Katarine monitoring } \\
\text { them. }\end{array}$ \\
\hline 3 & $\begin{array}{l}\text { Kahikatea and two boys } \\
\text { (Kereti and Keith) }\end{array}$ & $\begin{array}{l}\text { Kereti and Keith choosing what app to use with } \\
\text { Kahikatea monitoring them. }\end{array}$ \\
\hline 4 & $\begin{array}{l}\text { Kahukura and a girl } \\
\text { (Krissy) }\end{array}$ & $\begin{array}{l}\text { Krissy engaged with a literacy game on Katarine's } \\
\text { Samsung tablet using the stylus whilst Kahukura taught } \\
\text { her how to close ads when they popped up. }\end{array}$ \\
\hline 5 & $\begin{array}{l}\text { Two boys (Kereti and } \\
\text { Keith) and Kauri (Unseen } \\
\text { in the video) }\end{array}$ & $\begin{array}{l}\text { Kereti and Keith following Kauri's instructions to put } \\
\text { the iPad on the kitchen table. }\end{array}$ \\
\hline 6 & Katarine and a girl (Kathy) & $\begin{array}{l}\text { Kathy was playing a game on Katarine's Samsung } \\
\text { Tablet using the stylus. }\end{array}$ \\
\hline 7 & $\begin{array}{l}\text { Kahikatea and two boys } \\
\text { (Kereti and Keith) }\end{array}$ & $\begin{array}{l}\text { Kereti and Keith taking turns playing a matching game } \\
\text { on Kahikatea's iPad with Kahikatea monitoring them. }\end{array}$ \\
\hline 8 & $\begin{array}{l}\text { Kahikatea and two boys } \\
\text { (Kereti and Keith) }\end{array}$ & $\begin{array}{l}\text { Kahikatea with Kereti and Keith choosing and } \\
\text { watching a YouTube video about dinosaurs. }\end{array}$ \\
\hline
\end{tabular}

Table 6.3. Phase 2B SR-video episodes: User home-based service.

During the focus group interviews, the visiting teachers and educators shared that their reasons for using touchscreen devices included that they had become commonplace in society and that primary schools in their neighbourhood expected new entrants to know how to use digital technology. This was the service's way of accommodating these changes in the education of young children. Kahikatea explained that "things are changing... in education, we're teaching all these children about apps and how to use iPads and computers" [U-HB/P2A/449-450]. Although some parents were against their children using tablets, Kauri's reason for using tablets was that children going to school "are going to be exposed to it... it is the way of the world" [U-HB/P2A/237-238]. Kahikatea believed that parents, when their children transitioned to primary school, "won't be buying the books... [they will] be buying a device" [U-HB/P2A/243]. Kauri recalled that in their community, school children who used iPads in classrooms had become "younger and younger" [U$\mathrm{HB} / \mathrm{P} 2 \mathrm{~A} / 98$ ] and thus the teachers/educators expected that "by the time these twoyear-olds go to school, it [iPads] will probably be just a compulsory component" [U$\mathrm{HB} / \mathrm{P} 2 \mathrm{~A} / 242-243]$. Because of this shift from print to digital media, the teachers and educators believed it was necessary to let children use digital devices, beginning with 
playing games and using creative apps on their iPads. Katarine did not want to be "left out behind in technology" and so, she bought her own Samsung tablet [U$\mathrm{HB} / \mathrm{P} 2 \mathrm{~A} / 23]$.

The tablets used by the educators at the service were personally-owned, but the visiting teachers' iPads were "provided by the service because we're the directors" [U-HB/P2A/16]. Thus, it was up to the teacher/educator's discretion which children could use them. For this reason, the educators who owned their own iPad expected children to use the devices properly. Knowing that she would "hate the responsibility of having a child break my tablet. It'd freak me" [U-HB/P2A/142], Katarine had a rule that her tablet "doesn't go outside" [U-HB/P2A/214]. The other members of the team explained that since these devices were reliant on wireless internet connections, the areas where children could use tablets were limited, usually indoors. Katarine, for example, extended the ways children could use her Samsung tablet to listen to music whilst playing outside by connecting it to "the Bluetooth speaker down that end and have the ...iPad here [indoors]" [U-HB/P2A/229]. Kahukura and Kauri preferred to use the iPads with older children:

Kahukura: Three and four-year-olds pretty much.

Kauri: There's only two... three and four-year-olds. I wouldn't let... little people. It's personal because its mine. [U-HB/P2B/124-125]

The teachers and educators at Koanga Wākāinga Homebased used their tablets in different ways. Katarine did not use Educa, she used her tablet for "photography... games, music, the writing one..." [U-HB/P2A/40]. Tablets were most often used for games, and the teachers/educators made sure these were educational or learning games. Kahikatea preferred games "without having internet" [U-HB/P2A/195] because the teachers/educators believed that the children did not need internet access to play games. Kauri used her iPad to "let the children play games but definitely the research" [U-HB/P2A/86]. As a visiting teacher, Kahukura used her tablet "whether an educator uses it or not... if that's what's needed at that particular moment when I'm there for a visit" [U-HB/P2A/483-484]. Kahikatea reported that her iPad use with children was usually:

.... a case-by-case basis... you don't always have the visits where there's an opportunity to do that necessarily... It depends what the children are doing when you're there on a visit. [U-HB/P2A/486-489] 
Tablets were mainly used for searching for and watching videos, looking at photos and retrieving information. The team appreciated the multifunctionality of tablets for teaching and learning because they could find information children were interested in various formats. The teachers/educators let the children choose the videos or photos but strictly monitored children's access and choice of online content because Kahukura was aware that "a whole... lot of stuff comes up that's all random and not good" [U-HB/P2A/562-563]. To address children's excessive tablet use, Kauri gave:

them a limited time on it and they would play on it and you take it away. Whereas you would let them have it for hours, then they wouldn't put it away. [U-HB/P2B/595-597]

When Kahukura recalled how she used Google to look up information that children were interested in, Kauri supported this by specifying having searched for butterflies and dinosaurs [U-HB/P2A/91-92]. Kahukura illustrated the positive reception of iPad use amongst educators in their service:

I actually made a few movies with a group of children a few years ago. And we used iMovie on the iPad. Oh, my God! I actually had to send it up to the educators so that they could keep watching it. Because of course, I took it away with me when I took the iPad. But they, oh, they loved it. They decided which photos to use. And they decided which bits of the movie to use, or the videos... it was actually a really great session. [U-HB/P2A/314-319]

Using tablets at Koanga Wākāinga Homebased also involved searching for apps and evaluating them. The teaching team looked for apps which extended the interests of children. They made sure to review the apps "first and decide whether or not it's right or suitable" [U-HB/P2A/597-598]. Kahikatea reported looking for apps based on popular toys such as "Shopkins" [U-HB/P2A/66] and "Hello Kitty" [UHB/P2A/75]. Kahukura acknowledged the possibility that some apps "seem to be rubbish, so I can never really seem to find really good apps for the children" [UHB/P2A/43-46] and thus preferred to use tablets for researching more educational games, often for literacy and numeracy learning.

Knowing the potential impacts that could affect children when they used tablets and access related digital media, the visiting teachers wanted to learn how to manage app use and internet access. Katarine's Samsung tablet had a "Kids mode... app that was already built into the tablet" [U-HB/P2A/35] that limited children's use of her tablet to specific apps. The team wanted to learn more about how to manage 
the settings of their tablets so that children "can't exit it. They cannot get out of this if I walk away. They can't go on Facebook..." [U-HB/P2A/503-504]. This supported the teaching team's beliefs on using tablet's settings to limit children's access to app and online content.

At Koanga Wākāinga Homebased, the teachers and educators preferred limited screen time, especially for infants in their care. Their main reason was the "societal thing around screen time" [U-HB/P2A/477]. By this, Kahukura explained that children already had too much access to digital technology and related screen media at home because she was aware that children are "spending time on screen during the day and then same screen stuff when they get home" [U-HB/P2A/256257]. Kahikatea said, "I'm not going to put them on screen time" [U-HB/P2A/492]. Kauri added that when visiting teachers arrived at her house, the younger children were sleeping which removed them from any exposure to screen time. Kauri understood that "some parents are against" [U-HB/P2A/118] screen time and tablet use. Kauri reported that parents "don't want their child come into my house and that's all they do for the day as part of what they pay because... there needs to be other things happening as well" [U-HB/P2A/120-121]. Because parents preferred that their children use tablets for educational purposes, Kauri supported this by providing a balance between activities using her tablet and other non-digital activities:

It's something I would not teach only on the iPad. They would always try lots of different ways so then they can work out what's the best way for them... I got a couple of children that aren't interested in, letters, numbers, anything like that but you give them a tablet and they're into it. So, for those children that don't like to do it on pen and paper, and that sort of thing it means that they still get that opportunity to be exposed to those things. [U-HB/P2B/802810]

Yet, Kahukura observed the children copying the behaviours of adults pretending to make phone calls on toy mobile phones, and "about sliding things and pushing the button... because they use mum and dad's phone or their iPad" [U$\mathrm{HB} / \mathrm{P} 2 \mathrm{~A} / 133-135]$. Despite parents stating that they preferred that their children's time using tablets was limited, the teachers and educators noticed that some parents often said, “Oh, I'm just, you know, using it as a baby sitter" [U-HB/P2A/266-267]. Therefore, Kahikatea had become aware of changes in the issue of children's screen time when 'it used to be, 'How much TV they are watching?' Now how much time 
are they gonna be on... how much screen time?" [U-HB/P2A/249-250]. Knowing these expectations, teachers and educators managed older children's screen time through "turn taking... sharing... and a whole lot of discussion around all sorts of things that's happening on the screen" [U-HB/P2A/616-618].

The teachers and educators named literacy and numeracy games which they used (examples of how children used these in Phase 2B are discussed later in this section). The literacy games were "matching pictures, matching letters, not so much phonics sounds or anything like that..." [U-HB/P2A/54-55]. Kahikatea specified a "game called ABC Kiddie... like letter matching" [U-HB/P2A/47-48]. As for numeracy games, the teachers and educators followed the children's interests and chose maths games which involved "putting animals in the right places - those sorts of things" [U-HB/P2A/89-90]. The teachers/educators changed the games often and Kahukura rationalised that "it's probably more exciting if people are doing different things instead of everybody just did the same game" [U-HB/P2A/74-75].

Koanga Wākāinga Homebased's visiting teachers and educators used Educa for documentation and allowed children to look at their online portfolios using tablets. Kauri used her tablet for documentation and would let children "log on the iPad through their books and see their stories on the app, on the Educa app" [UHB/P2A/307-308]. Kauri explained how she used her iPad to communicate with parents by sharing documentation:

To be able to send a picture to a parent is a great thing like especially new parents. It's lovely playing with children, other children. And they're happy, they can actually physically see that instead of me texting and telling them and they can actually see what's happening. [U-HB/P2A/299-302]

Teachers/educators used tablets for communication. All the focus group participants used their tablets to communicate with children's parents. The service used social media through a Facebook page, where they sent messages for parents to see at their convenience. This functionality enabled the team to respond to replies and review posted messages on their personally-owned phones. They observed that when children used tablets to communicate with their families, they began to like writing. Katarine commented that children: 
... are allowed to text their dad whenever they want. And their granddad. And they, their dad and their grandad will text back. They can't read it, but they still think it's cool because it made a noise and they write. [U-HB/P2A/293296]

Initially, Kahukura remarked that the gestural interface did not teach children how to properly grip a pen. When the stylus was introduced to the children, she realised the multifunctionality of the tablet which enabled children to swipe and use other gestures as well as using a stylus. During this discussion, Kahikatea brought out a stylus and asked Katarine to use it with her children saying:

Add a pen, add a stylus... I got another child who's not keen on writing at all, but he loves doing that on the iPad, the tablet... I don't know what he's got but he loves doing the letters, so I said to the educator, "Tell mum to get a stylus because he can still do that. He's doing the... pen grip!" [U$\mathrm{HB} / \mathrm{P} 2 \mathrm{~A} / 663-667]$

The issues faced by the service with using tablets revolved around their reliance on wireless internet connectivity. Using some internet reliant apps was "frustrating with the iPads and with tablets unless you've got Wi-Fi" [U$\mathrm{HB} / \mathrm{P} 2 \mathrm{~A} / 184]$ and remembering Wi-Fi passwords was troublesome for the visiting teachers. Despite these issues, they favored using tablets at their service and planned to "look at supplying educators with an iPad each" [U-HB/P2A/372-373].

Koanga Wākāinga Homebased's teaching team also wanted to use tablets to manage the administrative aspects of their jobs, particularly for documentation purposes. The visiting teachers expressed frustration regarding the paperwork involved in managing home-based services and so, Kahikatea suggested that since technologies had become commonplace:

If the Ministry [of Education] accepted digital signings that she could email that to me or, messenger it to me or whatever and that could just be stored in that computer instead of me having great big giant files of time sheets. [UHB/P2A/384-387]

Participants felt that this way of using tablets could be extended to using them to easily "fill-in an emergency form and send it to parents during the day" [UHB/P2A/402-403] necessitating the need for the "Ministry [of Education] to begin accepting digital signatures" [U-HB/P2A/365]. Aside from simply using tablets and similar devices to document events, they thought that this functionality could be extended to a diary-like feature where "you'd have tabs on the side. Open that diary app, tabs down the side: nappy, sleep, whatever... you just tap on the table and you 
just fill in the details" [U-HB/P2A/429-431]. Kahukura explained that this would be useful for documenting information "during the day like nappy changes, any extra food that's given" [U-HB/P2A/399-400] which could be shared with parents and whānau to make their administrative work more efficient.

Results from phases $2 \mathrm{~A}$ and $2 \mathrm{~B}$ revealed how tablets were used at the service and teachers'/educators' rationale for using them in these ways. This subphase involved video-SR interviews in which each of the video-recorded episodes of tablet use at Koanga Wākäinga Homebased were played back to the teaching team who, afterwards, were asked to give their reflections and rationale for using tablets in each episode. The first episode showed two boys, Kereti and Keith, using a writing app. The teachers'/educators' initial discussion around this episode revolved around using tablet apps which were often literacy or numeracy games followed by sporadic use of writing and drawing apps. Katarine described how the teaching team made sure to balance tablet use with non-digital activities which included "Shapes, colours, sizing, you name it. Blocks are fantastic. And that's the thing about, even with the [iPad], it enhances it" [U-HB/P2B/799-800]. Kauri let children choose and use apps which were "educational and not... just for games" [U-HB/P2B/59].

Teachers/educators preferred educational apps that engaged children at different levels of their learning. A video-recorded episode showed Krissy, a girl receiving home-based care and education at Katarine's house, use a drawing app that extended her interest in animals. Kahukura noted that these creative apps kept children engaged. Katarine balanced digital media use with non-digital learning by also letting Krissy draw with a pen and paper at a table specifically used for art. Katarine said she only had "five games on the tablet" [U-HB/P2B/221] and confirmed that she periodically changed which apps were used. Kahikatea agreed that it was important to balance the use of tablets and other educational tools.

Whilst viewing a video-recorded episode of children using literacy apps, the teachers and educators observed differences between writing apps available on different tablet operating systems. They noted that Kauri's iPad only allowed children to write non-capitalised letters. The app used arrows to tell children where to start writing and where to end, and could let children change the font colours. 
Compared to Kauri's app, the app on Katarine's iPad taught children to how to write capital letters by "always starting on top" [U-HB/P2B/32]. The team reflected on a video-recorded episode that showed the children using Kahikatea's stylus, and suggested that the stylus made learning how to grip a pen and draw or write on the tablet easier for children. Katarine provided feedback saying, "They went just like that..." snapping her fingers to show it was easy and quick, “... and they haven't used their fingers since" [U-HB/P2B/156-157]. Kauri agreed that writing using the sylus had to be taught "in addition to pen and paper and other forms" [U-HB/P2B/142]. Kahikatea argued that it was still important for children to learn how to grip a pen or pencil even if "schools actually don't use pencils anymore. Lots of pen" [U$\mathrm{HB} / \mathrm{P} 2 \mathrm{~B} / 559]$. Kauri stressed the importance of "teaching children to write on something all the time. Sometimes they need to learn to control the pen and make a shape" [U-HB/P2B/132-133]. Reflecting on the episode about literacy apps, Kauri commented that:

There are no lower-case letters in there which I think for me would be more important to teach children... I've discovered from talking to teachers that a lot of children only learn upper case, it's really hard to go back and teach lower case whereas it is easy to say the name that starts with a capital letter. [U$\mathrm{HB} / \mathrm{P} 2 \mathrm{~B} / 96-100]$

The teaching team used several numeracy apps which included number writing, counting, and identifying numbers. After Katarine viewed a video-recorded episode of children using a numeracy app, she commented that children had chosen a colourful educational game and knew how to play "even though they hadn't played it" [U-HB/P2B/96-728]. The teachers/educators noticed that it took time for children to learn how to use apps. When they viewed another episode of a child engaging with a numeracy app involving counting spots, Kahikatea noted that:

this one took a while for him to actually get the idea of what he was supposed to do cos all the ladybirds are all the same colour. It's just the spots numbers on the backs of the lady birds [that are different]. [U-HB/P2B/741-743]

The children were also allowed to watch videos and look up pictures using tablets. Using iPads in this way helped teachers and educators extend children's learning according to their interests. Kahikatea reflected on the video-recorded episode with her guiding Kereti and Keith in choosing a YouTube video about dinosaurs. She reflected on how she guided the two boys in the episode to choose 
what topic to search for pictures and videos using her iPad. Kahikatea "had picked one and Kereti had seen it before. And it was one of those, ... toy testing on YouTube ones" [U-HB/P2B/373-376]. After viewing the episode, Kahikatea commented that she guided them to avoid the violent-looking ones. Kahikatea believed that by:

using the iPad, it just opens up the world. They're not limited anymore to what's just inside the book. I mean... books still have their place, ...but it just opens it up so much more and gives them so much more and gives them so many options. [U-HB/P2B/905-909]

Although the team acknowledged the value of physical books as part of children's learning, they also discussed how iPads provided a wide range of content for children. Kahikatea found it useful to use the different apps on her iPad to divert Kereti and Keith, the children in Kauri's home-based service, from "picking the ones that looked like they were gonna be the most exciting or the loudest" [U$\mathrm{HB} / \mathrm{P} 2 \mathrm{~B} / 370-371]$. Kauri believed that if children were allowed to select apps on their own, they would choose the non-educational ones. The same applied to choosing what videos to watch when Kahikatea scaffolded Kereti and Keith's choices of videos. Kahikatea explained this further by saying that:

...there's the negotiation that's happening. There's the talking between themselves, then with the adult as well about what they can and can't do. [U$\mathrm{HB} / \mathrm{P} 2 \mathrm{~B} / 390-392]$

Screen time was also managed carefully by the teaching team. Tablets were used at Koanga Wākāinga Homebased up to a maximum of ten minutes. Kahikatea said that the children knew about the time limits and she would remind them that they "have ten minutes, so I'm going to put ten minutes in the timer and when it goes off, it's time to put it away" [U-HB/P2B/604-606]. Kauri confirmed this time limit when she stated that she "wouldn't let them normally play longer... It would be like a five- to ten-minute kind of job" [U-HB/P2B/582-583]. Some fast-paced apps also helped children play games in short bursts, such as the writing app in which children only had "a minute to create the letter" [U-HB/P2B/82-83].

Tablets were also useful in helping children self-regulate. Katarine found the tablet helpful as "a diversion. If one of the children is in a bad mood or needs cheering up" [U-HB/P2B/691-692]. Kahikatea explained how glitches with the tablet and apps frustrated her but she realised that the children showed resilience that 
"in the scheme of life, it's not that important. I can go back and do it later" [U$\mathrm{HB} / \mathrm{P} 2 \mathrm{~B} / 782-783]$. Kahukura explained that role modelling self-management was difficult as they had observed in their playgroups that other "adults don't selfmanage when it comes to devices" [U-HB/P2B/633-635]. Because the teachers/educators perceived that even teenagers and adults found it hard to selfmanage their own touchscreen device use, children needed constant supervision. Kahikatea did not believe that "there will ever come a time when they will just stop" [U-E\&C/P2B/610-611].

Teachers and educators reinforced good behavior by letting children choose from apps provided by the teacher/educator as a reward. Kahikatea observed Kereti and Keith's “one upmanship" [U-HB/P2B/403] behaviours when they used her iPad. Kauri commented that when Kereti or Keith “....would start crying about it and throw themselves on the ground" [U-HB/P2B/575-577], she would intervene by telling them to put away her iPad. Katarine used a similar approach with Krissy and Kathy, the children enrolled with her who had different interests and would often fight over her tablet. Katarine explained that when "there is that sort of fight with the girls" [U$\mathrm{HB} / \mathrm{P} 2 \mathrm{~B} / 671]$, she would intervene by putting her tablet away.

Koanga Wākāinga Homebased's teaching team identified several issues they had encountered with tablets. These included technical issues such as children potentially breaking their personal tablets, faulty wireless internet connections, and children viewing inappropriate content. When scaffolding children's tablet use, teachers/educators used apps designed for children's consumption such as Kids YouTube and deleted apps that showed inappropriate content. The teaching team explained that free apps would show ads which could risk exposing children to inappropriate content. Kahikatea explained that “...if you paid for it, you probably wouldn't get the ad... .... with YouTube ...I haven't paid... so of course, the ads are gonna keep popping up" [U-HB/P2B/428-430]. In additional, some free games "start off free but then if you want the extended levels" [U-HB/P2B/830-832], they had to buy them and this information only showed up after a few levels into the game.

Adding to their discussion on inappropriate content, teachers/educators also disliked ads because some were about violent games. Although Kahikatea believed 
that having the ads associated with free apps was reasonable, she observed that some ads still showed up on purchased apps; however, she had decided to keep the purchased apps because these were "good games" [U-HB/P2B/428-434].

Teachers/educators had become "ad managers" by anticipating ads and finding ways to close or skip ads as quickly as possible. In a video-recording of Kahukura using Katarine's tablet, Kahukura did not use Kids Mode and Krissy chose a free app with ads. This led to Kahukura teaching Krissy how to close or skip ads when these ads inadvertently showed up and disrupted learning, saying "that was the only learning that was happening... 'Push X'" [U-HB/P2B/442]. Kauri reported that sometimes the $\mathrm{X}$ marks did not appear and were replaced with numbers, saying "some of them had an X on the corner and other ones counted down 5, 4, 3, 2, 1" [U-HB/P2B/508509]. Kahukura explained how she used this as an opportunity to teach numeracy to Krissy by teaching her how to count backwards which the ad did before showing the $\mathrm{X}$ mark to close it. Kahukura said this whilst gesturing how pushing on the $\mathrm{X}$ on the tablet computer's screen closed the ad. Kahikatea summed up the team's view when she said that their role was to:

guide them away from that cos, well A) it's not our place to decide that they can watch those stuff cos we're not their parents; and B) there's enough stuff happening in the world, that they see it on TV and stuff they don't need it on this. [U-HB/P2B/364-367]

Towards the end of the interview after the team had watched all the videos, they also talked about cybersafety and looked at how they could change the settings of their own tablets. Aside from Kahikatea who knew how to manage some of the settings, the other teachers and educators admitted that they needed support in this area. The teachers/educators did not like apps which allowed users to purchase additional features whilst using the apps and they had issues with purchasing apps on iTunes. They noted difficulties with remembering passwords or billing information and expressed confusion when updates required billing information when they only wanted to download free apps. They found that changing settings was confusing. Kahikatea's experience with problems involving purchasing apps helped her understand how to change the settings to allow easier downloading of free apps. She taught her colleagues how to manage the settings:

It's actually in Settings. If you go iTunes App Store, Pictures, and Purchase... Free download you can turn off if you want a password or not. [U-HB/P2A/263265] 
After learning how to download apps, the team began checking their tablets for cybersafety features such as "guided access" which they referred to as safety apps. They also tried looking for apps such as "Kids Mode" with cybersafety features that they could download onto their tablets. Kahukura expected that "there are lots of safety apps out there... so that parents have got control." [U-HB/P2A/523-524]. Kahikatea found an app that "set a daily time limit and blocked your kids' apps at dinner time, ... during school hours and after bedtime" [U-HB/P2A/517-518] but these features were not what the teaching team preferred to use with children. They preferred an app similar to the one on Katarine's Samsung tablet called Kids Mode which limited children's access to other apps and other tablet functions and prevented children from "exiting out of the app and deleting things" [U-HB/P2A/535-536]. Teachers/educators learned how to use their tablets through, "trial and error" [U$\mathrm{HB} / \mathrm{P} 2 \mathrm{~B} / 307]$. Beyond this, if they had to resolve issues with ICT, including touchscreen tablets, phones, and Bluetooth speakers, they either called the local technical support or asked more knowledgeable family members to help them.

This section has presented Koanga Wākāinga Home-based's case. Although teachers/educators' tablets differed in brands and apps, they had similar ways of using them for teaching and learning. Teachers/educators used their personallyowned tablets for research, documentation and assessment, playing music and videos, and allowed children to engage with educational apps-particularly writing apps, and educational games. Koanga Wākāinga Homebased's teaching team limited app use to older children and facilitated turn-taking and children's access to digital media to mitigate issues such as in-app purchases, inappropriate ads, and difficulties in managing settings and purchasing apps. The visiting teachers believed that tablets for administrative work could potentially decrease their paperwork. The ways tablets and their apps were used by the teaching team at Koanga Wākäinga Homebased sits between using tablets for specific purposes and sometimes comprehensively. The next section presents the case of a user education and care service.

6.2.2. User education and care service: Manaakitanga ELC. This service was established in 2004. Manaakitanga ELC was one of four private education and care services managed by one umbrella organisation. This service employed five 
teachers whose teaching experiences ranged from five to fifteen years and ages ranged from their twenties to their forties. The teaching team had worked at the service from one term to seven years. One teacher skilled in and enthusiastic about ICT oversaw management of iPads and their apps. The head office employed an administrator who managed ICT for all its four services. Table 6.4 provides information about the participants.

\begin{tabular}{|c|c|c|}
\hline Pseudonym & Role & Participation \\
\hline Mahuika & $\begin{array}{c}\text { Fully certificated teacher } \\
\text { and appointed iPad manager by the team }\end{array}$ & Phases 2A \& 2B \\
\hline Makareta & Fully certificated teacher and assistant head teacher & Phases 2A \& 2B \\
\hline Marama & Fully certificated teacher & Phase 2A \& 2B \\
\hline Minerva & Fully certificated teacher and head teacher & Phase 2B \\
\hline Moana & Fully certificated teacher & Phase 2B \\
\hline
\end{tabular}

Table 6.4. User education and care service participants.

Manaakitanga ELC had the most iPads amongst the umbrella organisation's services because of the number of children on their roll, the number of teachers, and their service location being the biggest amongst the other services in the organisation. The umbrella organisation had a policy that teachers were not allowed to use their personal touchscreen devices at the centre. At Manaakitanga ELC, the five teachers shared the use of four iPads and allowed children to use these freely when they were not used for teaching. Another iPad was readily available for use with a small CD player which functioned as a loudspeaker in the mat time area to play YouTube videos or other audio that were not available amongst the service's music CDs and iPod files. This meant that there was a total of five iPads, and when distributed they were "one per each qualified teacher" [U-E\&C/P2A/330]. Makareta explained that the iPads had been available before they started working at the service "in the last two-and-a-half years" [U-E\&C/P2A/61]. Wireless internet enabled playing music from iPads to speakers in the sleep room and at the outside playground. iPads were generally used inside the building except when they were brought outside for documentation purposes. The service previously "had the laptops but basically we don't use them with the children" [U-E\&C/P2A/430]. This was because the teachers found that iPads had fewer issues compared to laptop and desktop computers [U-E\&C/P2A/83]. Makareta described:

...what happened when we used them, is that you pressed a button and the whole thing was gone. You had to reset the whole computer, but you don't get that with the iPads. Which is nice. [U-E\&C/P2A/70-72] 
The service had previously reviewed its iPad use when the teaching team applied for Heart Foundation's Healthy Heart award on children's appropriate screen time. Makareta explained how the Healthy Heart award aligned with how they used tablets at their service:

What they want us to do because in our policy we actually didn't have anything about the iPad usage in the centre. So Healthy Heart foundation has asked us to add that in because they need that for us to get our gold star. [U$\mathrm{E} \& \mathrm{C} / \mathrm{P} 2 \mathrm{~A} / 411-413]$

Mahuika clarified that this issue about "screen time in general... just means iPads, because... we only use iPads" [U-E\&C/P2A/420-421]. Manaakitang a ELC did not limit screen time to a specific number of minutes because the teachers reported that there had been no evidence of prolonged iPad use amongst children. Teachers discouraged prolonged use of apps. To them, tablets were good tools for settling but they were careful not to use tablets as "baby sitting" tools [U-E\&C/P2A/392]. Makareta said that the service had a:

...one-minute timer if need be but normally the children will take turns. So, if they're playing their games, ...they play one game, and they pass it on to their friend after they have finished that section of their game. And they are pretty good with that, we don't tend to have much of a problem. [U-E\&C/P2A/440445]

Phase 2A was held on 8 June 2017. Video recording of tablet use at Manaakitanga ELC was undertaken on 12 and 13 June 2017. There were nine videorecorded episodes shown in Phase 2B which was completed on 22 June 2017 (See

Table 5.10). 


\begin{tabular}{|c|c|c|}
\hline \multicolumn{2}{|r|}{ Participants } & Description \\
\hline 1 & $\begin{array}{l}\text { Moana with one boy (Mario) } \\
\text { seated next to her in front of } \\
\text { around small group of children } \\
\text { (unseen in the video) seated facing } \\
\text { her }\end{array}$ & $\begin{array}{l}\text { Jolly Phonics activity: An alphabet song was } \\
\text { being played whilst Moana made hand gestures } \\
\text { of objects/animals with Mario seated next to her } \\
\text { trying to copy her gestures. }\end{array}$ \\
\hline 2 & Mahuika and boy (Marvin) & $\begin{array}{l}\text { Mahuika let Marvin use Lego Movie Maker to } \\
\text { take photos and then made a video presentation } \\
\text { of the photos with him before posting it on } \\
\text { Educa. }\end{array}$ \\
\hline 3 & $\begin{array}{l}\text { Mahuika and another boy } \\
\text { (Makaio) with two other children } \\
\text { looking on }\end{array}$ & $\begin{array}{l}\text { Mahuika was teaching Makaio how to use the } \\
\text { Letter School writing app. }\end{array}$ \\
\hline 4 & $\begin{array}{l}\text { Mahuika and another boy } \\
\text { (Miguel). Makaio was offscreen } \\
\text { but his intentions with the iPad } \\
\text { could be heard in the background. }\end{array}$ & $\begin{array}{l}\text { Miguel was making a collage of pictures using } \\
\text { a creative app and Mahuika who was teaching } \\
\text { Makaio how to use Letter School periodically } \\
\text { checked back with Miguel to show him how to } \\
\text { resize some pictures. }\end{array}$ \\
\hline 5 & $\begin{array}{l}\text { Makaio and two unseen older boys } \\
\text { heard in the background }\end{array}$ & $\begin{array}{l}\text { Makaio was trying to unlock the iPad and use } \\
\text { the Toca Band music app whilst two older boys } \\
\text { passing by stopped to tell him what to do when } \\
\text { they noticed he had difficulty starting the app. }\end{array}$ \\
\hline 6 & $\begin{array}{l}\text { Marama and a large group of } \\
\text { children (unseen in the video) }\end{array}$ & $\begin{array}{l}\text { Marama plugged the iPad to the CD player and } \\
\text { played a waiata (a song) using YouTube. The } \\
\text { CD player functioned as a speaker. }\end{array}$ \\
\hline 7 & $\begin{array}{l}\text { Mahuika with a girl (Missy) in } \\
\text { front of her and a small group of } \\
\text { children (unseen in the video) } \\
\text { watching Missy's presentation }\end{array}$ & $\begin{array}{l}\text { Mahuika was using the iPad to record Missy } \\
\text { who was retelling the story of the Gruffalo } \\
\text { through shadow puppetry using an overhead } \\
\text { projector whilst other children watched and } \\
\text { waited for their turn. }\end{array}$ \\
\hline 8 & $\begin{array}{l}\text { Minerva and a younger boy } \\
\text { (Mikaere) }\end{array}$ & $\begin{array}{l}\text { Minerva and Mikaere were using Google Maps } \\
\text { to explore Mikaere's home and nearby } \\
\text { surroundings. }\end{array}$ \\
\hline 9 & $\begin{array}{l}\text { Minerva and an older boy (Matiu) } \\
\text { in transition class }\end{array}$ & $\begin{array}{l}\text { Minerva and Matiu were using Google Maps to } \\
\text { explore the nearby primary school and talk } \\
\text { about locations he went to during his school } \\
\text { visit. }\end{array}$ \\
\hline
\end{tabular}

Table 6.5. Phase 2B SR-video episodes: User education and care service.

At Manaakitanga ELC, groups of children could freely use apps without teacher scaffolding as long as a teacher was in the same room when children were using the iPad so, "everybody wants to use it so you can't go by yourself" [U$\mathrm{E} \& \mathrm{C} / \mathrm{P} 2 \mathrm{~A} / 166]$. The teachers role modelled iPad use and Makareta confirmed this when she said, "they watch me use it" [U-E\&C/P2A/109]. Marama acknowledged the fact that "a lot of parents have a problem with the amount of screen time the children are exposed to" [U-E\&C/P2A/388-389] and so made sure not to use iPads as "baby sitting tools" [U-E\&C/P2A/390]. Initially, Minerva found the iPads distracting to children's learning and other activities as the: 
...children freeze when you get the iPad out... and they [are] standing still waiting for you. That's when I actually put it away [and] kind of wait until they're back at play and then I make the judgement call if I really want to document this. [U-E\&C/P2A/723-726]

Marama observed that the novelty of iPads had faded away as children were "used to seeing it, it's just part of their day" [U-E\&C/P2A/445-455]. Marama continued that because "most of the children know how to use them from about age two as well" [U-E\&C/P2A/94-95]. Younger children at the service learned how to use iPads by observing other children use specific apps and from teaching each other. Tablets were not limited to older children because teachers also observed that younger children knew how to use them. Younger children learned to use iPads by observing older peers and teachers. Teachers explained that children always used tablets in groups and "not just solo" [U-E\&C/P2A/162].

Tablet use was scaffolded using "guided access" which limited children's iPad use to specific areas [U-E\&C/P2A/275-277] and their access to a limited number of apps. The service's iPads had guided access which limited children's access to a few apps at a time as allowed by teachers so that "the children can't just click out of things. There are certain parts of the page that they can't actually use" [U-E\&C/P2A/278-279]. Children who were aware of this functionality could approach teachers who would allow them to explore other apps. Mahuika explained how they set up guided access:

....in the settings... you can click to turn the guided access on and if you triple click the home button it will come up and you can put a password in... And you can see areas that the children can touch on the iPad. So, like if they have to press "play". So, they can touch that. But you can make it so that they can't get out of that app... set in an area, and so they could only do the time app. They could not come out of the time app. [U-E\&C/P2A/282-289]

Manaakitanga ELC's ways of using tablets revolved around using mainly open-ended apps such as the camera app and other creative apps. Mahuika explained that creative apps allowed teachers and children to print pictures using the service's "printer, then they can take their picture home" [U-E\&C/P2A/176-177] to show parents/whānau evidence of their children's learning. The teaching team used moviemaking and photography apps with children. Mahuika explaind how she used a moviemaker app so she and the children could "make a movie of like what was happening outside this morning and they love to be able to watch that back" [U- 
$\mathrm{E} \& \mathrm{C} / \mathrm{P} 2 \mathrm{~A} / 214-215]$. Another app the teachers used was a creative music app called Garage Band. Mahuika explained that the app teaches them "about different instruments, chords and notes" [U-E\&C/P2A/158-159]. She used the app with a group of children to make simple songs and music when "everybody started making different instruments and we were recording it" [U-E\&C/P2A/160-161].

iPads were used for research to build teachers' and children's knowledge. YouTube was the main app teachers and children used to watch videos and look up information. Mahuika used the app to enrich her discussion with a group of children about Team New Zealand and their boat. She used "YouTube to show the videos... how the boat looked like when it fell over" [U-E\&C/P2A/115-118]. Marama admitted that "I use YouTube a lot ... at group time today we did a cloud experiment. We went about water evaporating and watched a clip first to see how to do it" [UE\&C/P2A/224-226]. Marama described another situation when she:

...used it yesterday to make a paper airplane with the children. We had it at the middle of the table, and we had a set of instructions going. And I was learning from the iPad at the same time as the children. Some of them were watching on the iPad, some of them were watching me and we all managed to make a paper plane. [U-E\&C/P2A/126-130]

Manaakitanga ELC used a specific iPad app called Letter School, as part of their readers' programme that children could use independently or scaffolded by a teacher. Minerva explained that the app has different levels to accommodate children's varying levels of writing skills. Makareta added that before the children "start practising the writing in their book, we give them the iPad" [U-E\&C/P2A/141142]. Younger children began writing their names or the initial letters of their names by using the app. Mahuika explained the app and how it had levels in:

...three different difficulties, so like if they are drawing an A, it starts off and they just push a button and it will draw it. The next level, they pull around the letter and the last time, they actually have to draw it by themselves with no prompt. So, every letter, they go through... My children are not all on readers yet so quite often, I will introduce that to them in a group time or if there's a quiet time or play with that as well. So, they are getting ready for when they have their readers' programme. [U-E\&C/P2A/145-151]

Teachers found that their iPads made work easier and faster. Tablets made documentation and assessment convenient. To Makareta, having an iPad available made it easier for teachers to take "quick photos" [U-E\&C/P2A/295] and uploading these photos quicker. The multifunctionality of iPads and learning story apps 
benefitted teachers' work because it made documentation, assessment, and communication seamless. The service used Educa as their learning story app. Mahuika described how iPads were much better than using folder portfolios of children's learning stories:

...we can sit down with the children because there is another Educa app. And so they can actually relive everything there and then whereas the folders, they'd go home and get lost and things like that. Whereas now, you can't lose it, it's there. And when they leave, we can put it on a USB stick and they can keep it as well. ...It means that the children can just relive everything through the iPads as well. [U-E\&C/P2A/208-213]

Marama explained that through tablets and their apps, the teaching team could communicate with parents about their children's progress even if "some families that live overseas that have been invited to join Educa, so they get to have a look as well. ...if you used an app like moviemaker to make a video, they are seeing the results" [U-E\&C/P2A/263-265]. Tablets afforded the teachers the ability to instantaneously communicate evidences of children's learning through photos and videos. Mahuika remembered that when she started working in ECE at a time when digital technologies were not readily available, she "had to take the film out of the camera and go and get it printed and then bring it back to write the story. Parents get the photo weeks later" [U-E\&C/P2A/257-262]. The iPad's large screen let teachers and children view pictures immediately compared to digital cameras which required transferring photos to a computer or printing them out. Marama illustrated how iPads helped them share documentation to parents more quickly instead of waiting for teachers to share them during their non-contact time. She explained that:

I can tell you it's instantly faster. I have been here for a couple of months now, and so that's how long I've been using the iPad. And what I found is that learning is automatically translated to the parents and it's faster because you'd take notes before you take pictures on the camera and you'd wait for your non-contact end. They might get that story a week later... And now they're getting it, now we just save it to the iPad right away because it's that fast and go home... [U-E\&C/P2A/251-256]

iPads were still better than desktop computers because errors in desktop or laptop computers required the teachers to reset the entire computer if a wrong button was pressed. Makareta explained that the portability and durability of tablets were enhanced by sturdy cases so, teachers did not "get worried about dropping it anything like that cos even if it accidentally gets dropped, it's fine" [U-E\&C/P2A/9192]. Despite these affordances, using iPads at the service led to some technical 
issues especially when using them for the teaching and learning of young children. The teaching team found it necessary to evaluate iPads and their apps and report what they have observed to their umbrella organisation's ICT administrator. As the centre manager, Mahuika "can go to the admin and say 'This one we need because we can use it for this, this and this' As we look through things... on my iPad and say, "We can evaluate"” [U-E\&C/P2A/236-239]. Makareta experienced some instances when their iPads had errors because of "app problems" [U-E\&C/P2A/79-81], so they provided feedback to management regarding replacing repetitive apps with new apps. The iPads easily ran out of memory for photo storage and to resolve this issue, management provided more iPads. Makareta found that iPads:

...get filled really easily and when they're filled with different people's photos you have to go and get them to delete them or you can't take the photos or you have to ask them before you can delete them and that means that you can't use that iPad for the while because you can't take any photos off it. [U$\mathrm{E} \& \mathrm{C} / \mathrm{P} 2 \mathrm{~A} / 336-339]$

The teachers had different ways of resolving issues. Aside from "playing with settings" [U-E\&C/P2A/372], the teaching team also reported to management the challenges they have with using tablets. Mahuika explained that they did not want to simply use tablets for documentation so they:

...fed back to the management that was a struggle because one of the things that we evaluate is how we are using ICT and we did feedback and said, "This is a struggle for us because we are wanting to use it more with children in different ways but we are finding we can only use it for taking photos or videos." [U-E\&C/P2A/307-310]

There was no in-service training or professional development for learning how to use iPads at Manaakitanga ELC. Teachers explained how they learned to use iPads by themselves and by sharing what they knew with each other. Mahuika explained that meetings like this focus group was akin to a "mini PD" [U$\mathrm{E} \& \mathrm{C} / \mathrm{P} 2 \mathrm{~A} / 351]$ because it helped everybody share what they knew about tablet use. The teachers preferred to "have everybody together so everybody learned the same things at the same time" [U-E\&C/P2A/345-346] when receiving training on using iPads. Aside from sharing her knowledge with her colleagues, Mahuika explained that her role was to research ways to better use iPads and to communicate these to management: 
I go home and research all the apps on my iPad to see what's gonna work and what's really not worth it. And I can go to the Admin and say "Right, this one we need because we can use it for this, this and this..." ...as we look through things then I can always download them on my iPad and say, "We can evaluate." And I think it will be ...making sure they are thinking of different apps that will support the children's interests and everything. [U$\mathrm{E} \& \mathrm{C} / \mathrm{P} 2 \mathrm{~A} / 235-236]$

In the past, teachers told management what did not work and how the limitations of the iPad affected its use for documentation. This open feedback helped improved tablet use at the service. Mahuika believed "it would be good" [U$\mathrm{E} \& \mathrm{C} / \mathrm{P} 2 \mathrm{~A} / 358]$ to have professional development on using tablets for teaching and learning to benefit those teachers who did not have these devices at home.

In Phase 2B, the teaching team reflected on the video-recorded episodes of tablet use at Manaakitanga ELC. The team remarked that creative, open-ended apps were better than repetitive apps. Minerva reasoned that their service preferred "not using the iPads as baby sitting tools. If ...children are sitting there and starting to get that zombie look, that's when it usually goes away." [U-E\&C/P2B/858-861].

Minerva explained how some apps such as Toca Boca could become repetitive when "the song gets stuck on your head so quickly and play it over and over... it gets really hard to bear but we wouldn't take it away from them" [U-E\&C/P2B/475-478]. Yet, the Minerva noted that in the video-recorded episode, Makaio use the Toca Boca app and understood that this was "part of exploring. How he was pushing the different buttons and actually exploring cause and effect" [U-E\&C/P2B/483-485]. Reflecting on an episode involving moviemaking apps, teachers found these kinds of apps useful in extending children's interests. Minerva recalled how they evaluated apps to make sure that they were open-ended and creative. She noticed a music app did not fit their purposes for using the iPad and:

...went to management and like, "We need a proper music app because this one is just not... I understand what it's doing but I feel like that one is more a cause and effect rather than teaching music. So, I requested Garage Band. I was looking around for different apps and this one is one where they can pretend to virtually play instruments and it's teaching us about how to use it as much as an iPad can. It's about the sound and everything but we still kept the Toca Boca because the children just love it. [U-E\&C/P2B/497-503]

The teaching team primarily used iMovie as it came with iPads but also used other similar apps. Moana illustrated how Mahuika helped Marvin compile the "pictures... into a Lego movie theme just to extend his interest and getting him to use 
the iPad and working it with him how to use the iMovies as well" [U-E\&C/P2B/247249]. Minerva preferred to keep using iMovies because it was "simple to use and works for us. If ...it stops working because it's been overhauled and not on our iPads, or if ... something is missing, then we will probably look around" [U-

$\mathrm{E} \& \mathrm{C} / \mathrm{P} 2 \mathrm{~B} / 170-181]$. Minerva used this app to document a group of children making a pizza from "start to finish" [U-E\&C/P2B/170-181]. Minerva found that documentation was easier on the iPad and explained that:

...in the iPad it also compresses the movies when it uploads them on Educa. Which can get quite tricky if you put something on the computer and then upload it. Sometimes Educa will tell you, "It's too big." So, that's where iPads are really vital because it compresses the movie so I wouldn't otherwise have been able to put a five-minute movie up. And that's only, you know... I don't have any technological knowhow to do it on the computer whereas on iMovies it is so easy even I can do it. [U-E\&C/P2B/182-188]

Moviemaking apps held the interest of children because teachers and children could collect their photos into one slide show. The photos and videos could be organised into a theme to which teachers and children could include special effects such as listing children's names in the movie credits. Teachers noted that letting children use documentation apps such as photography apps helped teachers "see what the children are seeing" [U-E\&C/P2B/226-232]. Minerva repeated her satisfaction with iMovies but as head teacher allowed other teachers to be creative with the app. She described how "one teacher once did a really fun afterschool club superheroes movie where she got the children to describe what superpower they would have and on iMovies" [U-E\&C/P2B/204-206] added special effects "and kind of like a movie trailer, 'Coming soon!' And... the names in there... saying 'Starring so and so"" [U-E\&C/P2B/208-210]. Clips from iMovies and additional effects could be "put it in Educa... It's like a theme in the iMovie. So you add the clips into iMovie and you can change the song, you can change the font" [U-E\&C/P2B/164165]. Similarly, Marama:

was videotaping their interests and putting their interests on and talking about their interests on Educa for their parents. And I've got them to write the story in the morning. [U-E\&C/P2B/654-656]

Mahuika's role in the team was to try out different apps and share her knowledge to the team. She used a moviemaking app called Lego Movie Maker that was unfamiliar to the rest of the team. Teachers noted that some apps could be confusing to teachers and that children thought the Lego Movie Maker app was about 
the Lego movie and had Legos when it actually did not. Since Mahuika was not part of the Phase $2 \mathrm{~B}$ interview, the teachers planned to ask her about this new app and its difference with iMovie. Minerva planned to continue this way of collegial support when she said:

We'll probably ask her why the Lego Movie Maker and what's different. Cos none of us is actually aware that there is a difference. I wouldn't have known that it is part of the iMovie package. So, I do wonder what the difference is and why it's called Lego Movie Maker so there will be... a team going like, "Hey, what is it? Share it with us." [U-E\&C/P2B/235-239]

Teachers used photography apps to document children's learning. Aside from using digital cameras, teachers documented children's learning using their iPads for various purposes such as capturing evidence of a child's developing selfconfidence. Minerva reflected about Missy, the girl shown in the video-recorded episode, and how the teachers helped develop her self-confidence by stating that Missy:

...is quite timid and quite softly spoken. And ...one way of documenting her actually opening up and speaking a bit louder. She [Mahuika] would then explain it in Educa. And say, "I heard you used a big voice and engaged." So, there's all sorts of different reasons for documentation. [U-E\&C/P2B/754758]

Moana reported that she tends "to take photos if I know they're doing well of if it's based on their goals or their interests or 'Look at me! I'm doing it!'” [U$\mathrm{E} \& \mathrm{C} / \mathrm{P} 2 \mathrm{~B} / 704-705]$. Moana explained how they used their iPads to document the teaching and learning of their focus child for the week or to update children's learning portfolios. In repeating that the service used Educa for their learning story app, Moana admitted that even if the young children in her group do not understand it yet, they "look at Educa stories" [U-E\&C/P2B/808-809]. She even recalled occasions when children would proactively ask her to document their activites: ...so when they see me like, "Can you take a photo of this?" They know why I'm taking the photo. They know that we put it on Educa. ...we always encourage the parents to look at the Educa with them as well or just talk about it just to extend what's happening at school back to home. [U-E\&C/P2B/715718]

Another type of creative app used was a drawing app. The app required scaffolding by a teacher so children could learn the gestures required for engaging with the app such as shrinking and expanding pictures using pinching gestures [UE\&C/P2B/344-345]. Teachers explained that these apps helped children develop 
their self-confidence, fine motor skills, and digital literacy whilst engaging with content within the child's interest. Moana explained how she accommodated “children's preferences... One day, they might like that one. One day, they might like Garage Band. It depends on the day" [U-E\&C/P2B/514-515]. Minerva explained how they supported children's tablet use through:

...scaffolding. We give them as much support as we think they need and we take a step back and we see how far they get and the children know we're there. We try not to be overbearing and jump in and go on, "That's not how you do it." We kind of let them figure it out first. And the children know that if they need us, we're there. They can come to us and ask us to do it. But, also quite often if they come to us and we've been watching them. At the first problem, they come to us and they can't do it, we ask, "What have you tried?" and then we let him show us what he did. The whole idea of "Show me and let me do it, I'll remember. So, let me try again and again." So, again it's also the problem solving. [U-E\&C/P2B/393-401]

Initially, teachers found it disruptive to use their iPads to document children's activities because children were distracted from their activities and stopped to pose for a photo. However, after some time, the novelty of the iPad faded and these "freezing and cheesing" [U-E\&C/P2B/729] behaviours of children disappeared as iPads became commonplace.

Teachers observed children who used the iPads and were always ready to scaffold learning if they noticed that a child needed assistance. Moana explained that scaffolding differed across teachers and she "...preferred to observe first and see what's happened and then help them out" [U-E\&C/P2B/315-316]. Teachers' scaffolding of children's tablet use was evident during the reading programme. Minerva explained that the teachers knew that the children were "able to write that letter, it's just the progression that we're doing from easiest to hardest" [U-E\&C/P2B/304-305]. She explained how she scaffolded children's use of the Letter School app using the iPad by letting:

And then I'll let them try a few times. You ... watch the children to see if they are frustrated and see if or if they want help. Some are determined to do it by themselves. So, I often ask them, "would you like some help?" and I just wait for them. [U-E\&C/P2B/305-309]

Manaakitanga ELC was revising its screen time policy to meet Heart Foundation's Healthy Heart Award and Minerva admitted that they "still haven't gotten it here but the screen time policy will definitely be one in there" [U$\mathrm{E} \& \mathrm{C} / \mathrm{P} 2 \mathrm{~B} / 851-852]$. The revision included teaching children to moderate their own 
screen time. The teachers used a "storybook that's called 'Square Eyes"" [U$\mathrm{E} \& \mathrm{C} / \mathrm{P} 2 \mathrm{~B} / 854]$ to illustrate the importance of balancing sedentary screen time activities with physically active outdoor activities. The policy aimed to clarify the ways tablets were used with a teacher or by children in groups. Teachers discussed guidelines about avoiding prolonged iPad use, yet, they avoided negative statements on why children could not use iPads.

Teachers at Manaakitanga ELC connected their iPad or iPod to a CD player or speaker so children could listen to music in large groups. At mat time children sang along with music played from digital devices. The teaching team found using the iPad easier than the iPod when looking up "a few te reo songs" [U$\mathrm{E} \& \mathrm{C} / \mathrm{P} 2 \mathrm{~B} / 571]$ and videos on YouTube [U-E\&C/P2B/580]. Screen time was not always necessary when using iPads. The teaching used "the iPad in extension of the types of music we have. So, ...we have more songs available for children." [U$\mathrm{E} \& \mathrm{C} / \mathrm{P} 2 \mathrm{~B} / 548-549]$. If the teachers needed to only play music especially during mat time, they would "use the iPad and then we turn it the other way around" [U$\mathrm{E} \& \mathrm{C} / \mathrm{P} 2 \mathrm{~B} / 41]$. Marama reflected on a video-recorded episode of her using the iPad for children to sing along with a Māori waiata by saying she played back the video "as an extension" [U-E\&C/P2B/555-556]. Teachers played back waiata to "extend the children's repertoire of waiata that they know in the centre" [U-E\&C/P2B/563564]. Also, Minerva stressed that when they "play the songs out, the children are actually seeing it... It's just another way of pulling them in and just having that interest" [U-E\&C/P2B/42-44]. Marama found the iPad easier for playing back music and videos than the iPod and Minerva added that:

...having the words properly and being able to look at them also helps me figure out what the words actually mean, the individual ones. Because I can go, "I know that one." It's in the song and it's sung quite quickly, sometimes I struggle to tell them apart you know so, it's also learning for me but also making sure that what I teach them is correct. [U-E\&C/P2B/605609]

Teachers were able to look up videos to learn how to communicate with parents and children with English as a second language in their home languages. Minerva recalled how she learned the usefulness of accessing waiata by using iPads when she said "...my son came in listening to songs on the iPad, quite often because 
it's te reo Māori” [U-E\&C/P2B/599-600]. She further explained how accessing resources in te reo using the iPad helped her develop professionaly as well:

I'm getting there with learning the language but at the beginning it was so different from my home language and so different from English so having the words on the screen actually helped me remember them. [U-E\&C/P2B/600602]

Marama video-recorded children using sign language and directly shared it to parents using their learning portfolio, Educa. Marama had a child who only communicated using sign language. The iPad helped strengthen the teachers relationship with the family who could only communicate via sign language. Learning sign language by watching videos on tablets was more effective than using pictures for reference. The teachers learned how to use the sign language "for the national anthem" [U-E\&C/P2B/630-631]. They appreciated how the videos scaffolded learning sign language using "arrows... to [show] how you're supposed to move your hands. That's just something you won't be able to do without the technology" [U-E\&C/P2B/676-677]. Minerva described the effectiveness of using an iPad app to watch videos on how to sign:

...there'd been instances I knew that I had to talk to the parents at pick up time about something that had happened. It's one of those moments "I've got ten minutes... Right... Looking up the keywords on the app... so I could actually communicate." ... And it worked and the mom... really she even said, she signed, "Wow! Your sign language is great!". And I was thinking, "Only because I just watched you on the app." Because they were the ones who helped developed the app even, you know the sign language app. [U$\mathrm{E} \& \mathrm{C} / \mathrm{P} 2 \mathrm{~B} / 644-652]$

iPads were used to extend children's interests through research. The teachers and children were able to look up images of topics of interests often through Google searches [U-E\&C/P2B/619]. Moana recalled how she used the iPad to support "research on the sharks. ...and we look at the different images" [U-E\&C/P2B/813815]. Miverva extended children's interests involving places such as their homes and neighborhoods by using “Google Maps and look at people's houses..." [U$\mathrm{E} \& \mathrm{C} / \mathrm{P} 2 \mathrm{~B} / 769]$.

Manaakitanga ELC along with the services under its umbrella organisation used specific literacy programmes involving tablet use. They used Jolly Phonics to teach children literacy by associating a letter of the alphabet and its phonetic sound to a gesture. Moana developed this activity to extend children's literacy skills 
learning by playing a video of an alphabet song on the iPad whilst doing the gestures related to objects or animals beginning with a specific letter of the alphabet with the children. Moana appreciated how the iPad was a useful in supporting the teaching and learning of the song and its gestures to the children, saying "Your hands were actually in front of the iPad when you make the action cos the iPad in that instance was only a support tool" [U-E\&C/P2B/21-22]. She observed that this strategy held children's attention and allowed them to follow along with the gestures compared to using a laptop where children:

...zoned out. I kinda put the laptop here (gestures putting the laptop in front of her lap whilst sitting on the floor) because I can't put my hands on the front, so I find using the iPad easier rather than the laptop. [U-E\&C/P2B/36-38]

Teachers agreed that the multisensorial learning afforded by the iPad and the scaffolding by the teacher helped children visualise and remember the song. According to the teaching team, parents remarked that children extended their learning at home because the song and gestures were easily remembered and the songs could be played on their iPads. Teachers supported this home learning by giving parents action cards. Minerva acknowledged that they did not always rely on the iPad as they observed that "the kids... start singing to themselves and to just further develop their memory... We probably wouldn't use the iPad for that" [U$\mathrm{E} \& \mathrm{C} / \mathrm{P} 2 \mathrm{~B} / 70-73]$.

Scaffolding tablets at Manaakitanga ELC involved role modelling. In the video-recorded episode where Mahuika was teaching Miguel how to use an app's features to shrink or expand a picture, Moana explained that Mahuika "taught Miguel by role modelling and letting him do whatever he wants to do with it" [UE\&C/P2B/348-349]. Minerva gave her reflection on how Mahuika properly scaffolded Miguel's tablet use instead of her "just jumping in with him to show how it works" [U-E\&C/P2B/320].

At Manaakitanga ELC older or more knowledgeable children taught their peers how to use tablets and their apps. The teacher knew that "a lot of them already know how to swipe. It's not the first time they've seen an iPhone or an iPad and it's the way of the world these days" [U-E\&C/P2B/872-874]. Because if this reason, Minerva understood that "most of the children are self-taught" [U-E\&C/P2B/402]. 
The teachers also observed that other children "have seen their friends do it." [U$\mathrm{E} \& \mathrm{C} / \mathrm{P} 2 \mathrm{~B} / 403]$. Minerva continued that:

We see it quite a lot with the older children ... they really take the younger ones on and show them. I'm really impressed when they said, "Just push the button," and didn't say, "I'll do it for you." [U-E\&C/P2B/437-439]

Minerva described one episode wherein Makaio was trying to figure out how to use a Toca Boca music app. The teachers commented how in the video-recorded episode, the older children watched Makaio and scaffolded his engagement with the app by waiting "for him to see whether he actually did it. ...It's good that they give him the space as well instead of like be over him or probably be behind him" [U$\mathrm{E} \& \mathrm{C} / \mathrm{P} 2 \mathrm{~B} / 446-448]$. The teachers also assumed that perhaps another child "has left that app on for him" [U-E\&C/P2B/467]. They understood that Makaio:

...tends to kind of keep in the background and watch other children especially when there's a crowd and usually when there's an iPad. You've got four, five children wanting to take turns. So, he will often stand back a wee bit and look and blend into the background. [U-E\&C/P2B/273-276]

The teachers further explained that they were pleased to see other children teach Makaio because he often relied on teachers to teach him how to use the iPad:

He will probably wait till the big group disappears and then he'll come up to you "What's that? What are you doing?" And he'll probably, he likes a little one-on-one interaction as well. I think that's what Mahuika is doing. Mahuika probably thought that he doesn't know this iPad and that's why she took his hand. Just taught him how to use it but he could have done it by himself because he'll learn. [U-E\&C/P2B/285-290]

The teachers all agreed that tablets are just another tool and that "iPads in that sense, they do just play a role as a tool. It's not based on them" [U-E\&C/P2B/111112].

This section presented Manaakitanga ELC's case, a service that mainly used iPads to teach children phonics, writing, and creativity as well as use them for research and to document learning. The service's iPads had settings to limit the apps used to specific areas. One teacher managed the iPads, tested new apps, provided feedback to management, and shared new information with her colleagues. Teachers supported children's tablet use by allowing a wider range of digital activities and at times paired with other non-digital or multimodal ways of learning. The next section presents the collective case study results from a user kindergarten. 
6.2.3. User kindergarten service: Nunui Kindergarten. This kindergarten employed five teachers whose ECE experiences ranged from five to twenty years. The teachers' ages ranged between their twenties to their fifties. Teachers in the team had worked from one term to seven years at the kindergarten. The kindergarten's umbrella organisation provided each teacher with their own iPad to use for teaching and learning. In addition to the five teachers, the kindergarten employed a teacher-in-training and an administrator who worked as a support staff. This administrator managed the ICT in the kindergarten including two more iPads designated for children's use.

The Phase 2A focus group interview was held on 11 May 2017 and the Phase 2B video-SR interview was held on 18 May 2017. Table 6.6 provides information about the participants.

\begin{tabular}{|c|c|c|}
\hline Pseudonym & Role & Participation \\
\hline Naomi & Fully certificated teacher & Phases 2A \& 2B \\
\hline Nyree & Fully certificated teacher & Phases 2A \& 2B \\
\hline Nessa & Fully certificated teacher & Phase 2A \\
\hline Nina & Fully certificated teacher & Phase 2B \\
\hline Norah & Head teacher, fully certificated teacher & Phase 2B \\
\hline
\end{tabular}

\section{Table 6.6. User kindergarten participants.}

Video-recording of tablet use was undertaken immediately after Phase 2A on 11 and 12 May 2017. There were nine video-recorded episodes shown in Phase 2B (see Table 6.12). Because there were more than 20 children in the service at one time with their participation varying each day, children were not assigned pseudonyms. Thus, a child in one episode was not always the same one in the next episode. 


\begin{tabular}{|c|c|c|}
\hline \multicolumn{2}{|r|}{ Participants } & Description \\
\hline 1 & Five children & $\begin{array}{l}\text { Five children lying on a big beanbag in the comfortable area } \\
\text { whilst one boy in the group engaged with an alphabet } \\
\text { writing app (Letter School) on the iPad }\end{array}$ \\
\hline 2 & $\begin{array}{l}\text { Nyree and Nancy with } \\
\text { one boy plus a brief } \\
\text { appearance by Naomi }\end{array}$ & $\begin{array}{l}\text { Nyree and Nancy were figuring out the password for the } \\
\text { children's iPad because it suddenly updated whilst a boy } \\
\text { was using it. The boy waited whilst the teachers resolved } \\
\text { the issue. Naomi briefly talked to Nyree to ask what was } \\
\text { happening. Nancy was the kindergarten's ICT staff who } \\
\text { managed the iPads and thus was not part of the video-SR } \\
\text { sessions. }\end{array}$ \\
\hline 3 & $\begin{array}{l}\text { Nancy with one girl } \\
\text { and six boys }\end{array}$ & $\begin{array}{l}\text { Nancy plugged the iPad into the speaker to play a song from } \\
\text { the Disney movie, Moana whilst one boy sat next to it to } \\
\text { play with the xylophones and the other children listened or } \\
\text { danced to the song. }\end{array}$ \\
\hline 4 & Nyree and two boys & $\begin{array}{l}\text { Nyree talking to one of two boys using the iPads about } \\
\text { where to place his name on the turn-taking name board as } \\
\text { the boy started to use the iPad. }\end{array}$ \\
\hline 5 & Nyree and Naomi & $\begin{array}{l}\text { After taking the iPad from children, Naomi put it on the } \\
\text { kitchen counter to get the bag of groceries before doing } \\
\text { kitchen-related work as Nyree told her what to do with the } \\
\text { groceries in the bag. }\end{array}$ \\
\hline 6 & Norah & $\begin{array}{l}\text { Norah was looking for information on Facebook for a parent } \\
\text { and reading the information from the iPad to the parent. }\end{array}$ \\
\hline 7 & $\begin{array}{l}\text { Norah with two boys } \\
\text { and three girls }\end{array}$ & $\begin{array}{l}\text { Norah played a YouTube video of Storm Troopers dancing } \\
\text { to settle a boy wearing shoes with Star Wars Storm Trooper } \\
\text { prints. Children engaged with the video and associated the } \\
\text { dancers with the boy's shoes. }\end{array}$ \\
\hline 8 & $\begin{array}{l}\text { Norah with five boys } \\
\text { and two girls }\end{array}$ & $\begin{array}{l}\text { Norah talked about animals and their sounds whilst children } \\
\text { huddled close to her to watch the video and mimic the } \\
\text { animals' sounds. }\end{array}$ \\
\hline 9 & $\begin{array}{l}\text { Three boys and two } \\
\text { girls }\end{array}$ & $\begin{array}{l}\text { One boy held the iPad to show a YouTube video about } \\
\text { animals and their sounds as the other children walked with } \\
\text { him. They plugged the iPad into the speaker and watched } \\
\text { the video by themselves whilst mimicking the animal } \\
\text { sounds. }\end{array}$ \\
\hline
\end{tabular}

Table 6.7. Phase 2B SR-video episodes: User kindergarten.

Nunui Kindergarten had been using iPads before the current teachers started working at the kindergarten. These iPads were obtained through grants [UK/P2A/67]. The kindergarten's tablets were also insured so the teachers got "a new one for the broken one" [U-K/P2A/199] if some became damaged. Wireless internet connection was available within the building allowing internet access for the iPads inside and at some areas outside the kindergarten building. Inside the kindergarten building, there was a relaxation area, near the front door, where there were two childsized sofas and a beanbag for children to use whilst engaging with the iPads. In this area, children used two iPads independently and this encouraged collaboration 
between younger and older children who used iPads independently or in groups.

Naomi explained that an iPad was allocated to each teacher, there were seven iPads available, "two for the kids. ...there's five teachers" [U-K/P2A/36]. Naomi reported that "all of us" [U-K/P2A/9] use tablets and Nyree added the iPads were available "before we started" [U-K/P2A/14]. Naomi reported that the teachers' main reason for using iPads was that they were "given as a teaching tool just for writing learning stories and the children have their own ones that they use..." [U-K/P2A/17-19]. Nyree explained that iPads allowed them to work "faster and smarter" [U$\mathrm{K} / \mathrm{P} 2 \mathrm{~A} / 22]$.

Despite the availability of tablets, some teachers did not let children use their iPads. Naomi was one of these teachers who "never [got] the iPads out for the children. Other teachers do but I never do" [U-K/P2A/465]. She explained that she was "not a fan of the ...iPads because actually, at home they already get heaps. And... at the kindergarten, they are actually here just for a short time..." [U$\mathrm{K} / \mathrm{P} 2 \mathrm{~A} / 594-597]$ so she believed children should make use of their time at the kindergarten without using iPads. Naomi reasoned that when children used the iPad, it was "difficult to actually to take them away from the moment. Especially with three- and four-year-olds. ...they are not willing to literally move to hear the answer" [U-K/P2A/217-220]. She did not want children "sitting down there watching Peppa Pig for 20 minutes..." [U-K/P2A/517-520]. She thought that "sitting down playing games is so limiting" [U-K/P2A/567]. Naomi and Nyree added that when activities were done "on a screen, because it's facing... away from everyone else, there's no talking about the picture... Even if there's another kid leaning over and watching, they don't talk because they just focus on the screen" [UK/P2A/723-726]. A few teachers expressed that their preferences for not using tablets were based on their perceptions of the sedentary nature of television viewing:

Nyree: And it's interesting that some of the children that you know spend a lot of time online. You can see it in the air, you know interactions and stuff like that. I'm not saying that that's completely the reason for it, but you do see some from kids that spend a long time on... the way they communicate is a little bit different, eh? Nessa: And what they're watching too. Naomi: I remember when I was at the university, “Aww, it's not passive like TV. It's interactive." That's kind of how it was sold to us. They're not interactive. They're passive. Doing this is not interactive. It's passive. It's watching. ... It's not interacting. 
Nyree: Especially when they're doing a game. They don't have to think about it. They can just do it.

Naomi: They can just stare... I'm not a fan.

Nessa: I'm a fan within reason. [U-K/P2A/635-650]

Two teachers were cautious about letting children use their iPads. Nyree explained her perspective that tablets "should be used as a tool to extend learning rather than be the learning tool completely" [U-K/P2A/688-689]. Naomi believed that the iPad was "not really even useful as an educational tool. Actually, there'd be limits on it anyway" [U-K/P2A/514-515]. In relation to her beliefs, the other teachers were aware of the potential for overuse in that anyone "would get distracted and... easily spend eight hours... just binging. Going from one YouTube video to the next" [U-K/P2A/617-621]. Nyree expressed how the team understood this difference when she said, "Naomi would do something more than I would do it and that's kind of where we complement each other" [U-K/P2A/453-454].

The service also had a set "time limit, they usually get ten minutes and move from there" [U-K/P2A/400] and “...not every day" [U-K/P2A/423]. Nessa still found it "good that they learn how to use them because they'll need..." [U$\mathrm{K} / \mathrm{P} 2 \mathrm{~A} / 392]$ to be able to use technology as it is "part of life" [U-K/P2A/394-395] as Nessa and Nyree pointed out. Nyree understood the "need to teach children how to use them in a way that they are not prone to loving them like this" [U-K/P2A/610611]. Nessa believed that tablets could help "inspire different interests" [UK/P2A/633]. Nessa explained that they role modelled to children how to properly use iPads. Additionally, Nyree explained that the kindergarten had iPads because they were "making learning more interesting" [U-K/P2A/20-21]. Nessa added that, initially the novelty of tablets distracted children and that "if we're taking a photo half the time the children would go 'Cheese' or pose" [U-K/P2A/568] but they were able to solve this issue by letting "another child take the photo" [U-K/P2A/569] which resulted in more natural reactions from the children having their photos taken. Nyree had observed children adjusted to having tablets over time when the teachers wanted to use iPads with the children and they would, "say 'Nah... all good.' Don't wanna.” [U-K/P2A/427-428].

The teachers at Nunui Kindergarten frequently indicated that they used their iPads for documentation and assessment. iPads helped make learning visible. Nessa, 
Nyree, and Naomi described the iPad as a "great tool... to show... parents" [UK/P2A/259-263] children's work. Naomi specified that she used her iPad "often just for taking photos" [U-K/P2A/145] and "then using it in the children's assessment" [U-K/P2A/147]. Nyree found it "really nice to access photos that you took three weeks ago. ... Kids ask you... You can go back and show them. They can revisit and stuff like that" [U-K/P2A/48-51]. Nessa agreed that this was the "main thing" of using tablets [U-K/P2A/146]. Nessa explained how they used Pic Collage "to add, if you're taking photos and the child is telling you stuff... So, you actually write the chunkier learning story" [U-K/P2A/245-247].

Children took advantage of opportunities to use the teachers' iPads to access the internet. When this happened, teachers made sure children used iPads appropriately, preferably for photography. Teachers observed that letting children use their iPads for photography benefited their understanding of children's perspectives:

Nyree: But sometimes you find, a lot of times you find really gold ones where some of the older kids got a hold of it and you've got some really candid shots. Nessa: It's fascinating to see.

Nyree: Yeah. Through their eyes.

Nessa: Through their eyes.

Nyree: Yeah. You'll have them filming, like taking photos of children jumping off the boxes and stuff and it would be different angle whatever... a different view to what we would take... [U-K/P2A/554-561]

Nina remarked that iPads were effective settling tools. Showing children photos using the iPad helped them settle as well. Nessa found that tablets were "great for children who are settling as well, cos they like having a picture of themselves" [U-K/P2A/52-53]. She explained that they used iPads for settling if a "child gets upset and you can show them photos from the day, that they're having a great time" [U-K/P2A/253-254]. The children used the camera functionality of the iPad like "as a mirror for some of the kids. They love to kinda suss themselves out, like having a look" [U-K/P2A/58-59].

The teachers, together with children, looked at photos to revisit past events and activities. To Naomi, the iPad's camera and an app called Pic Collage were used for "children's assessment" [U-K/P2A/147-149]. Nyree recalled that compared to iPads which were "instant" [U-K/P2A/174-177], using film cameras necessitated waiting for photos to get printed. Documentation using iPads helped parents 
instantly see evidence of their children's activities. Nyree believed tablets were useful in providing parents with instantaneous documentation of children's activities because:

...when parents can see them during the day while we're doing it rather than, you know, waiting to put the photos on the walls or that sort of jazz. Or put them in the books... show them straight away. [U-K/P2A/264-266]

Nyree explained that because they had two tablets allocated for the children, they "have iPads and they can take photos and stuff" [U-K/P2A/25-26]. The only disadvantage to letting children use teachers' iPads for photography was that the teachers had "...to go through it at the end of the day. I never do that, so I've got lots and lots of photos on here that are literally grass, or someone's elbow" [U$\mathrm{K} / \mathrm{P} 2 \mathrm{~A} / 552-553]$.

Nyree reported that the camera app of their iPads or touchscreen phones was also useful for documenting events. A suggested solution to this was to assign one teacher to take photos. Naomi and Nyree described using their iPads:

Naomi: on an outing, one teacher or one adult is dedicated to just taking photos ...the other one has to document everything. Cos actually you do take a lot of photos on an outing because everyone wants a bit of a story about how they went to Te Papa Tongarewa.

Nyree: Oh, look at our last trip to Te Papa when we all forgot the iPads ... so we were using our phones to document with them. [U-K/P2A/330-336]

Aside from using tablets for documentation and assessment, the teachers also used them for research. Nyree found the iPad helpful in answering children's questions because she could "quickly Google it and find out. It fills holes in our knowledge." [U-K/P2A/24-25]. She added that she would "literally go straight to camera... or Google" [U-K/P2A/92]. Nessa also used "them for photos or for looking up information" [U-K/P2A/431]. She added that the children would ask them for information "and we'll look it up" [U-K/P2A/433]. Nessa preferred "finding out something that they're interested in. You can Google it and look it up with them" [U-K/P2A/56-57]. Nyree described how she used her iPad to research about "caterpillar stuff which was awesome. They have the whole life cycle and got to see the caterpillars" [U-K/P2A/673-676]. Nessa commented that researching with children using iPads "means they are researching not just playing a game" [UK/P2A/677-678]. 
Nunui Kindergarten's iPads for children had educational games loaded on them which Nessa identified were for "literacy and numeracy" [U-K/P2A/375]. While some teachers also had games on their iPads, others avoided putting games on their iPad because the children "have scraps. ...they would be like (gesturing grabbing of iPads between two kids)" [Nessa, U-K/P2A/363-364]. Instead, Nessa said that she "would rather play a board game" [U-K/P2A/702] and Nyree explained that with "a board game you get discussion" [U-K/P2A/706]. Nyree expressed that they had to "really be very careful on what you put on there, don't you? And some of the games have ads and stuff which are dodgy" [U-K/P2A/377-378].

When asked about other apps, Nyree explained that the kindergarten had numeracy apps such as "Bugs and Buttons. It kind of helps them with their numbers but they're still not like actually doing it... They are just following...” [U$\mathrm{K} / \mathrm{P} 2 \mathrm{~A} / 408-410]$. When asked who decided which games to put on the children's iPads, Naomi reported that the teaching team would "discuss it in a meeting" [UK/P2A/382]. Teachers "restrict the games" [U-K/P2A/355-358] to prevent children from spending all day using the iPads. Even if children did not directly control the iPad, teachers considered this as screen time saying that:

...even if a child's not having her turn, they are peering over the shoulder of the other children. So, even though they might actually only have ten minutes or so on, on it themselves, they've spent an hour doing nothing else but watching the screen, even if they're not the one controlling it. [U-K/P2A/365368]

Teachers used iPads to play music by connecting them to a speaker for children to dance along with and to view YouTube videos. Nyree perceived that watching videos directly on the iPads was better because children moved freely in the kindergarten and would have gone away "by the time you hooked it up to a projector" [U-K/P2A/233]. Nyree reported that the teaching team also used their iPads to play music and videos. So, if "the kids want to have a boogie or something like that, we'll put up, we'll connect it up to a speaker and have a dance" [U$\mathrm{K} / \mathrm{P} 2 \mathrm{~A} / 152-153]$. Norah who added that the teaching team used iPads to play "background so that children have something to listen to" [U-K/P2B/96-97]. Nancy plugged the iPad into the speaker and let the children choose the song for them to dance along. Naomi observed the children "actually often do dance, and it was nice that... they actually do get the instruments out a lot as well, when the music is on..." 
[U-K/P2B/87-90]. Teachers provided resources to support this child-led way of using their iPads to play and dance with music or videos:

Naomi: This is very child-interest... child-led...

Nina: It's where they take it...

Norah: Yeah, in control of their own learning...

Nina: And when we see that and find other resources if required. [U$\mathrm{K} / \mathrm{P} 2 \mathrm{~B} / 115-118]$

Teachers at Nunui Kindergarten were concerned about the physical and cognitive issues linked to tablet use. Nyree asserted that "you need to physically go work on their motor skills" [U-K/P2A/737-738]. Nyree explained that children tended to do the same activities on the iPads and that these limited their thinking because these activities were not:

...open-ended. They can't think... they don't have to think about it too much. They just do it and move on. And if they don't do it, it gives them the answers and do the next one and just do it straight away. [U-K/P2A/419-421]

Another issue the teaching team brought up regarding iPad use was its size as Nyree and Naomi described it as "too big" [U-K/P2A/161-168, 178] and Naomi added that their iPads were too "cumbersome" [U-K/P2A/82] to "stick in a pocket" [U-K/P2A/102-109]. To Naomi, the size was a challenge to how teachers worked because when they carried it around, "it means you are one arm down, always. Because you're holding on to it" [U-K/P2A/78]. The teaching team understood that if the iPad was smaller it would be difficult to watch videos and use them for documentation and assessment. When a teacher needed to put her iPad down to do something else, they reported that children tended to pick it up straightaway and use it for photos or games. They illustrated a common scenario:

Nessa: It would be nice to just be able to chuck it in your pocket when you've got a kid that's just fallen over so that you can go attend to them...

Naomi: Yeah. ...like if you're on the sand pit and you want to dig something...

Nessa: Spend all your time like that (showing the iPad pinned in the armpit). Naomi: ...It's not just into children, it's just everything you do you just require both your hands.

Nyree: Yeah. ... and I will forget about it and it will end up raining and I come back and "Oops, my iPad's soaking wet." Luckily, it's got this awesome case... [U-K/P2A/275-287]

Naomi reported that teachers primarily used their iPads for documenting events such as trips found it difficult to carry the iPad whilst "holding hands with children when you're out of the kindergarten" [U-K/P2A/315-326]. Naomi and 
Nyree found "the largeness of it, a pretty major thing. Especially when you're holding it and a kid falls over" [U-K/P2A/126-128]. They expressed the importance of making sure children did not stray away.

To mitigate the size issue and potential breakage, management provided big rubber cases that bounced when iPads fell to the ground. Nessa found the cases "fine in the rain" $[\mathrm{U}-\mathrm{K} / \mathrm{P} 2 \mathrm{~A} / 196]$ and Nyree added that "the weight doesn't worry me" [U$\mathrm{K} / \mathrm{P} 2 \mathrm{~A} / 272]$. Nyree who explained that the cases made the iPads slightly water resistant in the rain and to other forms of damage such as "scrapes" [U-K/P2A/207210]. These rubber cases allowed teachers to respond to emergencies and not worry about their iPads breaking.

Nunui Kindergarten's teachers scaffolded children's use of apps and games by making sure these apps, particularly YouTube videos because Nyree explained that the teachers did not want children exposed to "ads and stuff which are dodgy" [U-K/P2A/378]. They expressed caution that children did not spend too much time watching videos, especially those the teachers did not like. Nyree gave an example that at times "the kids will find it and they suddenly have Peppa Pig up. They are quite good at that" [U-K/P2A/436-437]. The teachers were aware that the children "are really good at finding what they want to find. They suddenly have cartoons up in the kindergarten" [U-K/P2A/440-441]. These usually happened when teachers were moving:

around and you see something, and you just discard [the iPad] and you're quickly going to do whatever it is. And then, after, five minutes later, you're like, "I might as well get a picture of this... Where's my iPad?" [U-K/P2A/134-136]

Nunui Kindergarten's teaching team believed in balancing children's use of iPads with other non-digital educational tools. Although the team was generally positive about using iPads, there were some tensions between the teachers who perceived that some children had too much exposure to technology. Some teachers observed that these children showed signs of dependency on the iPad and this affected their interactions with other people. Teachers who limited these children's iPad use such as Nessa who believed that the kindergarten should be "a safe haven from technology" [U-K/P2A/593] so the children could learn to "interact with people" [U-K/P2A/598]. Furthermore, iPads were not available every day and if so were "only out in the morning" [U-K/P2A/424] as Naomi reported. Nyree added 
that they were "more likely to have the iPad out on rainy days" [U-K/P2A/459]. They discussed how some of the teachers helped children interact and build friendships whilst extending learning using iPads. Other teachers still preferred to teach children different ways of interacting with each other through non-digital tools like playing board games, through drawing or painting, or by playing with physical toys and objects.

In Phase 2B, when shown a video-recording of five children engaging with writing on the iPad independently, Nyree remarked that the children "learn from observing others" [U-K/P2B/219] and worked together whilst using the iPads. To Nina, having two iPads available for children enabled the children to "share what they were seeing with each other because they are both sharing the same app" [U$\mathrm{K} / \mathrm{P} 2 \mathrm{~B} / 135-136]$. Upon reflecting on the episode, Nyree explained that "I think the older children with the expertise ... were showing the other child how to do it and the others were watching, learning how to make it work" [U-K/P2B/14-15]. The teachers agreed that this area in the kindergarten was easiest for them to monitor children's iPad use from within the staff room or adjacent kitchen area with Norah saying, “if we're down here, we can observe what's going on..." [U-K/P2B/212].

Teachers scaffolded iPad use in the comfortable area by sticking children's name tags on a small whiteboard to indicate whose turn it was to use the iPad next. This system taught children fairness and self-management because they were expected to take their names off the list after using the iPads. Nyree reported that the teachers oriented "the newer children [who] will come and let you know they want a go. So, that's why you kind of explain it to them" [U-K/P2B/226-227]. Teachers monitored this system to make sure that children placed their name in the correct order, and they took off names of children who had forgone their turn. They learned this system from how other kindergartens taught children turn-taking when using non-digital tools such as playing on the swings and decided to apply it to iPad use. The teaching team had a discussion on how the tablet contributed to teaching children turn-taking. Norah explained that, "if it's not their turn, it's the next person's turn, they go and do something else. ...Yeah, and most of the kids... understand it is a wait-for-your-turn just like everything else that we do here" [UK/P2B/201-209]. Norah added that this system also helped teach literacy because 
children became more familiar with their names and having their name tags allowed them to copy their names for writing practice or for naming their work.

After showing an episode of Norah using the iPad to communicate with parents, the teaching team explained how tablets made communication easier. Nina "found it improved the communication.... when we had the private messaging in Facebook" [U-K/P2B/360-361]. Norah understood that this way of communication was easier "especially for younger parents... the access was easier and there was much quicker turn around for them" [U-K/P2B/362-363]. Nyree described how the iPad apps helped teachers update parents with activities by providing all of them with "an overview of what the group's been up to rather than our individual learning" [UK/P2B/383-384] of their children. Nunui Kindergarten has "a Facebook page so parents can see what was happening. We put up pictures of what is happening and private messaging. And we can reply to them as well on it" [U-K/P2B/336-337]. Norah was aware that "a lot of the parents are happier to call up, but they don't need to have money on their phones to call in or to send a text. They can just reply back using [Facebook] Messenger" [U-K/P2B/339-340]. Compared to emails and texting, using the Facebook Messenger app allowed teachers to track if their correspondence with parents had been read:

...the thing with Facebook is that you can see when the message has been received. Because it would come up "seen". With a text, you don't know if ....it's been received, and they've not actioned it so... we can see that they've been received even though they don't reply. We know that they've got it. [U$\mathrm{K} / \mathrm{P} 2 \mathrm{~B} / 369-372]$

Teachers felt that this way of communicating with parents afforded quicker and more timely responses. To Nina, having learning story apps on their iPads let teachers and parents engage in "sharing the learning... Sharing at the end of the day what may have occurred during the day to everyone" [U-K/P2B/379-380]. Norah let children use her iPads "to take photos... I'm doing photography” [U-K/P2B/304] to support her documentation which she shared with parents. Nyree explained that children were encouraged to use iPads for photography as teachers noted that the children "go straight for the camera outside" [U-K/P2B/484]. Aside from photography, iPads were used to follow children's interests for a variety of other activities such as settling, research, games, music, and movement. Norah expressed how iPads were effective learning resources, because with tablets, "you can engage 
more, you can ask questions, you can challenge what they're thinking... It gives us so much information about each child who is involved in something like this, so you learn so much more" [U-K/P2B/462-471]. Norah and Nyree elaborated further:

Norah: Whatever their interest is in, we would try and find something along those line, through YouTube usually. It's a great resource.

Nina: And it's something they are interested in. It's not...

Norah: We'd change whoever the children is. We use it a lot for insects and animals and bugs at the moment... What interest is going on... the worms or...

Nyree: ...the caterpillars. [U-K/P2B/425-431]

Playing videos from the iPad helped teachers redirect attention from one child to a group of children. Nina reasoned that using iPads in groups helped shift the "focus for a wider group so the child you're settling isn't singled out... So, his friends become part of that foundation" [U-K/P2B/413-416]. Norah used her iPad to both settle a child according to his interest and to include a group of children in the activity:

...it is about finding an interest for them and he had on Star Wars shoes that were very cool, so I found the Star Wars video for him and it captured him... and obviously everyone else was interested... It's just following their interest and calming them. [U-K/P2B/397-401]

The portability of the iPad allowed teachers to pass the device to children for them to continue learning about an interest introduced by the teacher. However, Norah admitted that without a teacher, there was less learning but more participation when children gathered to share their interests using iPads. They were glad to see children "sharing what they were seeing with each other because they are both sharing the same app" [U-K/P2B/135-136]. Norah explained that this way of using iPads encouraged "collaboration... trial and error, especially for the younger children" [U-K/P2B/137$141]$.

Issues regarding the online access whilst using tablets including cybersafety and limiting access to inappropriate content were discussed in Phase 2. When asked about issues when using iPads at the kindergarten, the teaching team reported that the service's internet connection limited their iPad's functionality outdoors. Nessa confirmed that some areas in the kindergarten "don't have internet" [U-K/P2A/221]. They planned to resolve this by getting "an extender outside to extend internet outside." [U-K/P2B/476-477]. Yet, Nina and Naomi saw that the lack of internet connection outside afforded children to "engage in more physical activities" [U-K/P2B/487]. 
When a video-recorded episode of children using iPads in groups was shown to the teaching team, Nina, Norah, Nyree, and Naomi were pleased to see iPads being used by "a larger group" [U-K/P2B/490] as children's iPads could be used without strict monitoring because children "can't access the internet. So, it's safe..." [U$\mathrm{K} / \mathrm{P} 2 \mathrm{~B} / 302]$. With regards to children's access to the internet, potentially dropping the iPads, and using the device for a long time, Nina was:

not too worried because it's passworded. If a child picks it up and it does have the protective case on it so, that would only be a very short term need to put down. [U-K/P2B/293-295]

After showing the teaching team a video-recorded episode of Nyree and Nancy resolving the password issue on one of the children's iPads, Nyree explained that the iPad "had restarted itself so I had to set it back up again to go to work" [U-K/P2B/3637]. The teaching team admitted that with seven iPads at the service, teachers found passwords for each iPad hard to track. They resolved this by having a dedicated staff member, Nancy, manage the iPads designated for children's independent use. Norah explained that Nancy "keeps track of what they all are, so we don't have to really to know our own passwords" [U-K/P2B/60-62]. Reflecting on the video-recording of Nancy helping Nyree resolve the issue with the children's iPad, Nina explained that children learned to wait and be patient whilst the staff "went through that process" [UK/P2B/38-43]. Norah described that a frequently occurring issue with their iPads was when:

...they update overnight then you could put them out in the room but that didn't happen. It doesn't happen that often. ... It does get confusing which ones had similar but slightly different passwords cos that's how it had to be set up so it's just keeping track of which iPad has got that password. [U-K/P2B/51-58]

This section has presented the case report of Nunui Kindergarten. The service allowed children to independently use iPads whilst teachers used iPads for a wider variety of purposes. Teachers used their iPads for research, playing music/watching videos, documentation and assessment, and communication. Children could freely use two iPads which had educational games and were usually used within a comfortable area where teachers could observe them from a distance. Teachers used a turn-taking system to manage children's independent iPad use. Some teachers found that the iPads' size hindered their other work in the kindergarten. This collective case study report on the last user service is followed by a chapter summary. 


\subsection{Chapter summary}

This chapter has presented qualitative results from user services. Firstly, results from the qualitative survey responses of how user services supported children's learning using tablets were presented. Respondents reported scaffolding use and access of tablets and using them for research and extending children's interests.

Next, the results of Phase 2 involving three user services were outlined. Teachers/educators at Koanga Wākäinga Home-based used their personally-owned tablets for teaching and learning at educators' homes. Teachers/educators supervised children to guarantee that they used tablets to engage with educational games or creativity apps. The teaching team placed limitations on children's tablet use through apps and settings and set screen time limits or allowed tablet use only as a reward for good behaviour. iPads at Manaakitanga ELC were used in conjunction with the service's educational programmes. The iPads had settings which limited children's app use to specific areas at the service. One teacher managed their iPads and researched or trialled new apps. Finally, Nunui Kindergarten had a balance of independent and teacher-facilitated tablet use as children could freely engage with two iPads in groups or independently with a teacher-monitored turn-taking system in place. Each teacher was provided with an iPad and some of them used these iPads with children. Other teachers limited use by not bringing out their iPads or making children's iPads available at certain times only. Some teachers noted that the iPad's size hindered them from doing some of their other duties.

The qualitative results from user services presented in this chapter provided additional explanation particularly in relation to the national survey's quantitative results. The next chapter discusses these results in the order of each of the research questions. 


\section{Chapter 7}

\section{Discussion and conclusion}

This chapter discusses the findings of this study about the use and non-use of tablets by early childhood education (ECE) services in New Zealand. The next sections answer the following research questions:

1. What is the extent of tablet use and non-use for teaching and learning amongst teachers/educators in four ECE service types in New Zealand?

2. What are the reasons for the non-use of tablets amongst teachers/educators across four ECE service types in New Zealand?

3. How do teachers/educators use tablets in ECE settings to support children's learning?

4. What are the barriers and affordances to tablet use in ECE pedagogy?

Answers to these questions were based from data collected through a national survey (Phase 1) and a collective case study (Phase 2). In Phase 1, the national survey had 361 responses - a 10.4\% response rate, and addressed the first, second, and third research questions. The survey results revealed that there were slightly more tablet non-users than users. The collective case study undertaken in Phase 2 provided additional answers to each research question. Seven ECE services, comprising four non-users and three users, participated in the focus group interviews in Phase 2A. Their responses addressed the second and fourth questions. To answer the third and fourth questions, the three tablet user services participated again in video-SR sessions in Phase 2B. This chapter discusses and critiques the findings presented in Chapters 4 to 6, using headings rephrased from the four research questions to structure each section beginning with the first research question about the extent of tablet use and non-use in New Zealand. 


\subsection{The extent of tablet use and non-use for teaching and learning amongst teachers/educators in New Zealand ECE services}

This section discusses the extent of tablet use and non-use for teaching and learning amongst teachers/educators in four ECE service types in New Zealand. Services' responses in Phase 1, the national survey, will be elaborated first followed by specific examples from Phase 2, the collective case study. Through this, the qualitative information gained from Phase 2 will explain the quantitative results from Phase 1.

\subsubsection{Extent of use and non-use according to demographics. The} findings revealed differences in the use or non-use of tablets according to service type such as more kindergartens using tablets than home-based services and playcentres. As outlined in Chapter 4, kindergartens were more likely to use tablets whilst education and care services were equally divided between users and nonusers. Playcentres were more likely to be non-users followed by home-based services. These findings are in line with previous studies (Gerritsen et al., 2016; Mitchell \& Brooking, 2008) which indicated that these service types preferred that children engage in physically active and non-digital play. Mitchell and Brooking's (2008) research aligns with the findings of this thesis when their research found that education and care services and kindergartens showed a steadily increasing use of ICT.

The issues surrounding the use of personally-owned tablets were revealed in this study. Many non-users allowed teachers, parents/whānau to use their personallyowned touchscreen devices. Analyses of the national survey suggested that nonusers would allow the use of personally-owned tablets if use could be limited to two to four children at one time. Phase 1 found that more than half of responding kindergartens did not allow the use of personally-owned tablets despite kindergartens having the highest proportion of user services across all four service types. Almost half of education and care services allowed teachers/educators to use their own tablets in the centre. The results suggest that some kindergartens and education and care services which used service-owned tablets also limited use of personal touchscreen devices. This was evidenced in the user kindergarten and education and care services that participated in Phase 2 of the study. 
Umbrella organisations played a key role in the adoption of tablets in New Zealand's ECE services. One non-user service, Iorangi Playcentre and two user services, Manaakitanga ELC and Nunui Kindergarten were overseen by their own respective umbrella organisations which provided their teachers with tablets and support staff to help teachers with updates, app purchases, and technical concerns. Phase 2 also identified that Iorangi Playcentre's core leadership team decided to begin using the iPad provided by their umbrella organisation, the Playcentre Federation, for documentation of health and safety concerns and possibly to replace parents' and educators' use of their personally-owned tablets and phones. This finding suggests that many factors contribute to the fluid nature of tablet use and non-use.

This study found that services' decisions regarding the adoption of tablets could be based on whether they allowed the use of personally-owned tablets. Earlier international studies (e.g., Oliemat et al., 2018) explored teachers/educators who used their own personally-owned tablets with other studies on personally-owned touchscreen devices. The findings of this thesis add knowledge to the ECE sector in New Zealand because a search for literature revealed a scarcity in local empirical studies about this issue. Services who participated in this study expressed concern that using personally-owned tablets posed a risk to children's privacy and a service's overall cybersafety. In particular, the participants in Phase 2 stressed the challenges involving cybersafety of children when adults, such as parents/whānau, used their personally-owned devices for documentation and shared photos and videos of children outside the service. Teachers/educators who used their personally-owned tablets and similar devices expressed hesitance in letting children use these technologies because of the potential issues such as internet data costs and the risk of damaging their devices. Unfettered facilitation of personally-owned tablet use and their consequential issues related to cybersafety could be explored in further research to provide information on how services could adapt their policies and guidelines, especially now that the personal ownership of digital technologies has become commonplace.

Given the lack of existing research investigating the number of children using tablets, the findings in Phase 1 are important because it showed that New Zealand's 
ECE teachers/educators preferred that children use tablets in groups. With regards to the maximum number of children who could use tablets at one time, non-users and users who responded in Phase 1 preferred a small group of up to five children. Usually, a small group of three children would engage with one tablet. A possible reason was that the size of tablets best fit a small group of up to five children. In Phase 1, many non-users responded that they might use tablets in groups or individually if use was facilitated by a teacher/educator. These findings are supported by earlier international studies (Gray et al., 2017; Kirova \& Jamison, 2018) which also indicated that tablets afforded children's collaborative use, particularly in small groups. This research adds to these studies by focusing on New Zealand and its ECE sector. Whilst Walsh and Farren (2018) found that teachers were equally divided on whether they should let children use iPads individually or in groups, this study found that teachers/educators in New Zealand preferred that children used tablets in groups.

In Phase 1, some non-users responded that they intended to acquire tablets within six months. They did not explain their reasons in the survey but two non-user services in Phase 2 shared the different reasons they acquired tablets which were for use by teachers/educators and children in their transition groups and for use by educators to document health and safety issues. Whilst the collective case study identified two non-users that were considering using tablets at their services, of interest is the reverse of this scenario by former user services who responded in Phase 1 that they had discontinued using tablets. User services stopping the use of tablets is a new finding based on the results from this study's national survey. These results showed that a non-user service could shift to using tablets more comprehensively depending on the decision of the service's teaching team. The same implication could apply to user services, that their teaching team could decide to stop using tablets, or at the very least limit how it was used in their services. These results are important because they indicate that use or non-use is not a static concept.

Findings from this research have also highlighted differences in the size of user services' teaching teams compared to those of non-user services. Despite the exploratory nature of this study, it offers some insight into a possible relationship 
between the size of a teaching team and a service's acquisition of tablets. User services tended to have fewer teachers/educators (around five to ten) compared to non-users (around five to fifteen). User services also had a median of four or five teachers who used tablets for teaching and learning compared to non-users. Further inspection of the collected data revealed that services with small teaching teams were more likely to use tablets than those with bigger teaching teams. The findings contribute to a more nuanced understanding of the characteristics of services which chose to use or not use tablets in their programmes. Further research would be useful because this study did not explore why there were differences in use amongst differently sized teams.

7.1.2. Policies and guidelines on tablet use. Findings from this study have revealed that when services used tablets, it did not necessarily mean that they established and implemented policies and guidelines for staff around tablet use. Data in Phase 1 showed that user services with screen time policies had more teachers/educators who used tablets than those without screen time policies. Some teachers/educators did not let children under two-years of age use tablets. This practice is supported by international guidelines which have discouraged screen time for children under two-years-old (Chassiakos, et al., 2016; Strasburger \& Hogan, 2013; World Health Organization, 2019). Although more than half of user services implemented formal policies or guidelines for staff on tablet use, most of these services did not have a screen time policy. The evidence from this study suggests that policies or guidelines may not be necessarily implemented by some user services. User services which participated in Phase 2 explained that because tablets are like other resources in ECE, they did not require policies or guidelines. However, similar to other popular resources, scaffolding by teachers/educators for balanced use and self-regulated use by children was an important concern. Earlier literature supported these findings when they recommended that teachers/educators monitor young children's tablet use (Chassiakos, et al., 2016; Strasburger \& Hogan, 2013; World Health Organization, 2019).

Survey results from both users and non-users suggest that where screen-time policies were in place, they allowed an average of 10 minutes of screen time daily. Non-user services, especially those that allowed personally-owned devices to be 
used, were more likely to have a screen-time policy than other services.

Additionally, this study found that the more children a non-user service was licensed for, the more likely it would implement a screen time policy for children. The findings reveal that screen time policies regarding tablet use alone involved a complexity of various factors. These factors were the maximum number of children who could use tablets at one given time, services' preference for tablets in groups or independently, and services' prefered person who would monitor children's tablet use - which were fully certificated teachers. These intertwine with the purposes for which services use tablets and in relation to this, their policies, guidelines, and educaitonal philosophies regarding the issue. The findings are similar to the arguments of experts interviewed by the Associated Press (2019) and the Science Media Centre (2019) who explained that the issue of screen time itself is complex, involving different aspects such as screen time limits. Many non-users did not have a screen time policy whilst those that did limited tablet use to a maximum of 30 minutes. These results are similar to those found by prior studies which indicated that average screen time was around 20 to 30 minutes daily (Ahearne et al., 2015; Bedford et al., 2016; Neumann, 2014; O'Connor, 2017). Given the finding discussed above that non-user services often allowed teachers/educators to use their personallyowned tablets, it is possible that these services had identified the need to establish and implement policies and guidelines to cover the use of personally-owned tablets by teachers/educators and parents/whānau in the service.

This discussion of the factors influencing tablet use suggests that tablet adoption in ECE is not as straight-forward as a simple dichotomy between use and non-use but there is instead much more fluidity in how services move between use and non-use of tablets. The next section discusses this in more detail and presents a spectrum that illustrates this more nuanced view about tablet usage in ECE services.

7.1.3. The fluidity between tablet use and non-use. The study found that instead of a definite split between tablet users and non-users, there is a fluidity between touchscreen use and non-use. The findings of this study revealed that there is a continuum rather than a dichotomy with regards to adoption of tablets in ECE. This research informs ECE services of the possibility that they can move between non-use and use depending on their teaching and learning aims. This fluid nature of 
decision-making about using or not using tablets is an important finding as it reveals that decisions are not necessarily permanent.

Generally, tablet use is influenced by a variety of factors. Keirl (2015), Murdock (2002b), Selwyn (2003), and Wei et al. (2011) all suggested that digital divides were not simply a dichotomy involving access and use. A key finding from both phases of this study is that there were some non-user services shifting to using tablets for a variety of reasons; understanding these reasons enables deeper insights into the factors influencing the adoption of tablets in New Zealand's ECE sector. Phase 1 also identified some services discontinuing tablet use or deciding to limit them for use by adults only. A spectrum of tablet use/non-use can be illustrated using an adaptation of Keirl's (2015) curriculum scenarios as shown in Figure 7.1 below.

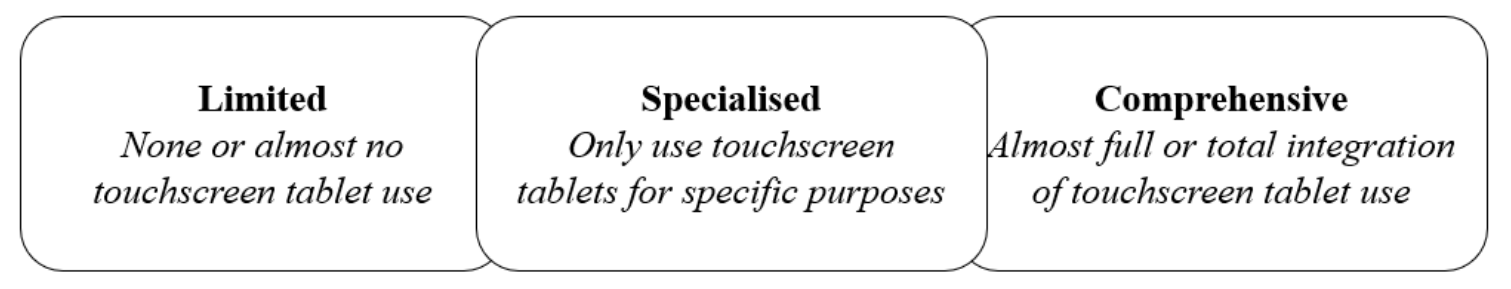

Figure 7.1. Spectrum of tablet use and non-use.

The spectrum has three groupings to distinguish the extent and ways tablets are currently used in New Zealand's ECE services, using an adaptation of Keirl's (2015) curriculum scenarios for Technology Education. At the far left of the spectrum is what Keirl (2015) called the "disillusionist case" (p. 31). This grouping applies to services that have little to no tablet use. I renamed this group to "limited" because in this study, non-user services's tablet use were limited according to their umbrella organisation's, service management's, teachers'/educators', or parents'/whānau's educational philosophies or service policies and guidelines. In this grouping, limitations could be enacted in a variety of ways. For example, tablet use could be limited to teachers'/educators' use only or they could be strictly facilitated by a teacher/educator when used with children. I renamed the middle group of the spectrum from "specialist" to "specialised". This renaming made it easier to understand that this group of services used tablets only for specific purposes. Children used tablets with teacher/educator scaffolding, such as specifying which apps could be used and limiting use to older age groups. Finally, in the 
"comprehensive" group, tablet use was almost fully or totally integrated within the service. Services in this group used tablets in almost all teaching and learning activities. Independent use was allowed, and children were often expected to selfmanage their own tablet use. This spectrum sheds new light into the intricacies involving tablet use and non-use in ECE services in New Zealand. The relevance of this spectrum to this study's findings will be discussed in Section 7.3.

This section has discussed how the extent of tablet use and non-use amongst ECE services in New Zealand was not simply a dichotomous split between non-users and users. A similarity amongst user services was that they had small numbers of children who used tablets at any one time and a smaller sized teaching team.

Additionally, results from this study have enhanced the understanding that the availability of personally-owned tablets could be a reason why some services preferred to stay as non-users. As for non-users that decided to become users, these services reported that that allowing the use of personally-owned touchscreen devices could pose a risk to children's privacy and cybersafety, thus necessitating the need to procure a service-owned tablet or to develop policies and guidelines around use of personally-owned tablets and similar devices. There was a variation across the nonusers such as some who allowed teachers/educators to use their own devices. Phase 2 revealed greater variation, such as non-user services transitioning to becoming emerging users, which would not have emerged by collecting data only through a survey.

To illustrate the extent of tablet use in ECE services in New Zealand, a diagram was used to present the range between non-use and use. The diagram grouped tablet use into three: limited, specialised, and comprehensive use. This diagram will be further discussed in the next sections using evidence which pointed out how some services moved from non-use to use and vice-versa because some services differed in their preferences in limiting or freely using tablets. The next section begins this by first explaining the findings regarding the reasons why services did not use tablets. 


\subsection{Reasons for the non-use of tablets amongst teachers/educators in New Zealand ECE services}

This section discusses the findings from the data to identify services' reasons for not using tablets. Analysis of the quantitative and qualitative data clarifies why many ECE services did not use tablets. According to survey responses in Phase 1, the top three reasons for non-use were educational philosophy, company or service policy, and funding constraints. Phase 2 findings aligned with and explained the results from the quantitative phase. The following section examines each of the three key reasons for non-use, starting with why educational philosophy was the foremost reason.

7.2.1. Educational philosophy. Based on the findings of Phases 1 and 2 of this research, the extent of use and non-use is influenced by the educational philosophy of each service and the decisions of each service's teaching team. For each service, there is a need to have consensus within the teaching team regarding how, when, and where to use tablets with children or not.

Many studies have outlined the impacts of tablets use to young children (e.g., Hipp et al., 2017) and how these devices were used in educational settings (e.g., Clarke \& Abbot, 2016), yet their connection to teachers'/educators' educational philosophies have not been explained thoroughly. This research clearly identified that educational philosophy plays a major role on whether services decide to use tablets for teaching and learning. For example, some non-user services believed that traditional or non-digital practices were still the best for supporting young children's learning. Other services expected that children who came to their service should engage in more physically active play, preferably outdoors, and that these types of activities supported their overall growth and development compared with the sedentary activities they thought occurred with tablet use. These findings are supported by earlier literature which discouraged young children's ICT use, including tablet use, because children did not engage in concrete activities, physically active play, and activities that were appropriate to their neurological and social development (Healy, 1998; Spitzer, 2013; Swaminathan \& Wright, 2003). 
In Phase 1, most non-users did not use tablets due to their educational philosophy. The top two reasons for non-use in relation to educational philosophy were teachers'/educators' preferences for traditional practices and apps not fitting with their educational goals. The findings on teachers'/educators' preference towards traditional or non-digital practices were also found by Neumann et al. (2018). Similarly, Fleer and Hedegaard (2010) have argued that teachers were expected to understand the commonly available tools in ECE and use them to support children's learning according to their educational philosophy. These findings proved useful in expanding our understanding of the impact of educational philosophy on practice in New Zealand's ECE sector.

In New Zealand's ECE sector, Te Whāriki (Ministry of Education, 2017a) encouraged teachers/educators to offer children the opportunity to use a wide range of tools. The Foundations for Discovery (Ministry of Education, 2005) regarded ICT as a tool for teaching and learning in ECE. Based on sociocultural theory, which Te Whāriki ascribes to, Vygotsky's $(1978,1999)$ concept of tool use involves social and cultural interactions between a child and a MKO such as their peers or teachers/educators (Vygotsky, 1978). Through these active interactions, children learned how to use tools which Fleer and Hedegaard (2010) argued as one of the many goals of ECE teachers/educators, dependent on their educational philosophy. Although this conceptualisation was prior to the advent of tablets, Reich et al. (2013) included tablets amongst these tools and argued that scaffolding the use of these devices benefitted children's learning in the same ways as with other earlier forms of tools. In Phase 2 of the study, teachers/educators acknowledged this same understanding that tablets are tools to support children's learning.

Non-users were firm in their beliefs that tablet use did not bring any benefits to teaching and learning in ECE. To them, activities such as mark making or handwriting on pen and paper, gross motor activities, and play using real-world toys could only be done without using tablets. Their perceptions contrasted with Di Cesare et al.'s (2019) findings that the multimodality of tablets supported children's mark making activities. Blackwell et al. (2013) emphasised the important role of ECE teachers'/educators' beliefs in deciding whether to adopt tablets. In this study non-users explained that, according to their educational philosophies, children were 
expected to engage in physically active play, preferably outdoors, using non-digital tools. These services felt that the lack of physically active play caused by tablets impacted on children's physical and gross motor development. A few international studies such as those by Flewitt et al. (2015) and Howie et al. (2017) argued that aside from tablets wasting children's valuable time through overstimulated and addictive gaming, they found that some teachers/educators also believed that using tablets resulted to a reduction in children's outdoor and physically active play time. Many non-users saw tablet use and outdoor play as diametrically opposite activities. This dichotomous perspective discussed in Section 2.2 of the literature review, has been ongoing despite proponents (e.g., Hipp et al. 2017; Neumann, 2018) of tablet use in ECE arguing the benefits of using these devices as long as children's use is scaffolded by teachers, particularly through scaffolding their engagement. To Neumann (2018), it was important that an MKO scaffolded children's interactions with tablets.

Despite the portability afforded by tablets, non-users in this study limited the use of these devices to indoor activities and, because of these limitations, teachers/educators held on to their perceptions about the negative impacts tablets bring such as sedentary learning that have also been found in earlier studies (Gerritsen et al., 2016; Howie et al., 2017). According to Gerritsen et al.'s (2016) New Zealand study, services preferred that children engage in more physically active play and because most of them perceived that tablets could not provide this, they did not use tablets. As for the services who limited tablet use, those who participated in the study held on to dichotomous perceptions between technology and outdoor, physically active play. To non-users, tablets did not fit their educational goals because of their beliefs that the same cognitive development could be attained through physically active play in which children interacted with real world things during free play.

Although user services reported that using digital technologies made teachers' work easier and supported a variety of learning activities, both phases of the study revealed that some teachers still preferred traditional methods. These findings build upon Tsumura's (2017) research which identified that because iPadbased activities did not match the aspects of play-based learning or traditional 
practices that teachers preferred to use for teaching handwriting instruction and activities involving printing. Numerous studies have suggested that tablets add to the diversity of children's play and other creative activities and thus could replace traditional practices (e.g., Aldemir \& Kermani, 2017). Yet, in this study, non-users perceived otherwise. International studies such as Bullock et al.'s (2017) and Holloway et al.'s (2018) research have found that the technical scaffolding provided by tablets were seen to limit children's options whilst Chassiakos, et al. (2016), Strasburger and Hogan (2013), and Choi et al. (2018) have suggested that playing with these devices did not engage children's real world or 3D senses. These studies help explain the findings regarding the central role that educational philosophy played in governing whether tablets are used or not used in New Zealand's ECE services.

Whilst educational philosophy was the central factor influencing centres that had chosen not to use tablets, two other reasons for not using tablets were the availability of company or service policy surrounding digital technology use and funding. Taken together, these two reasons contribute to whether a service chose to adopt tablets for teaching and learning in ECE and are discussed in the next section.

7.2.2. Company or service policy. The second reason was company and service policy which were based on educational philosophies. In Phase 2, services based their decisions on policies and guidelines according to their educational philosophy. However, there were services which did not use service-owned tablets but allowed teachers/educators and parents/whānau to use their personally-owned touchscreen devices such as smart phones. An ECE service's policy also governs whether they will allow use of touchscreen devices, especially those personallyowned by teachers/educators and parents/whānau.

This section discusses key findings regarding the impact of policies and guidelines related to tablet use in services. The study found that users and non-users differed in their policies and guidelines. If the service's educational philosophy underpinned whether it allowed the use of tablets or not, the umbrella organisation's or service's policy determined the procurement of the device and how its use was supported and managed. A significant finding to emerge from this study was that 
non-users often allowed the use of teachers'/educators' personally-owned tablets and similar devices, such as touchscreen phones, as substitutes for the non-use or unavailability of service-owned tablets. Many non-user services did not need to acquire newer forms of digital technologies as the service had other types of ICT equipment available. As personally-owned tablets could pose potential risks to cybersafety, this then leads to new issues which ECE services address by developing policies and guidelines. It is important for services to know that having policies and guidelines supports teachers'/educators' scaffolding of young children's tablet use as discussed in the literature review (e.g., Carson et al., 2013; Radesky et al., 2016; Winters \& Memme, 2017). Similar to the findings of this research, studies about tablet use in New Zealand's ECE sector (Gerritsen et al., 2016; Khoo et al., 2015) emphasised the importance of ECE teachers being knowledgeable about guidelines surrounding children's appropriate use of tablets.

Those services who allowed the use of personally-owned tablets preferred to develop policies and guidelines around use of these devices. Some services perceived that tablets did not provide sufficient learning for children's development in the early years. This finding is in line with Hedegaard (2007) who emphasised that teachers/educators did not base their decisions on commercialism but on what is appropriate to the development of children.

Some services that participated in this research had limited the ways tablets were used because of ownership and issues surrounding the privacy of children and their safety when accessing digital media online. Ernest et al. (2014) reported similar perceptions from adults who were wary that the use of tablets could lead to addictive and anti-social behaviour through exposure to inappropriate and harmful content. In line with this study's findings, Chaudron's (2015) research found that children were unaware of online risks which potentially led to their exposure to inappropriate content and other problems related to commercialism. Prior research (e.g., Edwards et al., 2018; Neumann et al., 2018) has argued that all of these impacts can be mitigated when teachers/educators scaffold children's appropriate use of tablets.

Although this study focused on teachers'/educators' decisions regarding adopting tablets in ECE, these reasons had a bearing on the role parents/whānau 
played in deciding the resources their children could access and use. In this study, teachers/educators at Hümārietanga Childcare and Iorangi Playcentre stressed the importance of gaining consensus from parents regarding how tablets would be used. Services believed in seeking input from parents' perspectives as recommended by the Ministry of Education (2017b). This was evident in Phase 2 which found how these two non-user services planned to consult parents regarding the adoption of tablets.

7.2.3. Funding. In Phase 2, it was revealed that many of the policies and guidelines involving the adoption of tablets in ECE were developed in relation to teachers/educators bringing in their own devices because the service could not or would not purchase these devices themselves. This is in parallel with Flewitt et al.'s (2015) finding that cost was one of the many reasons why ECE services did not adopt tablets. Since their study did not elaborate on this, I decided to examine some of the underlying reasons involving this issue. Their discussion of reasons for not adopting tablets mentioned the cost of the device in passing and did not elaborate on it further which is why this study aimed to determine some of the underlying reasons for services and their teachers/educators had regarding this issue. In relation to funding, because some services could not afford tablets, they allowed teachers to bring their own tablets as an alternative. Before fundraising and seeking other funding options, non-users expressed the need to gain feedback from members parents/whānau before using tablets with children. This builds upon the Ministry of Education's (2005) recommendations in Foundations for Discovery to encourage collaboration between ECE services and families/whānau on the use of digital technologies for effective learner-centred practices.

Many of these services identified as non-users whilst allowing their staff to use their own devices. These services were not entirely non-users because even when they did not have a service-owned tablet, these devices were still being used, whether for limited, comprehensive, or specific purposes. These findings are significant because they add new understandings about the nature of ownership and use of tablets with New Zealand ECE services.

This section has discussed that the main reason for non-use was a service's educational philosophy. Services explained that their educational philosophies were 
the basis of their decision-making on whether to adopt tablets. In particular, educational philosophies could be narrowed down to teachers'/educators' preference towards traditional or non-digital practices and their perceptions that tablet apps did not fit educational goals. This research identified that service policy and funding were the next two most significant reasons for non-use of tablets. A key finding was a relationship between teacher's/educators' use of their personally-owned tablets and some services deciding not to procure their own tablets. Many non-users in this study insisted that funding was the main reason for not acquiring tablets but upon further investigation, the availability of personally-owned tablets, educational philosophy, and teachers'/educators' dichotomous beliefs about young children's tablet use were the reasons why services did not procure these devices. This information is useful in understanding the complexities of tablet use or non-use in order to support ECE services in their decision-making around the adoption and use of tablets. The next section discusses user services' ways on how they utilised tablets to support children's learning.

\subsection{Teachers'/educators' use of tablets in ECE settings to support children's learning}

This study revealed the ways tablets were used by New Zealand ECE teachers/educators to support children's learning. In Phase 1, most user services reported that they used tablets for documentation and assessment. This was followed closely by playing music and using apps to support creativity. Services expected a fully certificated teacher/educator to scaffold children's tablet use with more services preferring that tablets were used in groups with a teacher/educator compared to individually with a teacher and educator. This finding links to arguments found in international literature on the importance of scaffolding by MKOs when children use digital tools (e.g., Beschorner \& Hutchison, 2013; Herodotou, 2017). This research strengthens the findings from previous literature regarding the different ways tablets could be used for teaching and learning in ECE.

The qualitative question in Phase 1 asked user services to explain how they supported young children's tablet use. Only education and care, home-based, and kindergarten service types responded to this because the playcentres all reported that 
they did not let children use tablets. Amongst these respondents, teachers/educators used tablets for research and extending children's interests, with education and care services specifying this way most frequently. Scaffolding children's access to and use of the device was another way in which services supported the use of tablets as indicated by the majority of home-based services and kindergartens. Some qualitative responses gave specific examples of teacher scaffolding such as monitoring undertaken by a teacher, collaboration, role modelling, managing children's tablets/internet access, and facilitating turn-taking. Amongst these a few services indicated scaffolding skills and correct use of the device. This connects to sociocultural theory in which MKOs support children's learning through the use of tools and by scaffolding learning using these tools. This evidence from this study aligns with Fleer and Hedegaard's (2010) argument that teachers/educators are not passive providers of learning tools because they play an active role in scaffolding how young children learn from using these tools. Just as other ECE experts in New Zealand regarded ICT as useful tools for children's learning (e.g., Carr et al., 2009; Merry, 2017), international studies have concluded that tablets benefitted children's learning because of their multifunctional capabilities as documentation tools (Tsumura, 2017), tools for creative activities (Moore et al., 2018), and communication tools (Vaughan \& Beers, 2017). The findings of Vaughan and Beers (2017) exemplified the multifunctionality of tablets when they enumerated the different ways ECE teachers used these devices.

The multifunctionality of a tablet is clearly supported by this study's findings. Documentation and assessment were the foremost ways in which teachers/educators used tablets to support young children's learning, reflecting findings from prior studies (e.g., Fagan \& Coutts, 2012; Khoo et al., 2013). A recently published local study by MacCallum and Bell (2019) reported how the multifunctionality of tablets supported ECE teachers in various ways, primarily through documentation and assessment which often involved collaborative and creative activities with children.

Other common ways how teachers/educators used tablets to support children's learning were by watching YouTube videos with children, looking up information to extend children's interests, and playing music in the background by hooking up iPads to speakers. Other studies have also reported that YouTube was 
the most frequently used app (e.g., Blackwell et al., 2016; Marsh et al., 2015; Oliemat, 2018). These ways of using tablets were not reported by all services in this study because each service preferred different ways. These ways have been explored in previous international studies such as using creative apps (e.g., Heydon et al., 2017; Moore et al, 2018; Rowe \& Miller, 2017) and games (e.g., Clark \& Abbot, 2016; Grey et al, 2017). How teachers/educators used tablets to support children's learning provides useful information in determining whether services adopted a specialised or comprehensive way of using these devices.

7.3.1. Documentation and assessment. The majority of services who participated in both phases of this study responded that they used tablets for documentation and assessment. This finding is supported by the literature discussed in Chapter 2 (Fleer, 2017a; Moore et al., 2018; Rowe \& Miller, 2017; Yelland \& Gilbert, 2017). Earlier studies have described the various ways tablets were used for documentation and assessment such as photography, video-recording, moviemaking, and linking these to children's learning stories. In this study, children's learning was often documented through photography or video-recording and assessments were made using learning stories apps and shared online to parents and whānau through these apps. Even personally-owned touchscreen devices such as iPads and mobile phones were used by services to document and assess children's learning. The research findings revealed that these ways of using tablets contribute in several ways to our understanding about the documentation of children's learning. According to services that participated in both Phases of this study, the foremost use of tablets was to document evidence of children's learning using photography apps and uploading these to learning stories or online portfolios which form children's assessment. Children were encouraged to use these apps on their own to take photos and videos or make drawings which could be combined to make video compilations or short movies and be uploaded to a learning story app or online portfolio. In parallel with international studies on how tablets were use for documentation (e.g., Gray et al., 2017), the findings provided additional empirical evidence of the same but in New Zealand's ECE context.

In the literature review, documentation and assessment were one of the commonly reported ways of using tablets (e.g., Arnott et al., 2016; Fagan \& Coutts, 
2012; Fleer, 2017a; Khoo et al., 2013). This study's findings add to the current literature including national studies which specified tablet use for both documentation and assessment (e.g., Almashaileh, 2016; Geist, 2014; Khoo et al., 2015; Mitchell \& Brooking, 2008). Non-users also reported that if they were to adopt the use of tablets they would most likely use them for documentation and assessment. Tablets were also used for exploration and documenting events. In particular, the findings revealed that using tablets was convenient for writing children's learning stories for uploading to Educa, KidReports, or Storypark. Learning story apps and online portfolios also allowed teachers/educators and children to communicate to parents/whānau. Services' ways of using tablets were supported by the recommendations of Kei Tua o Te Pai/Assessment for Learning: Early Childhood Exemplars, Information and Communication Technology (ICT) Te Hangarau Pārongo me te Whakawhitwhiti which indicated that ICT is beneficial for documentation and assessment of children's learning (Carr et al., 2009). Again, MacCallum and Bell's (2019) findings align with these recommendations which this study builds upon. Overall, tablets were used by teachers/educators to support documentation and assessment of children's learning.

7.3.2. Conceptualising New Zealand's ECE services' tablet use. To better illustrate how tablets were used in ECE using the proposed spectrum, each of the Phase 2 services were placed into one of three groups. Figure 7.2 shows the spectrum indicating where each case was placed according to how different groups used or did not use tablets.

To illustrate how the spectrum applies to each service in Phase 2, I give examples how services in this Phase used tablets for documentation and assessment. The services, Aniwaniwa Kindergarten and Ekengia Homecare, limited tablet use for documentation and assessment to both children and adults. Hūmārietanga Childcare were still in discussion on adopting tablets. Iorangi Playcentre already had an iPad available and limited use to adults who intended to use it specifically for documenting health and safety issues with a secondary specific purpose, for assessment. Visiting teachers and educators at Koanga Wākāinga Homebased did not use tablets extensively for documentation and assessment but only for 
educational games and creative apps as a form of reward to children. The teachers at Manaakitanga ELC and Nunui Kindergarten let children use tablets for documentation and assessment through photography, video-recording, and moviemaking. The only slight difference between these two services was the extent of supervision by Manaakitanga ELC's teachers who were always close to the children when they used tablets whilst Nunui Kindergarten's teachers allowed children to use tablets for documentation and assessment with minimal supervision. The next section continues this discussion on how using tablets for documentation and assessment is pervasive in the results from both phases of this study.

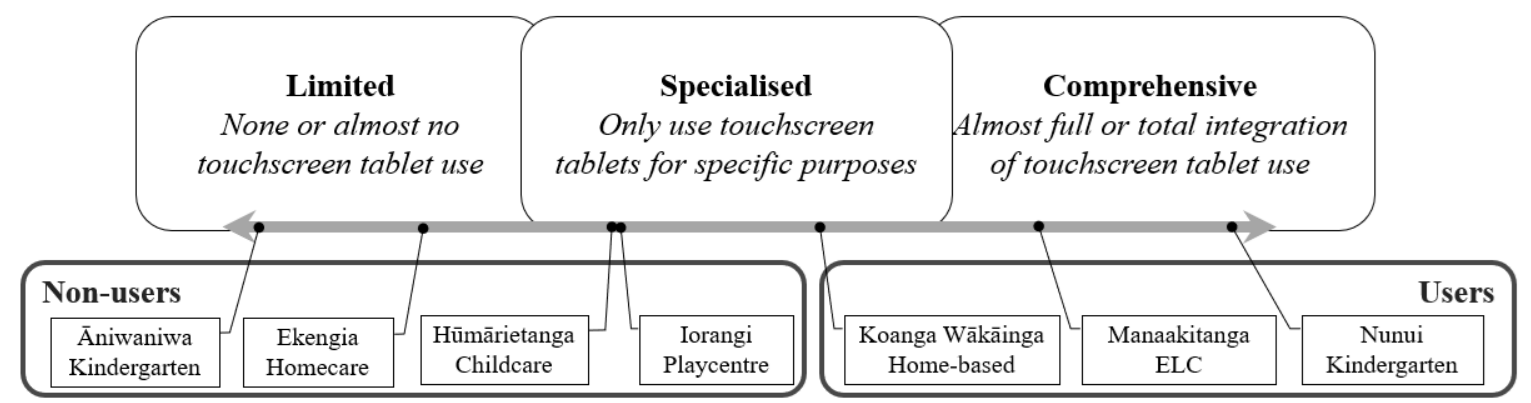

Figure 7.2. Spectrum of tablet use and non-use with cases.

From left to right, the spectrum of tablet use and non-use begins with the limited group. I begin the discussion with the services that limited the use of tablets to present the spectrum in order from the most extreme scenario. From the far left, the services that did not use tablets at all were Aniwaniwa Kindergarten followed by Ekengia Homecare. Compared to Aniwaniwa Kindergarten's complete non-use of digital technologies, at Ekengia Homecare, teachers'/educators' use of personal touchscreen devices were highly limited following a policy that if they used their own personal tablets and other ICT, children should not be allowed direct access and use of these digital technologies. One example was allowing personally-owned touchscreen devices to take photos for documentation or to play music in the background as long as children did not directly use these devices. Next, Iorangi Playcentre, Hūmārietanga Childcare, and Koanga Wakāinga Home-based were placed in the specialised group of the spectrum because whilst Iorangi Playcentre and Hümärietanga Childcare were still non-users at the time data were collected in Phase 2, they planned to use tablets for specific purposes in the near future. Aside from its two visiting teachers, Koanga Wakāinga Home-based only had four out of 
17 educators who used tablets. At these services, tablet use was limited to specific purposes such as documenting health and safety concerns, or for use by specific groups such as letting older children use tablets. The remaining two services belonged to the comprehensive group. Manaakitanga ELC allowed children to freely use tablets with a service policy which required teachers to always be present and to monitor children who were using tablets. Children at the service freely used tablets as long as there was teacher scaffolding or established settings such as using the iPad's guided access feature to limit access to the internet and use of a few selected apps. This result is supported by Ernest et al. (2014) and Flewitt et al. (2015) who argued that teachers/educators should be aware of the positive and negative impacts screen time and digital media use bring to children and thus should balance children's access and use of digital technology. Because of these slight limitations, whilst the service is placed in the comprehensive group, Manaakitanga ELC is situated closer to the specialised group. Nunui Kindergarten showed the most comprehensive use of tablets as they allowed children's independent use with some teachers trusting children to self-manage using an established turn-taking system. Additionally, the kindergarten's umbrella organisation provided separate tablets for teachers' use and for children's use. Even if children's tablets did not have internet access, they were able to use them individually or in groups with minimal supervision. Children who used a teacher's iPads they were closely supervised by the teacher responsible for that specific tablet.

The extent and ways of using tablets are not hierarchical. Whilst the number of services shown in Figure 7.2 is limited, the spectrum adds to our understanding that a service placed at the far left or right of the spectrum does not imply that it is providing ECE of a greater or lesser quality. There is no right or wrong group because services could move back and forth along the spectrum, depending on specific variables such as service type, educational philosophy, the size of a service's teaching team, the number of children who could use a service's tablet at one time, use of personally-owned devices, and formal policies and guidelines involving screen media and use of other digital technologies. Selwyn (2003) argued that there needed to be a shift in perspective from simply categorising groups from those who have ICT and those who do not have them to consider those who do not want to use digital 
technologies because of their philosophies and perceptions regarding ICT use. For example, in the cases of Iorangi Playcentre and Hümärietanga Childcare, both were initially thought to have belonged to the limited group but their intentions to use tablets at their services, with the former already possessing an iPad for specialised use, placed them in the specialised group.

In the limited group, tablets were either not used at all or were limited to teachers'/educators' use alone. Another specific way of limiting tablet use was limiting the group of children who could use them such as Hümārietanga Childcare's decision to use its iPad only to older children who were in transition to school classes. In these classes. This limited ways of using supported the service's teachers/educators who aimed to use tablets with four-and-a-half-year-old children to prepare them for primary schooling which required that children knew how to use digital technologies as early as their first year of schooling. They perceived that tablets, including digital technology and related media, could be used to support the learning of the older children. Teachers/educators belonging to the specialised group scaffolded children's learning using tablets in conjunction with technical scaffolds such as guided access or by closely monitoring children's app selection and screen time. For services belonging to the comprehensive group, this study found evidence of peer scaffolding with older or more experienced children teaching other children how to use tablets and their apps. Teachers/educators in these services encouraged children to manage their own tablet use. This evidence of peer scaffolding is supported by Kirova and Jamison's (2018) and Winter and Memme's (2017) studies which found that some children supported the tablet use of their less experienced peers. The spectrum sheds new light into how tablet use is scaffolded by teachers/educators. As found in this study, scaffolding tablet use is important to protect children from exposure to inappropriate content. The findings add to previous literature on the important role which adults, especially teachers/educators, played in mitigating children's exposure to harmful or inappropriate content when using digital technologies (e.g., Ernest et al., 2014; Neumann et al., 2018). Particularly, in New Zealand, the Foundations for Discovery (Ministry of Education, 2005), expected teachers/educators to guard young children against exposure to inappropriate content. 
7.3.3. Considering tablet use through a sociocultural lens. This study utilises sociocultural theory to understand tablet use in New Zealand ECE services. Data collected from this research highlight the important role of teachers/educators in deciding how tablet use could be scaffolded for the teaching and learning of young children.

I used sociocultural theory to understand how teachers/educators supported children's learning and development by scaffolding tablet use. In sociocultural theory, tablets are tools in the digital age which are linked to children's learning of everyday and scientific concepts (Reich et al., 2013; Stephen \& Edwards, 2018). Teachers/educators in most user services responded that they scaffolded children's use and access to tablets by scaffolding how young children used these devices in different ways. Numerous studies which have outlined the different ways children's use of tablets are scaffolded in ECE-such as imitation (Fleer, 2013), role modelling (Khoo et al., 2015; Kirova \& Jamison, 2018; Troseth et al, 2016), use of language and communication (Falloon \& Khoo, 2014), peer collaboration (Sakr, 2018; Yelland et al., 2014), and restrictive, active, or passive mediation (Marsh et al., 2015; Walsh \& Farren, 2018) - have connections to this study's findings. These different ways indicated a fluidity involving tablet use because not all services or even teacher/educators scaffolded the use of these devices in similar ways. The findings add to Tavernier and Hu's (2017) research which found that amongst the different ways of scaffolding tablets, demonstrating was most often used. These are all in parallel to Murdock's (2002a) argument about the complexities involving how digital technologies were used because it involved users moving between continuing or stopping ICT use.

To illustrate how services could move from non-use to use and back, Figure 7.2 describes the different ways in which services scaffolded children's access to and use of tablets. Teachers/educators who limited tablet use belonged to services in the limited group such as those from Ekengia Homecare. Iorangi Playcentre and Hümārietanga Childcare planned how to introduce tablets which they intended to restrict to adults or older children, respectively. Koanga Wakāinga Home-based leaned towards closely monitoring young children's touchcreen tablet use and fostering imitation of how teachers/educators used these devices at their services. 
Manaakitanga ELC focused on using tablets for language learning and communication with parents. Through active mediation, teachers at the service role modelled tablet use. Nunui Kindergarten encouraged more peer collaboration and passive mediation knowing that there were safety settings and rules in place and that children were aware of the limits in using tablets and could self-regulate use when necessary. This study's findings build upon Hirsh-Pasek et al.'s (2015) research on the importance of scaffolding tablet use to support children through cognitive and affective scaffolding.

Scaffolding with a teacher/educator, individually or in groups was preferred by user services. It is interesting to note that children's use of tablets individually and in groups at these services was not overly lengthy as children happily shared use in groups or allowed others to have their turn without much scaffolding from teachers/educators. Phase 1 responses were split between using tablets individually or in groups which Walsh and Farren (2018) also found in their research. Additionally, more than half of users preferred that fully certificated teachers/educators monitored children's tablet use. The possible reason for this was that services perceived that young children's tablet use needed to be scaffolded by qualified teachers. It is important to conduct further research using sociocultural theory to explore differences on how scaffolding of tablet use individually or in groups could inform teachers/educators.

Sociocultural theory is applicable to situations when teachers/educators monitored how children used tablets by proactively mitigating children's exposure to inappropriate content and other risks related to privacy and commercialism. These results build upon Edwards et al.'s (2018) argument which emphasised this important role in teaching children to be aware of online risks related to tablet use. This thesis found that teachers/educators played an important role in scaffolding children's tablet use which is in parallel to Edwards et al.'s (2018) research which linked sociocultural theory to teachers'/educators' role in making sure that children used these devices in appropriate ways. Scaffolding of young children's use of tablets and related digital technologies is necessary to mitigate threats to children's confidentiality and privacy. The findings of this research build upon Yelland and Masters (2007) who described technical scaffolding as including managing the 
restriction of internet access or using settings or apps that limit a device's functionality. Data from this study provides continuing evidence on the importance of setting up a turn-taking system when using tablets. Teachers/educators also role modelled appropriate ways of using tablets, paralleling previous studies (ReynoldsBlankenship, 2013). In earlier studies, services argued the need to protect children from threats to their privacy (Ernest et al., 2014), from inappropriate content (Chaudron, 2015; Ofcom, 2017), and commercialism (Ernest et al., 2014) and to educate them regarding internet safety (Choi \& Kirkorian, 2016; Walsh \& Farren, 2018).

The different functions available in tablets reported in earlier studies (e.g., Dooley \& Gattenhof, 2015; Eisen \& Lillard, 2017; Khoo et al., 2013) enabled young children to use them for a variety of purposes including gaming, communication, documentation, information retrieval, and creative ways such as moviemaking. Earlier research by Fagan and Coutts (2012), Gattenhof and Dezuanni (2015b), and Gray et al. (2017) showed how tablets could be used in creative ways to support learning in the areas of literacy, numeracy, musical, and fine motor skills. Neumann et al. (2018) reported similar findings to the results of this study on how the multifunctionality of tablets enabled children to learn new skills in a multimodal environment. Many different functionalities of tablets contribute to documenting children's learning and sharing them to online portfolios or learning story apps as a form of assessment. Whilst teachers/educators who participated in this study reported that children easily learned how to use tablets, using these devices for documentation and assessment necessitated scaffolding children's use of creative, photography, moviemaking through apps to maximise their use for documentation and assessment. In supporting children's learning, teachers/educators found tablets helpful primarily for documentation and assessment. Yet, despite all the affordances tablets provided to teaching and learning in ECE, there were still reported barriers. The next section answers the final research question involving the barriers and affordances to tablet use in ECE.

\subsection{Barriers and affordances to tablet use in ECE pedagogy}

This study sought to understand the barriers and affordances that impacted on tablet use in ECE pedagogy in New Zealand. Understanding these barriers and 
affordances will support more informed discussion and debate about the use of these devices in ECE. This section's discussion begins with barriers and is followed by affordances.

7.4.1. Barriers. Barriers to tablet use were mostly reported by non-users. Several of these issues were deliberate choices made by the service rather than barriers. It is interesting to note that the reasons for not using tablets were also considered barriers. Potential issues identified by non-user respondents to the survey that impacted on their use of tablets included their preference towards using traditional practices, apps not fitting their services' educational goals, a lack of professional development, and technical glitches and apps not working. Yet, in the collective case study, non-users reported that their educational philosophy was the major reason for not using tablets. This links with Hedegaard's (2007) argument that teachers/educators should not base their decisions on what educational materials to adopt simply because of commercial interests. Hedegaard explained that some of these materials and playthings may result in children being exposed to inappropriate content and may conflict with the services' educational philosophy as well as the child's overall development. The notion of 'ideological refusal' and social choice (Selwyn, 2003) should be considered when services decided whether to use or not use tablets. Selwyn's (2003) argument that the choice of not using technology should not be called a barrier was similar to the findings that, aside from technical glitches and apps not working, barriers involving educational philosophy are based on a service's choice and thus are not actual barriers.

The services in this study identified that the major barriers to tablet use were those involving technical issues. Both non-user and user services explained that tablets were reliant on wireless internet connections as supported by earlier studies (Bullock et al., 2017; Heydon et al., 2017; Walsh \& Farren, 2018) which reported that the reliance tablets have on consistent wireless internet limited their multifunctionality. User services in this study managed this barrier by limiting tablet use to indoors where wireless internet was accessible or by playing music from tablets through an outdoor Bluetooth speaker. This finding adds to previous research such as Rose et al.'s (2017) study which revealed that the multifunctionality of tablets allowed these devices to be used outdoors whether through photography of 
nature or through playing music or videos. In both their study and mine, teachers/educators also used other features of their iPads which were not reliant on internet connectivity such as taking photos and videos.

Other barriers identified were in relation to managing multiple iPads, remembering the passwords, and managing updates and settings. These issues were also identified in Blackwell's (2014) findings. To overcome these barriers, user services assigned a dedicated teacher/educator or management staff. The barriers indicated by survey respondents were teachers'/educators' preferences towards traditional practices and problems with internet connections. These two major responses were followed by a lack of professional development on the basics of ICT, issues involving updates, and glitches occurring when using apps. Evidence of these issues was captured in a video-recorded episode at Nunui Kindergarten when children could not use an app because the service's iPad started updating and to resolve the issue, the teacher and the children required assistance from the staff incharge of ICT systems. Manaakitanga ELC also had support staff available to support teachers/educators whilst teachers/educators at Hümārietanga Childcare planned to include their IT team to support them as they began to use their owner's iPad for their transition group. These examples from the collective case study phase of the research suggest that teachers/educators resolved technical barriers through collaboration with colleagues and their management team. The shared knowledge and action of a service's teaching team contributed to more effective ways of managing and working around technical issues.

Of interest is the finding from Phase 2 that some teachers/educators found tablets distracting and disruptive. For example, Nunui Kindergarten noticed how some children were distracted from their activities when they became aware that their picture was being taken by a teacher. While the novelty of tablets had worn off for some children, other children would still stop what they were doing to pose for a photograph. Similarly, non-user services such as Aniwaniwa Kindergarten and Ekengia Homecare which allowed teachers/educators to use their own devices, believed that tablets would be disruptive to children's play activities as many children tended to stop playing and wanted to use an adult's tablet or phone. This is 
a new finding because, despite the availability of tablets for almost a decade now, my search of earlier literature did not locate empirical studies about this issue.

Teachers/educators found it necessary to manage tablets and their apps to prevent children from viewing inappropriate content and to manage other issues involving cybersafety. These findings build on Chaudron's (2015) argument about the importance of awareness regarding these issues involving online risks, inappropriate content, and commercialism. In line with the findings from some of the teachers/educators in this study, Ernest et al.'s (2014) research indicated how these forms of advertising and marketing could be harmful to children. Some examples of harmful ways teachers in this research were wary about were threats to children's confidentiality and privacy as well as exposure to inappropriate content. These issues add to similar ones brought up in previous studies (Mohapatra \& Hasty, 2012; Neumann, et al., 2018; Ofcom, 2017). Holloway et al. (2013) argued that with the proliferation of ads in free apps, teachers/educators needed to teach children how to cancel or skip advertisements, but they could only do this when the advertisements appeared, thus requiring constant monitoring. Although this led to closer supervision of children's app use, some teachers/educators in this study wanted to learn ways to manage their tablet's settings to limit the commercialism of apps and also prevent children from circumventing these settings. The findings of this research revealed a range of practice around tablet use in ECE in relation to these issues. Two services, Hūmārietanga Childcare and Iorangi Playcentre, wanted to know how to manage children's tablet use. Other services had well established systems in place such as Koanga Wakāinga Home-based and Manaakitanga ELC who managed these barriers through cybersafety features which restricted children's access and use of tablets to specific apps.

The findings have also highlighted the importance of the teachers'/educators' role in evaluating apps before using them for teaching and learning. Teachers/educators expressed their need for professional development to better identify appropriate apps and related tablet functions to support young children's learning. At present, most users in the study reported that they relied on a colleague to test and evaluate apps. This collegial support took time and effort as Phase 2 participants who did this reported that their process involved trial and error. The 
findings build upon Walsh and Farren's (2018) research which revealed that teachers found it time consuming to search for engaging and appropriate apps, some of the participants in Phase 2 expressed that they needed professional development on using tablets and related digital technologies, not as basic users, but for teaching and learning including managing settings and scaffolding children's balanced use of these devices. Of interest is how Oldridge (2010) identified the same issue in her study about ICTs which was prior to tablet use in ECE. Teachers' lack of knowledge, interest, and technical skills were issues that needed to be addressed at that time. Currently, some services in this study have found ways to support teachers'/educators' tablet use. These teachers/educators resolved this main barrier through collegial support and by assigning a teacher-in-charge to test apps and provide feedback to management or the umbrella organisation about the use of apps.

The Phase 1 survey asked how teachers/educators learned or would learn to use tablets for teaching and learning in ECE. Both non-users and users specified through personal use followed by through collaboration with other teachers/educators. Phase 2 participants explained that most of them had learned how to use tablets by themselves based on their existing knowledge and skill with computers. Koanga Wākäinga Homebased exemplified this when their team admitted that they learned through trial and error. With regards to how teachers/educators upskilled each other on the use of tablets for teaching and learning, teachers/educators at Hümārietanga Childcare-a non-user service, and Manaakitanga ELC - a user service, expressed that this was not enough and that they needed professional development in using these devices more effectively as teaching tools. Amongst the Phase 2 participants, Manaakitanga ELC had a teacher responsible for testing and evaluating tablet features and apps. This teacher shared her knowledge and skill with her colleagues. This is connected to Oldridge's (2010) concept of collegial support and how ECE teachers/educators in New Zealand upskilled their ICT knowledge and abilities (e.g., Bolstad, 2004; Cherrington et al., 2009). International studies have argued the importance of providing professional development about the use of tablets and their apps to ECE teachers/educators.

The novelty of tablets as a new technology was perceived as a barrier. The teachers reported that this novelty encouraged more frequent use by children but also 
caused a disruption of their activities because the presence of tablets tended to distract children. In Phase 2 the educators at Iorangi Playcentre were cautious about this issue as they did not want children distracted from actual playcentre activities. The teachers at Manaakitanga ELC and Nunui Kindergarten reported that the novelty wore off and tablets were regarded like other tools in the service.

This section has explained that barriers to tablet use in New Zealand's ECE services were usually technology-based at the service-level. Although the most commonly reported barrier to tablet use for teaching and learning was the service's educational philosophy, this was actually a choice made by teachers/educators. The actual barriers could be overcome through supporting the role of teachers/educators and training them in the technicalities of using tablets for teaching and learning. In the next section, the specific affordances of tablets in ECE are discussed.

7.4.2. Affordances. As reported in earlier studies (e.g., Almashaileh, 2016), the main affordance of using tablets is their portability and ease of use. Melhuish and Falloon (2010) indicated how the portability of tablets enabled better collaboration and group work amongst children. The findings of this study highlight the ease of using tablets for documentation and assessment as reported by both nonusers and users. Aside from making teaching easier, the technical scaffolding afforded by apps helped teachers/educators to scaffold children's learning whilst using apps. Data from this research about these technical affordances add to previous research (e.g., Dubé \& McEwen, 2017). In their research, Dubé \& McEwen (2017) highlighted how tablets were useful because they were lightweight, mobile devices with a flat, panel screen used for both display and input making it easy to use in a variety of purposes.

As discussed earlier in Section 7.3.2, teachers/educators found that the multifunctionality of tablets afforded different varieties of learning content and ways of teaching and learning. User services in this research appreciated how using tablets enriched children's learning and made it easier to extend their interests through apps and functionalities that provided easy access to music, videos, and other creative content. This affordance found in this study is in line with by Kay's (1972) vision on how using tablets could potentially amplify children's activities. As discussed earlier 
in this chapter, the most often specified affordance was the documentation features of tablets. In parallel with Fleer's (2017a) research which found that the documentation features of tablets could be extended for use in creative activities and in conjunction with creative apps, user services in this study reported the same.

The multifunctionality and range of different learning opportunities that tablets provide supports how New Zealand's ECE teachers/educators are encouraged to provide a wide range of resources and opportunities for children's holistic learning as stated in Te Whāriki (Ministry of Education, 2017a). International and local studies (Gattenhof \& Dezuanni, 2015b; Khoo et al., 2013; Khoo et al., 2015; Vaughan \& Beers, 2017) have emphasised how the multifunctionality of tablets supports communication, exploration, and collaboration which are aims of $T e$ Whāriki (Ministry of Education, 2017a). The results of this study inform the management of ECE services and their teachers/educators, who are the decisionmakers with regards to resource acquisition and related learning content in ECE, of the factors they can consider in making choices on whether adopting tablets could be valuable to their educational philosophies and goals. Te Whāriki (Ministry of Education, 2017a) supports parents/whānau in making the decision to choose which ECE service meets their needs and preferences based on many factors, including educational philosophies.

The convenience of having bigger screen size for use in small groups and easier scaffolding at a distance was seen as a barrier by some teachers. This contradicting view was revealed in Phase 2 when teachers at Nunui Kindergarten reported that the bigger screen size allowed for easier viewing and typing in collaboration with others who are within physical proximity. However, whilst Nunui Kindergarten also reported that the bigger screen size restricted teachers'/educators' mobility as it limited their ability to use both hands for work, other services saw that the size of tablets was beneficial for sharing tablet use. This finding in this study was similar to the findings of Clarke and Abbot (2016) and Khoo et al. (2013) who described how children and teachers could view and discuss previously documented activities and events via the tablet's big screen. 
There are, however, two sides to this issue. When viewing tablets in groups, teachers/educators reported that the screen size could be easily blocked. Teachers/educators reported that tablets had affordances which supported educational use such as portability and ease of use for documentation and assessment. However, one affordance which was screen size could also become a barrier. Although generally, the screen size supported co-viewing and scaffolding from a distance, in certain situations it could detract other children from fully engaging with the content and prevent teachers/educators from using both their hands for other ECE-related work. The results of this research highlight that even an affordance could become a barrier, depending on the individual contexts and characteristics of each service. This new understanding can help services to consider how the impact of tablets varies depending on the situations where they are used. The next section outlines the limitations of this study followed by a discussion on possible topics for further research.

\subsection{Limitations of the research}

The scope of this study was limited to tablet use in ECE, specifically larger tablets from popular brands in New Zealand which were iPads or Samsung tablets. Although the findings revealed information on related touchscreen devices such as smartphones, these data were peripheral to this study and, thus, have not been examined in this research.

This study was conducted at the service level by collecting data from teachers/educators representing each service as a team. Survey responses were limited because the response rate of $10.4 \%$ in Phase 1 did not allow generalisation to all ECE services in New Zealand. This could be attributed to services' lack of interest in the topic, the availability of teachers/educators to respond to the survey as a team, and perceptions of respondents for or against ICT. As for the last possible reason, some services responded by email that they did not want to participate because they mistook that the study was only for tablet users.

Additionally, teachers'/educators' participation in focus group sessions were limited to their availability. Due to time constraints, the video-SR sessions in Phase 2B did not show all video-recorded episodes. The selection of episodes was based 
on what needed explanation according to the survey results Phase 1 and what were identified during initial correspondence with the service management and focus group interviews in Phase 2A. Although episodes of children's tablet use were video-recorded, I did not analyse data directly from these observations because the nature of this research's design utilised video-SR sessions to elicit teachers'/educators' reflections and reasoning regarding tablet use in the service, rather than focusing on observations of children.

Amongst the playcentres, only seven of 44 respondents to the national survey were tablet users. From these responding playcentres, only one initially indicated willingness to participate in the study. However, this playcentre withdrew prior to completion of the Phase 2 data collection, thus limiting the number of user services to three. Notwithstanding the relatively limited sample size, this work offers valuable insights into how tablets were used in ECE services in New Zealand.

The generalisability of these results is a limitation of this study. The study did not investigate the entire ECE sector as there were other service types which were not involved in data collection. Case studies are non-generalisable because of the nature of the participants and the circumstances when and where data were collected. This research did not address whether children's access to and use of tablets in ECE was beneficial to them or not. This thesis does, however, identify the intricacies involved in adoption, use, and management of tablet in ECE services. By understanding that ECE services based their decisions primarily on their educational philosophies, this thesis pinpoints key issues which could be further investigated in future research.

\subsection{Recommendations for further research}

As there was a paucity on how tablets were used in ECE services in New Zealand, this research explored the extent of use amongst four major service types and identified their reasons for use and non-use. Through a national survey and a collective case study on users and non-users from four service types, data on specific factors involving tablet use in ECE is now available. However, further in-depth research would enable greater attention to be paid to issues discussed in this exploratory study. Studies focusing on each service type and one or two of the major 
topics covered in Phase 1 such as educational philosophy, using tablets for documentation and assessment, individual and group use, type of person providing the scaffolding, potential issues, the use of personally-owned touchscreen devices, and services' guidelines on tablet use or related screen time policies could be carried out.

The groups in the spectrum did not specify the proportion of and how each major topic affected their decision-making involving tablet use and non-use. These variables, such as the extent and various ways a service uses tablets for documentation and assessment, could be better investigated in further studies. One example could be an examination of the specific differences between how each service type uses tablets for documentation and assessment. Although reasons for not using tablets were mainly centred on educational philosophy, each service type had their own unique issues. These specific issues could be further explored with the inclusion of parents as participants in future investigations. In relation to this, other service types could be included in future research. An investigation on how services from different service types transition from not using tablets to using them could also be carried out.

As tablet technology improves, continuing research on the barriers and affordances could be a useful way of keeping the research topic current. In relation to emerging technologies, other forms of digital technologies and related media could be researched further by using the methodology used in this study. In addition, because this research did not investigate touchscreen smartphones, a comparative study between touchscreen smartphones and tablets could be carried out. These studies could lend deeper insight on screen time now that children have increased access to and use screen media through personal portable devices. The findings on the potential of tablets to distract children from learning and teachers'/educators' varying perspectives regarding the optimal screen size for children learning with their peers and the teaching team imply that tablet and app designers need to consider enhancing the ways how tablets support children's learning. Evaluation and contribution to tablet and app designs by teachers'/educators' could be further investigated and could yield collaboration with tablet and app developers and thus enhance app and tablet designs for teaching/learning. 
Comparative studies on the different ways of using tablets could yield substantial data. A comparison on the differences between service types could be explored. For example, services which transition to non-use could be given more attention. A study on tablet use between ECE and the early years of primary schooling could provide information on how these devices support children's transition from ECE to primary schooling. Other longitudinal studies could also be explored. An example could be a more extensive study on tablets beginning from non-use, or restricted use, to adoption and until comprehensive use. The reverse- on how a tablet user service moved from comprehensive use to limited use or even discontinued use - could also be investigated.

Other topics beyond the scope of this research could be considered for further research. These include Māori perspectives and cultural frameworks as well as a closer investigation into how links between home and ECE services shape and extend teachers'/educators' and children's use of tablets. Tablet computers could be used or considered for use towards learning Māori culture and language which was found to a small extent in this study.

\subsection{Contributions to understanding tablet use in New Zealand's ECE contexts}

This thesis contributes to the small body of studies in New Zealand's ECE sector. In particular, this study is the first to report on tablet use and non-use involving four major ECE service types in New Zealand. Prior New Zealand studies have mostly paid peripheral attention to the use and non-use of tablets in ECE; therefore, this study has provided a more nuanced understanding of the issue by arguing that there is fluidity between services' use and non-use of tablets. Whilst earlier studies involved smaller case studies with a few surveys, this study included a national survey and a multi-qualitative phase. A larger scale study provides more knowledge which enables ECE teachers/educators to make an informed decision regarding the adoption and use of tabelts in their services.

By investigating, and giving more attention to the reasons for non-use, this study has contributed to further understanding the digital divides involving tablet use. This investigation has revealed the different reasons why tablets were not used by some services and the ways they were used in other services. The empirical 
findings in this study provide new understandings of the different factors involved in whether ECE services choose to use, or not use, tablets, the foremost of which is their educational philosophy. Primarily, this study found that educational philosophy was key to the decision-making of services and their teachers/educators regarding tablet use, together with consequent service policies and guidelines and funding for acquiring these devices. This research contributed to identifying the factors which involved tablet use and non-use. Of these, an important issue was ECE teachers'/educators' use of their personally-owned tablets. Other factors influencing decision-making on the adoption of tablets by ECE services were the number of children who could use tablets at one time, the size of a user service's teaching team, and ICT guidelines and policies. Amongst these factors, there were positive associations between the number of teachers/educators using tablets for teaching and learning including user services' implementation of a screen time policy. The findings on how ECE teachers/educators in New Zealand's services learned to use tablets also contribute to the existing literature.

A major contribution of this thesis was a spectrum to illustrate the varying extent and different ways tablets were used in ECE services. This is the first time a spectrum was used in in consideration of both literature and research findings. The spectrum made it easier to visualise the extent of tablet use and the complexities involved in various ECE settings because, upon closer inspection, tablet use by ECE services is not binary. The spectrum, as shown in Figure 7.2, illustrates a more nuanced conceptualisation of tablet use or non-use. This spectrum enables services to consider where they are situated and where they can move according to their goals with regards to using tablets. This study elaborates existing conceptualisations of digital divides by going beyond existing notions of haves and have-nots, or users and non-users.

The methods used in this study may be applied by services who plan to use tablets. The survey could help inform teachers/educators about the extent to which tablets are used in their service. The teachers/educators could use video-SR sessions to reflect on their teaching practices and policies surrounding tablet use. 
This study gave teachers/educators a voice, especially those from the nonusers services who were often not included in studies about tablets and digital media. The stance of my research allowed both sides to voice their perspectives regarding the issue. The socialised nature of ECE services in New Zealand revealed different scaffolding strategies. This thesis started pulling together information on the ways touchscreen tablets were scaffolded depending on the service type. Thus, tablet use was not often solitary, and monitoring was undertaken through scaffolding and paired or group use. Further studies could delve deeper into the specific forms of scaffolding used by services such as technical, cognitive, and affective.

Finally, my study contributed to further understanding of how tablets, a common type of digital technology, played a role in the practice of ECE and how policy should be adapted or modified to address the findings of this research. This study revealed that how teachers/educators learned to use tablets was patchy. They did not have a streamlined way of identifying and teaching quality content using apps. This stemmed from reliance on self-learning as opposed to formalised professional development. This led to lack of clear linkages to Te Whäriki. These findings suggest that in-service professional development into the use of technology in ECE, including its links to Te Whāriki, is required and may support the design of such professional development to enhance how tablets are used to support teaching and learning in ECE. The knowledge and information provided by this study could contribute to teachers'/educators' ongoing development of their digital literacy.

Despite the exploratory nature of this study, it offers insights into the differences and similarities of how tablets were used across different services. This research is valuable in helping non-user services articulate their reasons and beliefs for not using tablets and other digital technologies. Finally, the new understandings should help to improve practice and policies about tablets in ECE. These implications are discussed next.

\subsection{Implications of this study}

This research has implications for the ECE sector, its policies and practices, and to wider research. Some of these emerged from the findings such as how 
teachers/educators adopted tablets into their teaching practices and how services set policies and guidelines around this use.

Teachers/educators play a key role in deciding when and how to use tablets in ECE services. The findings provide additional knowledge for training and professional development of ECE teachers/educators. As children's access to and use of tablets and similar devices become commonplace, this research adds to knowledge in supporting current ECE teaching practices. The knowledge provided by this study helps teachers/educators become better informed ECE professionals as they educate and care for young children growing up in the digital age.

For services considering the use of tablets, this study identified factors involving decision-making around tablet use in ECE which should be considered in the planning and policy development of teaching teams and their service management. Services could identify which aspects of tablet use apply to their situation and consider how they could integrate tablets into their teaching, such as deciding on the levels of facilitation; training teachers/educators in how to manage settings, apps, and features; and evaluating and deciding which apps to procure that meet their educational philosophies.

This work adds to the existing research on tablets, and ICT in general, especially in the ECE context. The research design adds variety to existing studies on the topic which have often used qualitative case studies with few survey studies. This research provides greater understanding on the complexities regarding tablet use and non-use at the service level such as differentiated use of scaffolding and variation amongst spectrum groups. Future studies could build on the questions, research design, and findings of the study. More in-depth investigations of data revealed in the study such as teachers'/educators' beliefs and educational philosophies, different sized teaching teams, and the differences between individual and group-based scaffolding strategies could be researched in the future. Other potential areas that could be further explored are the consequences brought by unsupervised use of personally-owned tablets which could put children's cybersafety at risk. 


\subsection{Conclusion}

With regards to the ongoing debate whether tablets should be used or not used in ECE, the study has moved the issue forward by providing a better understanding of tablet use in New Zealand's ECE services. This exploratory study set out to investigate how tablets were or were not used in New Zealand's ECE sector. Phase 1 added home-based and playcentre service types to the more oftenresearched education and care and kindergarten service types in the national survey. Focus group interviews collected qualitative data from teachers/educators representing their respective services in Phase 2, including video-SR sessions for teachers/educators who used tablets.

The research found that the adoption of tablets in New Zealand's ECE services is simply not split between users and non-users but involved a range of factors which fell along a spectrum from non-use to comprehensive use. More kindergartens used tablets followed by education and care services. Fewer homebased services and playcentres used tablets. Amongst the factors that influenced the decision to use tablets in ECE, the foremost was educational philosophy followed by service policy or an umbrella organisation's policy and funding. Services that used tablets primarily used them for documentation and assessment. Other purposes for using tablets were to play music and videos and using creative apps. The study identified factors involving tablet use such as guidelines and policies, including screen time policies, individual or group use, the availability of personally-owned touchscreen devices, and sources of professional development. These aspects of this study are important for services to know what to consider when adopting tablets.

Overall, tablet use is fluid and is spread across a spectrum which includes non-user services becoming user services. This fluidity also included how some user services which discontinued the use of these devices. This thesis contributes to understanding that services and their teachers/educators used tablets in limited, specialised, or comprehensive ways. Understanding these differences on how tablets are used or not is important to support teachers/educators across different service types in their pedagogical decision making regarding digital technologies. Finally, 
the topics explored in this thesis advance research on tablets and their place in New Zealand's ECE services. 


\section{References}

Ahearne, C., Dilworth, S., Rollings, R., Livingstone, V., \& Murray, D. (2015). Touch-screen technology usage in toddlers. Archives of Disease in Childhood, 101(2), 181-183. http://dx.doi.org/10.1136/archdischild-2015309278

Aladé, F., Lauricella, A. R., Beaudoin-Ryan, L., \& Wartella, E. (2016). Measuring with Murray: Touchscreen technology and preschoolers' STEM learning. Computers in Human Behavior, 62, 433-441. https://doi.org/10.1016/j.chb.2016.03.080

Aldemir, J., \& Kermani, H. (2017). Integrated STEM curriculum: Improving educational outcomes for Head Start children. Early Child Development and Care, 187(11), 1694-1706. https://doi.org/10.1080/03004430.2016.1185102

Almashaileh, Y. (2016). The perceptions of teachers surrounding the potential of iPads in early childhood education (ECE) (Master's thesis, Auckland University of Technology, Auckland, New Zealand). Retrieved from http://hdl.handle.net/10292/10089

Apple Inc. (2010, April 5). Apple sells over 300,000 iPads first day. [Press release]. Retrieved from http://www.apple.com/pr/library/2010/04/05Apple-SellsOver-300-000-iPads-First-Day.html

Apple Inc. (2011 July 19). Apple reports third quarter results. [Press release]. Retrieved from http://www.apple.com/pr/library/2011/07/19Apple-ReportsThird-Quarter-Results.html

Arnott, L., Grogan, D., \& Duncan, P. (2016). Lessons from using iPads to understand young children's creativity. Contemporary Issues in Early Childhood, 17(2), 157-173. https://doi.org/10.1177\%2F1463949116633347

Associated Press. (24 April 2019). World Health Organization issues first-ever screen time guidelines for young kids. Here's what to know. TIME. Retrieved from http://time.com/5577349/world-health-organization-screen-timeguidelines-kids/

Atkinson, P. (2008). A bitter pill to swallow: The rise and fall of the tablet computer. Design Issues, 24(4), 3-25. https://doi.org/10.1162/desi.2008.24.4.3

Baralt, M. (2012), Coding second language data validly and reliably. In A. Mackey \& S. Gass (Eds.), Research methodologies in second language acquisition: A practical guide (pp. 222-244). Malden, MA: Wiley-Blackwell.

Bedford, R., Saez de Urabain, I. R. S., Cheung, C. H. M., Karmiloff - Smith, A., \& Smith, T. J. (2016). Toddlers' fine motor milestone achievement is associated with early touchscreen scrolling. Frontiers in Psychology, 7, 1-8. https://doi.org/10.3389/fpsyg.2016.01108 
Bergström, A., \& Höglund, L. (2014). A national survey of early adopters of e-book reading in Sweden. Information Research, 19(2), paper 621. Retrieved from http://InformationR.net/ir/19-2/paper621.html

Beschorner, B., \& Hutchison, A. C. (2013). iPads as a literacy teaching tool in early childhood. International Journal of Education in Mathematics, Science and Technology, 1(1), 16-24.

Bigelow, E. C. (2013). iWrite: Digital message making practices of young children (Doctoral thesis, Vanderbilt University, Nashville, TN). Retrieved from https://etd.library.vanderbilt.edu//available/etd-07192013-085011/

Blackwell, C. (2014). Teacher practices with mobile technology: Integrating tablet computers into the early childhood classroom. Journal of Education Research, 7(4), 1-25.

Blackwell, C. K., Lauricella, A. R., \& Wartella, E. (2016). The influence of TPACK contextual factors on early childhood educators' tablet computer use. Computers \& Education, 98, 57-69. https://doi.org/10.1016/j.compedu.2016.02.010

Blackwell, C. K., Lauricella, A. R., Wartella, E., Robb, M., \& Schomburg, R. (2013). Adoption and use of technology in early education: The interplay of extrinsic barriers and teacher attitudes. Computers \& Education, 69, 310-319. https://doi.org/10.1016/j.compedu.2013.07.024

Bolstad, R. (2004). The role and potential of ICT in early childhood education: A review of New Zealand and international literature. Wellington, New Zealand: Ministry of Education. Retrieved from https://www.educationcounts.govt.nz/_data/assets/pdf_file/0013/7024/TheRole-and-Potential-of-ICE-in-ECE.pdf

Borg, M. (2019). "It's not for real": The tablet as palette in early childhood education. International Journal of Education \& the Arts, 20(14). http://doi.org/10.26209/ijea20n14.

Brinkmann, S. (2018). The interview. In N. K. Denzin \& Y. S. Lincon (Eds.), The Sage handbook of qualitative research (5th ed., pp. 576-599). Thousand Oaks, CA: Sage.

Bruner, J. (1983). Child's talk: Learning to use language. New York, NY: Norton \& Company.

Bullock, E. P., Shumway, J. F., Watts, C. M., \& Moyer-Packenham, P. S. (2017). Affordance access matters: Preschool children's learning progressions while interacting with touch-screen mathematics apps. Technology, Knowledge and Learning, 22(3), 485-511. https://doi.org/10.1007/s10758-017-9312-5 
Burnett, C. (2017). The fluid materiality of tablets: Examining 'the iPad multiple' in a primary classroom. In C. Burnett, G. Merchant, A. Simpson \& M. Walsh (Eds.), The case of the iPad: Mobile literacies in education (pp. 15-29). Singapore: Springer Nature.

Buxton, W., Hill, R., \& Rowley, P. (1985). Issues and techniques in touch-sensitive tablet input. ACM SIGGRAPH Computer Graphics, 19(3), 215-224.

Carr, M., Lee, W., \& Jones, C. (2009). Kei tua o te paelassessment for learning: Early childhood exemplars - book 20: Information and communication technology (ICT) - te hangarau pārongo me te whakawhitwhiti. Wellington, New Zealand: Learning Media.

Carson, V., Tremblay, M. S., Spence, J. C., Timmons, B. W., \& Janssen, I. (2013). The Canadian sedentary behaviour guidelines for the early years (zero to four years of age) and screen time among children from Kingston, Ontario. Paediatrics \& Child Health, 18(1), 25-28. https://doi.org/10.1093/pch/18.1.25

Chassiakos, Y. L. R., Radesky, J., Christakis, D., Moreno, M., Cross, C., Hill, D., ... Swanson, W. S. (2016). Children and Adolescents and Digital Media. Pediatrics, 138(5), e1-e18. Retrieved from: http://pediatrics.aappublications.org/content/138/5/e20162593

Chaudron, C. (2015). Young children (0-8) and digital technology: A qualitative exploratory study across seven countries. Luxembourg, European Union: Joint Research Centre. https://doi.org/10.2788/00749

Cherrington, S., Oldridge, L., Green, V., Dalli, C., Davidson, S., Glasgow, A., ... \& Wansbrough, D. (2009). Evaluation of the early childhood education information and communication technology professional learning programme (ECE ICT PLP), final report. Wellington: New Zealand Ministry of Education. Retrieved from https://www.educationcounts.govt.nz/publications/e-Learning/41987

Cheung, C. H., Bedford, R., Saez de Urabain, I. R., Karmiloff-Smith, A., \& Smith, T. J. (2017). Daily touchscreen use in infants and toddlers is associated with reduced sleep and delayed sleep onset. Scientific Reports, 7(1), 1-7. https://doi.org/10.1038/srep46104

Chiong, C., \& Shuler, C. (2010). Learning: Is there an app for that? Investigations of young children's usage and learning with mobile devices and apps. New York, NY: The Joan Ganz Cooney Center at Sesame Workshop. Retrieved from https://clalliance.org/wpcontent/uploads/files/learningapps_final_110410.pdf.

Choi, K., \& Kirkorian, H. L. (2016). Touch or watch to learn? Toddlers' object retrieval using contingent and noncontingent video. Psychological Science, 5, 726-736. https://doi.org/10.1177/0956797616636110 
Choi, K., Kirkorian, H. L., \& Pempek, T. A. (2018). Understanding the transfer deficit: Contextual mismatch, proactive interference, and working memory affect toddlers' video-based transfer. Child Development, 89(4), 1378-1393. https://doi-org.helicon.vuw.ac.nz/10.1111/cdev.12810

Christensen, R. A. (2017). The effects of using computer and iPad story-writing applications for creative writing with kinder year students in a Montessori early childhood program (Master's thesis, St. Catherine University, St. Paul, MN). Retrieved from https://sophia.stkate.edu/maed/243/

Christians, C. G. (2018). Ethics and politics in qualitative research. In N. K. Denzin \& Y. S. Lincoln (Eds.), The Sage handbook of qualitative research (5th ed., pp. 125-167). Thousand Oaks, CA: Sage.

Cingel, D., \& Piper, A. M. (2017, February). How parents engage children in tabletbased reading experiences: An exploration of haptic feedback. In Proceedings of the 2017 ACM Conference on Computer Supported Cooperative Work and Social Computing (pp. 505-510). Portland, OR: ACM.

Clarke, L., \& Abbott, L. (2016). Young pupils', their teacher's and classroom assistants' experiences of iPads in a Northern Ireland school: "Four and five years old, who would have thought they could do that?" British Journal of Educational Technology, 47(6), 1051-1064. https://doi.org/10.1111/bjet.12266

Cohen, M., Hadley, M., \& Frank, M. (2011). Young children, apps \& iPad. New York, NY: Michael Cohen Group. Retrieved from http://mcgroup.wpengine.com/wp-content/uploads/2015/03/ipad-study-coverpage-report-mcg-info_new-online.pdf

Couse, L. J., \& Chen, D. W. (2010). A tablet computer for young children? Exploring its viability for early childhood education. Journal of Research on Technology in Education, 43(1), 75-96. https://doi.org/10.1080/15391523.2010.10782562

Crescenzi, L., Jewitt, C., \& Price, S. (2014). The role of touch in preschool children's learning using iPad versus paper interaction. The Australian Journal of Language and Literacy, 37(2), 86-95.

Creswell, J. W. (2015a). A concise introduction to mixed methods research. Thousand Oaks, CA: Sage.

Creswell, J. W. (2015b). Educational research: Planning, conducting, and evaluating quantitative and qualitative research (5th ed.). Boston, MA: Pearson Education.

Creswell, J. W., \& Creswell, J. D. (2018). Research design: Qualitative, quantitative and mixed methods approaches (5th ed.). Thousand Oaks, CA: Sage. 
Creswell, J. W., \& Poth, C. N. (2017). Qualitative inquiry and research design: Choosing among five approaches. Thousand Oaks, CA: Sage.

Da Cunha, D. (2016). iPads and preschool: Integrating iPads into a preschool classroom to support learning centers and phonological awareness (Master of Education thesis, The William Paterson University of New Jersey, Wayne, NJ). Available from ProQuest Dissertations \& Theses Global database. (UMI No. 10014968) Retrieved from https://search-proquestcom.helicon.vuw.ac.nz/docview/1767387302?pq-origsite=primo

Dalli, C., \& Stephenson, A. (2010). Involving children in research in early childhood education settings: Opening up the issues. In J. Loveridge (Ed.). Involving children and young people in research in educational settings: Report to the Ministry of Education (pp. 11-46). Wellington, New Zealand: Ministry of Education.

Danby, S. (2017) Technologies, child-centred practice and listening to children. In L. Arnott (Ed.), Digital technologies and learning in the early years (pp. 127138). London, England: Sage.

Daniels, K. (2017). Children's engagement with iPads in early years classrooms: Exploring peer cultures and transforming practices. In C. Burnett, G. Merchant, A. Simpson, \& M. Walsh (Eds.), The case of the iPad: Mobile literacies in education (pp. 195-210). Singapore: Springer. https://doi.org/10.1007/978-981-10-4364-2_12

Denzin, N. K., \& Lincoln, Y. S. (2018a). Introduction: The discipline and practice of qualitative research. In N. K. Denzin \& Y. S. Lincoln (Eds.), The Sage handbook of qualitative research (5th ed., pp. 1-26). Thousand Oaks, CA: SAGE Publications Ltd.

Denzin, N. K., \& Lincoln, Y. S. (2018b). Part II: Paradigms and perspectives in contention. In N. K. Denzin \& Y. S. Lincoln (Eds.), The Sage handbook of qualitative research (5th ed., pp. 97-107). Thousand Oaks, CA: SAGE Publications Ltd.

Denzin, N. K., \& Lincoln, Y. S. (2018c). Part III: Strategies of inquiry. In N. K. Denzin \& Y. S. Lincoln (Eds.), The Sage handbook of qualitative research (5th ed., pp. 309-340). Thousand Oaks, CA: SAGE Publications Ltd.

Di Cesare, D. M., Hardwood, D., \& Rowsell, J. (2019). It is real colouring? Mapping children's im/material thinking in a digital world. In M. Khosrow-Pour, S. Clarke, M. E. Jennex, A. Becker, \& A. V. Anttiroiko (Eds.), Early childhood development: Concepts, methodologies, tools, and applications (pp. 13391364). Hershey, PA: IGI Global. https://10.4018/978-1-5225-7507-8.ch067

Dooley, K., \& Gattenhof, S. (2015). In and out of preschool learning with iPads. In M. Dezuanni, K. Dooley, S. Gattenhof, \& L. Knight (Eds.), iPads in the early 
years: Developing literacy and creativity (pp. 123-141). Oxon, England: Routledge.

Dubé, A. K., \& McEwen, R. N. (2017). Abilities and affordances: Factors influencing successful child-tablet communication. Educational Technology Research and Development, 65(4), 889-908. https://doi.org/10.1007/s11423016-9493-y

Duff, R., \& Leggett, S. (2012). CHILDWISE monitor pre-school report 2012. Norwich, England: CHILDWISE. Retrieved from: http://childnetsic.s3.amazonaws.com/downloads/Research_Highlights/UKCC IS_RH46_Childwise_Monitor_Pre-School_Report_2012.pdf

Ebbeck, M., Yim, H. Y. B., Chan, Y., \& Goh, M. (2015). Singaporean parents' views of their young children's access and use of technological devices. Early Childhood Education Journal, 44(2), 127-134. https://doi.org/10.1007/s10643-015-0695-4

Education Counts. (2017). Early childhood directory [Microsoft Excel data file]. Retrieved from https://www.educationcounts.govt.nz/dataservices/directories/early-childhood-services

Edwards, S., Nolan, A., Henderson, M., Mantilla, A., Plowman, L., \& Skouteris, H. (2018). Young children's everyday concepts of the internet: A platform for cyber-safety education in the early years. British Journal of Educational Technology, 49(1), 45-55. https://doi.org/10.1111/bjet.12529

Ehren, J., \& Leggett, S. (2015). CHILDWISE monitor pre-school report 2015. Norwich, England: CHILDWISE. Retrieved from: https://d1afx9quaogywf.cloudfront.net/sites/default/files/Research\%20Highli ghts/UKCCIS_RH84_CHILDWISE_Monitor_Pre-School_Report_2015.pdf

Eisen, S., \& Lillard, A. S. (2017). Young children's thinking about touchscreens versus other media in the US. Journal of Children and Media, 11(2), 167179. https://doi.org/10.1080/17482798.2016.1254095

Elkind, D. (2016). Touchscreens and young children: Benefits and risks. Young Children, 71(1), 90-93. Retrieved from https://search-proquestcom.helicon.vuw.ac.nz/docview/1789778221 ?accountid=14782

Ernest, J. M., Causey, C., Newton, A. B., Sharkins, K., Summerlin, J., \& Albaiz, N. (2014). Extending the global dialogue about media, technology, screen time, and young children. Childhood Education, 90(3), 182-191. https://doi.org/10.1080/00094056.2014.910046

Estevez-Menendez, M., An, H., \& Strasser, J. (2019). The effects of interactive multimedia iPad e-books on preschooler's literacy. In M. Khosrow-Pour, S. Clarke, M. E. Jennex, A. Becker, \& A. V. Anttiroiko (Eds.), Early childhood 
development: Concepts, methodologies, tools, and applications (pp. 841856). Hershey, PA: IGI Global. https://10.4018/978-1-5225-7507-8.ch041

Fagan, T., \& Coutts, T. (2012). To iPad or not to iPad? Wellington, New Zealand: CORE Education. Retrieved from http://core-ed.org/legacy/sites/coreed.org/files/Fagan-Coutts-iPad-research.pdf?url=/sites/coreed.org/files/Fagan-Coutts-iPad-research.pdf

Falloon, G. (2013). Young students using iPads: App design and content influences on their learning pathways. Computers \& Education, 68, 505-521. https://doi.org/10.1016/j.compedu.2013.06.006

Falloon, G., \& Khoo, E. (2014). Exploring young students' talk in iPad-supported collaborative learning environments. Computers \& Education, 77, 13-28. https://doi.org/10.1016/j.compedu.2014.04.008

Finch B., \& Arrow A. W. (2017). Digital technologies in the literate lives of young children. In C. McLachlan \& A. Arrow (Eds.), Literacy in the early years, international perspectives on early childhood education and development, (Vol. 17, pp. 221-238). Singapore: Springer. https://doi.org/10.1007/978-98110-2075-9_12

Fleer, M. (2013). Digital positioning for inclusive practice in early childhood: The cultural practices surrounding digital tablets in family homes. Computers in New Zealand Schools: Learning, Teaching, Technology, 25(1-3), 56-76.

Fleer, M. (2014). The demands and motives afforded through digital play in early childhood activity settings. Learning, Culture and Social Interaction, 3(3), 202-209. https://doi.org/10.1016/j.lcsi.2014.02.012

Fleer, M. (2017a). Digital pedagogy: How teachers support digital play in the early years. L. Arnott (Ed.), Digital technologies and learning in the early years (pp. 114-126). London, England: SAGE.

Fleer, M. (2017b). Digital role-play: The changing conditions of children's play in preschool settings, Mind, Culture, and Activity, 24(1), 3-17. https://doi.org/:10.1080/10749039.2016.1247456

Fleer, M., \& Hedegaard, M. (2010). Early learning and development: Culturalhistorical concepts in play. New York, NY: Cambridge University Press.

Flewitt, R., Messer, D., \& Kucirkova, N. (2015). New directions for early literacy in a digital age: The iPad. Journal of Early Childhood Literacy, 15(3), 289-310. https://doi.org/10.1177/1468798414533560

Fraenkel, J. R., Wallen, N. E., \& Hyun, H. H. (2015). How to design and evaluate research in education (9th ed.). New York, NY: McGraw-Hill. 
Fridberg, M., \& Redfors, A. (2018). Children's collaborative learning in science scaffolded by tablets. In S. J. Danby, M. Fleer, C. Davidson, \& M.

Hatzigianni (Eds.), Digital childhoods: Technologies and children's everyday lives, international perspectives on early childhood education and development (Vol. 22, pp. 101-115). Singapore: Springer. https://doi.org/10.1007/978-981-10-6484-5

Friedman, D. (2012). How to collect and analyze qualitative data. In A. Mackey \& S. Gass (Eds.), Research methodologies in second language acquisition: A practical guide (pp. 180-200). Malden, MA: Wiley-Blackwell.

Gass, S. M., \& Mackey, A. (2016). Stimulated Recall Methodology in Applied Linguistics and L2 Research (2nd Ed.) New York, NY: Routledge. https://doi.org/10.4324/9781315813349

Gattenhof, S., \& Dezuanni, M. (2015a). Arts education and iPads in the early years. In M. Dezuanni, K. Dooley, S. Gattenhof, \& L. Knight (Eds.), iPads in the early years: Developing literacy and creativity (pp. 30-43). Oxon, England: Routledge.

Gattenhof, S., \& Dezuanni, M. (2015b). Drama, storymaking and iPads in the early years. In M. Dezuanni, K. Dooley, S. Gattenhof, \& L. Knight (Eds.), iPads in the early years: Developing literacy and creativity (pp. 86-102). Oxon, England: Routledge.

Geist, E. (2014). Using tablet computers with toddlers and young preschoolers. Young Children, 69(1), 58. Retrieved from https://www-jstororg.helicon.vuw.ac.nz/stable/ycyoungchildren.69.1.58

Geng, G., Disney, L., \& Mason, J. (2016). Transference of learning from play with iPads in early childhood. In W. Chen, J-C. Yang, S. Murthy, S. L. Wong, \& S. Iyer (Eds.), ICCE - Mumbai, India, 2016: The 24th international conference on computers in education, Nov. 28th - Dec. 2nd, 2016-"Think global act local"-main conference proceedings (pp. 431-436). Taoyuan City, Taiwan: Asia-Pacific Society for Computers in Education. Retrieved from https://researchmgt.monash.edu/ws/portalfiles/portal/239942309/239536992_ oa.pdf

Gerritsen, S., Morton, S. M. B., \& Wall, C. R. (2016), Physical activity and screen use policy and practices in childcare: Results from a survey of early childhood education services in New Zealand. Australian and New Zealand Journal of Public Health, 40(4), 319-325. https://doi.org/10.1111/17536405.12529

Gray, C., Dunn, J., Moffett, P., \& Mitchell, D. (2017). Mobile devices in early learning: Evaluating the use of portable devices to support young children's learning, Report. Belfast, Northern Ireland: Education Authority. 
Greene, J. C., \& Caracelli, V. J. (1997). Defining and describing the paradigm issue in mixed-method evaluation. In J.C. Greene \& V. J. Caracelli (Eds). Advances in mixed-method evaluation: the challenges and benefits of integrating diverse paradigms (pp. 5-18). San Francisco, CA: Jossey-Bass Publishers.

Green, J. C. \& Hall, J. N. (2010). Dialectics and pragmatism: Being of consequence. In A. Tashakkori \& C. Teddlie (Eds.), Sage handbook of mixed methods in social and behavioral research (2nd ed., pp. 119-144). Thousand Oaks, CA: Sage. https://dx.doi.org/10.4135/9781506335193.n5

Hart-Davis, G. (2017). Deploying iPads in the Classroom. Durham, England: Apress. https://doi.org/10.1007/978-1-4842-2928-6

Hatherly, A., \& Chapman, B. (2013). Fostering motivation for literacy in early childhood education using iPads. Computers in New Zealand Schools: Learning, Teaching, Technology, 25(1-3), 138-151.

Healy, J. M. (1998). Failure to connect: How computers affect our children's minds-for better and worse. New York, NY: Simon \& Schuster.

Hedegaard, M. (2007). The development of children's conceptual relations to the world, with a focus on concept formation in preschool children's activity. In H. Daniels, M. Cole, \& J. V. Wertsch (Eds.), The Cambridge companion to Vygotsky (pp. 246- 75). Cambridge, MA: Cambridge University Press.

Henderson, L., \& Tallman, J. (2006). Stimulated recall and mental models: Tools for teaching and learning computer information literacy. Lanham, MD: The Scarecrow Press.

Herodotou, C. (2017). Mobile games and science learning: A comparative study of 4 and 5 years old playing the game Angry Birds. British Journal of Educational Technology, 49(1), 6-16. https://doi.org/10.1111/bjet.12546

Heydon, R., McKee, L., \& Daly, B. (2017). iPads and paintbrushes: Integrating digital media into an intergenerational art class, Language and Education, 31(4), 351-373. https://doi.org/10.1080/09500782.2016.1276585

Hill, D., Ameenuddin, N., Chassiakos, Y. L. R., Cross, C., Radesky, J., Hutchinson, J., ... Swanson, W. S. (2016). Media Use in School-Aged Children and Adolescents. Pediatrics, 138(5), 1-6. https://doi.org/10.1542/peds.2016-2592

Hipp, D., Gerhardstein, P., Zimmermann, L., Moser, A., Taylor, G., \& Barr, R. (2017). The dimensional divide: Learning from TV and touchscreens during early childhood. In R. Barr \& D. N. Linebarger (Eds.), Media exposure during infancy and early childhood (pp. 33-54). Cham, Switzerland: Springer. https://doi.org/10.1007/978-3-319-45102-2_3 
Hirsh-Pasek, K., Zosh, J. M., Golinkoff, R. M., Gray, J. H., Robb, M. B., \& Kaufman, J. (2015). Putting education in "educational" apps: Lessons from the science of learning. Psychological Science in the Public Interest, 16(1), 334. https://doi.org/10.1177/1529100615569721

Holloway, D., Green, L., \& Livingstone, S. (2013). Zero to eight: Young children and their internet use. London, England: EU Kids online. Retrieved from http://eprints.lse.ac.U-K/52630/1/Zero_to_eight.pdf

Holloway, D., Haddon, L., Green, L., \& Stevenson, K. (2018). The parent-child-app learning assemblage: Scaffolding early childhood learning through app use in the family home. In N. Kucirkova, J. Rowsell, \& G. Falloon (Eds.), The Routledge international handbook of playing and learning with technology in early childhood (pp. 210-218). Abingdon UK: Routledge. https://doi.org/10.4324/9781315143040-15

Howie, E. K., Coenen, P., Campbell, A. C., Ranelli, S., \& Straker, L. M. (2017). Head, trunk and arm posture amplitude and variation, muscle activity, sedentariness and physical activity of 3 to 5 year-old children during tablet computer use compared to television watching and toy play. Applied Ergonomics, 65, 41-50. https://doi.org/10.1016/j.apergo.2017.05.011

Jacobs, G. M. (2001). Providing the scaffold: A model for early childhood/primary teacher preparation. Early Childhood Education Journal, 29(2), 125-130. https://doi.org/10.1023/A:1012581113983

Jeong, H. I., \& Kim, Y. (2017). The acceptance of computer technology by teachers in early childhood education. Interactive Learning Environments, 25(4), 496512. https://doi.org/10.1080/10494820.2016.1143376

Johnson, B., \& Gray, R. (2010). A history of philosophical and theoretical issues for mixed methods research. In A. Tashakkori \& C. Teddlie (Eds.), Sage handbook of mixed methods in social and behavioral research (2nd ed., pp. 69-117). Thousand Oaks, CA: Sage. https://dx.doi.org/10.4135/9781506335193.n3

Johnson, B., \& Christensen, L. (2017). Educational research: Quantitative, qualitative, and mixed approaches (6th ed.). Thousand Oaks, CA: Sage.

Kabali, H. K., Irigoyen, M. M., Nunez-Davis, R., Budacki, J. G., Mohanty, S. H., Leister, K. P., \& Bonner, R. L. (2015). Exposure and use of mobile media devices by young children. Pediatrics, 136(6), 1-7. https://doi.org/10.1542/peds.2015-2151

Kay, A. (2012). The future of reading depends on the future of learning difficult-tolearn things. In B. Junge, Z. Berzina, W. Scheiffele, W. Westerveld, \& C. Zwick (Eds.), The digital turn: Design in the era of interactive technologies (pp. 20-31). Zürich, Switzerland: Park Books. 
Kay, A. C. (1972, August). A personal computer for children of all ages. In Proceedings of the ACM annual conference-Volume 1 (pp. 1-11). New York, NY: ACM.

Kay, A., \& Goldberg, A. (1977). Personal dynamic media. Computer, 10(3), 31-41.

Keirl, S. (2015). 'Seeing' and 'interpreting' the human-technology phenomenon. In P. J. Williams, A. Jones \& C. Buntting (Eds.), The future of technology education (pp. 13-34). Singapore: Springer. https://doi.org/10.1007/978-981287-170-1_2

Khoo, E., Merry, R., Nguyen, N. H., \& MacMillan, N. (2015). iPads and opportunities for teaching and learning for young children (iPads n kids). Hamilton, New Zealand: Wilf Malcolm Institute of Educational Research.

Khoo, E., Merry. R., Nguyen, N. H., Bennett. T., \& MacMillan. N. (2013). Early childhood education teachers' iPad supported practices in young children's learning and exploration. Computers in New Zealand Schools: Learning, Teaching, Technology, 25(1-3), 3-20.

Kirkorian, H. L. (2018). When and how do interactive digital media help children connect what they see on and off the screen? Child Development Perspectives, 12(3), 210-214. https://doi.org/10.1111/cdep.12290

Kirova, A., \& Jamison, N. M. (2018). Peer scaffolding techniques and approaches in preschool children's multiliteracy practices with iPads. Journal of Early Childhood Research, 16(3), 245-257. https://doi.org/10.1177/1476718X18775762

Knoblauch, H., Schnettler, B., \& Raab, J. (2006). Video-analysis. Methodological aspects of interpretive audiovisual analysis in social research. In $\mathrm{H}$. Knoblauch, B. Schnettler, J. Raab, \& H. G. Soeffner (Eds.), Video-analysis: Methodology and methods - qualitative audiovisual data analysis in sociology (pp. 9-26). Frankfurt, Germany: Peter Lang. Retrieved from http://www.soz.uni-bayreuth.de/_pdfs/VideoAnalysis_2006_Introduction.pdf

Krcmar, M., \& Cingel, D. P. (2014). Parent-child joint reading in traditional and electronic formats. Media Psychology, 17(3), 262-281. https://doi.org/10.1080/15213269.2013.840243

Krueger, R. A., \& Casey, M. A. (2015). Focus groups: A practical guide for applied research. Thousand Oaks, CA: SAGE Publications, Inc.

Kucirkova N., \& Sakr M. (2016). Digital technologies, children's learning, and the affective dimensions of family relationships in the home. In S. Punch, R. Vanderbeck, \& T. Skelton (Eds.), Families, intergenerationality, and peer group relations. Geographies of children and young people (Vol. 5, pp. 129148). Singapore: Springer. https://doi.org/10.1007/978-981-4585-92-7_29-1 
Laidlaw, L., O'Mara, J., \& Wong, S. (2015). "Daddy, look at the video I made on my iPad!": Reconceptualizing "readiness" in the digital age. In J. M. Iorio \& W. Parnell (Eds.), Rethinking readiness in early childhood education (pp. 65-76). Palgrave Macmillan, New York. https://doi.org/10.1057/9781137485120_5

Lantolf, J., \& Thorne, S. L. (2007). Sociocultural theory and second language learning. In B. van Patten \& J. Williams (Eds.), Theories in second language acquisition (pp. 201-224). Mahwah, NJ: Lawrence Erlbaum.

Lantolf, J. P. (2000). Introducing sociocultural theory. In J. P. Lantolf (Ed.), Sociocultural theory and second language learning (pp. 1-26). Oxford, England: Oxford University Press.

Lawrence, S. M. (2018). Preschool children and iPads: Observations of social interactions during digital play. Early Education and Development, 29(2), 207-228. https://doi.org/10.1080/10409289.2017.1379303

Lin, L. Y., Cherng, R. J., Chen, Y. J., Chen, Y. J., \& Yang, H. M. (2015). Effects of television exposure on developmental skills among young children. Infant Behavior and Development, 38, 20-26. https://doi.org/10.1016/j.infbeh.2014.12.005

Lincoln, Y. S., Lynham, S. A., \& Guba, E. G. (2018). Paradigmatic controversies, contradictions, and emerging confluences, revisited. In N. K. Denzin \& Y. S. Lincoln (Eds.), The Sage handbook of qualitative research (5th ed., pp. 108150). Thousand Oaks, CA: SAGE Publications Ltd.

Liu, S. (2019). Tablet shipments worldwide by operating system from 2010 to 2019 (in million units). Retrieved from

https://www.statista.com/statistics/273268/worldwide-tablet-sales-byoperating-system-since-2nd-quarter-2010/

Loveridge, J. (2010). Introduction. In J. Loveridge (Ed). Involving children and young people in research in educational settings: Report to the Ministry of Education (pp. 1-10). Wellington, New Zealand: Ministry of Education.

Lu, Y., Ottenbreit-Leftwich, A., Ding, A., \& Glazewski, K. (2017). Experienced iPad-using early childhood teachers: practices in the one-to-one iPad classroom. Computers in the Schools, 34(1-2), 9-23. http://doi.org.10.1080/07380569.2017.1287543

Lyle, J. (1999). Coaches' decision making, In J. Lyle, \& N. R. Cross (Eds.), The coaching process: Principles and practice for sport (pp. 210-232). Oxford, England: Butterworth-Heinemann.

Lynch, J., \& Redpath, T. (2014). 'Smart'technologies in early years literacy education: A meta-narrative of paradigmatic tensions in iPad use in an 
Australian preparatory classroom. Journal of Early Childhood Literacy, 14(2), 147-174. https://doi.org/10.1177/1468798412453150

MacCallum, K., \& Bell, H. R. (2019). Improving teaching practice in early childhood supported by mobile technology. In M. Khosrow-Pour, S. Clarke, M. E. Jennex, A. Becker, \& A. V. Anttiroiko (Eds.), Early childhood development: Concepts, methodologies, tools, and applications (pp. 1066-182). Hershey, PA: IGI Global. https://10.4018/978-1-5225-7507-8.ch053

Mackey, A., \& Gass, S.M. (2016). Second language research: Methodology and design (2nd ed.). New York, NY: Routledge.

Marsh, J., Plowman, L., Yamada-Rice, D., Bishop, J.C., Lahmar, J., Scott, F., ... Winter, P. (2015). Exploring play and creativity in pre-schoolers' use of apps: Final project report. Swindon, England: Technology and Play, Economic and Social Research Council. Retrieved from http://www.techandplay.org/reports/TAP_Final_Report.pdf.

Masataka, N. (2014). Development of reading ability is facilitated by intensive exposure to a digital children's picture book. Frontiers in Psychology, 5, 5-8. https://doi.org/10.3389/fpsyg.2014.00396

McEwen, R., \& Dubé, A. K. (2015). Engaging or distracting: Children's tablet computer use in education. Educational Technology \& Society, 18(4), 9-23.

McEwen, R., \& Dubé, A. K. (2016). Intuitive or idiomatic: An interdisciplinary study of child-tablet computer interaction. Journal of the Association for Information Science and Technology, 67(5), 1169-1181. https://doi.org/10.1002/asi.23470

Melhuish, K., \& Falloon, G. (2010). Looking to the future: M-learning with the iPad. Computers in New Zealand Schools: Learning, Leading, Technology, 22(3), 1-16. https://hdl.handle.net/10289/5050

Merchant, G. (2015). Keep taking the tablets: iPads, story apps and early literacy. The Australian Journal of Language and Literacy, 38(1), 3-11.

Merriam, S. B., \& Tisdell, E. J. (2016). Qualitative research: A guide to design and implementation (4th ed.). San Francisco, CA: Jossey-Bass.

Merry, R. (2017). Teacher education ICT appropriation model TEAM: A model for ICT appropriation in early childhood initial teacher education (Doctoral thesis, University of Waikato, Hamilton, New Zealand). Retrieved from https://hdl.handle.net/10289/10844

Mertens, D. M. (2015). Research and evaluation in education and psychology: Integrating diversity with quantitative, qualitative, and mixed methods (4th ed.). Thousand Oaks, CA: Sage. 
Ministry of Education. (1996). Te Whāriki, He whāriki mātauranga mō ngāa mokopuna o Aotearoa: Early childhood curriculum. Wellington, New Zealand: Learning Media.

Ministry of Education. (2005). Foundations for discovery-supporting learning in early childhood education through information and communication technologies: A framework for development. Wellington, New Zealand: Learning Media.

Ministry of Education. (2014). Choices. Wellington, New Zealand: Crown. Retrieved from https://parents.education.govt.nz/assets/Parents/Documents/EarlyLearning/ECE-Choices-Booklet.pdf

Ministry of Education. (2017a). Te Whāriki, He whāriki mātauranga mō ngā mokopuna o Aotearoa: Early childhood curriculum. Wellington, New Zealand: Crown.

Ministry of Education. (2017b). Early childhood directory [Microsoft Excel data file]. Retrieved from https://www.educationcounts.govt.nz/dataservices/directories/early-childhood-services

Ministry of Education. (2018a). Overview of attendance at licensed ECE services in 2018. Wellington, New Zealand: Education Counts. Retrieved from https://www.educationcounts.govt.nz/_data/assets/pdf_file/0009/192942/EC E-Summary-page-1Attendance-in-2018.pdf

Ministry of Education. (2018b). The national picture: What does the ECE census 2017 tell us about enrolments/attendances? Wellington, New Zealand: Education Counts. Retrieved from https://www.educationcounts.govt.nz/_data/assets/pdf_file/0006/184353/EC E-Summary-Page-Enrolments.pdf

Mitchell, L., \& Brooking, K. (2008). Early childhood education services in 2007: Key findings from the NZCER national survey. Wellington, New Zealand: New Zealand Council For Educational Research. Retrieved from: http://www.nzcer.org.nz/system/files/15318_0.pdf

Moffett, P., Gray, C., Dunn, J., \& Mitchell, D. (2017). Benefits of mobile digital devices in early learning. Early Years Educator, 19(5), 26-28. https://doi.org/10.12968/eyed.2017.19.5.26

Mohapatra, M., \& Hasty, A. (2012). Mobile apps for kids: Disclosures still not making the grade. Washington, D.C.: Federal Trade Commission. Retrieved from https://www.ftc.gov/sites/default/files/documents/reports/mobile-appskids-disclosures-still-not-making-grade/121210mobilekidsappreport.pdf

Mondada, L. (2006). Video-recording as the reflexive preservation and configuration of phenomenal features for analysis. In H. Knoblauch, B. Schnettler, J. Raab, \& H. G. Soeffner (Eds.), Video-analysis: Methodology and methods- 
qualitative audiovisual data analysis in sociology (pp. 51-68). Frankfurt, Germany: Peter Lang. Retrieved from http://www.soz.unibayreuth.de/_pdfs/Video-Analysis_2006_Introduction.pdf

Moon, J., Cho, S., Lim, S., Roh, J., Koh, M., Kim, Y., \& Nam, E. (2019). Smart device usage in early childhood is differentially associated with fine motor and language development. Acta Paediatrica, 108(5), 903-910. https://doi.org/10.1111/apa.14623

Moore, D., Hoskyn, M., \& Mayo, J. K. (2018). Thinking language awareness at a science centre: iPads, science, and early literacy development with multilingual kindergarten children in Canada. International Journal of Bias, Identity and Diversities in Education, 3(1), 40-63. https://doi.org/10.4018/IJBIDE.2018010104

Morse, J. (2018). Reframing rigor in qualitative inquiry. In N. K. Denzin \& Y. S. Lincoln (Eds.), The Sage handbook of qualitative research (5th ed., pp. 797817). Thousand Oaks, CA: SAGE Publications Ltd.

Murdock, G. (2002a). Review article: Debating digital divides. European Journal of Communication, 17(3), 385-390. https://doiorg.helicon.vuw.ac.nz/10.1177/0267323102017003695

Murdock, G. (2002b, February 19). Tackling the digital divide: Evidence and intervention. Paper presented to British Educational Communications and Technology Agency seminar, The digital divide: A collection of papers from the Toshiba/Becta digital divide seminar (19), 23-31.

Neumann, M. M. (2014). An examination of touch screen tablets and emergent literacy in Australian pre-school children. Australian Journal of Education, 58(2), 109-122. https://doi.org/10.1177/0004944114523368

Neumann, M. M. (2018). Using tablets and apps to enhance emergent literacy skills in young children. Early Childhood Research Quarterly, 42(1), 239-246. https://doi.org/10.1016/j.ecresq.2017.10.006

Neumann, M. M., \& Neumann, D. L. (2014). Touch screen tablets and emergent literacy. Early Childhood Education Journal, 42(4), 231-239.

Neumann, M., Merchant, G., \& Burnett, C. (2018). Young children and tablets: The views of parents and teachers. Early Child Development and Care, 1-12. https://doi.org/10.1080/03004430.2018.1550083

NZ On Air. (2015). Children's media use study: How our children engage with media today. Wellington, New Zealand: Colmar Brunton. Retrieved from https://bsa.govt.nz/images/assets/Research/Childrens_Media_Report_2015_F INAL_for_publishing_2.pdf 
O’Connor, J. (2017). Under 3s and technology. In L. Arnott (Ed.), Digital technologies and learning in the early years (pp. 87-98). London, England: SAGE.

O’Mara, J., Laidlaw, L., \& Blackmore, J. (2017). The new digital divide: Digital technology policies and provision in Canada and Australia. In C. Burnett, G. Merchant, A. Simpson, \& M. Walsh (Eds.), The case of the iPad (pp. 87104). Singapore: Springer. https://doi.org/10.1007/978-981-10-4364-2_6

Ofcom. (2017). Children and parents: Media use and attitudes report. London, England: Ofcom. Retrieved from https://www.ofcom.org.U-

K/_data/assets/pdf_file/0020/108182/children-parents-media-use-attitudes2017.pdf

Oldridge, L. A. (2010). Digital foundations: A study of perceptions and practices surrounding the use of ICT in ECE centres (Doctoral thesis, Massey University, Palmerston North, New Zealand). Retrieved from http://hdl.handle.net/10179/1705

Oliemat, E., Ihmeideh, F., \& Alkhawaldeh, M. (2018). The use of touch-screen tablets in early childhood: Children's knowledge, skills, and attitudes towards tablet technology. Children and Youth Services Review, 88, 591-597. https://doi.org/10.1016/j.childyouth.2018.03.028

Palmér, H. (2015). Using tablet computers in preschool: How does the design of applications influence participation, interaction and dialogues? International Journal of Early Years Education, 23(4), 365-381. https://doi.org/10.1080/09669760.2015.1074553

Patchan, M. M., \& Puranik, C. S. (2016). Using tablet computers to teach preschool children to write letters: Exploring the impact of extrinsic and intrinsic feedback. Computers \& Education, 102, 128-137. https://doi.org/10.1016/j.compedu.2016.07.007

Plowman, L., McPake, J., \& Stephen, C. (2010). The technologisation of childhood? Young children and technology in the home. Children \& Society, 24(1), 6374. https://doi.org/10.1111/j.1099-0860.2008.00180.x

Radesky, J., Christakis, D., Hill, D., Ameenuddin, N., Chassiakos, Y. L. R., Cross, C., ... Swanson, W. S. (2016). Media and young minds. Pediatrics, 138(5), 16. https://doi.org/10.1542/peds.2016-2591

Radesky, J. S., Schumacher, J., \& Zuckerman, B. (2015). Mobile and interactive media use by young children: The good, the bad, and the unknown. Pediatrics, 135(1), 1-3. https://doi.org/10.1542/peds.2014-2251

Radich, J. (2013). Technology and interactive media as tools in early childhood programs serving children from birth through age 8. Every Child, 19(4), 1819. Retrieved from 
https://search.informit.com.au/documentSummary;dn=728719428486158;res $=$ IELAPA

Ralph, R. (2018). Media and technology in preschool classrooms: manifesting prosocial sharing behaviours when using iPads. Technology, Knowledge and Learning, 23(2), 199-221. https:/doi.org.10.1007/s10758-017-9342-z

Ralph, R. and Petrina, S. (2018). Social learning with mobile devices in preschool classrooms. European Journal of STEM Education, 3(3), 12. https://doi.org/10.20897/ejsteme/3872

Reich, S. M., Korobkova, K. A., Black, R. W., \& Sumaroka, M. (2013). "Hey! Can you show me how to do this?": Digital games as a mediator of family time. In A. Burke \& J. Marsh (Eds.), Children's virtual play worlds. Culture, learning, and participation (pp. 134-150). New York, NY: Peter Lang Publishing. https://doi.org/10.3726/978-1-4539-1069-6

Research New Zealand. (2015). A report on a survey of New Zealanders' use of smartphones and other mobile communication devices 2015. Wellington, New Zealand: Author. Retrieved from http://www.researchnz.com/pdf/Special\%20Reports/Research\%20New\%20Z ealand \%20Special\%20Report $\% 20-\% 20$ Use $\% 20$ of\%20Smartphones.pdf

Révész, A. (2012), Coding second language data validly and reliably. In A. Mackey \& S. Gass (Eds.), Research methodologies in second language acquisition: A practical guide (pp. 203-221). Malden, MA: Wiley-Blackwell.

Reynolds-Blankenship, T. L. (2013). An action research study investigating children's use of an iPad during free play in a kindergarten classroom: An exploration of teaching pedagogy and children's learning, social interactions, and digital literacy (Doctoral thesis, Texas Woman's University, TX). Retrieved from http://hdl.handle.net/11274/753

Rideout, V. (2011). Zero to eight: Children's media use in America. San Francisco, CA: Common Sense Media.

Rideout, V. (2013). Zero to eight: Children's media use in America 2013-A Common Sense Media research study. San Francisco, CA: Common Sense Media.

Rideout, V. (2017). The Common Sense census: Media use by kids age zero to eight. San Francisco, CA: Common Sense Media.

Rogoff, B. (1990). Apprenticeship in thinking: Cognitive development in social context. New York, NY: Oxford University Press.

Rogoff, B. (1995). Observing sociocultural activity on three planes: Participatory appropriation, guided participation, and apprenticeship. In J. V. Wetsch (Ed.), 
Sociocultural studies of mind (pp. 139-164). Cambridge, England: Cambridge University Press.

Rose, S., Fitzpatrick, K., Mersereau, C., \& Whitty, P. (2017). Playful pedagogic moves: Digital devices in the outdoors. In D. Harwood, Crayons and iPads: Learning and teaching of young children in the digital world (pp. 16-28). London, England: Sage.

Roskos, K., \& Burstein, K. (2012). Descriptive observations of e-book shared reading at preschool. Journal of Literacy and Technology, 13(3), 27-57. Retrieved from: http://www.literacyandtechnology.org/uploads/1/3/6/8/136889/jlt_volume_13 _3_roskos_burstein.pdf

Rowe, D. W., \& Miller, M. E. (2017). The affordances of touchscreen tablets and digital cameras as tools for young children's multimodal, multilingual composing. In C. Burnett, G. Merchant, A. Simpson, \& M. Walsh (Eds.), The case of the iPad: Mobile literacies in education (pp. 159-178). Singapore: Springer. https://doi.org/10.1007/978-981-10-4364-2_10

Sakr, M. (2018). Multimodal participation frameworks during young children's collaborative drawing on paper and on the iPad. Thinking Skills and Creativity, 29, 1-11. https://doi.org/10.1016/j.tsc.2018.05.004

Sammons, P. (2010). The contribution of mixed methods to recent research on educational effectiveness. In A. Tashakkori \& C. Teddlie (Eds.) Sage handbook of mixed methods in social and behavioral research (2nd ed., pp. 697-724). Thousand Oaks, CA: Sage.

https://dx.doi.org/10.4135/9781506335193.n27

Sandvik, M., Smørdal, O., \& Østerud, S. (2012). Exploring iPads in practitioners' repertoires for language learning and literacy practices in kindergarten. Nordic Journal of Digital Literacy, 7(3), 204-221. Retrieved from https://www.idunn.no/dk/2012/03/exploring_ipads_in_practitioners_repertoir es_for_language_

Science Media Centre (24 April 2019). Expert reaction to guidance on physical activity, sedentary behaviour and sleep for children under 5 years of age. Science Media Centre. Retrieved from: https://www.sciencemediacentre.org/expert-reaction-to-guidance-onphysical-activity-sedentary-behaviour-and-sleep-for-children-under-5-yearsof-age/

Schacter, J., \& Jo, B. (2016). Improving low-income preschoolers mathematics achievement with Math Shelf, a preschool tablet computer curriculum. Computers in Human Behavior, 55, 223-229. https://doi.org/10.1016/j.chb.2015.09.013 
Schwandt, T. A., \& Gates, E. F. (2018). Case study methodology. In N. K. Denzin \& Y. S. Lincoln (Eds.), The Sage handbook of qualitative research. (5th ed., pp. 341-358). Thousand Oaks, CA: Sage.

Selwyn, N. (2003). Apart from technology: Understanding people's non-use of information and communication technologies in everyday life. Technology in Society, 25(1), 99-116. https://doi.org/10.1016/S0160-791X(02)00062-3

Shuler, C., Levine, Z., \& Ree, J. (2012). iLearn II: An analysis of the education category of Apple's app store. New York, NY: The Joan Ganz Cooney Center at Sesame Workshop. Retrieved from http://joanganzcooneycenter.org/wp-content/uploads/2012/01/ilearnii.pdf

Souto, P. H. S., Santos, J. N., Leite, H. R., Hadders-Algra, M., Guedes, S. C., Nobre, J. N. P., .. \& Morais, R. L. (2019). Tablet use in young children is associated with advanced fine motor skills. Journal of Motor Behavior, 1-8. http://doi.org.10.1080/00222895.2019.1602505

Spencer, P. (2013). iPads: Improving numeracy learning in the early years. In V. Steinle, L. Ball, \& C. Bardini (Eds.), Mathematics education: Yesterday, today, and tomorrow (pp. 610-617). Melbourne, Australia: MERGA. Retrieved from https://files.eric.ed.gov/fulltext/ED573028.pdf

Spitzer, M. (2013). To swipe or not to swipe? - The question in present-day education. Trends in Neuroscience and Education, 2(3-4), 95-99. https://doi.org/10.1016/j.tine.2013.09.002

Stake, R. E. (1995). The art of case study research. Thousand Oaks, CA: Sage.

Stake, R. E. (2006). Multiple case study analysis. New York, NY: The Guilford Press.

Stephen, C., \& Edwards, S. (2018). Young children playing and learning in a digital age: A cultural and critical perspective. Oxon, England: Routledge.

Straker, L., Zabatiero, J., Danby, S., Thorpe, K., \& Edwards, S. (2018). Conflicting guidelines on young children's screen time and use of digital technology create policy and practice dilemmas. The Journal of Pediatrics, 202, 300-303.

Strasburger, V. C., \& Hogan, M. J. (2013). Policy statement: Children, adolescents, and the media. Pediatrics, 132(5), 958-961.

http://www.pediatrics.org/cgi/doi/10.1542/peds.2013-2656

Sulaymani, O., \& Fleer, M. (2019). Perezhivanie as a phenomenon and a unit of analysis for studying children's interactions with iPads in the early years of school in Saudi Arabia. Early Child Development and Care, 189(2), 255-269. https://doi.org/10.1080/03004430.2017.1316267

Swaminathan, S., \& Wright, J. L. (2003). Educational technology in the early and primary years. In J. P. Isenberg \& M. R. Jalongo (Eds.), Major trends and 
issues in early childhood education (2nd ed., pp. 136-149). New York, NY: Teachers College Press.

Tagawa, D. (2018). iPads in preschools: A collective case study about tablet technology in subsidized preschool programs (Doctoral thesis, Liberty University, Lynchburg, VA, USA). Retrieved from https://digitalcommons.liberty.edu/doctoral/1682/

Tashakkori, A., \& Teddlie, C. (2010). Epilogue: Current developments and emerging trends in integrated research methodology. In A. Tashakkori \& C. Teddlie (Eds.), Sage handbook of mixed methods in social and behavioral research (2nd ed., pp. 803-826). Thousand Oaks, CA: Sage. https://dx.doi.org/10.4135/9781506335193.n31

Tavernier, M., \& Hu, X. (2017). Developing young children's technology - based communication skills using iPads and creation apps: An action study. In S. Erdelez \& N. Agarwal (Eds.), Proceedings of the Association for Information Science and Technology (Vol. 54, pp. 415-425). Somerset, NJ: John Wiley \& Sons. https://doi.org/10.1002/pra2.2017.14505401045

Teddlie, C., \& Tashakkori, A. (2010). Overview of contemporary issues in mixed methods research. In A. Tashakkori \& C. Teddlie (Eds.), Sage handbook of mixed methods in social and behavioral research (2nd ed., pp. 1-41). Thousand Oaks, CA: Sage. https://dx.doi.org/10.4135/9781506335193.n1

Terreni, L. (2009). A case study: How young children and teachers use an interactive whiteboard in a New Zealand kindergarten setting for visual art learning experiences (Master's thesis, Victoria University of Wellington, Wellington, New Zealand). Retrieved from http://hdl.handle.net/10063/983

Terreni, L. (2010). Adding new possibilities for visual art education in early childhood settings: The potential of interactive whiteboards and ICT. Australasian Journal of Early Childhood, 35(4), 90-94.

Tesch, R. (2013). Qualitative research: Analysis types and software. Oxon, England: Routledge.

Thornton, K. R. (2009). Blended action learning: Supporting leadership learning in the New Zealand ECE sector (Doctoral thesis, Victoria University of Wellington, Wellington, New Zealand). Retrieved from http://hdl.handle.net/10063/996

Troseth, G. L., Russo, C. E., \& Strouse, G. A. (2016). What's next for research on young children's interactive media? Journal of Children and Media, 10(1), 54-62. https://doi.org/10.1080/17482798.2015.1123166

Tsumura, L. (2017). Educators' insights on utilizing iPads to meet kindergarten goals (Master's thesis, University of Ontario Institute of Technology, Ontario, Canada). Retrieved from http://hdl.handle.net/10155/808 
Vaughan, M., \& Beers, C. (2017). Using an exploratory professional development initiative to introduce iPads in the early childhood education classroom. Early Childhood Education Journal, 45(3), 321-331.

https://doi.org/10.1007/s10643-016-0772-3

Verenikina, I., \& Kervin, L. (2011). iPads, digital play and pre-schoolers. Не Kupu, 2(5), 4-19. Retrieved from https://www.hekupu.ac.nz/article/ipads-digitalplay-and-pre-schoolers

Vygotsky, L. S. (1978). Interaction between learning and development. In M. Cole, V. John-Steiner, S. Scribner, \& E. Souberman (Eds.), Mind and society: The development of higher psychological processes (pp. 79-91). Cambridge, MA: Harvard University Press.

Vygotsky, L. S. (1999). The collected works of L. S. Vygotsky: Volume 6: Scientific legacy. R. W. Rieber (Ed.), (M. J. Hall, Trans.). New York, NY: Kluwer/Plenum.

Walsh, V., \& Farren, M. (2018). Teacher attitudes regarding barriers to meaningfully implementing iPads in a primary school setting, Computers in the Schools, 35(2),152-170. https://doi.org/10.1080/07380569.2018.1462674

Walter-Laager, C., Brandenberg, K., Tinguely, L., Pfiffner, M. R., Schwarz, J., \& Moschner, B. (2016). Media-assisted language learning for young children: Effects of a word-learning app on the vocabulary acquisition of two-yearolds. British Journal of Educational Technology, 48(4), 1062-1072. https://doi.org/10.1111/bjet.12472

Wang, F., Xie, H., Wang, Y., Hao, Y., \& An, J. (2016). Using touchscreen tablets to help young children learn to tell time. Frontiers in Psychology, 7, 1-8. https://doi.org/10.3389/fpsyg.2016.01800

Wartella, E., Kirkpatrick, E., Rideout, V., Lauricella, A., \& Connell, S. (2014). Revised media, technology, and reading in Hispanic families: A national survey. Evanston, IL: Center on Media and Human Development, Northwestern University. Retrieved from http://cmhd.northwestern.edu/wpcontent/uploads/2014/08/NWU.MediaTechReading.Hispanic.FINAL2014.pd $\mathrm{f}$

Watts, C. M., Moyer-Packenham, P. S., Tucker, S. I., Bullock, E. P., Shumway, J. F., Westenskow, A., ... Jordan, K. (2016). An examination of children's learning progression shifts while using touch screen virtual manipulative mathematics apps. Computers in Human Behavior, 64, 814-828. https://doi.org/10.1016/j.chb.2016.07.029

Wei, K. K., Teo, H. H., Chan, H. C., \& Tan, B. C. (2011). Conceptualizing and testing a social cognitive model of the digital divide. Information Systems Research, 22(1), 170-187. https://doi/org.10.1287/isre.1090.0273 
Wiersma, W., \& Jurs, S. G. (2009). Research methods in education: An introduction (9th Ed.). Upper Saddle River, NJ: Pearson Education.

Winters, K., \& Memme, L. (2017). Digital inquiry and socio-critical negotiations in two early childhood classrooms. In D. Harwood (Ed.), Crayons and iPads: Learning and teaching of young children in the digital world (pp. 29-41). London, England: Sage.

Wood, D., Bruner, J. S., \& Ross, G. (1976). The role of tutoring in problem solving. Journal of Child Psychology and Psychiatry, 17(2), 89-100. https://doi.org/10.1111/j.1469-7610.1976.tb00381.x

World Health Organization. (2019). Guidelines on physical activity, sedentary behaviour and sleep for children under 5 years of age. Genève, Switzerland: World Health Organization. Retrieved from http://www.who.int/iris/handle/10665/311664.

Yelland, N., \& Gilbert, C. (2017). Transformative technologies and play in the early years: Using tablets for new learning. Global Studies of Childhood, 8(2), 152161. https://doi.org/10.1177/2043610617734985

Yelland, N., \& Masters, J. (2007). Rethinking scaffolding in the information age. Computers \& Education, 48(3), 362-382. https://doi.org/10.1016/j.compedu.2005.01.010

Yelland, N., Gilbert, C., \& Turner, N. (2014). iPlay, iLearn, iGrow: Using iPads in a play-based kindergarten program. Every Child, 20(3), 14-15.

Young, J. G., Trudeau, M., Odell, D., Marinelli, K., \& Dennerlein, J. T. (2012). Touchscreen tablet user configurations and case-supported tilt affect head and neck flexion angles. Work, 41(1), 81-91.

Zipparo, S., Robinson, C., \& Hazeldene, R. (2015). Using mobile technology in an early childhood setting. In Z. Yu (Ed.), Handbook of mobile teaching and learning (pp. 663-667). Heidelberg, Germany: Springer Berlin Heidelberg. https://doi.org/10.1007/978-3-642-54146-9_51 


\title{
Appendices
}

\section{Appendix A}

\author{
Information letter for early childhood teachers \\ for Phase 1: Survey emailed to online survey respondent \\ and posted to paper-based survey respondents \\ Research Project: \\ Touchscreen Tablet Pedagogy in Early Childhood Education
}

Tēnā koe,

My name is Luke Santamaria, a PhD student of the School of Education at Victoria University of Wellington. I am writing to request your permission to conduct research at your early childhood education service.

This research will explore touchscreen tablet use in four major service types: education and care centres, home-based services, kindergartens, and playcentres. Children today have increasing access to touchscreen tablets. According to the early childhood curriculum, Te Whäriki, children growing up in the context of a changing society could benefit from the use of technology. In Te Whäriki each of the strands - well-being, belonging, contribution communication and exploration - make reference to technology. The Ministry of Education's Foundations for Discovery - Supporting Learning in Early Childhood Education through Information and Communication Technologies (ICT) released in 2005, defined ICT as the equipment and computer programmes that allow access, use and sharing of information. This definition includes touchscreen tablets, which are multimodal handheld devices with computer programmes called apps.

The project will investigate touchscreen tablet use for teaching and learning in early childhood education services. For this study, teachers/educators include adults working in early childhood services who are in contact with children through distal and proximal pedagogical practices. This research has been approved by the Victoria University of Wellington Human Ethics Committee \#23433. If you have any concerns about the ethical conduct of the research, you may contact the Victoria University HEC Convener: Associate Professor Susan Corbett. Email: susan.corbett@vuw.ac.nz or telephone +64-4-463-5480.

This is an information letter about the phases of my research. Phase 1 will involve a national survey that will be sent to all early childhood providers from the four major service types. Services without email addresses will receive a postal copy of the survey. The survey will ask questions about touchscreen tablet use and non-use at each service and will take approximately 10-15 minutes to complete. 
The survey can be completed:

- by the head teacher/supervisor individually,

- by the teaching team in your service, or

- if you are a visiting teacher working with a home-based network, please feel free to complete either individually or with educators from your network.

The survey asks you to provide a contact email address for your service if you wish: a) to enter into the draw for one of ten $\$ 20$ gift vouchers (one winner from each of the ten education regions can choose from app, book, or grocery), b) would like a summary of the research results, and/or 3) are willing to participate in Phase 2 of the study. All information provided will be treated as confidential, and names of individuals and services will not be used in reporting responses.

Phase 2 will involve a multiple-case study that will be conducted in two sub-phases. Participants will be selected from services who expressed their willingness to participate in this part of the research.

- Phase 2A will consist of focus group interviews with:

○ a service from each of the four service types where touchscreen tablets are used for teaching and learning purposes, and

- a service from each of the four service types where touchscreen tablets are not used for teaching and learning purposes.

- Phase 2B will consist of stimulated recall (SR) focus group interviews with the same services who use touchscreen tablets who participated in Phase 2A. SR will involve five-to-ten-minute video-recordings of touchscreen tablet use for teaching and learning in each service. Selected video-recorded episodes will be played during a second set of focus group interviews to help teachers/educators recall and verbalise the thinking behind their teaching using touchscreen tablets. I envisage that I need to spend two days collecting data in each touchscreen tablet user service in this phase of the project.

Gift vouchers and interview transcripts will be given to participating services. Each participating service in Phase $2 \mathrm{~A}$ and $2 \mathrm{~B}$ will receive a $\$ 20$ gift voucher from a choice of app, book or grocery voucher.

Participation in this research is voluntary and you may withdraw from the research at any time up to the end of data collection period without giving any reason. The data collection period for this survey in Phase 1 is until February 28, 2017.

Access to the data from the research will be restricted to my supervisors and me. The data will be securely stored as hard and soft copies. Both will be kept in passwordprotected files in a private computer and locked in filing cabinets in my home and my office. The data will be destroyed five years after the conclusion of the research. The data from the research will be published in my $\mathrm{PhD}$ thesis and in academic and professional journals and shared at academic and professional conferences. 
For online survey respondents: If you consent to participating, please click this online link below.

$$
\text { http://vuw.qualtrics.com/SE/?SID=SV_8q7QzSftErSCMux }
$$

The first question in the survey asks if you give consent to participate in the survey. If you consent, you will then be able to access the full survey; if you choose not to consent, it will skip to the end of the survey and ask if you would like to receive a summary of my research.

For paper-based survey respondents. If you consent to participating, I have included a paper-copy of the survey. Please complete the survey and use the enclosed stamped return envelope to send the completed survey back to me.

If you require any further information or have any questions about this study, please do not hesitate to contact me or my supervisors listed below.

Researcher:

Michael Luke M. Santamaria

Email: Luke.Santamaria@vuw.ac.nz

Mobile Phone: 021-258-5495
Supervisors:

Dr Sue Cherrington

Associate Dean (Academic)

School of Education

Phone: +64-4-463-9552

Email: sue.cherrington@vuw.ac.nz

Dr Mary Jane Shuker

Senior Lecturer

School of Education,

Phone: +64-4-463-9659

Email: mary-jane.shuker@vuw.ac.nz 


\section{Appendix B}

\section{Online Survey on Touchscreen Tablet Use in Early Childhood Education}

Tēnā koutou katoa!

I am Luke Santamaria, a PhD student in the School of Education at Victoria University of Wellington.

I would like to invite you to take part in this survey on the use of touchscreen tablets amongst early childhood education (ECE) services in New Zealand. This survey will investigate touchscreen tablet use for teaching and learning in four major ECE services: education and care, home-based, kindergarten, and playcentre.

According to the early childhood curriculum, Te Whäriki, children growing up in the context of a changing society could benefit from the use of technology. In Te Whäriki each of the strands-well-being, belonging, contribution, communication and exploration-make reference to technology. The aim is to gather data so I can better understand how one type of technology, touchscreen tablets, are used in ECE services.

If you choose to participate, this survey will take you around ten to fifteen minutes to complete.

You may quit anytime, and you may resume anytime. The survey is open until 23:59 on February 28, 2017. Please discuss and respond to the questions in this survey as teachers/educators representing your service/centre.

If you complete this survey, you can enter into a draw for one of ten $\$ 20$ gift vouchers from a choice of app, book or grocery voucher. One service from each of the ten education regions will receive a gift voucher.

At the end of the survey, you will be invited to indicate whether you are interested in participating in a follow-up multiple-case study on touchscreen tablets. This will involve a focus group interview, to will take place at your service location at a time and date that suits as many teachers/educators from your service as possible.

The research questions of my study are:

1. What is the extent of touchscreen tablet use for teaching and learning amongst practitioners (teachers/educators) in four ECE service types in New Zealand?

2. What are the reasons for the use and non-use of touchscreen tablets amongst practitioners (teachers/educators) across four ECE service types in New Zealand?

3. How are practitioners (teachers/educators) using touchscreen tablets in ECE settings to support children's learning? 
4. What are the barriers and affordances to touchscreen tablet use in ECE pedagogy?

I look forward to your contribution to this study which will benefit the ECE sector regarding touchscreen tablets!

If you are willing and consent to participate in this survey you will be able to access the full survey by selecting "I agree" below to begin; if you choose not to consent, it will skip to the end of the survey and ask if you would like to receive a summary of the research.

- I agree.

- I disagree.

If I disagree. Is Selected, Then Skip to The aim of the research is to help EC...

1 Please select your service type

- Education and care

- Home-based

- Kindergarten

- Playcentre

2 Please select the educational region of your service:

○ Auckland

- Bay of Plenty/Rotorua/Taupo

- Canterbury

- Hawkes Bay/Gisborne

- Nelson/Marlborough/West Coast

○ Northland/Whangarei

- Otago/Southland

- Taranaki/Whanganui/Manawatu

- Waikato

○ Wellington

3 Please indicate the maximum number of children your service is licensed for:

4 What is the total number of teachers/educators in your service team?

5 Are teachers/educators in your service presently using touchscreen tablets (i.e., the iPad, Samsung Tab, etc.) at your service?

- NO, our teachers/educators do not use touchscreen tablets at our service at this time.

- YES, our teachers/educators use touchscreen tablets at our service at this time. (Please indicate the number of months you have been using touchscreen tablets):

If Yes, our teachers/educators... Please indicate... Is Selected, Then Skip to Please indicate which touchscreen tab... 
A1 The following are reasons why some services do not use touchscreen tablets. Please identify which of these apply to your service.

\begin{tabular}{|c|c|c|c|c|}
\hline & $\begin{array}{l}\text { Almost always } \\
\text { applies }\end{array}$ & $\begin{array}{l}\text { Sometimes } \\
\text { applies }\end{array}$ & $\begin{array}{l}\text { Rarely } \\
\text { applies }\end{array}$ & $\begin{array}{l}\text { Never } \\
\text { applies }\end{array}$ \\
\hline Company/service policy & O & $\mathrm{O}$ & 0 & O \\
\hline Educational philosophy & $\mathrm{O}$ & $\mathrm{O}$ & $\mathrm{O}$ & $\mathrm{O}$ \\
\hline $\begin{array}{l}\text { Equipment needs } \\
\text { repair/incompatibility }\end{array}$ & $\mathrm{O}$ & $\mathrm{O}$ & $\mathrm{O}$ & $\mathrm{O}$ \\
\hline Funding & O & $\mathrm{O}$ & $\mathrm{O}$ & $\mathrm{O}$ \\
\hline Lack of professional development & O & $\mathrm{O}$ & $\mathrm{O}$ & $\mathrm{O}$ \\
\hline Lack of technical expertise & $\mathrm{O}$ & O & $\mathrm{O}$ & O \\
\hline $\begin{array}{l}\text { Use of another type of technology } \\
\text { (Smartboards, overhead projectors, } \\
\text { laptop computers) }\end{array}$ & $\mathrm{O}$ & O & $\mathrm{O}$ & $\mathrm{O}$ \\
\hline $\begin{array}{l}\text { Initial teacher training did not cover } \\
\text { touchscreen tablets }\end{array}$ & O & $\mathrm{O}$ & $\mathrm{O}$ & $\mathrm{O}$ \\
\hline $\begin{array}{l}\text { We used them before, but we } \\
\text { stopped. Please state the main } \\
\text { reason or indicate not applicable: }\end{array}$ & $\mathrm{O}$ & $\mathrm{O}$ & $\mathrm{O}$ & O \\
\hline
\end{tabular}

A2 Are parents, children and/or teachers/educators currently allowed to use their personal touchscreen tablets for teaching and learning?

○ Yes

$\circ$ No

A3 What is your service's view on using touchscreen tablets for teaching and learning?

- My/our service does not intend to use them for teaching and learning.

- My/our service intends to acquire them in the near future (Please specify approximate number of months).

○ My/our service is not sure about using them at this time.

If My/our service does not intend... Is Selected, Then Skip to -Do you have a screen time policy for...

A4 Please indicate which touchscreen tablet(s) your service will acquire (excluding personal ownership) as well as the number of units you intend to acquire. iPad (10" and Pro):

iPad mini

Samsung Tab (9" and larger)

Samsung Tab (Smaller than 9")

LeapPad (or similar children's tablet)

Other tablet 9" or larger. Please specify if known or indicate not applicable:

Other tablet smaller than 9", e.g., iPod. Please specify if known or indicate not applicable:

Unsure of brand 
A5 If your service did have a touchscreen tablet, for which purpose(s) would your service's teachers/educators use it?

\begin{tabular}{|c|c|c|c|c|}
\hline & $\begin{array}{l}\text { Most } \\
\text { likely }\end{array}$ & Likely & $\begin{array}{l}\text { Least } \\
\text { likely }\end{array}$ & Never \\
\hline Communication with children's families/whānau & O & $\mathrm{O}$ & $\mathrm{O}$ & $\mathrm{O}$ \\
\hline $\begin{array}{l}\text { Communication with institutions (universities, } \\
\text { government offices, etc.) }\end{array}$ & O & O & $\mathrm{O}$ & O \\
\hline $\begin{array}{l}\text { Communication with other services or umbrella } \\
\text { corporation }\end{array}$ & $\mathrm{O}$ & O & $\mathrm{O}$ & $\mathrm{O}$ \\
\hline Creativity (using music, art, and other creative apps) & $\mathrm{O}$ & O & $\mathrm{O}$ & O \\
\hline $\begin{array}{l}\text { Documentation and assessment (for Learning } \\
\text { Stories, portfolios, blogs, and websites) }\end{array}$ & $\mathrm{O}$ & O & $\mathrm{O}$ & O \\
\hline Documenting events (trips, celebration, etc.) & $\mathrm{O}$ & O & $\mathrm{O}$ & $\mathrm{O}$ \\
\hline $\begin{array}{l}\text { Exploration (using camera or maps to explore } \\
\text { surroundings) }\end{array}$ & $\mathrm{O}$ & O & $\mathrm{O}$ & O \\
\hline $\begin{array}{l}\text { Information retrieval (using web-search, maps or } \\
\text { timetables) }\end{array}$ & $\mathrm{O}$ & O & $\mathrm{O}$ & O \\
\hline Playing games & $\mathrm{O}$ & $\mathrm{O}$ & $\mathrm{O}$ & O \\
\hline Playing music & O & 0 & 0 & 0 \\
\hline Watching videos & 0 & 0 & $\mathrm{O}$ & O \\
\hline
\end{tabular}

A6 If your service did have a touchscreen tablet, would your service have a policy or guidelines for staff to use it for teaching and learning?

○ Yes

○ No

A7 If your service did have a touchscreen tablet, please indicate the maximum number of children who could use your service's touchscreen tablet at any one time.

A8 If your service did have a touchscreen tablet, who would monitor children's touchscreen tablet use? [Multiple answers possible.]

- There is no monitoring/facilitator

- A fully certificated teacher/educator

- Parents or adult whānau

- A provisionally certificated teacher/educator

- Older children

$\circ$ Peers the same age or younger

A9 If your service were to use touchscreen tablets, would children use them individually or in groups? [Multiple answers possible.]

○ Individually

- Individually with a teacher/educator

- In groups

○ In groups with a teacher/educator 
A10 Which of these potential issues do teachers/educators in your service think might happen when using touchscreen tablets?

\begin{tabular}{|c|c|c|c|c|}
\hline & $\begin{array}{l}\text { Most } \\
\text { likely }\end{array}$ & Likely & $\begin{array}{l}\text { Least } \\
\text { likely }\end{array}$ & Never \\
\hline Apps do not fit educational goals & O & O & O & $\mathrm{O}$ \\
\hline Battery problems, charging time & $\mathrm{O}$ & O & $\mathrm{O}$ & $\mathrm{O}$ \\
\hline Children circumventing security functions & O & O & O & O \\
\hline Finding appropriate material & O & O & O & O \\
\hline Glitches and apps not working & O & O & $\mathrm{O}$ & $\mathrm{O}$ \\
\hline Internet connection problems & $\mathrm{O}$ & O & O & O \\
\hline $\begin{array}{l}\text { Lack of functionality (no Flash software, no front } \\
\text { camera, no loudspeaker) }\end{array}$ & $\mathrm{O}$ & O & $\mathrm{O}$ & $\mathrm{O}$ \\
\hline Lack of professional development on basics of ICT & $\mathrm{O}$ & $\mathrm{O}$ & $\mathrm{O}$ & $\mathrm{O}$ \\
\hline Lack of support from administration & O & O & O & $\mathrm{O}$ \\
\hline Lack of touchscreen tablet technical training & $\mathrm{O}$ & $\mathrm{O}$ & $\mathrm{O}$ & $\mathrm{O}$ \\
\hline New apps and their incompatibility & $\mathrm{O}$ & O & $\mathrm{O}$ & $\mathrm{O}$ \\
\hline Personal beliefs on technology & $\mathrm{O}$ & $\mathrm{O}$ & $\mathrm{O}$ & $\mathrm{O}$ \\
\hline Preference towards traditional practices & $\mathrm{O}$ & $\mathrm{O}$ & $\mathrm{O}$ & $\mathrm{O}$ \\
\hline Tracking children's progress using apps & $\mathrm{O}$ & O & O & O \\
\hline Updates and updating problems & 0 & O & $\mathrm{O}$ & O \\
\hline
\end{tabular}

A11 Does your service have a screen time policy for children who engage with screen media (TV/DVD, computer, smartphones, etc.)?

- Yes (Please indicate how many minutes per day).

○ No.

A12 How would teachers/educators at your service most likely learn how to use touchscreen tablets for teaching?

\begin{tabular}{|c|c|c|c|c|}
\hline & $\begin{array}{l}\text { Most } \\
\text { likely }\end{array}$ & Likely & $\begin{array}{l}\text { Least } \\
\text { likely }\end{array}$ & Never \\
\hline From books and printed material & 0 & O & 0 & $\mathrm{O}$ \\
\hline From IT related professional development courses & 0 & $\mathrm{O}$ & $\mathrm{O}$ & 0 \\
\hline From Ministry resources & O & $\mathrm{O}$ & $\mathrm{O}$ & $\mathrm{O}$ \\
\hline From other professional development courses & O & O & O & $\mathrm{O}$ \\
\hline From university courses & O & O & O & $\mathrm{O}$ \\
\hline Through collaboration with other teachers/educators & O & $\mathrm{O}$ & O & $\mathrm{O}$ \\
\hline Through personal use & O & O & O & $\mathrm{O}$ \\
\hline Through videos and online information & O & O & O & O \\
\hline From the children & $\mathrm{O}$ & 0 & 0 & 0 \\
\hline
\end{tabular}


A13 Would you like to participate in a case study involving teachers/educators at your service participating in a focus group interview so I can further understand why your service does not use touchscreen tablets?

○ Yes

O No

If Yes Is Selected, Then Skip to Please provide information about your... If No Is Selected, Then Skip to Thank you for your time and effort in...

B1 Please indicate which touchscreen tablet(s) your service owns (excluding personal ownership) as well as the number of units owned.

iPad (10" and Pro):

iPad mini

Samsung Tab (9" and larger)

Samsung Tab (Smaller than 9")

LeapPad (or similar children's tablet)

Other tablet 9" or larger. Please specify if known or indicate not applicable:

Other tablet smaller than 9", e.g., iPod. Please specify if known or indicate not applicable:

B2 Please indicate which personally-owned touchscreen tablet(s) personally-owned have been used at your service and indicate ownership.

\begin{tabular}{|l|c|c|c|c|c|}
\hline & \multicolumn{5}{|c|}{ You may have multiple answers. } \\
\hline $\begin{array}{l}\text { iPad (9" and Pro) } \\
\text { iPad mini }\end{array}$ & $\begin{array}{c}\text { Teacher/educator } \\
\text { or staff }\end{array}$ & $\begin{array}{c}\text { Parent, } \\
\text { whānau } \\
\text { or child }\end{array}$ & $\begin{array}{c}\text { Aide or } \\
\text { student } \\
\text { teacher }\end{array}$ & $\begin{array}{c}\text { Other (e.g., } \\
\text { borrowed) }\end{array}$ & $\begin{array}{c}\text { Not } \\
\text { applicable }\end{array}$ \\
$\begin{array}{l}\text { Samsung Tab (9" } \\
\text { and larger) }\end{array}$ & $\square$ & $\square$ & $\square$ & $\square$ \\
$\begin{array}{l}\text { Samsung Tab } \\
\text { (Smaller than 9") }\end{array}$ & $\square$ & $\square$ & $\square$ & $\square$ & $\square$ \\
$\begin{array}{l}\text { LeapPad (or } \\
\text { similar children's } \\
\text { tablet) }\end{array}$ & $\square$ & $\square$ & $\square$ & $\square$ & $\square$ \\
$\begin{array}{l}\text { Other tablet 9" or } \\
\text { larger. Please } \\
\text { specify or indicate } \\
\text { not applicable: } \\
\begin{array}{l}\text { Other tablet } \\
\text { smaller than 9", } \\
\text { e.g., iPod. Please } \\
\text { specify or indicate } \\
\text { not applicable: }\end{array}\end{array}$ & $\square$ & $\square$ & $\square$ & $\square$ & $\square$ \\
\hline
\end{tabular}

B3 How many teachers/educators use the touchscreen tablet in their teaching? 
B4 For which of the following purposes do you use touchscreen tablets?

\begin{tabular}{|l|c|c|c|c|}
\hline $\begin{array}{l}\text { Communication with children's } \\
\text { families/whānau }\end{array}$ & $\begin{array}{c}\text { Almost } \\
\text { everyday }\end{array}$ & $\begin{array}{c}\text { Twice/thrice } \\
\text { a week }\end{array}$ & $\begin{array}{c}\text { Once a } \\
\text { week or less }\end{array}$ & Never \\
$\begin{array}{l}\text { Communication with institutions } \\
\text { (universities, government offices, etc.) }\end{array}$ & 0 & 0 & 0 & 0 \\
$\begin{array}{l}\text { Communication with other services or } \\
\text { umbrella corporation }\end{array}$ & 0 & 0 & 0 & 0 \\
$\begin{array}{l}\text { Creativity (using music, art, and other } \\
\text { creative apps) }\end{array}$ & 0 & 0 & 0 & 0 \\
$\begin{array}{l}\text { Documentation and assessment (for } \\
\text { Learning Stories, portfolios, blogs, and } \\
\text { websites) }\end{array}$ & 0 & 0 & 0 & 0 \\
$\begin{array}{l}\text { Documenting events (trips, celebration, } \\
\text { etc.) }\end{array}$ & 0 & 0 & 0 & 0 \\
$\begin{array}{l}\text { Exploration (using camera or maps to } \\
\text { explore surroundings) }\end{array}$ & 0 & 0 & 0 & 0 \\
$\begin{array}{l}\text { Information retrieval (using web- } \\
\text { search, maps or timetables) }\end{array}$ & 0 & 0 & 0 & 0 \\
$\begin{array}{l}\text { Playing games } \\
\text { Playing music }\end{array}$ & 0 & 0 & 0 & 0 \\
Watching videos & 0 & 0 & 0 & 0 \\
\hline
\end{tabular}

B5 Does your service have a formal policy or guidelines for staff about the use of touchscreen tablets for teaching and learning?

○ Yes

○ No

B6 Do you have a screen time policy for children who engage with screen media (TV/DVDs, touchscreen tablets, computers, smartphones, etc.)?

○ Yes. Please specify how many minutes a day:

○ No. 
B7 How did your service's teachers/educators learn how to use touchscreen tablets for teaching?

\begin{tabular}{|c|c|c|c|c|}
\hline & $\begin{array}{l}\text { Almost } \\
\text { always true }\end{array}$ & $\begin{array}{l}\text { Occasionally } \\
\text { true }\end{array}$ & $\begin{array}{c}\text { Rarely } \\
\text { true }\end{array}$ & $\begin{array}{c}\text { Never } \\
\text { true }\end{array}$ \\
\hline From books and printed material & $\mathrm{O}$ & $\mathrm{O}$ & O & O \\
\hline $\begin{array}{l}\text { From IT related professional } \\
\text { development courses }\end{array}$ & O & $\mathrm{O}$ & O & O \\
\hline From Ministry resources & O & $\mathrm{O}$ & $\mathrm{O}$ & O \\
\hline $\begin{array}{l}\text { From other professional } \\
\text { development courses }\end{array}$ & O & $\mathrm{O}$ & O & O \\
\hline From university courses & O & $\mathrm{O}$ & O & $\mathrm{O}$ \\
\hline $\begin{array}{l}\text { Through collaboration with other } \\
\text { teachers/educators }\end{array}$ & $\mathrm{O}$ & $\mathrm{O}$ & O & O \\
\hline Through personal use & O & $\mathrm{O}$ & O & $\mathrm{O}$ \\
\hline $\begin{array}{l}\text { Through videos and online } \\
\text { information }\end{array}$ & O & $\mathrm{O}$ & O & O \\
\hline From the children & $\mathrm{O}$ & $\mathrm{O}$ & 0 & $\mathrm{O}$ \\
\hline
\end{tabular}

B8 Is/are your service's touchscreen tablet/s used individually or in groups? [Multiple answers possible.]
$\circ$ Individually
- Individually with a teacher/educator
In groups
○ In groups with a teacher/educator

B9 Please indicate the maximum number of children who use your service's touchscreen tablet at any one time?

B10 Who monitors children's touchscreen tablet use? [Multiple answers possible.]

$\circ$ There is no monitoring/facilitator

- A fully certificated teacher/educator

○ Parents or adult whānau

- A provisionally certificated teacher/educator

- Older children

- Peers the same age or younger

○ Not applicable

B11 Please explain how teachers/educators in your service support children using touchscreen tablets. [Narrative section] 
B12 If your service has not used touchscreen tablets in the past, what were the reasons for this?

\begin{tabular}{|c|c|c|c|c|}
\hline & Most likely & Likely & Least likely & Never \\
\hline Company/service policy & $\mathrm{O}$ & $\mathrm{O}$ & $\mathrm{O}$ & 0 \\
\hline Educational philosophy & $\mathrm{O}$ & O & $\mathrm{O}$ & O \\
\hline $\begin{array}{l}\text { Equipment needs } \\
\text { repair/incompatibility }\end{array}$ & $\mathrm{O}$ & $\mathrm{O}$ & $\mathrm{O}$ & $\mathrm{O}$ \\
\hline Funding & $\mathrm{O}$ & $\mathrm{O}$ & $\mathrm{O}$ & $\mathrm{O}$ \\
\hline Lack of professional development & $\mathrm{O}$ & $\mathrm{O}$ & $\mathrm{O}$ & $\mathrm{O}$ \\
\hline Lack of technical expertise & $\mathrm{O}$ & O & $\mathrm{O}$ & $\mathrm{O}$ \\
\hline $\begin{array}{l}\text { Use of another type of technology } \\
\text { (Smartboards, overhead projectors, } \\
\text { laptop computers) }\end{array}$ & $\mathrm{O}$ & $\mathrm{O}$ & $\mathrm{O}$ & $\mathrm{O}$ \\
\hline $\begin{array}{l}\text { Initial teacher training did not cover } \\
\text { touchscreen tablets. }\end{array}$ & O & $\mathrm{O}$ & $\mathrm{O}$ & $\mathrm{O}$ \\
\hline $\begin{array}{l}\text { We used them before and just } \\
\text { stopped. Please state the main } \\
\text { reason or indicate not applicable: }\end{array}$ & $\mathrm{O}$ & O & $\mathrm{O}$ & O \\
\hline
\end{tabular}

B13 Would you like to participate in a case study on your service's touchscreen tablet use for teaching and learning?

The case study phase would involve your teachers/educators participating in two focus group interviews. The first one will explore your reasons for using touchscreen tablets and the second one will involve video-recordings of your service's touchscreen tablet use followed by a Stimulated Recall focus group interview using the video-recorded episodes. The video-recorded episodes will be played back to your teachers/educators during the focus group interview to understand your service's use of touchscreen tablets for teaching and learning.

All the data collected will be strictly confidential. Video-recorded episodes will be used for the focus group interviews of their respective services only and will not be shares to other services.

If you choose "Yes" and your service is selected to be part of the multiple-case study, I will send information letters and consent forms to your management and will wait for their permission before I contact you again.

o Yes.

○ No

If No Is Selected, Then Skip to Thank you for your time and effort in... 
B14 Please provide information about your ECE service:

Early childhood service name (and corporate/umbrella organisation name)

Management/Contact person's first and last name

Street Address

Suburb

City

Postal Code

Region

Telephone number with area code

Email address

6 Thank you for your time and effort in completing the survey.

As appreciation for completing the survey, I would like to invite your service into a draw for one of ten $\$ 20$ gift vouchers. One service from each education region will be drawn. Winners will be able to select their preferred gift voucher (a choice of app voucher [iTunes or PlayStore], book voucher, or grocery voucher: a choice of New World or Countdown).

Please indicate your service's email address as your entry into the draw and I will only contact your service if you win. Your service's email address will not be shared and will only be used for contacting your service if your service wins the draw.

You can go into a draw for one of ten $\$ 20$ gift vouchers. One service from each education region will be drawn. Winners will be able to select their preferred gift voucher (apps: a choice of iTunes or PlayStore, book, or grocery voucher: a choice of New World or Countdown).

- Yes, we would like our service to join the draw for the gift voucher. Our email address is

- We would like to join the draw and have given our email address in the previous question.

- We opt out of the draw for the gift voucher.

7 The aim of the research is to help early childhood services have a greater understanding of touchscreen tablet use. Would you/your service like to receive a summary of this research?

○ Yes. Please indicate your email address:

- Yes, we would like to receive a summary of this research and have given our contact information in the previous question.

○ No. 
Appendix C

\section{Paper-based survey on \\ touchscreen tablet use in early childhood education}

Tēnā koutou katoa!

I am Luke Santamaria, a PhD student in the School of Education at Victoria University of Wellington.

I would like to invite you to take part in this survey on the use of touchscreen tablets amongst early childhood education (ECE) services in New Zealand. This survey will investigate touchscreen tablet use for teaching and learning in four major ECE services: education and care, home-based, kindergarten, and playcentre.

According to the early childhood curriculum, Te Whäriki, children growing up in the context of a changing society could benefit from the use of technology. In Te Whäriki each of the strands-well-being, belonging, contribution, communication and exploration-make reference to technology. The aim is to gather data so I can better understand how one type of technology, touchscreen tablets, are used in ECE services.

If you choose to participate, this survey will take you around fifteen to twenty minutes to complete.

The survey period is until February 28, 2017. You may post your responses until that date. Please discuss and respond to the questions in this survey as teachers/educators representing your service/centre.

If you complete this survey, you will can enter a draw for one of ten $\$ 20$ gift vouchers from a choice of app, book or grocery voucher. One service from each of the ten education regions will receive a gift voucher.

At the end of the survey, you will be invited to indicate whether you are willing to participating in a follow-up multiple-case study on touchscreen tablets. This will involve a focus group interview, to will take place at your service location at a time and date that suits as many teachers/educators from your service as possible. Phase 2 will involve a multiple-case study conducted in two sub-phases. Participants will be selected from services who expressed their willingness to participate in this part of the research.

- Phase 2A will consist of focus group interviews with:

○ a service from each of the four service types where touchscreen tablets are used for teaching and learning purposes, and

- a service from each of the four service types where touchscreen tablets are not used for teaching and learning purposes.

- Phase 2B will consist of stimulated recall (SR) focus group interviews with the same services who use touchscreen tablets who participated in Phase 2A. 
SR will involve five-to-ten-minute video-recordings of touchscreen tablet use for teaching and learning in each service. Selected video-recorded episodes will be played during a second set of focus group interviews to help participants recall and verbalise the thinking behind their teaching using touchscreen tablets. I envisage that I need to spend two days collecting data in each touchscreen tablet user service in this phase of the project.

The research questions of my study are:

1. What is the extent of touchscreen tablet use for teaching and learning amongst practitioners (teachers/educators) in four ECE service types in New Zealand?

2. What are the reasons for the use and non-use of touchscreen tablets amongst practitioners (teachers/educators) across four ECE service types in New Zealand?

3. How are practitioners (teachers/educators) using touchscreen tablets in ECE settings to support children's learning?

4. What are the barriers and affordances to touchscreen tablet use in ECE pedagogy?

I look forward to your contribution to this study, which will benefit the ECE sector regarding touchscreen tablets!

If you are willing and consent to participating, I have included a paper-copy of the survey. Please complete the survey and use the enclosed reply-paid return envelope to send the completed survey back to me. The envelope is addressed to

\section{Luke Santamaria c/o The School of Education / Faculty of Education PO Box 600, Kelburn Wellington 6140 New Zealand}

If you are not willing to consent to participating, I thank you for your time. You do not need to return this survey to me but if you would like to receive a summary of the findings of this survey, please write your service name, email address or postal (where applicable, preferably email address) on a piece of paper and use the return envelope to send your contact information to me. I will then send you the findings of this research by post or by email. 
PLEASE FOLLOW THE INSTRUCTIONS OF THIS SURVEY CAREFULLY.

Question A.1. Please circle your service type [Circle one answer only]

- Education and care

- Home-based

- Kindergarten

- Playcentre

Question A.2. Please circle the educational region of your service [Circle one answer only]

- Auckland

- Bay of Plenty/Rotorua/Taupo

- Canterbury

- Hawkes Bay/Gisborne

- Nelson/Marlborough/West Coast

- Northland/Whangarei

- Otago/Southland

- Taranaki/Whanganui/Manawatu

- Waikato

- Wellington

Question A.3. On the blank below, write the maximum number of children your service is licensed for:

Question A.4. On the blank below, write the total number of teachers/educators in your service team:

Question A.5. Are teachers/educators in your service presently using touchscreen tablets (i.e., the iPad, Samsung Tab, etc.) at your service? [Circle one answer only]

- NO, our teachers/educators do not use touchscreen tablets at our service at this time. [CONTINUE to QUESTION B.1.]

- YES, our teachers/educators use touchscreen tablets at our service at this time. Please indicate the number of months you have been using touchscreen tablets on the blank:

[SKIP to QUESTION C.1.] 
Question B.1. The following are reasons why some services do not use touchscreen tablets. Please identify which of these apply to your service. [You may tick only one answer per row. Please do not leave any row blank.]

\begin{tabular}{|l|l|l|l|l|}
\hline Company/service policy & $\begin{array}{c}\text { Almost } \\
\text { always } \\
\text { applies }\end{array}$ & $\begin{array}{c}\text { Sometimes } \\
\text { applies }\end{array}$ & $\begin{array}{c}\text { Rarely } \\
\text { applies }\end{array}$ & $\begin{array}{c}\text { Never } \\
\text { applies }\end{array}$ \\
\hline Educational philosophy & & & & \\
\hline $\begin{array}{l}\text { Equipment needs } \\
\text { repair/incompatibility }\end{array}$ & & & & \\
\hline Funding & & & & \\
\hline Lack of professional development & & & & \\
\hline Lack of technical expertise & & & & \\
\hline $\begin{array}{l}\text { Use of another type of technology } \\
\text { (Smartboards, overhead projectors, } \\
\text { laptop computers) }\end{array}$ & & & & \\
\hline $\begin{array}{l}\text { Initial teacher training did not cover } \\
\text { touchscreen tablets }\end{array}$ & & & & \\
\hline $\begin{array}{l}\text { We used them before, but we } \\
\text { stopped. Please state the main } \\
\text { reason or indicate not applicable: }\end{array}$ & & & & \\
\hline
\end{tabular}

Question B.2. Are parents, children and/or teachers/educators currently allowed to use their personal touchscreen tablets for teaching and learning? [Please circle either YES or NO]

- Yes

- No

Question B.3. What is your service's view on using touchscreen tablets for teaching and learning? [Please circle one answer only].

- My/our service does not intend to use them for teaching and learning. [If you circled this SKIP to QUESTION B.10.]

- My/our service intends to acquire them in the near future (Please specify approximate number of months).

- My/our service is not sure about using them at this time. 
Question B.4. Write the number of units of touchscreen tablet(s) your service will acquire (excluding personal ownership) as well as the number of units you intend to acquire. [You may have multiple answers. You may use the extra space provided below if you have numerous devices from brands not listed below. Tick "Unsure of brand" if you are still unsure which touchscreen tablet you will acquire at this point in time.]

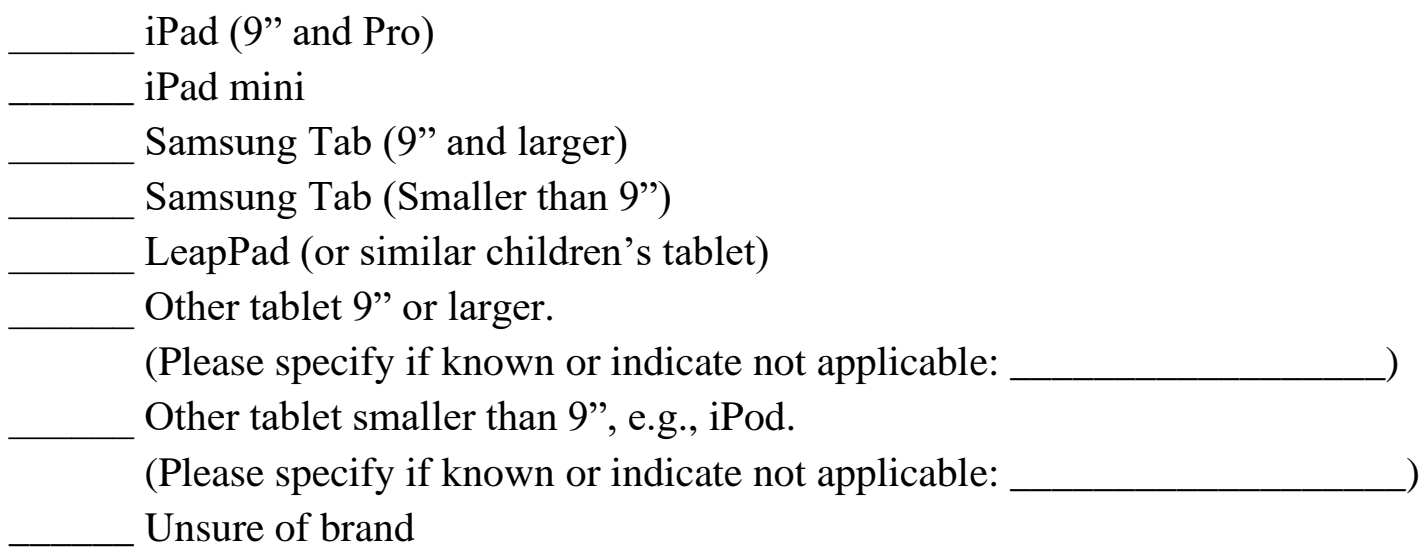

Question B.5. If your service did have a touchscreen tablet, for which purpose(s) would your service's teachers/educators use it? [You may tick only one answer per row. Please do not leave any row blank.]

\begin{tabular}{|l|l|l|l|l|} 
& $\begin{array}{c}\text { Most } \\
\text { likely }\end{array}$ & Likely & $\begin{array}{c}\text { Least } \\
\text { likely }\end{array}$ & Never \\
\hline $\begin{array}{l}\text { Communication with children's } \\
\text { families/whānau }\end{array}$ & & & & \\
\hline $\begin{array}{l}\text { Communication with institutions (universities, } \\
\text { government offices, etc.) }\end{array}$ & & & & \\
\hline $\begin{array}{l}\text { Communication with other services or umbrella } \\
\text { corporation }\end{array}$ & & & & \\
\hline $\begin{array}{l}\text { Creativity (using music, art, and other creative } \\
\text { apps) }\end{array}$ & & & & \\
\hline $\begin{array}{l}\text { Documentation and assessment (for Learning } \\
\text { Stories, portfolios, blogs, and websites) }\end{array}$ & & & & \\
\hline Documenting events (trips, celebration, etc.) & & & & \\
\hline $\begin{array}{l}\text { Exploration (using camera or maps to explore } \\
\text { surroundings) }\end{array}$ & & & & \\
\hline $\begin{array}{l}\text { Information retrieval (using web-search, maps } \\
\text { or timetables) }\end{array}$ & & & & \\
\hline Playing games & & & & \\
\hline Playing music & & & & \\
\hline Watching videos & & & \\
\hline
\end{tabular}

Question B.6. If your service did have a touchscreen tablet, would your service have a policy or guidelines for staff to use it for teaching and learning? [Please circle either YES or NO] $\bullet$ Yes $・$ No 
Question B.7. If your service did have a touchscreen tablet, please indicate the maximum number of children who could use your service's touchscreen tablet at any one time.

Question B.8. If your service did have a touchscreen tablet, who would monitor children's touchscreen tablet use? [You may either circle multiple answers, or circle "Not applicable"]

- There is no monitoring/facilitator

- A fully certificated teacher/educator

- Parents or adult whānau

- A provisionally certificated teacher/educator

- Older children

- Peers the same age or younger

- Not applicable

Question B.9. If your service were to use touchscreen tablets, would children use them individually or in groups? [You may circle multiple answers].

- Individually

- Individually with a teacher/educator

- In groups

- In groups with a teacher/educator

Question B.10. Which of these potential issues do teachers/educators in your service think might happen when using touchscreen tablets? [Please tick only one answer per row. Please do not leave any row blank.]

\begin{tabular}{|l|l|l|l|l|}
\hline \hline Apps do not fit educational goals & $\begin{array}{c}\text { Most } \\
\text { likely }\end{array}$ & Likely & $\begin{array}{c}\text { Least } \\
\text { Likely }\end{array}$ & Never \\
\hline Battery problems, charging time & & & & \\
\hline Children circumventing security functions & & & & \\
\hline Finding appropriate material & & & & \\
\hline Glitches and apps not working & & & & \\
\hline Internet connection problems & & & & \\
\hline $\begin{array}{l}\text { Lack of functionality (no Flash software, no front } \\
\text { camera, no loudspeaker) }\end{array}$ & & & & \\
\hline Lack of professional development on basics of ICT & & & & \\
\hline Lack of support from administration & & & & \\
\hline Lack of touchscreen tablet technical training & & & & \\
\hline New apps and their incompatibility & & & & \\
\hline Personal beliefs on technology & & & & \\
\hline Preference towards traditional practices & & & & \\
\hline Tracking children's progress using apps & & & & \\
\hline Updates and updating problems & & & & \\
\hline
\end{tabular}


Question B.11. Does your service have a screen time policy for children who engage with screen media (TV/DVD, computer, smartphones, etc.)? [Please circle either YES or NO]

- Yes, (Please indicate how many minutes per day:

- No.

Question B.12. How would teachers/educators at your service most likely learn how to use touchscreen tablets for teaching? [Please tick only one answer per row. Please do not leave any row blank.]

\begin{tabular}{|l|l|l|l|l|} 
& $\begin{array}{c}\text { Most } \\
\text { likely }\end{array}$ & Likely & $\begin{array}{c}\text { Least } \\
\text { likely }\end{array}$ & Never \\
\hline From books and printed material & & & & \\
\hline From IT related professional development courses & & & & \\
\hline From Ministry resources & & & & \\
\hline From other professional development courses & & & & \\
\hline From university courses & & & & \\
\hline Through collaboration with other teachers/educators & & & & \\
\hline Through personal use & & & & \\
\hline Through videos and online information & & & & \\
\hline From the children & & & & \\
\hline
\end{tabular}

Question B.13. Would you like to participate in a case study involving teachers/educators at your service participating in a focus group interview so I can further understand why your service does not use touchscreen tablets? [Please circle either YES or NO]

- Yes

- No

If you circled YES, please provide information about your Early Childhood service (Please write in print and then skip to the Question in the last page of this survey)

Early childhood service name (and corporate/umbrella organisation name)

Management/Contact person's first and last name

Street Address

Suburb

City and Postal Code

Region

Telephone number with area code

Email address 


\section{IF YOU WERE INSTRUCED TO SKIP TO QUESTION C.1., PLEASE SKIP TO THE LAST PAGE OF THIS SURVEY}

Question C.1. Write the number of units of touchscreen tablet(s) your service owns (excluding personal ownership) on the blank beside each brand/type. [You may have multiple answers]. You may use the extra space provided below if you have numerous devices from brands not listed below.

iPad (9" and Pro)

iPad mini

Samsung Tab (9" and larger)

Samsung Tab (Smaller than 9")

LeapPad (or similar children's tablet)

Other tablet 9" or larger.

(Please specify if known or indicate not applicable:

Other tablet smaller than 10", e.g., iPod.

(Please specify if known or indicate not applicable:

Question C.2. Please indicate which personally-owned touchscreen tablet(s) personally-owned have been used at your service and indicate ownership. [Please tick as many boxes per row as applicable. If you tick "Not applicable", all other ticks in the same row will not be considered.]

\begin{tabular}{|l|l|l|l|l|l|}
\hline & $\begin{array}{c}\text { Teacher, } \\
\text { educator } \\
\text { or staff }\end{array}$ & $\begin{array}{c}\text { Parent, } \\
\text { whānau } \\
\text { or child }\end{array}$ & $\begin{array}{c}\text { Aide or } \\
\text { student } \\
\text { teacher }\end{array}$ & $\begin{array}{c}\text { Other (e.g., } \\
\text { borrowed) }\end{array}$ & $\begin{array}{c}\text { Not } \\
\text { applicable }\end{array}$ \\
\hline iPad (10" and Pro) & & & & & \\
\hline iPad mini & & & & & \\
\hline $\begin{array}{l}\text { Samsung Tab } \\
\text { (9" and larger) }\end{array}$ & & & & & \\
\hline $\begin{array}{l}\text { Samsung Tab } \\
\text { (Smaller than 9") }\end{array}$ & & & & & \\
\hline $\begin{array}{l}\text { LeapPad (or similar } \\
\text { children's tablet) }\end{array}$ & & & & & \\
\hline $\begin{array}{l}\text { Other tablet 10" or } \\
\text { larger. Please specify } \\
\text { or indicate not } \\
\text { applicable: }\end{array}$ & & & & & \\
\hline $\begin{array}{l}\text { Other tablet smaller } \\
\text { than 10", e.g., iPod. } \\
\begin{array}{l}\text { Please specify or } \\
\text { indicate not applicable: }\end{array}\end{array}$ & & & & & \\
\hline
\end{tabular}

Question C.3. Write the number of teachers/educators who use the touchscreen tablet in their teaching: 
Question C.4. For which of the following purposes do you use touchscreen tablets? [Please tick only one answer per row. Please do not leave any row blank.]

\begin{tabular}{|l|l|l|l|l|}
\hline & $\begin{array}{c}\text { Almost } \\
\text { everyday }\end{array}$ & $\begin{array}{c}\text { Twice/thrice } \\
\text { a week }\end{array}$ & $\begin{array}{c}\text { Once a } \\
\text { week } \\
\text { or less }\end{array}$ & Never \\
\hline $\begin{array}{l}\text { Communication with children's } \\
\text { families/whānau }\end{array}$ & & & & \\
\hline $\begin{array}{l}\text { Communication with institutions } \\
\text { (universities, government offices, etc.) }\end{array}$ & & & & \\
\hline $\begin{array}{l}\text { Communication with other services or } \\
\text { umbrella corporation }\end{array}$ & & & & \\
\hline $\begin{array}{l}\text { Creativity (using music, art, and other } \\
\text { creative apps) }\end{array}$ & & & & \\
\hline $\begin{array}{l}\text { Documentation and assessment } \\
\text { (for Learning Stories, portfolios, blogs, } \\
\text { and websites) }\end{array}$ & & & & \\
\hline $\begin{array}{l}\text { Documenting events } \\
\text { (trips, celebration, etc.) }\end{array}$ & & & & \\
\hline $\begin{array}{l}\text { Exploration (using camera or maps to } \\
\text { explore surroundings) }\end{array}$ & & & & \\
\hline $\begin{array}{l}\text { Information retrieval (using web-search, } \\
\text { maps or timetables) }\end{array}$ & & & & \\
\hline Playing games & & & & \\
\hline Playing music & & & & \\
\hline Watching videos & & & \\
\hline
\end{tabular}

Question C.5. Does your service have a formal policy or guidelines for staff about the use of touchscreen tablets for teaching and learning? [Please circle either YES or $\mathrm{NO}]$
- Yes
- No

Question C.6. Do you have a screen time policy for children who engage with screen media (TV/DVDs, touchscreen tablets, computers, smartphones, etc.)? [Please circle either YES or NO]

- Yes. Please specify how many minutes a day:

- No. 
Question C.7. How did your teachers/educators learn how to use touchscreen tablets for teaching? [Please tick only one answer per row. Please do not leave any row blank.]

\begin{tabular}{|l|c|c|c|c|}
\hline & $\begin{array}{c}\text { Almost } \\
\text { always true }\end{array}$ & $\begin{array}{c}\text { Occasionally } \\
\text { true }\end{array}$ & $\begin{array}{c}\text { Rarely } \\
\text { true }\end{array}$ & $\begin{array}{c}\text { Never } \\
\text { true }\end{array}$ \\
\hline From books and printed material & & & & \\
\hline $\begin{array}{l}\text { From IT related professional } \\
\text { development courses }\end{array}$ & & & & \\
\hline From Ministry resources & & & & \\
\hline $\begin{array}{l}\text { From other professional } \\
\text { development courses }\end{array}$ & & & & \\
\hline From university courses & & & & \\
\hline $\begin{array}{l}\text { Through collaboration with other } \\
\text { teachers/educators }\end{array}$ & & & & \\
\hline Through personal use & & & & \\
\hline $\begin{array}{l}\text { Through videos and online } \\
\text { information }\end{array}$ & & & & \\
\hline From the children & & & & \\
\hline
\end{tabular}

Question C.8. Is/are your service's touchscreen tablet/s used individually or in groups? [You may circle multiple answers].

- Individually

- Individually with a teacher/educator

- In groups

- In groups with a teacher/educator

Question C.9. Please write the maximum number of children who use your service's touchscreen tablet at any one time on the blank:

Question C.10. Who monitors children's touchscreen tablet use? [You may either circle multiple answers or circle "Not applicable"].

- There is no monitoring/facilitator

- A fully certificated teacher/educator

- Parents or adult whānau

- A provisionally certificated teacher/educator

- Older children

- Peers the same age or younger

- Not applicable

Question C.11. In the space provided please explain how teachers/educators in your service support children using touchscreen tablets. [I would appreciate it if you could write in print.] 
Question C.12. If your service has not used touchscreen tablets in the past, what were the reasons for this. [Please tick only one answer per row. Please do not leave any row blank.]

\begin{tabular}{|l|l|l|l|l|}
\hline Company/service policy & $\begin{array}{c}\text { Almost always } \\
\text { applies }\end{array}$ & $\begin{array}{c}\text { Sometimes } \\
\text { applies }\end{array}$ & $\begin{array}{c}\text { Rarely } \\
\text { applies }\end{array}$ & $\begin{array}{c}\text { Never } \\
\text { applies }\end{array}$ \\
\hline Educational philosophy & & & & \\
\hline $\begin{array}{l}\text { Equipment needs } \\
\text { repair/incompatibility }\end{array}$ & & & & \\
\hline Funding & & & & \\
\hline Lack of professional development & & & & \\
\hline Lack of technical expertise & & & & \\
\hline $\begin{array}{l}\text { Use of another type of technology } \\
\text { (Smartboards, overhead projectors, } \\
\text { laptop computers) }\end{array}$ & & & & \\
\hline $\begin{array}{l}\text { Initial teacher training did not } \\
\text { cover touchscreen tablets }\end{array}$ & & & & \\
\hline $\begin{array}{l}\text { We used them before, but we } \\
\text { stopped. Please state the main } \\
\text { reason or indicate not applicable: }\end{array}$ & & & & \\
\hline
\end{tabular}

Question C.13. Would you like to participate in a case study on your service's touchscreen tablet use for teaching and learning?

The case study phase would involve your teachers/educators participating in two focus group interviews. The first one will explore your reasons for using touchscreen tablets and the second one will involve video-recordings of your service's touchscreen tablet use followed by a Stimulated Recall focus group interview using the video-recorded episodes. The video-recorded episodes will be played back to your teachers/educators during the focus group interview to understand your service's use of touchscreen tablets for teaching and learning.

All the data collected will be strictly confidential. Video-recorded episodes will be used for the focus group interviews of their respective services only and will not be shares to other services.

If you choose "Yes" and your service is selected to be part of the multiple-case study, I will send information letters and consent forms to your management and will wait for their permission before I contact you again. [Please circle either YES or NO]

$$
\text { - Yes } \bullet \text { No }
$$


If you circled YES, please provide information about your ECE service (Please write in print and then proceed to the last page of this survey)

Early childhood service name (and corporate/umbrella organisation name)

Management/Contact person's first and last name

Street Address

Suburb

City and Postal Code

Region

Telephone number with area code

Email address 


\section{[LAST PAGE]}

The aim of the research is to help ECE services have a greater understanding of touchscreen tablet use. Would you like to receive a summary of this research? [Please circle either YES or NO]

- Yes. (If you have provided your email address/contact information in the previous question, you do not need to fill this up). Our email address/contact information is

- No.

\section{For respondents who completed the survey:}

Thank you for your time and effort in completing the survey. As appreciation for completing the survey. I would like to invite you to go into a draw for one of ten $\$ 20$ gift vouchers. One service from each education region will be drawn. Winners will be able to select their preferred gift voucher (apps, book, or grocery voucher).

Please indicate your email address/contact information as your entry and I will contact you if you win. Your email address/contact information will not be shared with anybody and will only be used for contacting you if you win the draw. [Please circle either YES or NO]

- Yes, we would like our service to join the draw for the gift voucher. (If you have provided your email address/contact information in the previous question, you do not need to fill this up). Our email address/contact information is

Telephone number:

Complete postal address:

Circle your preferred voucher type:

- App voucher (Please circle if iTunes or Playstore)

- Book voucher

- Grocery voucher (Please circle if New World or Countdown)

- No, we opt out of the draw for the gift voucher.

\section{Final instructions}

Once again, thank you for participating in my study. Please return all the pages of this survey to me using the enclosed return envelope I have provided. 


\section{Appendix D-1}

\section{Information sheet for umbrella organisations}

\section{Research Project: \\ Touchscreen Tablet Pedagogy in Early Childhood Education}

Tēnā koe Sir/Madam,

My name is Luke Santamaria, a PhD student of the School of Education at Victoria University of Wellington. I am writing to request your permission to conduct research at your early childhood education service providers belonging to your organisation.

This research will explore touchscreen tablet use in four major service types: education and care centres, home-based services, kindergartens, and playcentres. Children today have increasing access to touchscreen tablets. According to the early childhood curriculum, Te Wharriki, children growing up in the context of a changing society could benefit from the use of technology. In Te Whäriki each of the strands - well-being, belonging, contribution communication and exploration - refer to technology. The Ministry of Education's Foundations for Discovery - Supporting Learning in Early Childhood Education through Information and Communication Technologies (ICT) released in 2005, defined ICT as the equipment and computer programmes that allow access, use and sharing of information. This definition includes touchscreen tablets, which are multimodal handheld devices with computer programmes called apps.

The project will investigate touchscreen tablet use for teaching and learning in early childhood education services. For this study, teachers/educators include adults working in early childhood services who are in contact with children through distal and proximal pedagogical practices. This research has been approved by the Victoria University of Wellington Human Ethics Committee \#23433. If you have any concerns about the ethical conduct of the research, you may contact the Victoria University HEC Convener: Associate Professor Susan Corbett. Email: susan.corbett@vuw.ac.nz or telephone +64-4-463-5480.

There will be two phases to the research. Phase 1 will involve a national survey that will be sent to all early childhood providers from the four major service types ${ }^{1}$. Services without email addresses will receive a postal copy of the survey. The survey will ask questions about touchscreen tablet use and non-use at each service and will take approximately 10-15 minutes to complete. The survey can be completed by the head teacher/supervisor or collectively by the teaching team in each service ${ }^{2}$. Participants will be asked to identify the name of their service on the survey if they wish to a) enter into a draw for one of ten $\$ 20$ gift vouchers (one winner from each of the ten education regions can choose from app, book or grocery), b) would like a summary of the research results, and/or c) are willing to participate in Phase 2 of the study. All information provided will be treated as 
confidential, and names of individuals or services will not be used in reporting responses.

Phase 2 will involve a multiple-case study conducted in two sub-phases. Participants will be selected from services who expressed their willingness to participate in this part of the research.

- Phase 2A will consist of focus group interviews with:

- a service from each of the four service types where touchscreen tablets are used for teaching and learning purposes, and

- a service from each of the four service types where touchscreen tablets are not used for teaching and learning purposes.

- Phase 2B will consist of stimulated recall (SR) focus group interviews with the same services who use touchscreen tablets who participated in Phase 2A. SR will involve five-to-ten-minute video-recordings of touchscreen tablet use for teaching and learning in each service. Selected video-recorded episodes will be played during a second set of focus group interviews to help teachers/educators recall and verbalise the thinking behind their teaching using touchscreen tablets. I envisage that I need to spend two days collecting data in each touchscreen tablet user service in this phase of the project.

Participants will be selected from survey respondents who expressed their willingness to participate in Phase 2. Selection will be based on geographical location (preferably the Wellington region), ease of access according to the timetable of this research, and responses to specific survey questions. If multiple services from each service type would like to participate in Phase 2, I will use random sampling to select the representative service from each service type.

Focus group interviews will be held at each service location, preferably during noncontact time. Participants will comprise the teaching team from each service, limited to a maximum of 12 teachers/educators. Each focus group interview will be separate from other participating services and will be a maximum of 60 minutes. Focus group interviews will be video- and audio-recorded to gather verbal and non-verbal interactions for transcription and analysis. I will personally video edit and transcribe the focus group interviews but in the event, I need to use a video editor or interview transcriber, they will be required to complete a confidentiality agreement.

Gift vouchers and interview transcripts will be given to participating services. Each participating service in Phase $2 \mathrm{~A}$ and Phase $2 \mathrm{~B}$ will receive a $\$ 20$ gift voucher from a choice of app, book, or grocery voucher.

Participation in the research is voluntary and each participant may withdraw from the research at any time up to the end of data collection period without giving any reason. The data collection period for Phase 1 is until February 28, 2017 and the data collection for Phase 2 is until June 30, 2017. 
I am aware of the requirements of the 2014 Vulnerable Children Act and hold a current provisional practicing certificate (\#338751) issued by the Education Council of Aotearoa New Zealand.

Access to the data from the research will be restricted to my supervisors and me. The data will be securely stored as hard and soft copies. Both will be kept in passwordprotected files in a private computer and locked in filing cabinets in my home and my office. The data will be destroyed five years after the conclusion of the research. The data from the research will be published in my $\mathrm{PhD}$ thesis and in academic and professional journals and shared at academic and professional conferences.

I am requesting your permission to distribute the survey to the services that belong to your organisation and, if selected, for them to participate in the multiple-case study. If you are willing for your early childhood services to participate in this study, I would appreciate it if you would communicate to your services that you have consented to them being invited to participate.

I have included the consent form for you to complete, sign, scan and return by email to me.

If you require any further information or have any questions about this study, please do not hesitate to contact me or my supervisors listed below.

Researcher:

Michael Luke M. Santamaria

Email: Luke.Santamaria@vuw.ac.nz

Mobile Phone: 021-258-5495
Supervisors:

Dr Sue Cherrington

Associate Dean (Academic)

School of Education

Phone: +64-4-463-9552

Email: sue.cherrington@vuw.ac.nz

Dr Mary Jane Shuker

Senior Lecturer

School of Education,

Phone: +64-4-463-9659

Email: mary-jane.shuker@vuw.ac.nz

${ }^{1}$ In order to meet the requirements of the New Zealand Playcentre Federation, I am sending information letters to both the NZ Playcentre Federation for their research approval and respective playcentre associations for their approval as legal entities involved in the management of playcentres. 
${ }^{2}$ As for home-based services, I understand that their service locations may vary. Since they are overseen by a certificated visiting teacher, one survey response will be sought from each visiting teacher. I am requesting the managing organisation of each homebased network listed in the ECE directory to ask each visiting teacher to complete the survey, either in collaboration with home-based educators within their network or as individual visiting teachers. 


\section{Appendix D-2}

\section{Consent form for umbrella organisations \\ Research Project: \\ Touchscreen Tablet Pedagogy in Early Childhood Education}

- I/We have been given information about this research project and have had an opportunity to ask questions and have them answered to my/our satisfaction.

- I/We understand what is required of the participants from our early childhood services who take part in this research.

- I/We understand that participation in the research is voluntary and the participants may withdraw from the study any time up to the end of the data collection period without giving a reason. Phase 1 is until February 28, 2017 and Phase 2 is until June 30, 2017.

- I/We understand that the identities of participating services and individual respondents will be confidential, and that names of individuals or services will not be used in any publications or presentations arising from this research.

- I/We understand that all research information will be stored in password-protected files and locked filing cabinets, with access restricted to the researcher and his supervisors. All data will be destroyed five years after the conclusion of the research.

- I/We understand that the data collected will be used for a doctoral thesis and academic purposes only.

Please circle as appropriate:

I/We consent for early childhood service providers belonging to Yes No our national organisation to be invited to participate in the research under the conditions stated on the information sheet.

I/We wish to receive a summary of the research findings Yes No

Name of person responding (Print)

Organisation name
Signature 
Appendix E-1

\section{Information letter to early childhood services (Phase 2A: Touchscreen tablet non-user services)}

\section{Research Project: \\ Touchscreen Tablet Pedagogy in Early Childhood Education}

Tēnā koe [Contact Person's and ECE Service's Names (Based from survey response)],

I would like to re-introduce myself. My name is Luke Santamaria, a $\mathrm{PhD}$ student of the School of Education at Victoria University of Wellington. Thank you for expressing your willingness to participate in the second phase of my research, which involves a multiple-case study on touchscreen tablet pedagogy. This letter provides you with information about this second phase.

This research has been approved by the Victoria University of Wellington Human Ethics Committee \#23433. If you have any concerns about the ethical conduct of the research, you may contact the Victoria University HEC Convener: Associate Professor Susan Corbett. Email: susan.corbett@ vuw.ac.nz or telephone +64-4-463-5480.

My research explores touchscreen tablet use and non-use in four major service types: education and care centres, home-based services, kindergartens, and playcentres. This phase follows on from the national survey of early childhood providers from the four major service types and involves focus group interviews of teachers/educators amongst services that use and do not use touchscreen tablets. For this study, teachers/educators include adults working in early childhood services who are in contact with children through distal and proximal pedagogical practices.

As your service indicated that you do not use touchscreen tablets for teaching and learning, I would like to undertake a focus group interview with teachers/educators from your service in order to understand more fully the reasons behind your decision not to use touchscreen tablets.

I would like to hold the focus group interview in your service, at a time convenient to your team (e.g., either during non-contact time or after children have left for the day). I would like to invite all the teachers/educators in your team who are interested in participating in this interview, to a maximum of 12 participants. Each focus group interview will be for a maximum of 60 minutes. I will video- and audio-record the interview in order to gather verbal and non-verbal interactions for transcription and analysis. Each participant will be given a transcript of the interview for accuracy and makes changes. I will personally video edit and transcribe the focus group interviews, but in the event I need to use a video editor or interview transcriber, they will be required to complete a confidentiality agreement.

I am aware of the requirements of the 2014 Vulnerable Children Act and hold a current provisional practicing certificate (\#338751) issued by the Education Council of Aotearoa New Zealand. 
Your service will receive a \$20 gift voucher from a choice of app, book or grocery voucher as a token of thanks for participating in this phase of my research.

Your participation in this research is voluntary and each participant may withdraw from the research at any time up to the end of data collection period without giving any reason. The data collection period for Phase 2 is until June 30, 2017.

All information provided will be treated as confidential, and the names of individuals or services will not be used in reporting responses. Access to the data from the research will be restricted to my supervisors and me. The data will be securely stored as hard and soft copies. Both will be kept in password-protected files in a private computer and locked in filing cabinets in my home and my office. The data will be destroyed five years after the conclusion of the research. The data from the research will be published in my $\mathrm{PhD}$ thesis and in academic and professional journals and shared at academic and professional conferences.

I have included a consent form for you to complete, sign, scan and return to me.

If you require any further information or have any questions about this study, please do not hesitate to contact me or my supervisors listed below.

Researcher:

Michael Luke M. Santamaria

Email: Luke.Santamaria@vuw.ac.nz

Mobile Phone: 021-258-5495
Supervisors:

Dr Sue Cherrington

Associate Dean (Academic)

School of Education

Phone: +64-4-463-9552

Email: sue.cherrington@vuw.ac.nz

Dr Mary Jane Shuker

Senior Lecturer

School of Education,

Phone: +64-4-463-9659

Email: mary-jane.shuker@vuw.ac.nz 


\section{Appendix E-2}

\section{Consent form for early childhood services (Phase 2A: Touchscreen tablet non-user services)}

\section{Research Project: \\ Touchscreen Tablet Pedagogy in Early Childhood Education}

- I/We have been given information about this research project and have had an opportunity to ask questions and have them answered to my/our satisfaction.

- I/We understand what is required of the participants from our early childhood service who take part in this research.

- I/We understand that participation in the research is voluntary and the participants may withdraw from the study any time up to the end of the data collection period without giving a reason. Phase 2 is until June 30, 2017.

- I/We understand that the identities of our service and individual respondents will be confidential, and that names of individuals or our service will not be used in any publications or presentations arising from this research.

- I/We understand that all research information will be stored in password-protected files and locked filing cabinets, with access restricted to the researcher and his supervisors. All data will be destroyed five years after the conclusion of the research.

- I/We understand that the data collected will be used for a doctoral thesis and academic purposes only.

\section{Please circle as appropriate:}

I/We agree to be involved in the multi-case study, and I/we give consent to participate in the focus group interview for this phase of Yes No the research.

I/We wish to receive a summary of the research findings.

Yes No

Name of person responding (Print)

Service name
Signature 


\section{Appendix E-3}

\section{Consent form for early childhood services}

(Phase 2A: Teachers/Educators)

\section{Research Project: \\ Touchscreen Tablet Pedagogy in Early Childhood Education}

- I have been given information about this research project and have had an opportunity to ask questions and have them answered to my satisfaction.

- I understand what is required of me and the participants from our early childhood service who take part in this research.

- I understand that participation in the research is voluntary and that I may withdraw from the study any time up to the end of the data collection period without giving a reason. Phase 2 is until June 30, 2017.

- I understand that my identity will be confidential, and that names of individuals or our service will not be used in any publications or presentations arising from this research.

- I understand that I will have the opportunity to check the summary and transcripts for accuracy and make changes.

- I understand that all research information will be stored in password-protected files and locked filing cabinets, with access restricted to the researcher and his supervisors. All data will be destroyed five years after the conclusion of the research.

- I understand that the data collected will be used for a doctoral thesis and academic purposes only.

\section{Please circle as appropriate:}

I agree to be involved in the multi-case study, and I give consent to participate in the focus group interview for this phase of the research for phase $2 \mathrm{~A}$ of the research.

Yes No

I wish to receive a summary of the research findings. $\quad$ Yes No

Name of teacher/educator (Print)

Service name
Signature 


\section{Appendix F-1}

\section{Information letter to early childhood services (Phase 2A and 2B: Touchscreen tablet user services)}

\section{Research Project: Touchscreen Tablet Pedagogy in Early Childhood Education}

Tēnā koe [Contact Person's and ECE Service's Names (Based from survey response)], I would like to re-introduce myself. My name is Luke Santamaria, a PhD student of the School of Education at Victoria University of Wellington. Thank you for expressing your willingness to participate in the second phase of my research, which involves a multiple-case study on touchscreen tablet pedagogy. This letter provides you with information about this second phase, which consists of two sub-phases.

This research has been approved by the Victoria University of Wellington Human Ethics Committee \#23433. If you have any concerns about the ethical conduct of the research, you may contact the Victoria University HEC Convener: Associate Professor Susan Corbett. Email: susan.corbett@ vuw.ac.nz or telephone +64-4-463-5480.

My research explores touchscreen tablet use and non-use in four major service types: education and care centres, home-based services, kindergartens, and playcentres. This phase follows on from the national survey of early childhood providers from the four major service types and involves focus group interviews of teachers/educators amongst services that use and do not use touchscreen tablets. For this study, teachers/educators include adults working in early childhood services who are in contact with children through distal and proximal pedagogical practices.

As your service indicated that you use touchscreen tablets for teaching and learning, for the first sub-phase, I would like to undertake a focus group interview with teachers/educators from your service in order to understand more fully the reasons behind your decision to use touchscreen tablets. For the second sub-phase, I would like to conduct stimulated recall (SR) focus group interviews in your service after video-recording touchscreen tablet use in your service. SR will involve five-to-tenminute video-recordings of touchscreen tablet use for teaching and learning in each service. Selected video-recorded episodes will be played during the second focus group interview to help teachers/educators from your service recall and verbalise the thinking behind their teaching using touchscreen tablets. I envisage that I need to spend two days collecting data in your service to video-record data and to conduct the focus group interview for this phase of the project.

I would like to hold the focus group interview in your service, at a time convenient to your team (e.g., either during non-contact time or after children have left for the day). I would like to invite all the teachers/educators in your team who are interested in participating in this interview, to a maximum of 12 participants. Each focus group interview will be for a maximum of 60 minutes. I will video- and audio-record the 
interview in order to gather verbal and non-verbal interactions for transcription and analysis. I will personally video edit and transcribe the focus group interviews, but in the event I need to use a video editor or interview transcriber, they will be required to complete a confidentiality agreement.

I am aware of the requirements of the 2014 Vulnerable Children Act and hold a current provisional practicing certificate (\#338751) issued by the Education Council of Aotearoa New Zealand.

Your service will receive two $\$ 20$ gift vouchers from a choice of app, book or grocery voucher as a token of thanks for participating in each phase of my research.

Your participation in this research is voluntary and each participant may withdraw from the research at any time up to the end of data collection period without giving any reason. The data collection period for Phase 2 is until June 30, 2017.

All information provided will be treated as confidential, and the names of individuals or services will not be used in reporting responses. Access to the data from the research will be restricted to my supervisors and me. The data will be securely stored as hard and soft copies. Both will be kept in password-protected files in a private computer and locked in filing cabinets in my home and my office. The data will be destroyed five years after the conclusion of the research. The data from the research will be published in my $\mathrm{PhD}$ thesis and in academic and professional journals and shared at academic and professional conferences.

I have included consent forms for you to complete, sign, and return by email. I am including information letters and consent forms to hand out to the parent/s and the children in your service. I can help handout the consent forms and information letters during mat time or at a gathering time before or after each session and would appreciate it if you could let me explain my research to the parents and their children.

If you require any further information or have any questions about this study, please do not hesitate to contact me or my supervisors listed below.

Researcher:

Michael Luke M. Santamaria

Email: Luke.Santamaria@vuw.ac.nz

Mobile Phone: 021-258-5495
Supervisors:

\author{
Dr Sue Cherrington \\ Associate Dean (Academic) \\ School of Education \\ Phone: +64-4-463-9552 \\ Email: sue.cherrington@vuw.ac.nz \\ Dr Mary Jane Shuker \\ Senior Lecturer \\ School of Education, \\ Phone: +64-4-463-9659 \\ Email: mary-jane.shuker@vuw.ac.nz
}




\section{Appendix F-2}

\section{Consent form for early childhood services}

(Phase 2A and 2B: Touchscreen tablet user services)

\section{Research Project: \\ Touchscreen Tablet Pedagogy in Early Childhood Education}

- I/We have been given information about this research project and have had an opportunity to ask questions and have them answered to my/our satisfaction.

- I/We understand what is required of the participants from our early childhood service who take part in this research.

- I/We understand that participation in the research is voluntary and that participants may withdraw from the study any time up to the end of the data collection period without giving a reason. Phase 2 is until June 30, 2017.

- I/We understand that the identities of our service and individual respondents will be confidential, and that names of individuals or our service will not be used in any publications or presentations arising from this research.

- I/We understand that all research information will be stored in password-protected files and locked filing cabinets, with access restricted to the researcher and his supervisors. All data will be destroyed five years after the conclusion of the research.

- I/We understand that the data collected will be used for a doctoral thesis and academic purposes only.

\section{Please circle as appropriate:}

I/We consent for our early childhood service to participate in a focus group interview for Phases $2 \mathrm{~A}$ and $2 \mathrm{~B}$ of the research.

Yes No

I/We wish to receive a summary of the research findings. $\quad$ Yes No

Name of person responding (Print)

Service name
Signature 


\section{Appendix F-3}

\section{Consent form for early childhood services}

(Phase 2A and 2B: Teachers/Educators)

\section{Research Project: \\ Touchscreen Tablet Pedagogy in Early Childhood Education}

- I have been given information about this research project and have had an opportunity to ask questions and have them answered to my satisfaction.

- I understand what is required of me and the participants from our early childhood service who take part in this research.

- I understand that participation in the research is voluntary and that I may withdraw from the study any time up to the end of the data collection period without giving a reason. Phase 2 is until June 30, 2017.

- I understand that my identity will be confidential, and that names of individuals or our service will not be used in any publications or presentations arising from this research.

- I understand that all research information will be stored in password-protected files and locked filing cabinets, with access restricted to the researcher and his supervisors. All data will be destroyed five years after the conclusion of the research.

- I understand that the data collected will be used for a doctoral thesis and academic purposes only.

\section{Please circle as appropriate:}

I give permission for my interactions with the touchscreen tablet, teachers/educators, parents, and other children in the service/centre Yes No to be video-recorded and consent to participate in a focus group interview for phases $2 \mathrm{~A}$ and $2 \mathrm{~B}$ of the research.

I wish to receive a summary of the research findings.

Yes No

Signature

Service name

Position

Date 


\section{Appendix G-1}

\section{Information letter for parent/s and their child/ren \\ (Phase 2B: Touchscreen tablet user services)}

\section{Research Project: \\ Touchscreen Tablet Pedagogy in Early Childhood Education}

Tēnā koe,

My name is Luke Santamaria, a PhD student of the School of Education at Victoria University of Wellington. I am writing to you because the service your child(ren) attends has agreed to participate in my research.

My research is exploring touchscreen tablet use in New Zealand early childhood education services. In this phase of the research I am undertaking stimulated recall (SR) focus group interviews with teachers/educators in services who use touchscreen tablets for teaching and learning purposes. This will involve me collecting five-to-tenminute video-recordings of touchscreen tablet use for teaching and learning in your child(ren)'s service. These video-recorded episodes will be played during a focus group interview with the teachers/educators to help them recall and verbalise the thinking behind their teaching using touchscreen tablets. I envisage that I will be in your child(ren)'s service for two days in order to collect the video-recorded data for this phase of the project.

This research has been approved by the Victoria University of Wellington Human Ethics Committee \#23433. If you have any concerns about the ethical conduct of the research, you may contact the Victoria University HEC Convener: Associate Professor Susan Corbett. Email: susan.corbett@vuw.ac.nz or telephone +64-4-463-5480.

Focus group interviews will be held at each service location, preferably during noncontact time. Participants will comprise the teaching team from each service, limited to a maximum of 12 participants. Each focus group interview will be separate from other participating services and will be a maximum of 60 minutes. Focus group interviews will be video- and audio- recorded to gather verbal and non-verbal interactions for transcription and analysis. I will personally video edit and transcribe the focus group interviews, but in the event I need to use a video editor or interview transcriber, they will be required to complete a confidentiality agreement.

I am aware of the requirements of the 2014 Vulnerable Children Act and hold a current provisional practicing certificate (\#338751) issued by the Education Council of Aotearoa New Zealand.

Participation in the research is voluntary and each participant may withdraw from the research at any time up to the end of data collection period without giving any reason. The data collection period for Phase 2 is until June 30, 2017. 
Access to the data from the research will be restricted to my supervisors and me. The data will be securely stored as hard and soft copies. Both will be kept in passwordprotected files in a private computer and locked in filing cabinets in my home and my office. The data will be destroyed five years after the conclusion of the research. The data from the research will be published in my $\mathrm{PhD}$ thesis and in academic journals and shared at academic and professional conferences.

I have included the consent forms for you to complete, sign, return to the teachers/educators in your service who will pass these on to me.

If you require any further information or have any questions about this study, please do not hesitate to contact me or my supervisors listed below.

Researcher:

Michael Luke M. Santamaria

Email: Luke.Santamaria@vuw.ac.nz

Mobile Phone: 021-258-5495
Supervisors:

Dr Sue Cherrington

Associate Dean (Academic)

School of Education

Phone: +64-4-463-9552

Email: sue.cherrington@vuw.ac.nz

Dr Mary Jane Shuker

Senior Lecturer

School of Education,

Phone: +64-4-463-9659

Email: mary-jane.shuker@vuw.ac.nz 


\section{Appendix G-2}

\section{Consent form for parent/s and their child/ren (Phase 2B: Touchscreen tablet user services)}

\section{Research Project: \\ Touchscreen Tablet Pedagogy in Early Childhood Education}

- I/We have been given information about this research project and have had an opportunity to ask questions and have them answered to my/our satisfaction.

- I/we understand that the researcher will be sensitive to my child(ren)'s response(s) to being video-recorded and will cease recoding if my child is uncomfortable.

- Participation in the research is voluntary and that my/our child(ren) may withdraw from the study any time up to the end of the data collection period without giving a reason. Phase 2 is until June 30, 2017.

- Identities will be confidential. I/we understand that my/our child(ren)'s name/s will not be used, along with the names of our ECE centre, staff, parents and children in any of the findings, reports, publications or presentations resulting from this research study. There will be no identifying information revealed; only pseudonyms will be used.

- All research information will be stored in password-protected files and locked filing cabinets, and access will be restricted to the researcher and his supervisors. It will be destroyed five years after the conclusion of the research.

- The data collected will be used for a doctoral thesis and academic and professional purposes only, and I/we consent for it to be used in this manner.

Please circle as appropriate:

I/we give permission for my/our child(ren)'s interactions with the touchscreen tablet, teachers/educators, parents, other children, and Yes No myself/us in the service/centre to be video-recorded.

\begin{tabular}{lll}
\hline $\begin{array}{l}\text { I/we give permission for the researcher to collect data from } \\
\text { informal conversations with my/our child(ren) relating to their use } \\
\text { of touchscreen tablets in the service/centre. }\end{array}$ & Yes & No \\
\hline I wish to receive a summary of the research findings & Yes & No
\end{tabular}

Name of parent (Print)

Child/ren's name/s (Print)

Child/ren's name/s (Print)
Signature

Date

ECE Service Name 


\section{Appendix H}

\section{Phase 2A focus group questions}

\section{For services that use touchscreen tablets:}

1. How many of you use touchscreen tablets for teaching and learning at your service?

2. Why did you start using touchscreen tablets?

3. What are the issues you have faced in using touchscreen tablets and how did you address them?

4. What do you think could enhance touchscreen tablet use in your service?

\section{For services that do not use touchscreen tablets:}

1. What are your reasons for choosing not to use touchscreen tablets?

2. Depending on the response:

a. Can you explain more about the disadvantages of touchscreen tablet use at your service?

b. Can you explain how these barriers prevented you from using touchscreen tablets?

c. Do you have any plans in using touchscreen tablets at your service? Why or why not?

3. What do you think are the advantages of not using touchscreen tablets at your service? 
Appendix I

\section{Phase 2B focus group questions}

(After watching each video episode)

1. Is this a common use of touchscreen tablets at this service? (Probe: "Why do you think this scenario is happening?", "What is your role in this scenario?", or "Is this a typical scenario of your roles?")

2. Do you think this method of teaching and learning can be used at other service types?

3. How would you use touchscreen tablets to enhance teaching and learning in this scenario?

4. (For teachers/educators not involved in the episode) How could things have been if there were not touchscreen tablets in this scenario?

5. What are other practices you use with touchscreen tablets to support children's learning?

6. What do you think are ways to further teaching and learning using touchscreen tablets? 